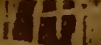

Gith

minute

-

initi

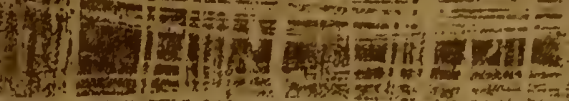

Munts

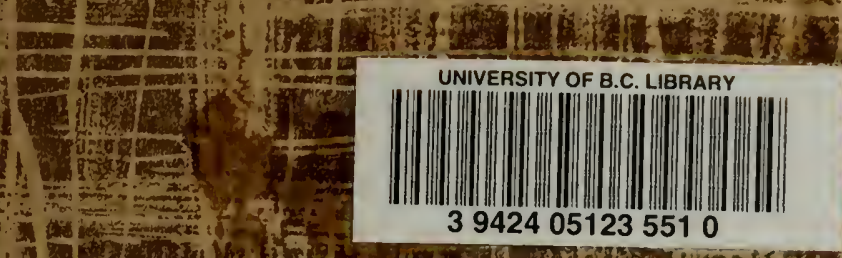

14. 39424051235510

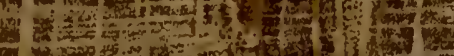

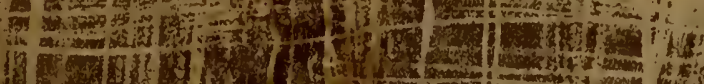

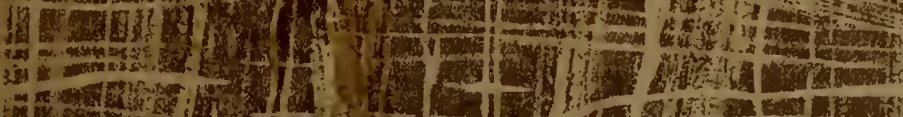

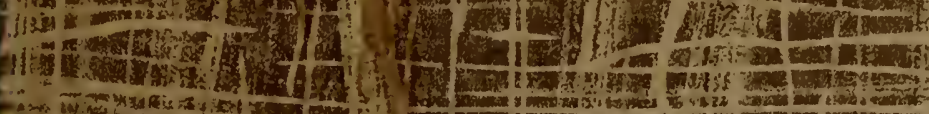

3)

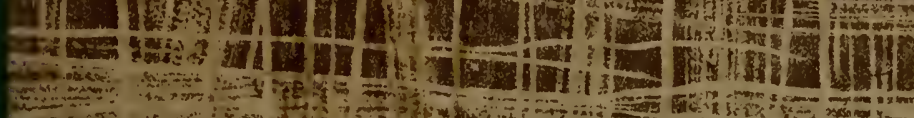

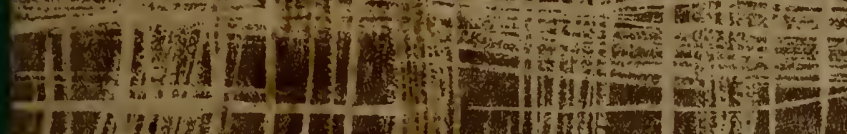

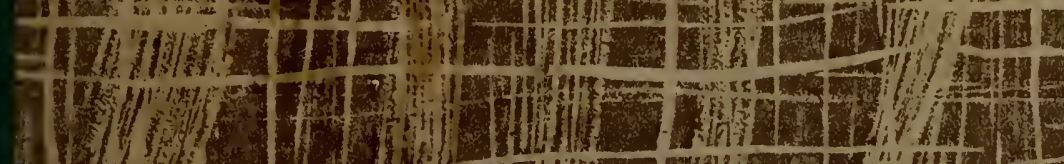

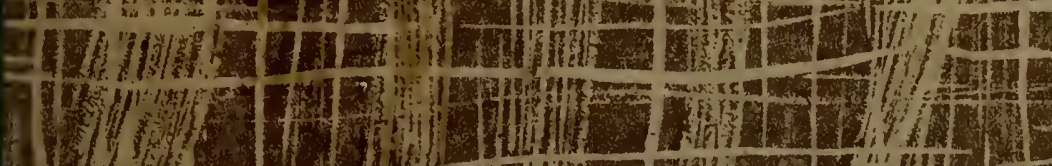

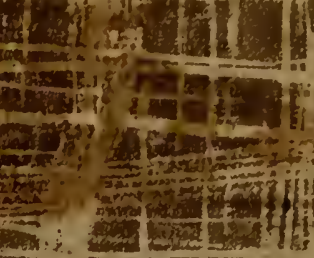

11. -1

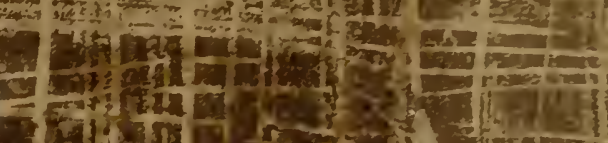

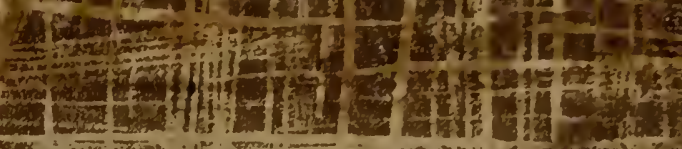

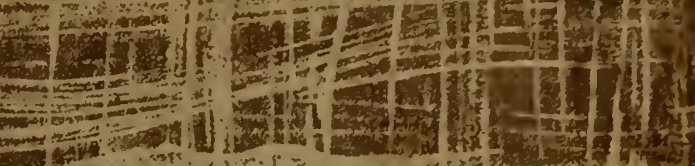

17 and

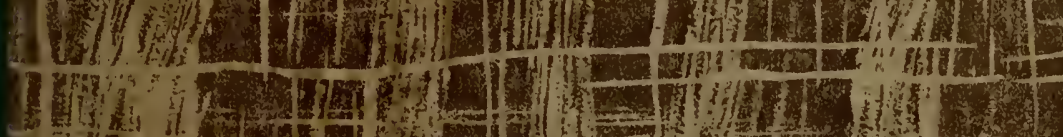

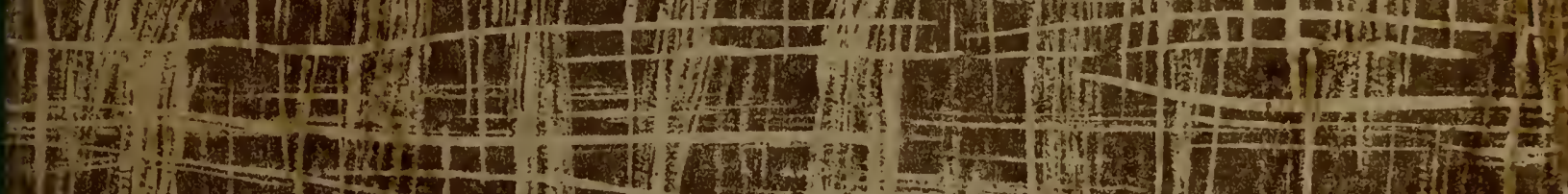

1 II

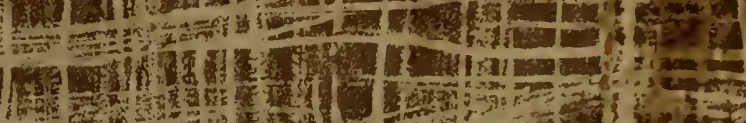

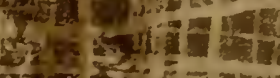

cas? 



\title{
ANALYSIS OF
}

\section{Logging Costs and Operating Methods}

\author{
IN THE
}

\section{DOUGLAS Fir REgION}

\author{
By \\ AXEL J. F. BRANDSTROM \\ Senior Forest Economist \\ Pacific Northwest Forest Experimental Station \\ Forest Service \\ United States Department of Agriculture
}

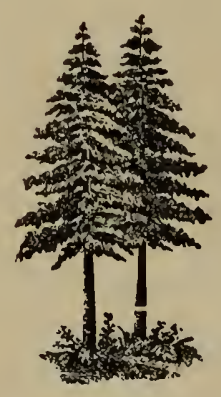

Published by the Charles Lathrop Pack Forestry Foundation under the auspices of the West Coast Lumbermen's Association

June, 1933 


\section{FOREWORD}

IT IS A FAR CRY from the bull team of the nineties that logged only large, highgrade trees on easy ground to the 100-ton skidder that works the hardest shows and makes a clean sweep of all sizes, species and qualities of timber.

The Pacific Northwest logger leads the world as a practical and resourceful engineer. He has developed many types of logging machinery and methods, new devices, new rigs, new ways of using equipment. His genius has run strongly to high-powered machines and mass production. His creed is low cost on a big volume.

The Pacific Coast logger has solved many difficult problems in selecting the method and kind of equipment best adapted to a particular show. From tract to tract, he has encountered wide differences in topography, size and density of timber, weather conditions, and practical limitations on cost. The most efficient method for one operator may be quite the opposite for his neighbor. A money-making set-up for one show may be wasteful and extravagint for another. Even the sound principle of low cost on a big volume may not pay out if the volume contains too large a percentage of logs that do not return their own cost.

Believing that, in many instances, capital, labor, and timber may be wasted by failure to employ the logging method or equipment best suited to the conditions, the U. S. Forest Service, through its Pacific Northwest Forest Experiment Station, began in 1931 a thorough-going study of the cost of every step in logging, from stump to pond, under almost every variety of machinery and rigging used in the region. Time studies and cost analyses were made of some 40 million feet of $\log$ s at a number of representative operations.

This study was conducted by Axel J. F. Brandstrom, who formerly, while on the faculty of the University of Washington College of Forestry and Lumbering, became interested in analyzing possibilities for improved logging practice and made preliminary investigations in collaboration with Burt P. Kirkland, also of the Washington faculty. The present report, by $\mathrm{Mr}$. Brandstrom, is the first formal publication of the results of his work. With scientific precision and faithful attention to detail, it analyzes an enormous mass of evidence on each item of logging cost. It shows that mistaken logging methods often cause waste of capital, labor and timber; may indeed put the whole operation in red ink. Brandstrom ascribes such losses mainly to lack of specialization and selection in logging methods, that is, to too general and blind a drive for low cost on big volume.

Brandstrom's analysis of these factors is wholly constructive. He is not content simply to point out weaknesses in West Coast logging. He indicates how they can be corrected, and reveals unmistakable possibilities for greater profit to the industry and better conservation of forest resources.

This report is confined largely to analyses of logging costs. It is directly useful to the logging engineer, whether he is working a property for the largest immediate cash return or for a sustained yield. Brandstrom and Kirkland contemplate a second report, which will deal with the financial side of forest management and compare returns under clean cutting with selective cutting that leaves growing stock on the land.

The West Coast Lumbermen's Association is indebted to the Forest Service for the opportunity of presenting this report to the industry and the public. Both the Association and the Forest Service are indebted to the Charles Lathrop Pack Forestry Foundation for furnishing the funds for printing this report and making it widely available.

This report, in my judgment, gives the West Coast Logging Industry an extremely valuable hand book on logging costs and the selection of the most efficient equipment or method for a particular show. It will help the logger in solving his master problemhow can this tract of timber be operated for the largest cash return? It lays the ground work for practical and promising developments in selective logging-a vital factor both in liquidating present investments and in keeping our forests productive. I heartily commend it to the industry for study and use.

W. B. GREeley.

Seattle, Washington,

August 5, 1933. 


\section{CONTENTS}

PAGE

I. The Growth and Development of Lumbering in the Douglas fir region ..... 7

1. Historical

2. Selection policy of pioneer logger is industry's need today

3. General scope and purpose of logging cost studies

II. General Description of Logging Machinery and Methods Studied

4. Primary importance of stump-to-rail haul

5. Specialization in machinery and methods

6. Skyline systems

7. High-lead system

8. Tractor systems

9. Loading systems

III. Basis of Time and Cost Analysis

10. Deficiencies in present cost information

11. Objects and functions of time and cost studies

12. Adaptability of cost data to changing cost levels

13. Basis of machine rates

14. General overhead costs not included in machine rates

15. Basis of capital charges

16. Other costs

IV. Yarding Studies

17. General importance of the yarding operation

18. Scope and object of yarding studies

19. Manner of study

20. Distinction between external yarding distance and actual yarding distance

21. Report on yarding with 60 h.p. tractors

22. Reports on yarding with donkeys28 studies

V. Comparison of Yarding Costs for Different Types of Machinery and Methods

23. Basis of comparison

24. How to read the cost comparison chart
8

8

7
7
8
8

25. Density of timber, efficiency of crew, and topography are factors affecting the cost comparison

26. Comparison of yarding variable costs 38

27. Rigging-ahead costs ....................... 38

28. Reasons for high cost of yarding with large machines.

29. Limitations of small yarding machinery

VI. Skyline Swinging Studies

41

30. Scope of studies

31. Swinging from cold decks shows higher turn volumes than yarding

32. North Bend swing studies (Tables 29 to 32 inclusive)

33. Tyler swing study (Table 33 )

34. Steam skidder swing studies (Table 34)

35. Steam slackline swing study (Table 35)

36. Comparison of results.

37. Large cold decks cause increase of swinging costs.

VII. Comparison of Direct Yarding with Combined Cold Decking and Swinging.

38. Comparison of costs.

39. One problem-many solutions

40. Size of cold deck is controlling factor

41. Effect of volume of $\log$ on comparative costs.

42. Objections to foregoing conclusions.-

43. Example showing adaptability of cold-deck system to rough topography

44. Significance of foreyoing findings

VIII. Tractor Roading Studies

48

45. Distinction between roading, swinging, and yarding with tractors.

46. Scope of study.

47. Tabulation of results

48. Importance of favorable grades in tractor roading 48

49. Effect of slope on hauling and haulback (return) time

50. Relation of distance to cost

51. Effect of volume of load on total trip time. 
52. Roading cost table

53. Relation of load volume to $\log$ volume

54. Large load volume is essential to low cost of downhill roading

IX. Comparison of Tractor Roading with Skyline Swinging

55. Basis of comparison

56. Explanation of graph (Fig. 33)

57. Roading from large cold decks introduces additional costs.....................

58. Comparison of results................... 54

59. Significance of low cost of long distance roading

60. Reduction of breakage is important factor

61. Construction of tractor roads broadens the use of tractors in the Douglas fir region

62. Limitations of the tractor-roading system

$X$. Loading Studies

63. Relation of loading to yarding and railroad transportation

64. Scope of studies

65. Factors affecting the cost of loading

66. Comparison of costs

67. Adaptation of equipment to $\log$ size brings reduction of cost

52

52

52

54

54

54

55

XI. Comparison of Cost Relations in Transport from Stump to Car...............

68. The effect of volume of $\log$ on yarding-variable cost..

69. Volume of the average $\log$ as an index to steepness of cost curves...-

70. The effect of distance on yardingvariable costs.

71. The effect of volume of $\log$ on swinging-variable costs

72. The effect of volume of $\log$ on loading costs

73. Summary graph-comparison of typical cost relations covering all phases of logging

XII. Railroad Transportation

74. General

75. Carload capacity studies

76. Relative costs of logs of various sizes

77. Effect of volume of load on cost per carload

78. Items of cost which are governed by the carload variable
79. Variations in yarding costs may control variations in railroad transportation costs

80. Staked cars show increased load capacity for small logs.

81. Use of staked cars is impracticable under clear-cutting system

XIII. Motor Truck 'Transportation

82. Relation of $\log$ size to load volume and hauling cost

83. Truck hauling costs for various distances

84. Comparison with tractor roading and railroad transportation

XIV. Water Transportation

85. Low cost of water haul

86. The relation of volume of $\log$ to cost of booming and rafting

XV. Felling and Bucking

87. Relation of diameter of tree to felling and bucking costs

XVI. Selective Cost Analysis of a Logging Operation as a Whole

88. Consistency shown in the relations of $\log$ and tree size to logging cost

89. Application of relative costs to complete cost analysis of operating or nonoperating timber properties

90. Analysis of a logging cost statement

91. Adaptation of cost averages to specific operating conditions.

92. Allocation of fixed per acre costs 77

93. Allocation of capital charges

XVII. Further Examples of Selective Cost Analysis of Typical Operations

94. Case studies-basis of comparison

95. Small logs and trees show relatively high costs

96. Present clear cutting practice penalizes the small log or tree

XVIII. General Summary and Comparison of Log Transportation Costs

97. Transportation as a fundamental eji ment in logging cost

XIX. Possibilities of Cost Reduction Through Adaptation of Machinery and Methods Under Clear Cutting

98. Planning of logging operations for low cost methods.

99. Example-comparison of present with proposed methods 
100. Elimination of spur construction leads to important economies

101. Substitution of skyline swinging for tractor roading offers practical solution of difficult problems

102. Further modification to solve special problems

103. Hauling by motor truck may eliminate some long distance roading.

104. Some general points established from foregoing comparisons.

105. Comparison based on clear cutting is not final.

XX. Possibilities of Cost Reduction Through Selective Specialization

106. Specialization reduces cost of smalltimber logging in general

107. Selective specialization is needed in this region

108. An estimate of potential possibilities for cost reduction through selective specialization

109. Flexibility in the yarding operation is essential

110. Clear cutting leads to inefficiency in all phases of operation

XXI. An Experiment in Tractor Logging and Tree Selection Points the Way to a New Logging Plan

111. Experiment needed to verify conclusions reached in studies

112. Description of study area and logging conditions

113. General logging plan and methods....

114. Reduction in road construction cost leads to a denser network of tractor roads

115. Object and plan of tree selection experiments
116. Results show advantages of tree

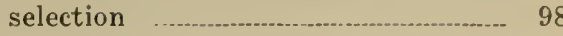

117. Large timber is no handicap to tractor logging

118. Comparison with conventional donkey logging

119. Closer attention to load volume will bring further savings...___......... 101

120. Reduction of breakage, another advantage of tractor method.

121. Summary and conclusions of logging experiment

XXII. Application of Findings from Logging Studies and Experiment.

122. Conclusions reached in studies of various phases of logging suggest complete logging plan

123. The construction program 104

124. General logging plan 105

125. The logging program for the large-timber cuts

126. The logging program for the smalltimber cuts

127. The logging program for the mediumtimber cuts

128. Specialization of equipment may involve new radical changes

129. A summary and comparison of cost advantages of the proposed plan.-. 112

130. Application to rough country logging and other problems

131. Flexible logging methods promote adaptation of operating and timber investments to changing conditions 



\section{THE GROWTH AND DEVELOPMENT OF LUMBERING IN THE DOUGLAS FIR REGION}

1. Historical.-In 1827 Dr. John McLaughlin, Chief Factor of the Hudson's Bay Company, set up a small, water-driven sawmill near Fort Vancouver. This was the first mill on the Pacific Coast and also the first west of the Mississippi River. In 1830 a visiting government official, highly impressed with what he had seen, wrote in his diary the following:

"The sawmill is a scene of constant toil. Thirty or forty Sandwich Islanders (Hawaiians) are felling pines (i.e., Douglas fir) and dragging them to the mill; sets of hands are plying two gangs of saws by night and day; 3,000 feet of lumber per day-900,000 feet per annum, are constantly being shipped to foreign lands." 1

Further operations were soon added by Americans in the Willamette Valley, on the Columbia River, and at Olympia, Seattle and other points on Puget Sound. Following the California gold rush of 1849 came the first modest "boom" in the industry. Prior to the gold strike rough lumber sold generally at $\$ 20$ to $\$ 30$ per $M$ feet board measure at the mills. By November 1849 the price had risen to $\$ 50$, and in March 1850 , to $\$ 100$; but by the following year it had dropped back to $\$ 30$ and even to $\$ 10$ before the end of that decade. By this period these magnificent forests immediately adjacent to deep-water shipping facilities leading to the ports of the world attracted attention to the commercial opportunities they offered to pioneer lumber operators.

The next great impetus to development of the industry came with the transcontinental railroad era. Expansion began with furnishing materials for the Union Pacific in California, and was further fostered by the building of the Northern Pacific to Puget Sound. The latter made rail lumber trade possible to the interior states, which, however, developed slowly for nearly twenty years. With further railroad building in the Northwest in the nineties, rail trade began in earnest, closely coincident with further development of coastwise and foreign water shipments. The final milestone in this = develcrment came with the opening of the Panama Canal, which threw open to the West
Coast the markets of the Atlantic Seaboard.

With this expansion of markets, there followed a gradual improvement in the mechanics of lumbering with a definite trend toward larger and larger operations, particularly those catering to the export trade. Sawmills built prior to 1850 were driven by water power, often combined with grist mills, and produced generally from 2,000 to 10,000 board feet per day. After 1850 steam driven mills were introduced, and a few years later plants producing as much as 100,000 board feet per day were making lumbering history on Puget Sound. In the woods, progress had likewise made itself felt-in the replacement, first, of hand labor by oxen, then oxen by horses and mules, and, in the seventies, through the gradual inroads of steam "donkeys" and the beginning of railroad operations to overcome the increasing distance of haul as the timberline receded before the logger's axe. The steam donkeys grew in size, speed, and power; the railroad increased in length. At the end of the century the earlier methods of hand and animal logging were largely a thing of the past. (See frontispiece and Figure 1.)

Up to this time, the main emphasis in logging was placed on the logger's knowledge of what to take and what to leave. The early logger, in other words, practiced economic selection. He was careful to select only such trees as were prime for lumber and which would yield a net profit when put on the market. The rest he left standing in the woods. This policy frequently left the forest in good producing condition.

In the last three decades there have grown up many wood uses in addition to lumber, of which shingles, pulp and paper, and plywood are most important. Markets for these have gradually been expanded. Thus there has developed the great volume of industries now supported by the forests of the Douglas fir region, aggregating approximately one-third of the total United States production. At the same time the industry has continued to undergo a remarkable transformation in the mechanics of production both in the mills and in the woods.

The author wishes to acknowledge his indelstedness to all who have aided in any way the accomplishment of this project, particularly to D. S. Denman, E. P. Stamm, and Charles Nichols of the Crown Willamette Pulp and Iaper Company for their interest and cooperation in the project as a whole; to John E. Liersch for valuable data contributed in the follow -up of the conclusions of the studies; and to the Aloha Lumber Co., The Alberni Pacific Lumber Co., Crown Willamette Pulp and Paper Co., Kerr and Hawson Co.. Long-Bell Lumber Co., McCormick Lumber Co., Merrill \& Ring Lumber Co., North Bend Timber Co., Simpson Logging Co., Snoqualnie Falls Lumber Co., Tidewater Timber Co., West Fork Logging Co., and the Weyerhaeuser 1 imber Co., for their help and cooperation extended in the studies made on their logging operations, and to the faculty of the College of Forestry of the University of IVashington for their cooperation in providing office space and facilities for the compilation of the field data.

'The Timherman. 
This short historical sketch serves to remind us that lumbering in this region has at all times been undergoing change. Continuous adaptation to economic conditions, location and topography of forest areas, and mechanical development has proceeded in rapid order. At each period the rank and file may have felt that stability in methods had been attained, but nevertheless changes were being brought about through constant efforts to lower costs or otherwise increase profit margins. That further important changes should be made is one of the principal conclusions reached in this report.

2. Selection Policy of Pioneer Logger is Industry's Need Today.-In late year's cutting has receded farther and farther from the level or gently sloping ground near the shores of the bays and rivers into the rough and mountainous areas. To meet these conditions the industry developed the various types of high-lead and skyline logging machinery, which are described in the following chapter. In this development, speed, size, and power became the symbols of efficiency, mass production the slogan of the day. At the same time, however, the management method of basing operating policies on average costs and returns failed to warn operators either as to the dangers attendant on overloading the market with an excess of low grade material, or those attendant on great investments in machines adapted only to wholesale removal of heavy stands. There has also, until very recently, been a lack of realization of the impossibility of quick liquidation of so large a forest resource as the Douglas fir region possesses. Growing recognition of these factors has focused attention on the need for revision in present operating policies to better fit the economies of timberland management, and has pointed out the need for new adaptations of logging methods which will enable the operator to select for the current cut those areas of timber and sizes, species, and types of trees which justify cutting or require priority in cutting. This is the policy from which the industry derived its strength during the first 75 years of its existence in this region. The pioneer logger hewed closely to the lines of intensive selection of profitable values by area, species, tree and $\log$, and so succeeded in reaping a profit from timberlands where-had he relied on wholesale clear cutting methodsthere would have resulted only financial loss. The evidence here presented goes to prove that this plan of operation, modified and readapted to fit present conditions, is just as sound and just as important to the industry as it was forty years ago.

3. General Scope and Purpose of Logging Cost Studies.-This report is confined to the presentation of the results of basic studies of machinery and methods for the purpose of coordinating effective methods of logging with sound principles of timber management. Back of these results stands a comprehensive series of detailed time and cost studies of all important phases of logging in the Douglas fir region. Sixty-four separate cost studies were made in the spring and summer of 1931 . These studies were conducted in 14 different logging operations scattered throughout the region. They represent a wide variety of topographic and other environmental conditions together with a representative use of virtually every existing type of logging machinery. Approximately 40,000 logs, scaling roughly $35,000,000$ board feet $\log$ scale, are included in detailed stopwatch time studies of yarding, swinging, anci loading, in addition to large quantities of $\log \mathrm{s}$ covered in detailed cost studies of activities, in the analysis of which stop-watch time observa. tions were unnecessary.

\section{GENERAL DESCRIPTION OF LOGGING MACHINERY AND METHODS STUDIED}

4. Primary Importance of Stump-to-Rail Haul.Logging in the Douglas fir region is today a highly mechanized industry, characterized by long-distance transport of logs over standard gauge railroads which reach out to virtually every 40 -acre subdivision of the logging area, and generally by large units of power skidding, yarding, swinging, ${ }^{2}$ and loading machinery for transporting the logs by drum and cable from the stump to the car. The old systems of hand and animal logging have been superseded by modern steam, gasoline, diesel, and electrically driven machinery, which varies greatly in

${ }^{2}$ For definition of logging terms used see glossary, page 117 . power, design, and methods of operation. In recent years, crawler tractors have come into use and are rapidly gaining favor under certain conditions of logging.

In general, logging operations comprise thre? major steps:

1. Log making (felling and bucking).

2. The hauling of logs from the stump and assembling at railroad or other means of general transportation.

3. Transportation by railroad, waterway, or highway. 

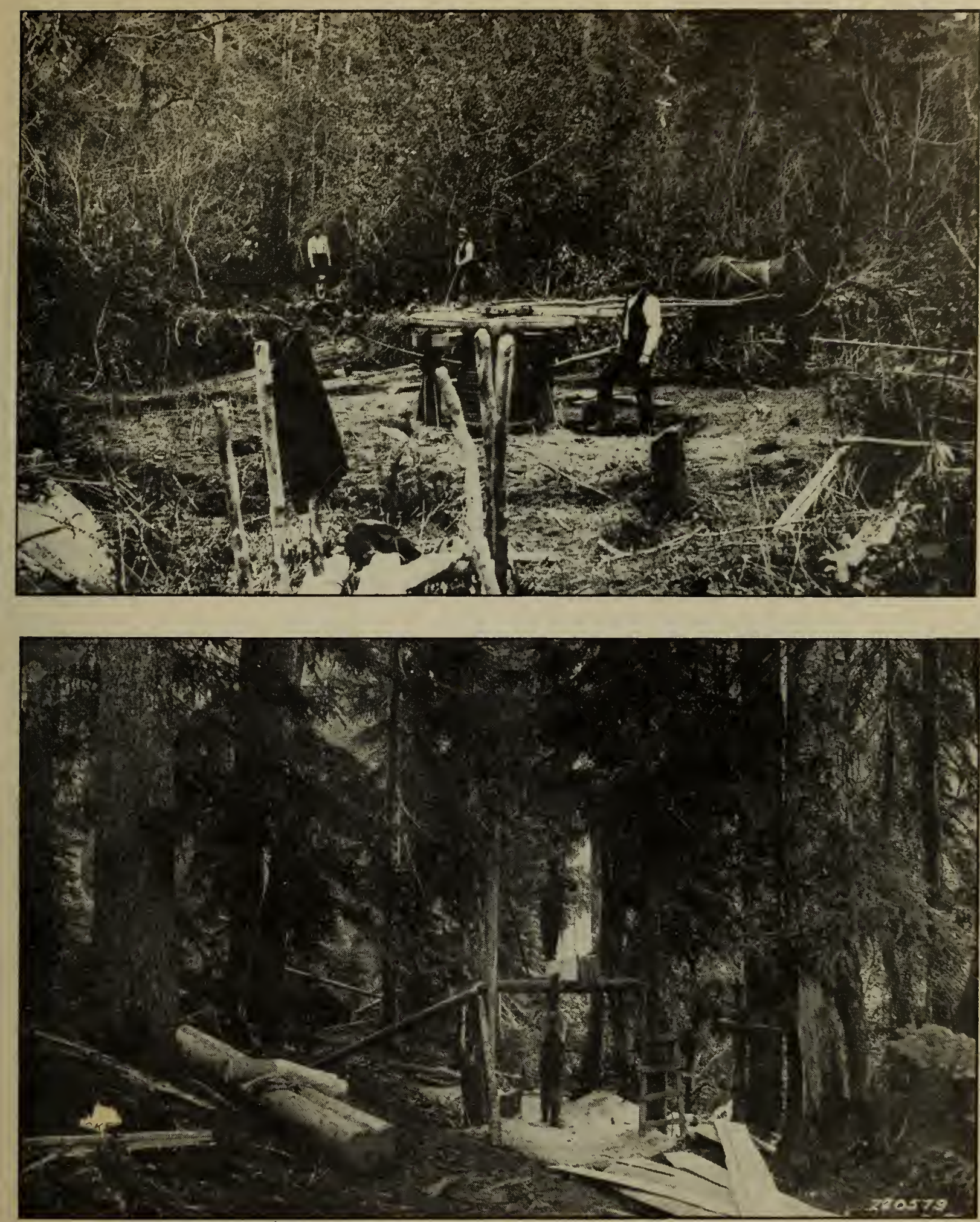

FIG. 1-LUMBERING SCENES IN THE DOUGLAS FIR REGION BEFORE THE DAYS OF POWER MACHINERY

TOP-AN EARLY CONCEPT OF THE DONKEY ENGINE, COMPRISING WINDLASS AND MULE FOR HAULING LOGS OUT OF SWAMP 
Of these the major problems have to do with the hauling of logs from the stump to railroad (or highway), and the correct balancing of these two principal methods of transport. This report deals primarily with this phase. Log making. which generally represents 10 to 20 per cent of the total logging cost, and general transportation, which is already too well standardized to require intensive investigation, are treated more briefly in the later part of the report.

5. Specialization in Machinery and Methods.Adaptation of machinery and methods to special logging problems, as well as to prospective investment and output required, has nowhere leached a higher development than in the Douglas fir region. Initial cost of machinery units may vary from $\$ 1,000$ to $\$ 100,000$; weight, from a few tons to nearly 200 tons; crews from 2 to 20 men; daily output, from a few thousand board feet to several hundred thousand feet; and other contrasts of like nature.

This wide variety in types of equipment does not, however, mean that the individual logging operator is always in a position to exercise a wide degree of choice within his own operation. In striking the necessary balance between capital investment structure and temporary operating economy, he is often limited to one or two standard machinery types, which, like "Jack-of-all-trades", are expected to handle after a fashion all situations to be met with, but which may not be particularly well fitted for any one specific case.

The accompanying illustrations, Figures 2 to 4 , show the general plan of operation of machinery and methods studied. Brief descriptions follow.

6. Skyline Systems.-The skyline systems of yarding (skidding) and swinging are shown in Figure 2. The chief characteristic of all skyline systems is the cable (skyline) suspended between two supports (head spar and tail spar), and serving as a track for a trolley or carriage from which the rigging (choker line) is dropped to the ground to be hooked on to the $\operatorname{logs}$. The position of the carriage and the raising and lowering of rigging is controlled by drum and cable from the machine. This affords (by the tightening of main hauling and haulback lines) a more or less vertical lift of the $\log$ s, thus allowing full or partial suspension of the logs on their way in to the landing. Each set-up of the skyline is called a "road" which generally takes in a fanshaped area, 75 to 150 feet in width at the back end (tail spar), and tapering to the common meeting point of all roads at the head spar, as shown later in Figures 7 et seq.

In the "slack-line" system (Fig.-2,C), the rigging is lowered by slacking the skyline itself. which is reeled on a large drum. With the skidder, on the other hand, the rigging is paid out from the suspended carriage by means of a special slack pulling line, which either operates in the conventional manner shown in Figure $2 \mathrm{~A}$ or by means of a patented mechanical device built into the carriage (canyon carriage) which facilitates the lowering of the rigging from greater heights than is possible with the ordinary slack puller.

The term "interlocking" skidder refers to the arrangement whereby main line and haulback drums can be interlocked mechanically when desired. This allows the haulback receding line) to be paid out at approximately the same speed as the main line is taken in, thus keeping the lines taut to give better control of the load.

The large steam slack-line machines and skidders usually are mounted on railroad trucks and are thus restricted to operation directly from the railroad track. In some cases they are mounted on sleds. Their operating range from the track may be extended as far as 3,00n $\mathrm{OI}^{\circ}$ 4,000 feet, or more if the topography permits. Generally, however, the economical operating radius (yarding distance) varies between 1,000 and 2,500 feet. Gasoline-driven skidders and slack-line yarders in present use are mounted on sleds. This allows their placement either at or away from the track.

The North Bend and Tyler systems of skyline logging are used principally for swinging. Their advantage lies in the fact that they can be operated with the ordinary type of donkey engine, and hence may be improvised in high-lead operations without necessitating specially built machinery. Figure 2, E, F, and G, illustrates their departure from the systems described above.

7. High-lead System.-Figure 2, H illustrates the high-lead method of yarding. The principal feature of this system, as comparer svith the old fashioned ground yarding, is tl Cievation of the main hauling line through a high-lead block suspended from a spar tree at elevations usually ranging from 100 to 200 feet above the ground. The lifting tendency thus exerted on the load saves power and reduces hang-ups when the load strikes obstructions. Its effectiveness in this respect, however, is not nearly 

so great an with the skyline system, except within "-hurt listance of the spar tree.

I ars" that "r electric high-lead yarders are nituith minuted on railroad trucks together "I.. on waling unit, and operate when so wher wily from the railroad track. In 4 cnuline-driven yarders in present use 1. cases mounted on sleds, and are genin aced for gathering in the logs at some $i r=h$.

msediate point between the stump and the

Ithe economical operating radius of even the w ruer high-lead machines seldom exceeds 1,000 $\ldots+$. , and is generally confined to 600 or 800 i...1: for the smaller machines, usually somewhat less. Beyond these distances the advanwhe of the high-lead in lifting the loads over mintructions is lost; it becomes in effect a sround lead."

8. Tractor Systems.-The principle of operarm in yording or roalding with tractors difIf frum all the other power methods in that 1. He machune itself travels in and out with each wad. It s well adapted for logging on level yround hut uprerates most efficiently on slopes from 5 to 20 per cent. On steep ground it is largely limited to favorable slopes under 50 jar cent, or, with such heavy trailer attach-

\section{BASIS OF TIML}

10. Deficiencies in Present Cost Intormation.In order to gain a basic understanding of fogsgiig costs, it is necessary to obtain all intimate knowledge of cost relatims and to $\rightarrow$ tud clonely the extent to which varume factors mill alfet conts. It has long been eommon knowlidye among leggring operators that costs aro

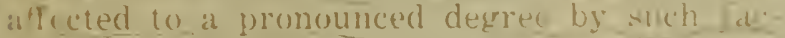
tor as size and density of tinbler, distance. grmund conditions, and topogralphy, ats well at thy the methods employed and the effi rentey wi and machines, ete. The seremingly infint (momplesties involved in tracing to the all

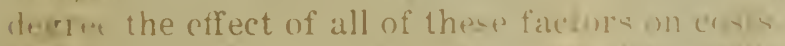
and further (lifficulties of applyille the restill in "verv-day logging have discouraped the m-

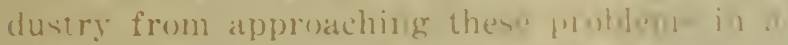
-1 stematic and thorougl'-gorine mantier

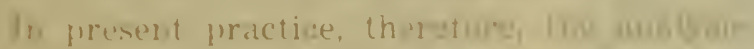

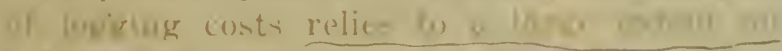

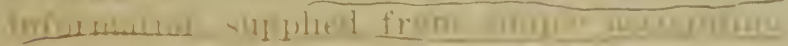

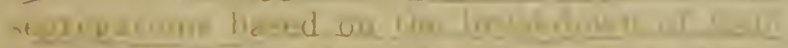

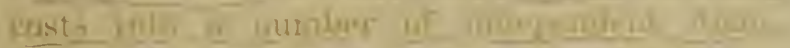

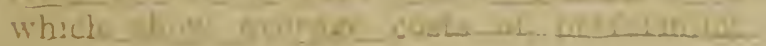

ments as the fair-leid arch shers in Figu $1-A$, and 6 , generally not war is por ce: Further limitations in its use orem in $\geqslant$ wam ground, or on clay soils in wet krather

Tractors can conveniently be con. rited to conventional method of high-lead salung mounting a special drum attachmenl urve on the tractor ds shown in Figure 3. It of $f$ quently so used under conditoms requiring $f$ quent moving and rigging thead for we quantities of timber. This $1, \ldots$ of an w will hereinafter be referred ! i "trac donkey."

9. Loading Systems.-The loadis yine frequently mounted together with $w$ ordi engine and operated from the same - a.p. power. This is generally true of the hi for system (Figure 2A), the McLoen l wom : (Figure $4\left(^{\circ}\right.$ ) and the duplex $x y-10$ (Fig 4D). The jammer or McGiffert load.r ( $F$ ure $4 \mathrm{~A}$ ) is a specially designed loader. wid used in other regions. It has fwn introduc in this region only recently in cununction * tractor logging. The locomotive mene (Fin $4 \mathrm{~B})$, originally designed for generst wdust purposes, has of late years found wide ust loading logs as well as in yardmux and loadi close to the track.

\section{ANI) COST ANALYSIS}

great number of widely differing lath Ex rience and judgment supply in surm meast the means of adapting these areragen to spec conditions.

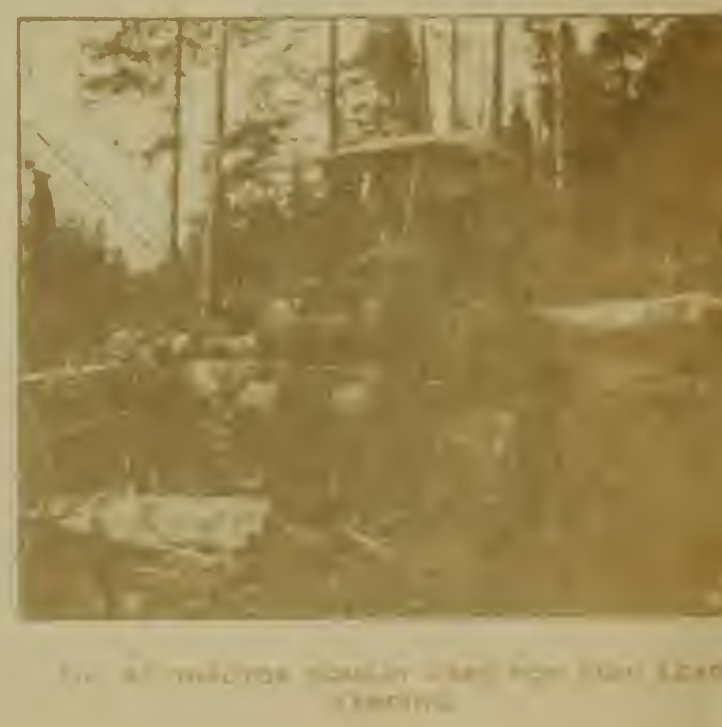





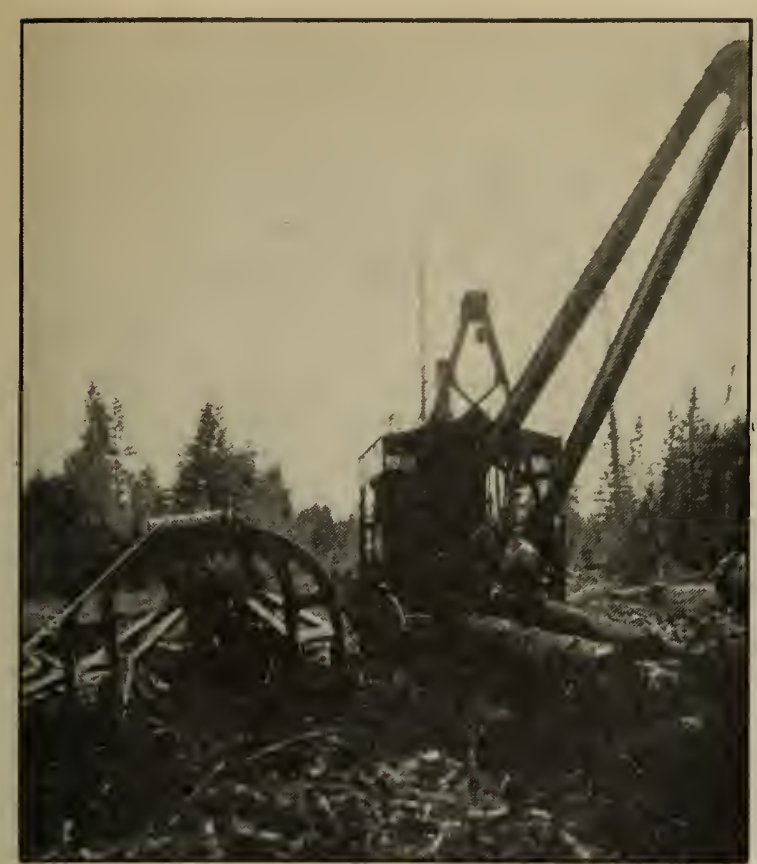

FIG. $4 A-12 \times 12$ MCGIFFERT LOADER (JAMMER) AND 10-TON TRACTOR DRAWING FAIRLEAD ARCH

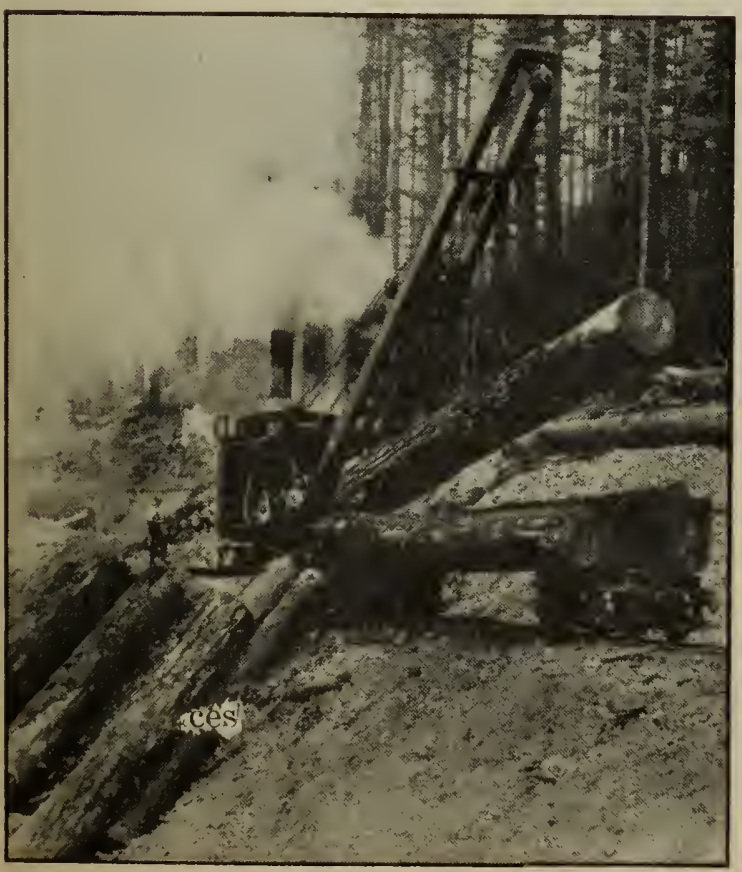

FIG. 4 B-LOCOMOTIVE CRANE WITH HEEL BOOM

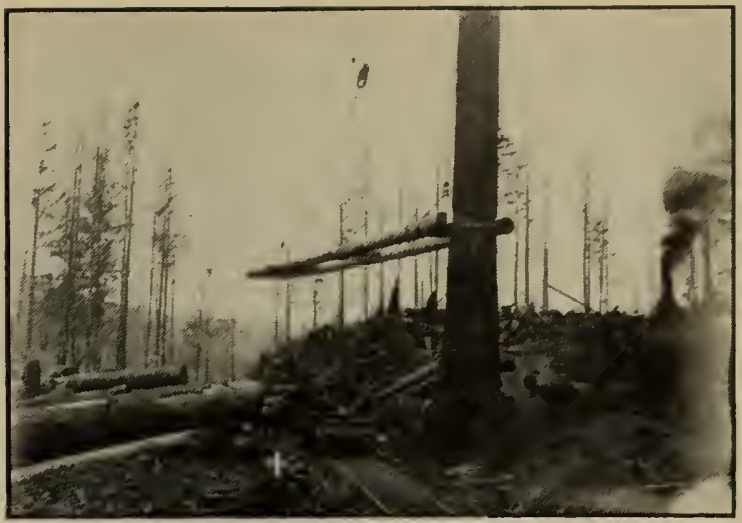

FIG. $4 C-10 " \times 12 "$ LOADER WITH MCLEAN BOOM

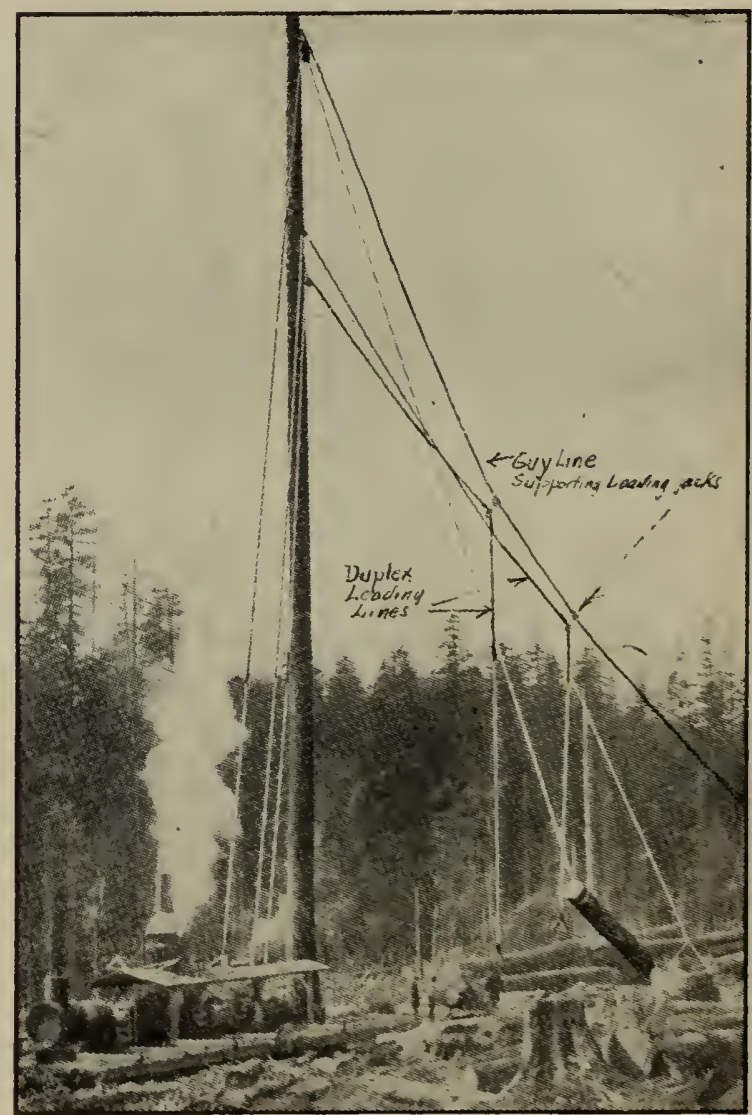

FIG. $4 D$-DLPLEX LOADING SYSTEM 
The following table shows the principal segregations called for in the standard accounting system used by the West Coast Lumbermen's Association, which with many additional subdivisions is widely used in the industry. The cost data in the table represent actual average costs reported by certain members of the association for the first six months of 1931, a period representative of the main period during which the field studies hereinafter reported were conducted.

TABLE 1

Operating costs detailed by tasks in dollars per. $M$ feet b.m.

\begin{tabular}{|c|c|c|c|}
\hline $\begin{array}{l}\text { Task } \\
\text { Rigging ahead }\end{array}$ & $\begin{array}{l}\text { otal cost } \\
\$ 0.11\end{array}$ & $\begin{array}{l}\text { Labor } \\
\$ 0.11\end{array}$ & Expense \\
\hline Felung and bucking & .86 & .84 & $\$ 0.02$ \\
\hline Yarding and loading. & 1.76 & 1.22 & .54 \\
\hline Wire rope & .24 & & .24 \\
\hline Railroad & 1.14 & .60 & .54 \\
\hline Spur track. & .39 & .25 & .14 \\
\hline Water haul & .35 & & .35 \\
\hline Booming and rafting & .17 & .08 & .09 \\
\hline Boom stick towing & .09 & 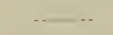 & .09 \\
\hline $\begin{array}{l}\text { Depreciation, lo } \mathrm{g} \mathrm{g} \text { in } \mathrm{g} \text { anc } \\
\text { transportation }\end{array}$ & .67 & & .67 \\
\hline $\begin{array}{l}\text { Administration a nd genera } \\
\text { expense }\end{array}$ & .73 & .26 & \\
\hline Stumpage & 2.75 & & 2.75 \\
\hline Total cost, details reported 2 & $-\$ 8.73$ & $\$ 3.07$ & $\$ 5.66$ \\
\hline $\begin{array}{l}\text { Taken from "Analysis of Douglas } \\
\text { West Coast Lumbermen's Associa } \\
\text { The figures do not balance in vert } \\
\text { averages carry different weights } \\
\text { averages. }\end{array}$ & Fir Costs & $\begin{array}{l}\text { nd Sales } \\
\text { of Junne, } \\
\text { because } \\
\text { se of the }\end{array}$ & $\begin{array}{l}\text { Returns," } \\
1931 . \\
\text { the tot:11 } \\
\text { e itemized }\end{array}$ \\
\hline
\end{tabular}

Such cost statements covering for any given logging operation the cost of handling the average thousand-foot unit of logs under average conditions are indispensable in the general control of the business, and are useful for many other specific purposes. However, they do not disclose variations from the average that may apply to specific portions of the total volume of logs represented in any given cost average, and, therefore, fail to reveal to what extent economically unsound practices, hidden behind what possibly may be considered a satisfactory group-average cost, may have crept in to destroy profits. Hence, they do not furnish a valid basis for the solution of a great number of the important internal operating and management problems which the logging operator must solve in order to secure maximum returns. Specific knowledge of cost and cost relations applicable to measured quantities of work is a basic requirement in industrial management. Such knowledge can best be obtained from time and cost studies, properly analyzed to reveal not only the average cost for the whole, but the departures from the average of constituent parts, which, in the aggregate, make up the whole.
11. Objects and Functions of Time and Cost Studies.-The primary object of the time and cost studies here reported is to demonstrate by means of a series of intensive studies the costs and cost relations that arise within any given logging operation through variations in certain conveniently measureable factors, which are known to have a definite effect on cost. Of these, size of timber is the most important in that it affects in varying degree virtually all items of cost from the stump to the pond or market. The effect of size variations has thus been investigated in connection with yarding, swinging, roading, loading, railroad operation, booming, and rafting, and other subdivisions of cost which intimately follow variations in the cost of one or the other of these items. A résumé of a study of the effect of size of timber on felling and bucking cost by the United States Forest Service is also included. Next in the order of general importance is the distance the log must travel from the stump to the car. Its effect on the cost of yarding, swinging, and roading has also been investigated closely. Finally there are a number of other factors such as density of timber, topography, and carloadings, which do not require actual time studies for their analysis, but which, nevertheless, must be analyzed systematically in order to determine their effect on costs.

Another object, different in character and independent of the objects stated above, is to compare the economic efficiency of the various types of yarding and swinging machinery under various conditions of logging. This question is an important one in considering the logging operation purely from the standpoint of costs. It becomes even more important in the ultimate coordination of efficiency in logging with various schemes of economic selection. The yarding operation occupies the key position in the intensive application of management principles, and much depends on how it can be performed best to further the ultimate purpose in view.

In reaching ultimate conclusions in studies of this character, many factors must be considered. To take the logging operation apart to find just how each minor part f ...n tions by itself may or may not give the final answer. The typical logging operation is composed of a series of operations or activities which follow €ach other in a certain sequence; railroads are built; trees fei'ed and bucked; logging machinery moved into place; logs are yarded and loaded, or perhaps cold decked, swung, and 
loaded, etc.; log cars are brought to the landing, loaded with logs, and sivitched to the make-up track; then hauled to the pond or market for unloading, booming, rafling, etc. Some of these activities, such as felling and bucking, and cold decking, are largely independent of the rest; costs and cost relations, therefore, may be derived with the assurance that they are significant.

Other activities such as direct yarding, swinging, loading, roading, and switching, etc., are usually carried on concurrently with each other and may become so interrelated that cost studies of any particular one are not conclusive without full consideration of those that precede or follow. One or the other in such a series of more or less interdependent activities will usually set the pace to which each of the oth rrs will either adjust itself or else in turn assume the function of pace setter for the others for various intervals of time. The significance of cost relations applicable to each of such activities thus depends on whether it is a controlling or a controlled activity or both.

Likewise, it may not be of immediately practical significance to find, for example, that yarding can be done cheaper with one type of equipment or method than with another, if thereby the synchronization of the combined yarding-loading-switching or yarding-swinging-loading-switching operation, etc., will be adversely affected. The operation as a whole must be considered along with each individual activity. Interdependent activities which are carried on concurrently have to be synchronized; railroad construction and operation must be balanced against alternative costs of other means of transportation. Viewed through the tiny peephole of a study of any particular activity, some of these considerations may fall beyond the immediate field of vision and so require a readjustment in the final analysis. It is the function of organization and management to choose the machines and methods which separately or in combination with others are best adapted to perform a given task or series of tasks, and to combine these with proper planning of the logging area and proper operating practices $\because$ to the most profitable operation. To assist in this, time and cost studies of individual activities serve to furnish basic information.

12. Adaptability of Cost Data to Changing Cost Levels.-In general, the procedure followed in studying various activities consists of taking stop-watch time observations of all principal time elements of the logging operation, and of measuring the amount of work performed in terms of distance transported and volume produced. The time required in yarrling, swinging, loading, etc., for logs of various sizes and for different distance segregations is thus determined for each machine. From thase data is calculated the time in $m$ nutes per thousand-foot urit of logs, which represants the ultimate answer in the time studies proper.

In order to translate time in minutes pe! thousand into cost per thousand, it is necessary to set up the cost of operating each machine. From this is derived the operating cost per minute, which, multiplied by the time in minutes per thousand, gives the cost pel thousand-foot unit of logs.

The fact that money costs lack stability, particularly during the present period of economic upheaval, is an inconvenience, but does not seriously impair the significance of the results obtained. Each cost study table lists in the footnotes the machine rate (cost of operation of a given operating unit) on the basis of which the cost per thousand board feet is computed. To reestablish costs on the basis of a different machine rate, if that were desired, it would be necessary to calculate the ratio between th? machine rate desired and the machine rate originally used in the tables and to multiply per $M$ costs by this ratio. Test cost data may thus be brought up to date as often as desired, or they may be made to fit any particular cost level that the logging operator may wish to establish for his own standard in preference to the one used in the cost table. This, of course, does not carry the suggestion that the results of any one of the studies here reported can be made to fit a set of conditions that are not reflected in the study itself, but implies only that the flexibility of the cost data is unlimited insofar as adaptation to changing cost levels or machine rates is concerned.

Another significant use of time-study results consists of their direct adaptation to the current cost record of the logging operation whereby cost figures are obtained that are correcterl currently both for variations in the rarious machine rates and for variations in the time per $\mathrm{M}$, as this item changes for one location or another. Further detail on this method of analysis is given in Chapter XVI. In this case. time studies serve to furnish data on cost relations only, while corresponding actual costs are interpreted directly from current performance records. For this particular purpose it plainly does not matter what the basis of cost may be 
in the original time-study table; in fact it would not matter whether the time study carried any cost data or not, because the time per $\mathbf{M}$ data would serve the same purpose.

13. Basis of Machine Rates.-Data on machine operating cost were obtained where available directly from records kept in the logging operations studied, supplemented by data from other sources as needed. Table 2 shows a record of cost data applying to one of the machines covered in the study. Similar tabulations were made for all machines. A summary for different groups of machines is given in Table 3.

TABL:L: 2

Machine heates--zon h.p. Diesel High-lead Y'arder.

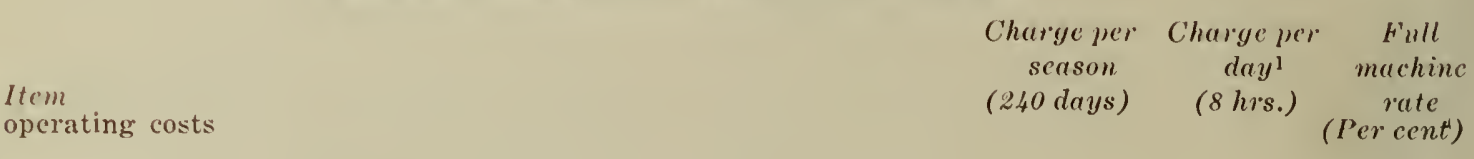

Labol :

1 hook tender

1 rigging slinger

1 chaser

4.00

1 signal man

3 chokersetters

12.00

1 engineer

Extra labor (Av.)

3.50

Industrial insurance, $5 \%$

2.08

Total labor

$\$ 43.58$

Supplies:

Fuel

Grease, oil, waste, etc.

Wire rope and rigging

Total supplies

$\$ 3,300.00$

$\$ 19.34$

21.1

Maintenance and repairs (2 yrs. Av.)

$2,244.50$

9.35

10.2

Uninsured risks, etc. (rate, $5 \%$ of Av. value), $\$ 17,040 \times 0.05$

852.00

3.55

Ownership costs

Depreciation (D)

Initial cost (I) $\$ 21,300$ (Present age $3 \mathrm{yrs}$.)

Rate of depreciation, $10 \%$-until depreciated to $\frac{\mathrm{I}}{2}: \$ 21,300 \times 0.10$

$2,130.00$

8.88

9.7

Interest: Rate, $6 \%$ of av. value (5-yr. av.)

$$
\frac{\frac{\mathrm{I}+\mathrm{I}+\mathrm{D}}{2}}{2}=\frac{21,300+10,650+2,130}{2}=17,040
$$

Fire insurance: Rate, $2.5 \%$ of Av, value (5-yr. average) $\$ 17,040 \times 0.025$

Taxes: Rate, $1.5 \%$ of av. value $\$ 17,040 \times 0.015$

255.60

Total (Full machine rate)

$\frac{1.07}{\$ 91.80} \quad \frac{1.1}{100.0}$


TABLE 3

Machine rates per 8-hour day

(Yarding Only)

12"x14" Steam Skidders ${ }^{1}$

$12^{\prime \prime} \times 17^{\prime \prime}$ Slackline Yarder 1

300 H.P. Gas. Slackline Yarder

$12^{\prime \prime} \times 14^{\prime \prime}$ High-Lead Yar'der 1

200 H.P. Diesel High-Lead Yarders

125 H.P. Gas. Diesel H.L. Yarders

100 H.P. Gas. Diesel H.L. Yarders

30-35 H.P. Gas. Diesel H.L. Yarder's

60 H.P. Gas. Crawler Tractor with

Fair-Lead Arch \& Yarding Crew

350 H.P. 12x14" Skidders ${ }^{1}$

$12^{\prime \prime} \times 17^{\prime \prime}$ S'ackline Swing ${ }^{1}$

12 "x 11 " North Bend Swing 1

60 H.P. Crawler Tractor with

Fair-Lead Arch-Driver Only

$12 " x 14 "$ Skidders

$12^{\prime \prime} \times 14 "$ High-Lead Units

Percentagc distribution of full machine rate Average

Current operating costs

Labor $F$ int,

$\begin{array}{rll}\text { Labor Fuel, } & & \text { manday employed } \\ \text { Full } & \text { incl. wire Maint. Unim including }\end{array}$

machine indus. rope and and stered I)epre. Interest Insur. indus. extre

Basis rate insur. rigging repairs risk ciation and toxes ance insur. labor

Number lollars I'erCent PerCent P'erCent J'erCent PerCent PerCent PerCent Dollars Number

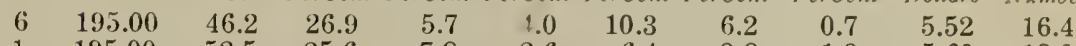

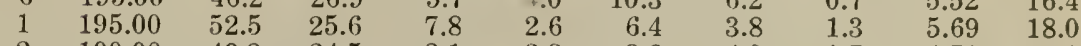

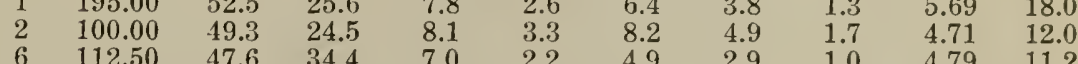

$\begin{array}{rrrrr}3 & 92.00 & 49.6 & 34.4 & 7.0 \\ 1 & 62.55 & 51.2 & 30.0 & 6.2\end{array}$

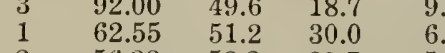

$\begin{aligned} & 1 \\ & 2\end{aligned}-56.33-52.3-29.7-6.2$

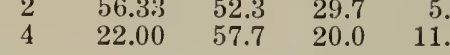

$4.1 \quad 10.2$

$2.2 \quad 6.0$

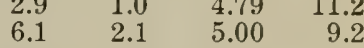

$\begin{array}{lllll}1.4 & 6.8 & 2.1 & 0.7 & 4.29\end{array}$

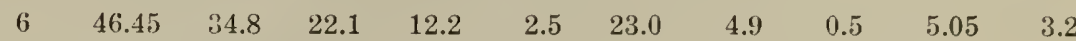

(Swinging Only)

$\begin{array}{rrrrrrrrrrr}4 & 160.75 & 40.7 & 28.4 & 6.8 & 5.3 & 11.2 & 6.7 & 0.9 & 5.39 & 12.1 \\ 1 & 155.00 & 40.2 & 32.3 & 9.8 & 3.2 & 8.1 & 4.8 & 1.6 & 5.20 & 12.0 \\ 4 & 115.20 & 37.5 & 44.4 & 7.0 & 2.0 & 4.7 & 3.3 & 1.1 & 4.80 & 9.0\end{array}$

$2 \quad 33.80 \quad 16.8 \quad 30.4 \quad 16.7$

(i) $\quad 250.00 \quad 46.7$ (Yarding and Loading)

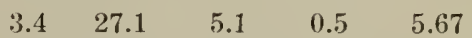

1.0

$\begin{array}{llll}165.00 & 49.3 & 31.0 & 7.2\end{array}$

(Loading Only)

Jammer

$1 \quad 59.43$

$\begin{array}{lll}44.4 & 17.7 & 10.6\end{array}$

$\begin{array}{llllll}4.1 & 10.6 & 6.3 & 0.8 & 5.80 & 20.2\end{array}$

$\begin{array}{rrrrrr}2.4 & 5.8 & 3.1 & 1.2 & 5.35 & 15.2\end{array}$

$\begin{array}{llllll}5.3 & 13.2 & 8.0 & 0.8 & 4.80 & 5.5\end{array}$

'Yardinx and swingins integrated with loading, but costs have heen allo-ated to each operation separately. Loading costs are obtained by doducting in each case the costs allocated to yarding or swinging from total yarding and loading or swinging and loading costs.

Based on the data in Table 3, the following summary, which gives percentage distribuiton of costs, represents the average yarding-swinging-loading operation:

\section{TABLE 4}

Summary of percentage distribution of machine rate for yarding, swinging, and loading operations

Total

machine rate

(Percent)

Opelating labor

43.0

Industrial insurance at $5 \%$ of pay roll

2.2

27.8

Fuel, wire rope, and rigging supplies

7.3

3.7

9.5

Uninsured risks, etc.

5.5

Interest and taxes

1.0

Fire insurance

100.00

$$
\text { Total }
$$

In present cost-keeping practice only a portion of these costs are ordinarily so segregated as to identify them directly with the particular activity to which they apply. Ordinarily the costs directly identified with a given activity, such as yarding, cold decking, swinging, etc., will be found to range from 40 to 80 per cent of the full machine rate. All cost data given in these reports refer to full machine rates unless otherwise specified.

\section{General Overhead Costs Not Included in} Machine Rates.-

Certain items of general overhead costs have been excluded from the machine rate set-up, such as supervision, management, office expense, interest on liquid working capital, etc. These represent generally from 10 to 20 per cent 0 : the full cost of operation. However, the small scale operator may often carry most of his overhead costs "under his hat", while the larger operations may be weighted down with a relatively heavy overhead burden. Such differences from one operation to another may be of importance in weighing the relative merits of different plans of organizing the operations but they have no direct bearing on the relative merits of different types of machinery as independent operating units. These variations in overhead costs have, therefore, been excluded at this stage of the report so as to confine the comparison to comparable items of cost. They will be considered later on in dealing with the logging operation as a whole (Chapters XVI and XVII).

\section{Basis of Capital Charges.-}

As may be noted in Table 2, annual capital charges or ownership costs are reduced to cost per day by dividing the working year into 240 8-hour days, which usually is considered a normal working year for logging machinery in this region. This figure has been applied to all machines in order to secure a fair basis for comparing costs for different machines and operations.

A similar treatment is given to charges set up to cover interest, fire insurance, operating risks, etc., in order to overcome inequalities in the provisions which different logging operators make for these items. Some companies, for example, insure themselves against virtually all insurable risks, while others carry little or no insurance, but do, for that reason carry the corresponding risk. Differences of this sort 
are, of eourse, less real than apparent. They have been smonthed by applying uniform rates of interest at 6 per cent: uninsured risks, 5 per cent; property taxes, 1.5 per cent; fire insurance, 0.75 per cent for machines mounted on wheels, and 2.5 per cent for machines mounted on sleds-all percentages applying to the current value of the machine. The allowance of 5 per cent of current capital value for uninsured risks is an arbitraly estimate designed to cover risks not otherwise provided for: These include weckage, employer's public liability, boiler insurance, fire protection. limited fire damage liability not covered by standard fire policies, and fire risk on lines and rigging (not included in machinery investment).

Depreciation elarges are treated in various ways to fit the different types of machinery. The investment in tractors is thus written of at the rate of 25 per cent annually, and small gasoline yarders $(30-35$ h.p.) at the rate of 20 per cent annually. For these two classes of short-life machinery, the straight line method of charging depreciation is used, i.c.. depreciation is carried through the life of the machine at a fixed percentage of initial cost until the capital investment is fully amortized.

For long-life logging engines the annual depreciation rate used is ten per cent of the initial cost for the first five years and five per cent for the second five year period. The five per cent rate may either be carried through until fully amortized or halved again at the end of the five-year period. This step by step reduction of depreciation charges provides for quick amortization at the beginning as a safeguard against obsolescence and tends to equalize depreciation and maintenance costs as the machine grows older.

Three of the larger machines listed in the table had been witten off the books of the company, but were nevertheless in good working order, having been more or less completely rebuilt in recent years. Capital charges for these were set up on the basis of fair appraisal value.

\section{Other Costs.-}

Considerable variation in the operating costs of identical kinds of machines in different operations was due to variation in the number of men in the crew and to difference in wage scales, which at the time of these studies, were in a state of flux, wage reductions having been put into effect in some operations earlies than in others. Other differences may in some cases have been duc more to incompleteness of eost recolds than to actual valiations in costs. Fully reliable cost data on such items as wire rope, rigging, maintenance, and repairs were difficult to get, because cost records were rarely kept for indivirlual machines.

The differences shown in the average man-day wage for different kinds of machines are due partly to actual differences in comparative wage rates, and partly to the fact that the opcration of some machines involves harder and more hazardous work or calls for a greater share of highly skilled labor than others. For example, the difference in wages between the $\$ 4.29$ per day for the 35 h.p. gasoline yarder class and the $\$ 5.52$ for the 12 " $\times 14$ "skidder class is largely to be accounted for by the different type of work involved.

Extra labor covers prorated time of watchmen, woods foreman, delivery of fuel or water, etc. This charge is translated into equivalent man-days at the approximate rate paid to common labor. Thus, the number of men for the machine listed in Table 2 is given as 9 although only 8 men are actually employed in the regular crew.

\section{YARDING STUDIES}

17. General Importance of the Yarding Operation.-In a very broad sense, yarding is often understood to include swinging and loading, i.e., takes in the whole operation from stump to car. In this sense it generally represents 20 to 50 per cent of the total logging costs (exclusive of stumpage). In the stricter sense of including only the actual yarding of the log from the stump to the first landing, it represents on the average only 10 to 20 per cent of total costs, thus ranking about equally with felling and bucking, or swinging and loading, or railroad construction, or railroad operation. From the standpoint of cost analysis, however, yarding as conducted in typical operations in this region is by far the most important phase of the logging operation because it is in most cases a pace-setting activity or the "bottleneck" which controls the flow of logs to other activities. For this reason, as well as on account of the fact that yarding costs fluctuate widely with variation in the yarding show, the yarding operation has received a great deal more attention in this series of logging cost studies than have any of the other activities.
18. Scope and Object of Yarding Studies.Yarding time and cost studies were conducted in 30 different settings distributed among 14 logging operations scattered throughout the region. They represent wide variations of topography, size and density of timber, operating practices and types of yarding equipment and methods. The objective in each of these studies was to determine the relation of size of $\log$ and yarding distance to yarding costs. Study areas were selected with a view to obtaining for each major group of yarding machinery a fairly representative sampling of good, poor, and average yarding shows; allowing contrasts to be made between dense timber and scattered timber, small timber and large timber, rough ground and smooth ground, uphill yarding an ${ }^{\prime}{ }^{1}$ downhill yarding, etc. These conditions are illustrated in Figures Nos. 5 to 27. A total of approximately 20,000 logs, scaling nearly $20,000,000$ board feet log scale, are included in these studies.

19. Manner of Study.-In general the time study work consisted in recording for each 
turn, the diameter, length, and scale of each $\log$ in the turn, the distance yarded and the total turn time, as well as detailed time segregations of hauling, haulback, hooking-on, unhooking, and various classifications of delay time. In this work field crews of two to four men, equipped with stop watches, scale sticks, etc., were stationed at strategic points where all details of the yarding operation could be observed. Scaling was done with the Scribner Dec. C. rule and diameters recorded to the nearest inch according to U. S. Forest Service practice. No deductions were made for defect. After the time study on a yarding area had been completed profiles were run of the yarding roads and a topographic map was made, using a contour interval of ten feet. (See Figs. 5 to 27 ).

From the analysis of these data were derived detailed time, cost, and output tables similar to Table 5A. Close inspection of these tables is required in order to trace the effect of yarding distance and volume of log on yarding costs. The tables are divided into sections, each section representing a certain yarding distance. Differences between corresponding values from one section of the table to another show, then, the effect of yarding distance on time and cost. Differences between values listed opposite the log volumes show the effect of volume of $\log$ on time and cost. Footnotes in the tables give the basis of translating time into cost as well as further explanatory data.

20. Distinction Between External Yarding Distance and Actual Yarding Distance.-Table 5 gives a summary of costs and outputs for six different $\log$ volumes and yarding distances. The data in the leit hand side of the table listed under the heading "actual yarding distances" have been read directly from the detailed time study tables (Table 5A). "Actual yarding distance" here represents the actual distance from $\log$ to landing; this being the sense in which yarding distance was dealt with in recording distances in the field.

In the right hand half of the table, costs and output are shown for various "external" yarding distances. By "external yarding distance" is here meant the distance from the landing to the outside boundary of the logging area. This is the sense in which the term "yarding distance" is used in every-day logging parlance. In translating the cost at the actual yarding distances to cost of yarding within the external yarding distances it has been assumed that the density and size distribution of the timber is uniform over the entire yarding area.

TABLE 5

Costs and outputs of yarding with 60-h.p. craw cr tractor with fair-lead arch, for various distances and $\log$ volumes

(Cost in dollars per M feet B.M.)

rol. of loy

in fert b.m.

100

200

400

800

1600

3200

\section{0}

200

400

800

1600

3200

\section{0}

200

400

800

1600

3200

$\begin{array}{rr}0000 & 1000 \\ 3.10 & 3.60 \\ 1.70 & 1.96 \\ 1.00 & 1.17 \\ .65 & .79 \\ .46 & .58 \\ .30 & .40\end{array}$

15

27
47

71

101

155

150
136
117
89
63
48

150
136
117
89
63
48

$\begin{array}{cccc} & & \\ 1500 & 2000 & 2500 & 3000 \\ 4.18 & 4.68 & 5.22 & 5.71 \\ 2.24 & 2.54 & 2.80 & 3.07 \\ 1.33 & 1.50 & 1.68 & 1.87 \\ .95 & 1.09 & 1.24 & 1.39 \\ .72 & .86 & 1.00 & 1.13 \\ .51 & .63 & .75 & .87\end{array}$

(Output per 8-hour day-M feet B.M.)

$\begin{array}{rrrrrr}11 & 10 & 9 & 8 & 17 & 1 \\ 21 & 18 & 17 & 15 & 30 & 27 \\ 35 & 31 & 28 & 25 & 52 & 4 \\ 49 & 42 & 37 & 33 & 82 & 7 \\ 64 & 54 & 47 & 41 & 120 & 98 \\ 90 & 73 & 62 & 54 & 188 & 15\end{array}$

(Output per 8-hour day-No. of Logs)

$\begin{array}{rr}89 & 111 \\ 119 & 103 \\ 100 & 87 \\ 74 & 61 \\ 50 & 40 \\ 36 & 28\end{array}$

600
2.80
1.54

1.54
.88

.56

.56
.38

.38
.25

1000 Hixtc

\subsection{6}

1.73

1.01

.67

.47

.31

15
27
46
70
98
151

99
91
77
53
34
23

89

$\begin{array}{lll}81 & 166 & 148\end{array}$

76

62

69

47

29
20

42
26

26
17

$131 \quad 114$

$103 \quad 87$

$75 \quad 61$

$\begin{array}{cccc} & & & \\ 1500 & 2000 & 2500 & 3000 \\ 3.54 & 3.92 & 4.28 & 4.60 \\ 1.93 & 2.12 & 2.31 & 2.49 \\ 1.15 & 1.26 & 1.37 & 1.47 \\ .78 & .88 & .98 & 1.08 \\ .57 & .66 & .75 & .84 \\ .39 & .47 & .54 & .61\end{array}$

.39

$\begin{array}{rrrr}13 & 12 & 11 & 10 \\ 24 & 22 & 20 & 19 \\ 40 & 37 & 34 & 32 \\ 58 & 53 & 47 & 43 \\ 82 & 70 & 62 & 54 \\ 119 & 103 & 87 & 74\end{array}$

$\begin{array}{rrrr}131 & 119 & 109 & 101 \\ 120 & 108 & 101 & 93 \\ 100 & 92 & 85 & 79 \\ 73 & 66 & 59 & 54 \\ 51 & 44 & 39 & 34 \\ 37 & 32 & 27 & 23\end{array}$

'Costs listed tul these columns in the upper division of the talle are taken from column 14 in the time study table (Table $5-\mathrm{A}$ ); they ren. resent the turn by turn cost (yarding variable) at various actual yarding distances.

-Costs represent average yarding vartable costs withis: the extcrul yarding distance stated. 
600 F() O T Y $\triangle R$ L I N G I) IS T A N E

\begin{tabular}{|c|c|c|c|c|c|c|c|c|c|c|c|c|c|c|c|}
\hline \multirow{2}{*}{$\begin{array}{l}\text { Volume } \\
\text { of log } \\
\text { in } \mathrm{ft} \text {. } \\
\text { b.m. }\end{array}$} & \multirow{2}{*}{$\begin{array}{c}\text { Top } \\
\text { diameter } \\
32-\mathrm{ft} . \\
\log \\
\text { (curved) }\end{array}$} & \multirow[b]{2}{*}{$\begin{array}{l}\text { No. of } \\
\text { logs } \\
\text { per } \\
\text { turn }\end{array}$} & \multirow[b]{2}{*}{$\begin{array}{l}\text { Volume } \\
\text { in feet } \\
\text { b. m. per } \\
\text { turn }\end{array}$} & \multicolumn{6}{|c|}{ Time in minutes per turu } & \multirow{3}{*}{$\begin{array}{c}\text { Time } \\
\text { per } \\
\text { M b.m. } \\
\text { Minutes }\end{array}$} & \multicolumn{2}{|c|}{$\begin{array}{l}\text { Production } \\
\text { per 8-hr. dity }\end{array}$} & \multirow{2}{*}{$\begin{array}{c}\text { Yarding } \\
\text { variable } \\
\text { cost at } \\
\$ .0968 \mathrm{per} \\
\text { yarding } \\
\text { minutes }\end{array}$} & \multirow{2}{*}{$\begin{array}{l}\text { Approx. } \\
\text { tree } \\
\text { diam. } \\
\text { (dbh) }\end{array}$} & \multirow[b]{2}{*}{$\begin{array}{l}\text { Basis } \\
\text { No. o } \\
\text { log } 3\end{array}$} \\
\hline & & & & $\begin{array}{l}\text { Haul- } \\
\text { back }\end{array}$ & Mauling" & $\begin{array}{l}\text { Hook, } \\
\text { nhook and } \\
\text { hang-ups }\end{array}$ & $\begin{array}{l}\text { Pro- } \\
\text { rated } \\
\text { delays }\end{array}$ & $\begin{array}{l}\text { Side- } \\
\text { lining }\end{array}$ & $\begin{array}{l}\text { Total } \\
\text { yarding } \\
\text { time }\end{array}$ & & $\begin{array}{l}\text { No. } \\
\text { of } \\
\text { logs }\end{array}$ & $\begin{array}{c}\text { Gross } \\
\text { scale } \\
M \text { b.m. }\end{array}$ & & & \\
\hline $\mathbf{B}, \mathbf{m}$. & Inches & Pes. & $13 . \mathrm{m}$ & Minutes & Minutes & Minutes & Minutes & Minutes & Minutes & & P's. & M b.m. & 1)ollars & Inches & Pes. \\
\hline 100 & 9.3 & 4.30 & 430 & 2.85 & 2.64 & 6.31 & 1.27 & 0.70 & 13.77 & 32.02 & 150 & 15 & 3.10 & 16 & 542 \\
\hline 200 & 13.3 & 3.75 & 750 & 2.85 & 2.83 & 5.65 & 1.27 & .60 & 13.20 & 17.60 & 136 & 27 & 1.70 & 22 & 1118 \\
\hline 300 & 15.5 & 3.38 & 1014 & 2.85 & 3.05 & 5.20 & 1.27 & .52 & 12.89 & 12.71 & 126 & 38 & 1.23 & 27 & 6() 1 \\
\hline 400 & 17.5 & 3.03 & 1212 & 2.85 & 3.10 & 4.79 & 1.27 & .45 & 12.46 & 10.28 & 117 & 47 & 1.00 & 31 & 350 \\
\hline 600 & 20.5 & 2.50 & 1500 & 2.85 & 3.18 & 1.20 & 1.27 & .35 & 11.85 & 7.90 & 101 & 61 & .76 & 38 & 465 \\
\hline 800 & 24.0 & 2.11 & 1688 & 2.85 & 3.213 & 3.79 & 1.27 & .25 & 11.39 & (i. 75 & $8 ! 1$ & 71 & .65 & 12 & 274 \\
\hline 1000 & 26.0 & 1.83 & 1830 & 2.85 & 3.27 & 3.50 & 1.27 & .20 & 11.09 & 6.06 & 79 & 79 & .59 & 47 & 117 \\
\hline 1200 & 28.7 & 1.64 & 1968 & 2.85 & 3.30 & 3.31 & 1.27 & .15 & 10.88 & 5.53 & 72 & 87 & .54 & 52 & 101 \\
\hline 1600 & 34.0 & 1.11 & 2256 & 2.85 & 3.34 & 3.10 & 1.27 & .10 & 10.66 & $4.7: 3$ & 63 & 101 & .46 & 59 & 103 \\
\hline 2000 & 36.8 & 1.26 & 2520 & 2.85 & 3.39 & 2.95 & 1.27 & .08 & 10.54 & 4.18 & 57 & 115 & .40 & 65 & 56 \\
\hline 3000 & 44.5 & 1.07 & 3210 & 2.85 & 3.47 & 2.78 & 1.27 & .01 & 10.41 & 3.21 & $4 !$ & 148 & .31 & 79 & 6 \\
\hline 1000 & 51.8 & 1.00 & 4000 & 2.85 & 3.55 & 2.72 & 1.27 & .01 & 10.40 & 2.601 & 46 & 185 & .25 & $\$ 1$ & 1 \\
\hline \multicolumn{16}{|c|}{1000 FoOT Y A R I ) $1 \mathrm{NG}$ D $1 \mathrm{~S} T$ A N ( : E } \\
\hline 100 & 9.3 & 4.60 & 460 & 4.13 & 4.27 & 6.67 & 1.27 & .77 & 17.11 & 37.20 & 129 & 13 & 3.60 & 16 & 542 \\
\hline 200 & 13.3 & 4.20 & 840 & 4.13 & 4.73 & 6.18 & 1.27 & .69 & 17.00 & 20.24 & 119 & 24 & 1.96 & 22 & 1118 \\
\hline 300 & 15.5 & 3.73 & 1119 & 4.13 & 4.98 & 5.62 & 1.27 & $.5 !$ & $16.5 ?$ & 14.83 & 108 & 32 & 1.44 & 27 & 601 \\
\hline 400 & 17.5 & 3.35 & 1340 & 4.13 & 5.07 & 5.16 & 1.27 & .51 & 16.14 & 12.04 & 100 & 40 & 1.17 & 31 & 350 \\
\hline 600 & 20.5 & 2.75 & 1650 & 4.13 & 5.20 & 4.45 & 1.27 & .40 & 15.45 & 9.36 & 85 & 51 & .91 & 38 & 465 \\
\hline 800 & 24.0 & 2.29 & 1832 & 4.13 & 5.28 & 3.96 & 1.27 & .30 & 14.9 .1 & 8.16 & 74 & 59 & .79 & 42 & 274 \\
\hline 1000 & 26.0 & 1.96 & 1960 & 4.13 & 5.33 & 3.63 & 1.27 & .22 & 14.58 & 7.41 & 65 & 65 & .72 & 47 & 117 \\
\hline 1200 & 28.7 & 1.74 & 2088 & 4.13 & 5.37 & 3.41 & 1.27 & .17 & 14.35 & 6.87 & 58 & 70 & .67 & 52 & 101 \\
\hline 1600 & 34.0 & 1.47 & 2352 & 4.13 & 5.44 & 3.15 & 1.27 & .12 & 14.11 & 6.00 & 50 & 80 & .59 & 59 & 103 \\
\hline 2000 & 36.8 & 1.30 & 2600 & 4.13 & 5.50 & 3.00 & 1.27 & .08 & 13.98 & 5.38 & 45 & 89 & .52 & 65 & 56 \\
\hline 3000 & 44.5 & 1.08 & 3240 & 4.13 & 5.65 & 2.79 & 1.27 & .04 & 13.88 & 4.28 & 37 & 112 & .41 & 79 & 6 \\
\hline 4000 & 51.8 & 1.00 & 4000 & 4.13 & 5.80 & 2.72 & 1.27 & .01 & 13.93 & 3.48 & 34 & 138 & .34 & 91 & 1 \\
\hline
\end{tabular}

\begin{tabular}{|c|c|c|c|c|c|c|c|c|c|c|c|c|c|c|c|}
\hline 100 & 9.3 & 4.90 & 490 & 5.67 & 6.33 & 7.05 & 1.27 & $.8: 3$ & 21.15 & 43.16 & 111 & 11 & 4.18 & 16 & 542 \\
\hline 200 & 13.3 & 4.65 & 930 & 5.67 & 7.12 & 6.73 & 1.27 & .78 & 21.57 & 23.19 & $10: 3$ & 21 & 2.24 & 22 & 1118 \\
\hline 300 & 15.5 & 4.23 & 1269 & 5.67 & 7.43 & 6.22 & 1.27 & .70 & 21.29 & 16.78 & 95 & 29 & 1.612 & 27 & 601 \\
\hline 400 & 17.5 & 3.78 & 1512 & 5.67 & 7.58 & 5.68 & 1.27 & .60 & 20.80 & 13.76 & 87 & 35 & 1.33 & 31 & 350 \\
\hline 600 & 20.5 & 3.03 & 1818 & 5.67 & 7.78 & 4.78 & 1.27 & .45 & 19.95 & 10.97 & 73 & 41 & 1.06 & 38 & 465 \\
\hline 800 & 24.0 & 2.47 & 1976 & 5.67 & 7.89 & 4.15 & 1.27 & .34 & 19.32 & 9.78 & 61 & 19 & .95 & 12 & 274 \\
\hline 1000 & 26.0 & 2.10 & 2100 & 5.67 & 7.93 & 3.77 & 1.27 & .25 & 18.89 & 9.00 & 53 & 53 & .87 & 47 & 117 \\
\hline 1200 & 28.7 & 1.85 & 2220 & 5.67 & 7.98 & 3.52 & 1.27 & .20 & 18.64 & 8.40 & 48 & 57 & .81 & 52 & 101 \\
\hline 1600 & 34.0 & 1.54 & 2464 & 5.67 & 8.06 & 3.21 & 1.27 & .14 & 18.35 & 7.45 & 40 & 61 & .72 & 59 & 103 \\
\hline 2000 & 36.8 & 1.35 & 2700 & 5.67 & 8.14 & 3.05 & 1.27 & .09 & 18.22 & 6.75 & 36 & 71 & .65 & 65 & 56 \\
\hline 3000 & 44.5 & 1.10 & 3300 & 5.67 & 8.34 & 2.80 & 1.27 & .04 & 18.12 & 5.49 & 29 & 87 & .53 & 79 & 6 \\
\hline 4000 & 51.8 & 1.00 & 4000 & 5.67 & 8.55 & 2.72 & 1.27 & .01 & 18.22 & 4.56 & 26 & 105 & .44 & 91 & 1 \\
\hline
\end{tabular}

2000 FOOT YARDING DISTANCE

\begin{tabular}{|c|c|c|c|c|c|c|c|c|c|c|c|c|c|c|c|}
\hline 100 & 9.3 & 5.20 & 520 & 7.18 & 8.42 & 7.40 & 1.27 & .89 & 25.16 & 48.38 & 99 & 10 & 4.68 & 16 & 542 \\
\hline 200 & 13.3 & 4.95 & 990 & 7.18 & 9.58 & 7.10 & 1.27 & .84 & 25.97 & 26.23 & 91 & 18 & 2.54 & 22 & 1118 \\
\hline 300 & 15.5 & 4.50 & 1350 & 7.18 & 9.90 & 6.55 & 1.27 & .75 & 25.65 & 19.00 & 84 & $r+25$ & 1.84 & 27 & 601 \\
\hline 400 & 17.5 & 4.07 & 1628 & 7.18 & 10.13 & 6.03 & 1.27 & .66 & 25.27 & 15.52 & 77 & 31 & 1.50 & 31 & 350 \\
\hline 600 & 20.5 & 3.21 & 1926 & 7.18 & 10.39 & 5.00 & 1.27 & .48 & 24.32 & 12.63 & 63 & 38 & 1.22 & 38 & 465 \\
\hline 800 & 24.0 & 2.61 & 2088 & 7.18 & 10.49 & 4.30 & 1.27 & .36 & 23.60 & 11.30 & 53 & 42 & 1.09 & 42 & 274 \\
\hline 1000 & 26.0 & 2.21 & 2210 & 7.18 & 10.55 & 3.89 & 1.27 & .28 & 23.17 & 10.48 & 46 & 46 & 1.01 & 47 & 117 \\
\hline 1200 & 28.7 & 1.93 & 2316 & 7.18 & 10.61 & 3.60 & 1.27 & .22 & 22.88 & 9.88 & 40 & 49 & .96 & 52 & 101 \\
\hline 1600 & 34.0 & 1.59 & 2544 & 7.18 & 10.73 & 3.26 & 1.27 & .14 & 22.58 & 8.88 & 34 & 54 & .86 & 59 & 103 \\
\hline 2000 & 36.8 & 1.38 & 2760 & 7.18 & 10.83 & 3.06 & 1.27 & .10 & 22.44 & 8.13 & 30 & 59 & .79 & 65 & 56 \\
\hline 3000 & 44.5 & 1.11 & 3330 & 7.18 & 11.08 & 2.81 & 1.27 & .04 & 22.38 & 6.72 & 24 & 71 & .65 & 79 & 6 \\
\hline 4000 & 51.8 & 1.00 & 4000 & 7.18 & 11.35 & 2.72 & 1.27 & .01 & 22.53 & 5.63 & 21 & 85 & .54 & 91 & 1 \\
\hline
\end{tabular}


TABLE 5-A (Continued)

Relation of volume of log and yarding distance to time and cost of direct yarding with 60 -h.p. tractor and falrlead arch.

Based on 37.34 logs.

2500 FOOT YARI) IN ( D D I TAN (: E

\begin{tabular}{|c|c|c|c|c|c|c|c|c|c|c|c|c|c|c|c|}
\hline \multirow{2}{*}{$\begin{array}{l}\text { Volume } \\
\text { of log } \\
\text { in } 1 \mathrm{t} \text {. } \\
\mathrm{b} . \mathrm{m} \text {. }\end{array}$} & \multirow{2}{*}{$\begin{array}{l}\text { Top } \\
\text { diam. } \\
32 \mathrm{ft} \text {. } \\
\text { lcg } \\
\text { (curved) }\end{array}$} & \multirow{2}{*}{$\begin{array}{l}\text { No. of } \\
\text { logs } \\
\text { per } \\
\text { turn }\end{array}$} & \multirow{2}{*}{$\begin{array}{l}\text { Volume } \\
\text { in leet } \\
\text { b.m. Fer } \\
\text { turn }\end{array}$} & \multicolumn{6}{|c|}{ Time in minutes per turn } & \multirow[b]{2}{*}{$\begin{array}{c}\text { Tine } \\
\text { per } \\
\text { M b.m. }\end{array}$} & \multicolumn{2}{|c|}{$\begin{array}{l}\text { Production } \\
\text { per } 8-\mathrm{hr} \text {. day }\end{array}$} & \multirow{2}{*}{$\begin{array}{c}\text { Yarding } \\
\text { variable } \\
\text { cost at } \\
\$ .0968 \text { per } \\
\text { yarding } \\
\text { minute }\end{array}$} & \multirow{2}{*}{$\begin{array}{l}\text { Approx. } \\
\text { tree } \\
\text { diam. } \\
\text { (dbh) }\end{array}$} & \multirow[b]{2}{*}{$\begin{array}{l}\text { Basis } \\
\text { No. of } \\
\text { logs }\end{array}$} \\
\hline & & & & $\begin{array}{l}\text { Haul- } \\
\text { back }\end{array}$ & llauling & $\begin{array}{c}\text { Hook, } \\
\text { hanhook and } \\
\text { hang-ups }\end{array}$ & $\begin{array}{l}\text { Pro- } \\
\text { rated } \\
\text { delays }\end{array}$ & $\begin{array}{l}\text { Side- } \\
\text { lining }\end{array}$ & $\begin{array}{c}\text { Total } \\
\text { yarding } \\
\text { tin e }\end{array}$ & & $\begin{array}{l}\text { No. } \\
\text { of } \\
\text { logs }\end{array}$ & $\begin{array}{c}\text { Gross } \\
\text { scale } \\
\text { M b.m. }\end{array}$ & & & \\
\hline B.m. & Inches & Pes. & B.m. & Minutes & Minutes & Minutes & Minutes & Minutes & Minutes & Minutes & Pes. & M b.m. & Dollars & Inches & Pes. \\
\hline 100 & 9.3 & 5.40 & 540 & 8.72 & 10.52 & 7.65 & 1.27 & 0.94 & 29.10 & 53.89 & 89 & 9 & 5.22 & 16 & 542 \\
\hline 200 & 13.3 & 5.25 & 1050 & 8.72 & 12.00 & 7.47 & 1.27 & .90 & 30.36 & 28.91 & 83 & 17 & 2.80 & 22 & 1118 \\
\hline 300 & 15.5 & 4.77 & 1431 & 8.72 & 12.42 & 6.88 & 1.27 & .80 & 30.09 & 21.03 & 76 & 23 & 2.04 & 27 & 601 \\
\hline 400 & 17.5 & 4.27 & 1708 & 8.72 & 12.73 & 6.27 & 1.27 & .70 & 29.69 & 17.38 & 69 & 28 & 1.68 & 31 & 350 \\
\hline 600 & 20.5 & 3.37 & 2022 & 8.72 & 13.06 & 5.18 & 1.27 & .52 & 28.75 & 14.22 & 56 & 34 & 1.38 & 38 & 465 \\
\hline 800 & 24.0 & 2.72 & 2176 & 8.72 & $1: 1.16$ & 4.42 & 1.27 & .39 & 27.96 & 12.85 & 47 & 37 & 1.24 & 42 & 274 \\
\hline 1000 & 26.0 & 2.30 & 2300 & 8.72 & 13.23 & 3.98 & 1.27 & .30 & 27.50 & 11.96 & 40 & 40 & 1.16 & 47 & 117 \\
\hline 1200 & 28.7 & 2.00 & 2400 & 8.72 & 13.29 & 3.68 & 1.27 & .24 & 27.20 & 11.33 & 35 & 42 & 1.10 & 52 & 101 \\
\hline 1600 & 34.0 & 1.63 & 2608 & 8.72 & 13.42 & 3.30 & 1.27 & .15 & 26.86 & 10.30 & 29 & 47 & 1.00 & 59 & 103 \\
\hline 2000 & 36.8 & 1.41 & 2820 & 8.72 & 13.55 & 3.10 & 1.27 & .10 & 26.74 & 9.48 & 25 & 51 & .92 & 65 & 56 \\
\hline 3000 & 44.5 & 1.12 & 3360 & 8.72 & 13.83 & 2.83 & 1.27 & .05 & 26.70 & 7.95 & 20 & 60 & .77 & 79 & 6 \\
\hline 4000 & 51.8 & 1.00 & 4000 & 8.72 & 14.15 & 2.72 & 1.27 & .01 & 26.87 & 6.72 & 18 & 71 & .65 & 91 & 1 \\
\hline \multicolumn{16}{|c|}{3000 FOOT YARDING DISTA N E } \\
\hline 100 & 9.3 & 5.60 & 560 & 10.23 & 12.67 & 7.90 & 1.27 & .98 & 33.05 & 59.02 & 81 & 8 & 5.71 & 16 & 542 \\
\hline 200 & 13.3 & 5.45 & 1090 & 10.23 & 14.37 & 7.71 & 1.27 & .95 & 34.53 & 31.68 & 76 & 15 & 3.07 & 22 & 1118 \\
\hline 300 & 15.5 & 4.93 & 1479 & 10.23 & 14.90 & 7.08 & 1.27 & .84 & 34.32 & 23.20 & 69 & 21 & 2.25 & 27 & 601 \\
\hline 400 & 17.5 & 4.40 & 1760 & 10.23 & 15.26 & 6.43 & 1.27 & .72 & 33.91 & 19.27 & 62 & 25 & 1.87 & 31 & 350 \\
\hline 600 & 20.5 & 3.47 & 2082 & 10.23 & 15.66 & 5.31 & 1.27 & .54 & 33.01 & 15.85 & 50 & 30 & 1.53 & 38 & 465 \\
\hline 800 & 24.0 & 2.80 & 2240 & 10.23 & 15.78 & 4.52 & 1.27 & .40 & 32.20 & 14.38 & 42 & 33 & 1.39 & 42 & 274 \\
\hline 1000 & 26.0 & 2.35 & 2350 & 10.23 & 15.86 & 4.04 & 1.27 & .30 & 31.70 & 13.49 & 36 & 36 & 1.31 & 47 & 117 \\
\hline 1200 & 28.7 & 2.04 & 2448 & 10.23 & 15.94 & 3.71 & 1.27 & .24 & 31.39 & 12.82 & 31 & 37 & 1.24 & 52 & 101 \\
\hline 1600 & 34.0 & 1.66 & 2656 & 10.23 & 16.09 & 3.34 & 1.27 & .16 & 31.09 & 11.71 & 26 & 41 & 1.13 & 59 & 103 \\
\hline 2000 & 36.8 & 1.43 & 2860 & 10.23 & 16.25 & 3.11 & 1.27 & .11 & 30.97 & 10.83 & 22 & 44 & 1.05 & 65 & 56 \\
\hline 3000 & 44.5 & 1.12 & 3360 & 10.23 & 16.57 & 2.83 & 1.27 & .05 & 30.95 & 9.21 & 17 & 52 & .89 & 79 & 6 \\
\hline 4000 & 51.8 & 1.00 & 4000 & 10.23 & 16.95 & 2.72 & 1.27 & .01 & 31.18 & 7.80 & 15 & 62 & .76 & 91 & 1 \\
\hline
\end{tabular}

Basis of cost: 480 minutes of actual operating time consists of:

Item 1 , tractor and driver .........\$25.75

Item 2, lairlead arch .......... 8.04

Item 3 , yarding crew............ 10.50

Item 4, reserve for idle tractors . . . . . . 2.16
1 No "fixed per acre" costs enter into the tractor yarding operation; all delays are incorporated in turn time and recorded as pro-rated delays. Hence, the yarding variable is equivalent to total yarding cost.

$\$ 46.45$, or $\$ 0.0968$ per yarding minute. 
21. Report on Yarding with 60 h.p. Tractors; Scope of Studies.-Tables 5 and $5 \mathrm{~A}$, reproduced above, were prepared incidentally to the report on yarding with 60 h.p. tractors drawing fair-lead arches. This is the only one of over twenty similar reports with detailed time study tables to be presented in full detail in this publication. In thus bringing the tractor to the fore, attention is called to a method of yarding that is still somewhat new to this region and to which there will be frequent occasions to refer later in this report.

A total of $3,734 \operatorname{logs}$, scaling $1,345,000$ board feet gross scale, form the basis of the data in Tables 5 and $5 \mathrm{~A}$. In addition a study was made of $282 \operatorname{logs}$ scaling 361,290 board feet for the prinary purpose of obtaining a comparison of average performance under contrasting topographic, density, and ground conditions. The results of the latter study have not been prepared in the form of complete time-study tables.

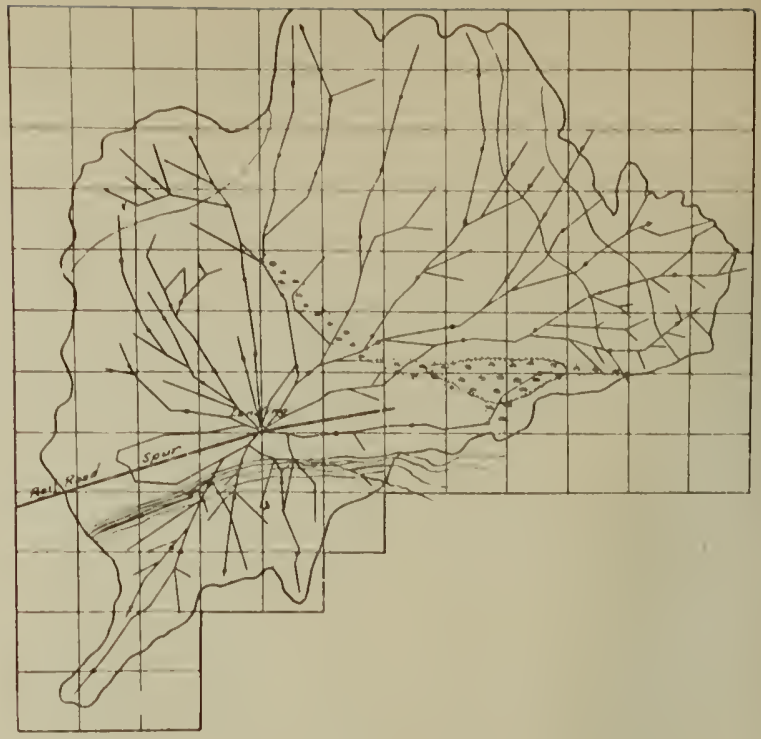

FIG. 5

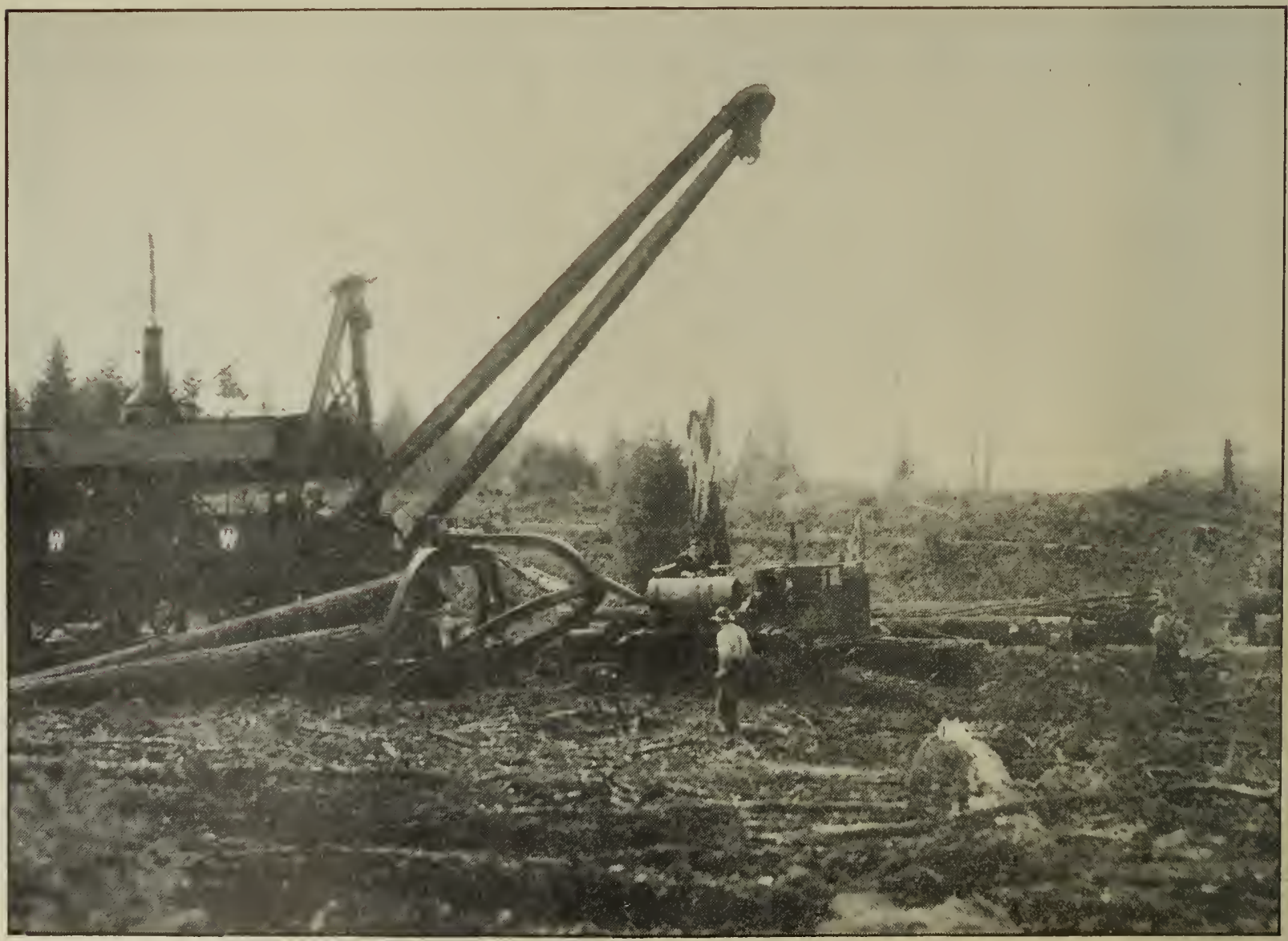

FIG. 6-MCGIFFERT LOADER ("JAMMER") AND TRACTOR ARCH UNIT AT LANDING 
Description of Tractor Operation.-The study on which Table 5 is based was conducted on an operation where conditions are favorable for yarding with tractors, but distinctly unfavorable for any of the conventional methods of high-lead or skidder yarding, owing to the scattered stand, long yarding distance, and small timber. Yarding distances extended as far as 3,400 feet. The stand averaged less than $\mathbf{1 5 , 0 0 0}$ board feet per acre, with an average log size of only 360 board feet. About 90 per cent of the area is virtually level. Short pitches up to a maximum of 40 per cent favorable, and 10 per cent adverse grade were encountered on the remainder of the area. These conditions are shown in the accompanying map (Figure 5) and photograph (Figure 6). They proved to have a negligible influence on total costs, although the adverse grades resulted in lower hauling speed during the brief intervals of time when the loaded tractors were negotiating these grades. A long, narrow swamp, cutting diagonally across the yarding area caused some delays due to the lack of solid footing for the tractors. Ground conditions were otherwise very good, consisting of gravelly soil under a few inches of light top soil, which latter mudded up the surface without in the least impeding the progress of the tractors. The study was conducted for a period of ten and a half working days. Heavy rains were a daily occurrence, but with seemingly no effect except on the general appearance of the chaser and loaders who had to wade nearly waist deep in the slushy mud which accumulated at each end of the landings.

This operation was organized as a fullfledged tractor operation, with a battery of six tractors available as needed to supply a steady flow of logs to a "jammer" (McGiffert Loader -see Figure 6).

Synchronization of loading and yarding capacities was attained by three different means:

(1) By increasing or decreasing the number of tractors at work; on the average four and one-half tractors were continuously at work while at various times from three to six were employed.

(2) By increasing or decreasing yarding distances for one or more or "ine tractors at work at any given time; that is, by shifting the tractors from one part of the yarding area to another.

(3) By shifting tractors from areas yielding large-sized logs to those yielding small-sized logs, or vice versa; this, in conjunction with changes in yarding distance.
By these three means of regulating the flow of logs to the landing a degree of synchronization of yarding-loading-switching operation was attained that was superior to that found in any other study; this in spite of the fact that the character of the yarding show, both in regard to yarding distance and composition of the stand, was such as to invite extreme fluctuation in the rate of production, had any of the conventional yarding methods been used.

In calculating the machine rate per tractor unit, the cost of providing the average reserve capacity of one and one half tractor-arch units, amounting to $\$ 9.72$ per day (fixed charges only) has been prorated against the units that were actually operating a full 480 minutes per day. (See machine rate set up at foot of Table 5A.) This accounts for $\$ 2.16$ per day out of the total daily cost of $\$ 46.45$ per operating unit. It may be argued, and with good reason, that this cost should not be charged to yarding but represents rather the price that is paid (and a low price under the circumstances here involved) to insure more efficient use of available loading and switching capacity as well as to lower the cost of overhead (supervision, management, office, camp expense, etc.) ; that it is not a cost that is assumed with a view to lowering yarding costs as such, but to lowering the cost of activities which are directly influenced by the ups and downs in the yarding output. The costs listed in Table 5 would thus be approximately 5 per cent too high insofar as representing yarding costs in the strict sense here defined.

The conditions applying in the second study contrast sharply with those of the study represented by Table 5 . Here tractors were employed to yard out windfalls ahead of the falling and bucking of standing timber. The timber in this study was large, old-growth fir, averaging well over 100,000 board feet per acre, approximately 10,000 feet per acre consisting of windfalls. The soil was loamy, offering poor traction, generally typical of conditions in heavy stands of big timber.

The high density of this stand often made it difficult to manipulate the tractor and arch unit. The slopes varied from 15 per cent favorable to 14 per cent adverse. In pulling the loads over the steep adverse grades a helper tractor, serving two yarding tractor's, was used. Yarding distances extended as far as 2,400 feet. The operation was conducted in dry weather, ground conditions being such that yarding in prolonged wet weather was impracticable. 


\section{Comparison of Results}

Below is a comparison of times and costs on the basis of identical log size and yarding distance. The values given for the second study (the windfall yarding) are actual grand average results for the study as a whole, representing an average log size of 1,280 feet, and average yarding distance of 1,370 feet. The values given for the first study are interpolated from the time-study table (Table 5A) for the average $\log$ size and yarding distance applying to the second study.

TABLE 6

Comparison of turn time and cost for a yarding distance of $13 \% 0$ feet

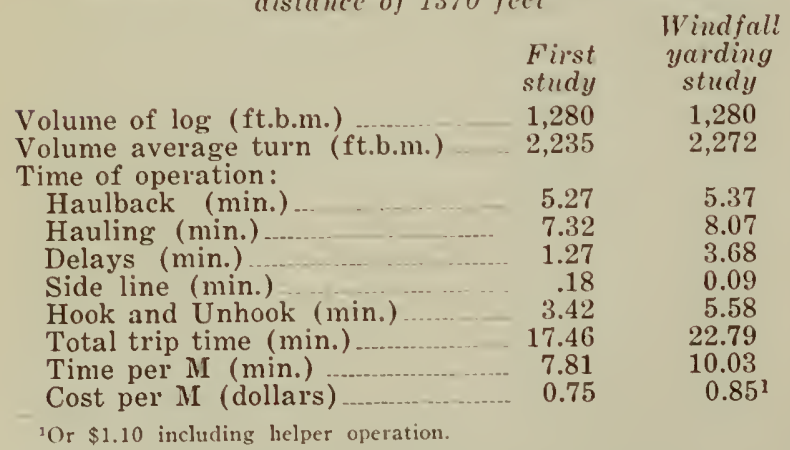

Close agreement occurs in the volume of the turn that corresponds to the given log size and in haulback time. Hauling time shows a difference of only 10 per cent. The principal differences between the two studies occur in "delay" time and "hooking and unhooking" time. The greater "hook and unhook" time is due principally to the fact that a smaller crew was employed in the windfall yarding. In the first study the crew for each complete tractor unit comprised 3.2 men, while only 2.5 men were employed in the windfall yarding. This explains in part why the cost of the windfall yarding is only ten cents per $\mathrm{M}$ feet b.m. (13.33 per cent) higher than in the Table 5 study while the time per $\mathrm{M}$ is 28.43 per cent higher.

A further increase in cost occurs in the windfall yarding study due to the fact that a "helper tractor" had to be employed in getting the loads over steep adverse grades (14 per cent maximum). This raised the cost from $\$ 0.85$ to $\$ 1.10$ per $\mathrm{M}$ on that portion of the yarding area where the adverse grades were encountered.

\section{Relation of Yarding Distance to Volume of Turn}

An interesting feature of the tractor study is the relation of yarding distance to volume of the turn. ${ }^{3}$ The greater the yarding distance, the larger are the turns that are built up in any

${ }^{3}$ Compare Section 54 given size class of logs. Thus, at a distance of 600 feet the 100 -foot volume class shows only $4.30 \log$ s per turn, while at 3,000 feet the same volume class shows $5.60 \operatorname{logs}$ per turn. Efforts to discover similar relations in the skyline and high-lead yarding studies failed to prove anything in this respect, probably because in the case of the large skyline and high-lead machines, traveling speeds of haul-back and hauling are high, or else, yarding distances, as for example, in the small high-lead machines, are short; so that the opportunities to adjust turn volume to yarding distance are relatively limited. In the case of tractor yarding, however, traveling speeds are low with the result that as the yarding distance increases the tractor is spending most of the working time traveling in and out, which leaves more time for the hookers to pre-set the chokers and to figure out a good-sized payload. Furthermore, delays in getting large loads together with the tractor mean relatively little on long hauls compared to similar delays on short hauls. A comparison of the large turn volumes secured in roading with tractors, as shown in Chapter VIII, suggests that possibilities exist to secure added efficiency in direct yarding by paying stricter attention to maximum turn volumes, especially at the longer distances.

22. Reports on Yarding with Donkeys-28 Studies.-Detailed time study tables and reports similar to those presented above for yarding with tractors have been prepared for 28 other studies covering yarding with skidders, slackline and high-lead yarders. On account of their great bulk these are not here presented in full. Summary cost and output tables, maps and other essential information, however, are presented below. Corresponding maps and tables are identified by the same numbers; for example, Table 20 and Figure 20 go together as parts of the same study. The map describes the yarding show, the topography, the layout of yarding roads, yarding distances, density and volume per acre of the stand, and the size of the average log. The corresponding table gives the results of the studies, showing yarding costs for logs of various volumes at various actual yarding distances and within various external yarding distances. The basis of cost (machine rate) is given at the foot of the table to facilitate revising the cost data to fit changing cost levels or machine rates.

In a few cases both the logging shows and the study results were found to be so closely 
similar that there was no reason for setting up separate tables. These cases are noted in the headings of the tables. One table may thus represent two or three separate studies, but in such cases only one map is shown as a sample of the logging shows involved.

\section{Distinction Between "Yarding-Variable" and Fixed Per-Acre Costs}

Yarding costs given in Tables 7 to 27 inclusive are of two different kinds namely "yarding-variable" costs and "fixed-per-acre" costs.

Yarding-variable costs represent costs incurred in yarding the individual turn subsequent to and irrespective of any previous costs connected with road changing, etc. By fixed-peracre costs are meant costs incurred in changing roads and delays incident thereto. They represent a lump sum cost against the area logged to each road and as such are not specifically chargeable against the individual turn or log. From a practical standpoint in cost appraisal they may be treated as fixed per acre per setting. If prorated as a fixed cost per $\mathrm{M}$ the reservation must be made that they remain so fixed only if the volume of logs to be removed remains fixed.

Fixed per-acre costs do not occur in connection with the tractor-yarding study reported in Table 5 because in this study all working time is accounted for in turn by turn time (yarding variable), there being no delays in changing roads.

In none of the tables has any account been taken of fixed per-acre costs incident to moving and rigging ahead-which is a lump sum cost against the setting as a whole-except to enter a notation at the foot of each table stating the amount of this cost.

A glance at any one of the tables brings to attention strikingly the effect of variation of log volume, and to a lesser extent the effect of variation of yarding distance, on yarding cost.

The relatively high cost of yarding small logs is, as discussed later, a characteristic feature of the present general system of clear cutting with large machinery. It does not, of course, represent any basic size-to-cost relationship except for $\operatorname{logs}$ within a given operating area which are all logged in one operation using only one given type of yarder and yarding method.

A comparison of the yarding-variable relationships of all studies is given in Chapter XI ; a similar comparison of the relations shown on the basis of total yarding costs is given in the next chapter.
TABLE 7

Relation of volume of log and yarding distance to output and cost of skidding with $12 x 14$ steam tower. skidders ${ }^{1} ; 3$ studies

I Rate of production in $\mathrm{M}$ ft.b.m. per 8-hour day? for various actual yarding distances.

\begin{tabular}{crrrr} 
& \multicolumn{4}{c}{ Yarding } \\
Volistume of $\log$ ft.b.m. & 600 & 1000 & 1400 & 1800 \\
100 & 32 & 29 & 26 & 24 \\
200 & 63 & 56 & 51 & 48 \\
400 & 122 & 109 & 98 & 91 \\
800 & 227 & 201 & 182 & 168 \\
1600 & 393 & 346 & 309 & 288 \\
3200 & 557 & 480 & 421 & 393
\end{tabular}

II Yarding variable cost in dollars per M ft.b.m. ${ }^{3}$ for various actual yarding distances

$\begin{array}{rrrrr}100 & 5.38 & 6.03 & 6.65 & 7.12 \\ 200 & 2.73 & 3.07 & 3.39 & 3.63 \\ 400 & 1.42 & 1.59 & 1.76 & 1.89 \\ 800 & .76 & .86 & .95 & 1.03 \\ 1600 & .44 & .50 & .56 & .60 \\ 3200 & .31 & .36 & .41 & .44\end{array}$

III Yarding variable cost in dollars per $\mathrm{M}$ ft.b.m. ${ }^{3}$ for various external yarding distances

$\begin{array}{rrrrr}100 & 5.06 & 5.49 & 5.92 & 6.34 \\ 200 & 2.38 & 2.78 & 3.02 & 3.23 \\ 400 & 1.34 & 1.45 & 1.56 & 1.68 \\ 800 & .71 & .78 & .84 & .90 \\ 1600 & .41 & .45 & .49 & .53 \\ 3200 & .29 & .32 & .35 & .38\end{array}$

'Crew, 15 men, excluding loading crew.

'Deduct $21 \%$ for road changing.

${ }^{3}$ Add $\$ 0.41$ per $M$ ft.b.m. for road changing.

Basis of Cost: Operating costs per 8-hour day consist of :

Item $1,379.55$ minutes actual yarding time at $\$ 0.36$ per minute

$\$ 136.64$

Item 2, 100.45 minutes road changing time at $\$ 0.29$ per minute

Item 3 , net labor cost rigging tail trees

Total per day (full machine rate; crew

15 men)

$\$ 185.21$

Item 1, termed "yarding variable" represents turn by turn cost in actual yarding.

Items 2 and 3 are "fixed per acre" costs averaging $\$ 14.72$ per acre or $\$ 0.41$ per $\mathrm{M}$ ft.b.m. based on the removal of $36 \mathrm{M} \mathrm{ft}$. per acre.

Items 2 and 3 do not include moving and track landing costs which amount to $\$ 0.10$ per M b.m.

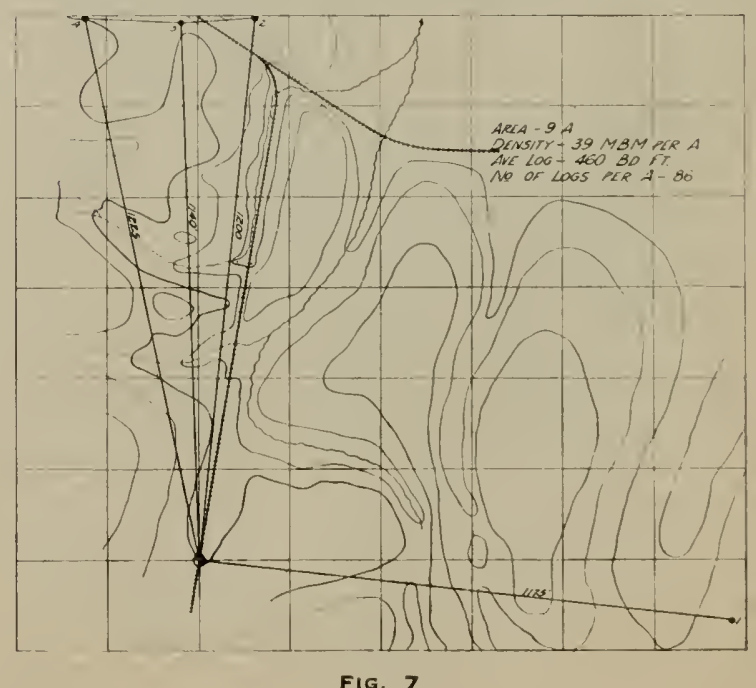


TABLE 8

Relation of volume of log and yarding distance to out met and cost of shirding with $12 . x 14$ steum towe' skidders': 2 studies

I Rate of production in M ft.b.m. per 8-hour day- for various actual yarding distances

\begin{tabular}{crrrr} 
& \multicolumn{3}{c}{ Yording distancer } \\
Folumc of $\log$ ft.b.m. & 600 & 1000 & 1400 & 1.500 \\
100 & 19 & 18 & 16 & 14 \\
200 & 38 & 35 & 32 & 28 \\
400 & 74 & 69 & 62 & 55 \\
800 & 141 & 130 & 117 & 104 \\
1600 & 252 & 232 & 208 & 185 \\
3200 & 373 & 342 & 310 & 272
\end{tabular}

II Yarding variablo cost in dollars per $M \mathrm{ft} . \mathrm{b} . \mathrm{m} .{ }^{3}$ for various actual yarding distances

$\begin{array}{rrrrr}100 & 10.46 & 11.32 & 12.49 & 13.99 \\ 200 & 5.29 & 5.73 & 6.32 & 7.09 \\ 400 & 2.71 & 2.94 & 3.25 & 3.65 \\ 800 & 1.43 & 1.55 & 1.72 & 1.93 \\ 1600 & .80 & .87 & .97 & 1.09 \\ 3200 & .54 & .59 & .65 & .74\end{array}$

II Yarding variable cost in dollar's per M ft.b.m.: for various external yarding distances

$\begin{array}{rrrrr}100 & 10.10 & 10.60 & 11.18 & 11.90 \\ 200 & .5 .09 & 5.36 & 5.67 & 6.01 \\ 400 & 2.60 & 2.75 & 2.90 & 3.09 \\ 800 & 1.37 & 1.45 & 1.53 & 1.64 \\ 1600 & .77 & .81 & .86 & .92 \\ 3200 & .52 & .55 & .58 & .62\end{array}$

'Crew. 16 men, excluding loading crew.

Deduct $23 \%$ for road changing.

${ }^{3}$ Add $\$ 0.28$ per II feet b.m. for road changing (fixed-per-acre costs) to get total yarding cost.

Basis of Cost: Operating cost per 8-houl day consists of :

Item 1, 368.21 minutes actual yarding time at $\$ 0.42$ per minute

$\$ 154.65$

Item 2, 111.79 minutes road changing time at $\$ 0.34$ per minute

38.00

Item 3, net labor, rigging tail trees____ 17.04

Total per day (full machine rate)

$\$ 209.69$

Item 1, termed "yarding variable" represents turn by turn cost in actual yarding; Items 2 and 3 are fixed-per-acre costs averaging $\$ 13.87$ per acre, or $\$ 0.28$ per M feet b.m. based on the removal of 49.5 M feet per acre.

Items 2 and 3 do not include moving and track landing costs which amount to $\$ 0.12$ per M b.m.

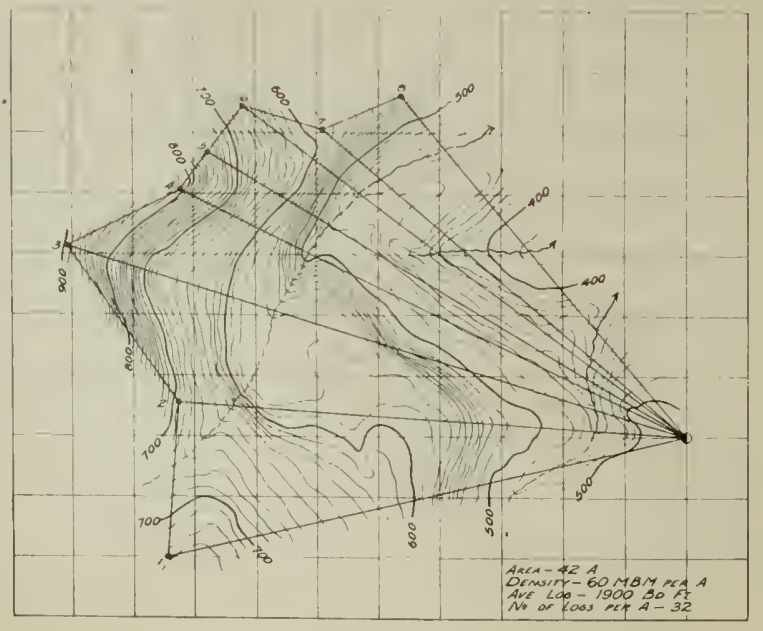

TABLE:

Relation of volume of log and yurding distance to out put und cost of shidding with 350 h.p. electric sliblderl

I Rate of production in M ft.b.m. per 8-hour day² for various actual yarding distances

\begin{tabular}{crrrr} 
& \multicolumn{4}{c}{ Yarding distuncer } \\
Jolume of log ft.b.m. & \multicolumn{6}{c}{ Goo } & 1000 & 1400 & 1800 \\
100 & 32 & 29 & 25 & 23 \\
200 & 64 & 56 & 50 & 45 \\
400 & 122 & 109 & 95 & 85 \\
800 & 228 & 200 & 175 & 157 \\
1600 & 388 & 338 & 294 & 261 \\
3200 & 538 & 468 & 397 & 351
\end{tabular}

II Yarding variable cost in dollar's per $M$ ft.b.m. ${ }^{3}$ for various acturel yarding distances

$\begin{array}{rrrrr}100 & 5.63 & 6.34 & 7.17 & 8.01 \\ 200 & 2.86 & 3.23 & 3.66 & 4.08 \\ 400 & 1.49 & 1.68 & 1.92 & 2.14 \\ 800 & .80 & .91 & 1.04 & 1.16 \\ 1600 & .47 & .54 & .62 & .70 \\ 3200 & .34 & .39 & .46 & .52\end{array}$

III Yarding variable cost in dollars per. M ft.b.m.3 for various retruml yarding distances

$\begin{array}{rrrrr}100 & 5.34 & 5.74 & 6.22 & 6.76 \\ 200 & 2.71 & 2.92 & 3.16 & 3.44 \\ 400 & 1.41 & 1.52 & 1.65 & 1.80 \\ 800 & .75 & .82 & .89 & .98 \\ 1600 & .44 & .48 & .53 & .58 \\ 3200 & .32 & .35 & .38 & .43\end{array}$

'Crew of 16 men, excluding loading crew.

Deduct $19 \%$ for road clinging.

Arld $\$ 0.22$ per M ft. b.m. for road changing (fixed per-acre cost) to find total yarding cost.

Basis of Cost: Costs per 8-hour day consist of:

Item 1, 390.29 minutes actual yarding time at $\$ 0.38$ per minute.

$\$ 148.30$

Item 2, 89.71 minutes road changing time at $\$ 0.31$ per minute

Item 3, net labor cost, rigging tail trees

Total per day (full machine rate)

$\$ 195.00$

Item 1, termed "yarding variable" represents turn by turn cost in actual yarding.

Items 2 and 3 ale "fixed per acre" costs averaging $\$ 18.00$ per acre, equivalent to $22 \mathrm{c}$ per M b.m. based on the removal of $84 \mathrm{M} f$. per acre.

Items 2 and 3 do not include moving and track landing costs which amount to $\$ 0.11$ per M b.m.

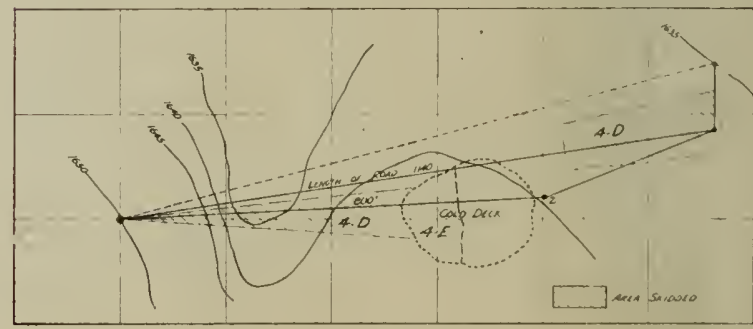

FIG. 9 
TABE 10

Relation of volume of log and yarding distunce to output and cost of yarding with $12 \times 17$ strum slackline yarder.

I Rate of production in M ft.b.m. per 8-houl day² for various actual yarding distances

Volume of $\log$ ft.b.m.

600
18
36
70
136
254
433

100

200

400
800

1600

3200
$1400 \quad 1800$

$15 \quad 14$

Yurding
1000
17
33
64
123
231
395

15

30

114

211

362
28

106

195

335
II Yarding variable cost in dollars per M ft.b.m. ${ }^{3}$ for various actual yarding distances

$\begin{array}{rrrrr}100 & 9.90 & 10.76 & 11.64 & 12.48 \\ 200 & 5.00 & 5.43 & 5.87 & 6.31 \\ 400 & 2.54 & 2.77 & 3.00 & .2 .22 \\ 800 & 1.31 & 1.44 & 1.56 & 1.68 \\ 1600 & .70 & .77 & .84 & .91 \\ 3200 & .41 & .45 & .49 & .53\end{array}$

III Yarding variable cost in dollars per M ft.b.m.3 for various external yarding distances

$\begin{array}{rrrrr}100 & 9.49 & 10.05 & 10.45 & 11.20 \\ 200 & 4.78 & 5.07 & 5.36 & 5.65 \\ 400 & 2.43 & 2.58 & 2.73 & 2.88 \\ 800 & 1.25 & 1.33 & 1.42 & 1.49 \\ 1600 & .66 & .71 & .76 & .80 \\ 3200 & .39 & .42 & .44 & .47\end{array}$

${ }^{1}$ Crew of 17 men, excluding loading crew.

${ }^{2}$ Deduct $16 \%$ for road changing.

${ }^{3}$ Add $\$ 0.20$ per M ft.b.m. for road changing (fixed per-acre costs) to find total yarding cost.

Basis of Cost: Operating cost per 8-hour day consists of :

Item 1, 402.91 minutes actual yarding time at $\$ 0.37$ per minute

$\$ 149.08$

Item 2, 77.09 minutes road changing time at $\$ 0.30$ per minute.

23.12

Item 3, labor cost rigging tail trees

22.80

Total per day (full machine rate)

$\$ 195.00$

Item 1, termed "yarding variable" represents turn by turn cost in actual yarding.

Items 2 and 3 are "fixed per acre" costs averaging $\$ 14.00$ per acre, equivalent to $\$ 0.20$ per M b.m. based on the removal of $70 \mathrm{M}$ ft. per acre. This does not include moving and rigging ahead costs which amount to $\$ 0.09$ per $\mathrm{M}$ ft.b.m.

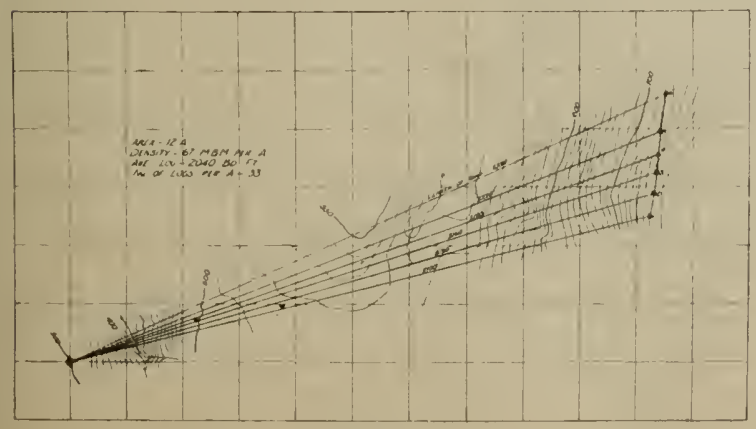

FIG. 10

\section{TABLE 11}

Relation of volume of log and yarding distances to oitput and cost of yarding with 3(1) h.p. gusolins slackline yarder.1 ; study

I Rate of production in M ft.b.m. per 8-hour dayz for various actual yarding distance:

Volume of $\log$ ft.b.m. $400 \quad$ Yording distance- 8001000

$\begin{array}{rrrrrr}100 & 15 & 14 & 13 & 12 & 11 \\ 200 & 29 & 27 & 25 & 24 & 22 \\ 400 & 55 & 52 & 48 & 45 & 41 \\ 800 & 101 & 93 & 86 & 80 & 75 \\ 1600 & 166 & 152 & 139 & 128 & 116 \\ 3200 & 223 & 204 & 185 & 168 & 150\end{array}$

II Yarding variable cost in dollars per $M \mathrm{ft} . \mathrm{b} . \mathrm{m}^{3}{ }^{3}$ for various artual yar.ling distances

$\begin{array}{rrrrrr}100 & 6.48 & 6.93 & 7.38 & 7.87 & 8.53 \\ 200 & 3.32 & 3.55 & 3.79 & 4.05 & 4.40 \\ 400 & 1.73 & 1.86 & 1.99 & 2.14 & 2.3 . \\ 800 & .95 & 1.03 & 1.11 & 1.20 & 1.31 \\ 1600 & .58 & .63 & .69 & .75 & .80 \\ 3200 & .43 & .47 & .52 & .57 & .64\end{array}$

III Yarding variable cost in dollars per M ft.b.m. ${ }^{3}$ for various externcl yarding distances

$\begin{array}{rrrrrr}100 & 6.15 & 6.48 & 6.81 & 7.14 & 7.48 \\ 200 & 3.14 & 3.32 & 3.50 & 3.67 & 3.85 \\ 400 & 1.63 & 1.73 & 1.83 & 1.93 & 2.03 \\ 800 & .89 & .95 & 1.01 & 1.07 & 1.13 \\ 1600 & .54 & .58 & .62 & .66 & .70 \\ 3200 & .40 & .43 & .46 & .49 & .52\end{array}$

'Crew, 11 men.

1)educt $27 \%$ for road changing.

${ }^{3}$ Add $\$ 0.42$ per MI ft.b.m. for road changing (fixed per-acre cost.s) to find total yarding cost.

Basis of Cost: Operating costs per 8-hour day consist of :

Item 1, 350.88 minutes actual yarding time at $\$ 0.20$ per minute $\$ 70.18$

Item 2, 129.12 minutes road changing time at $\$ 0.16$ per minute

20.66

Item 3, net labor cost rigging tail trees .... 9.16

Total per day (full machine rate) _..... $\$ 100.00$.

Item 1, termed "yarding variable" represents turn by turn cost in actual yarding.

Items 2 and 3 are "fixed per acre" costs averaging $\$ 12.60$ per acre, equivalent to $\$ 0.42$ per $M$, based on the removal of $30 \mathrm{M}$ feet per acre. This does not include rigging aheael and moving costs, which amount to $\$ 0.16 \mathrm{per}$. M additional.

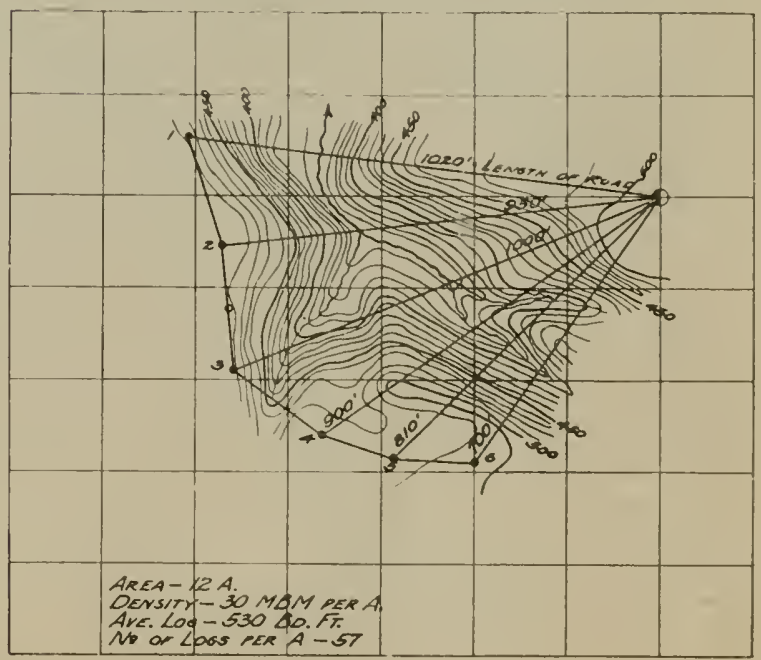

FIG. 11 
TABLE 12

Relation of volume of $\log$ and yording distunces to output and cost of yarding with 275 h.p. gasoline slackline yarder

I Rate of ploduction in Mr ft.b.m. per 8-hour day" for various actual yarding distances

Tolume of $\log$ it.b.m.

\begin{tabular}{rrrr}
\multicolumn{4}{c}{ Yurding distance } \\
400 & 600 & 800 & 1000 \\
22 & 21 & 20 & 18 \\
45 & 42 & 39 & 36 \\
87 & 82 & 76 & 71 \\
166 & 157 & 144 & 135 \\
309 & 279 & 262 & 240 \\
480 & - & & -
\end{tabular}

II Yarding variable cost in dollar's per $\mathbf{M}$ ft.b.m. ${ }^{3}$ for various actual yarding distances

$\begin{array}{rrrrr}100 & 3.85 & 4.12 & 4.40 & 4.71 \\ 200 & 1.94 & 2.08 & 2.22 & 2.38 \\ 400 & .99 & 1.06 & 1.14 & 1.22 \\ 800 & .52 & .55 & .60 & .64 \\ 1600 & .28 & .31 & .33 & .36 \\ 3200 & .18 & & & \end{array}$

III Yarding variable cost in dollars per M $\mathrm{ft} . \mathrm{b} . \mathrm{m}^{3}{ }^{3}$ for various external yarding distances

$\begin{array}{rcccc}100 & 3.49 & 3.85 & 4.02 & 4.21 \\ 200 & 1.75 & 1.94 & 2.04 & .2 .13 \\ 400 & .90 & .99 & 1.04 & 1.09 \\ 800 & .48 & .52 & .55 & .57 \\ 1600 & .24 & .28 & .30 & .32 \\ 3200 & & .18 & & .30\end{array}$

('rew, 11 men.

:Add $\$ 0.16$ per $M$ ft.b.m. for roal changing (fixed per-atcre costs) to get total yarding cost.

Basis of Cost: Cost per 8-hour day consists of:

Item 1, 401.09 minutes actual yarding time at $\$ 0.18$ per minute

$\$ 72.30$

Item 2, 78.91 minutes road changing time at $\$ 0.15$ per minute

11.85

Item 3, net labor cost rigging tail trees__ 15.85

Total yarding cost (full machine rate) $\$ 100.00$

Item 1, termed "yarding variable" represents turn by turn cost in actual yarding.

Items 2 and 3 are "fixed per acre" costs averaging $\$ 8.66$ per acre equivalent to $\$ 0.16$ per $M$ b.m., based on the removal of $54 \mathrm{M}$ feet per acre. This does not include rigging ahead and moving, which amounts to $\$ 0.09$ per M b.m.

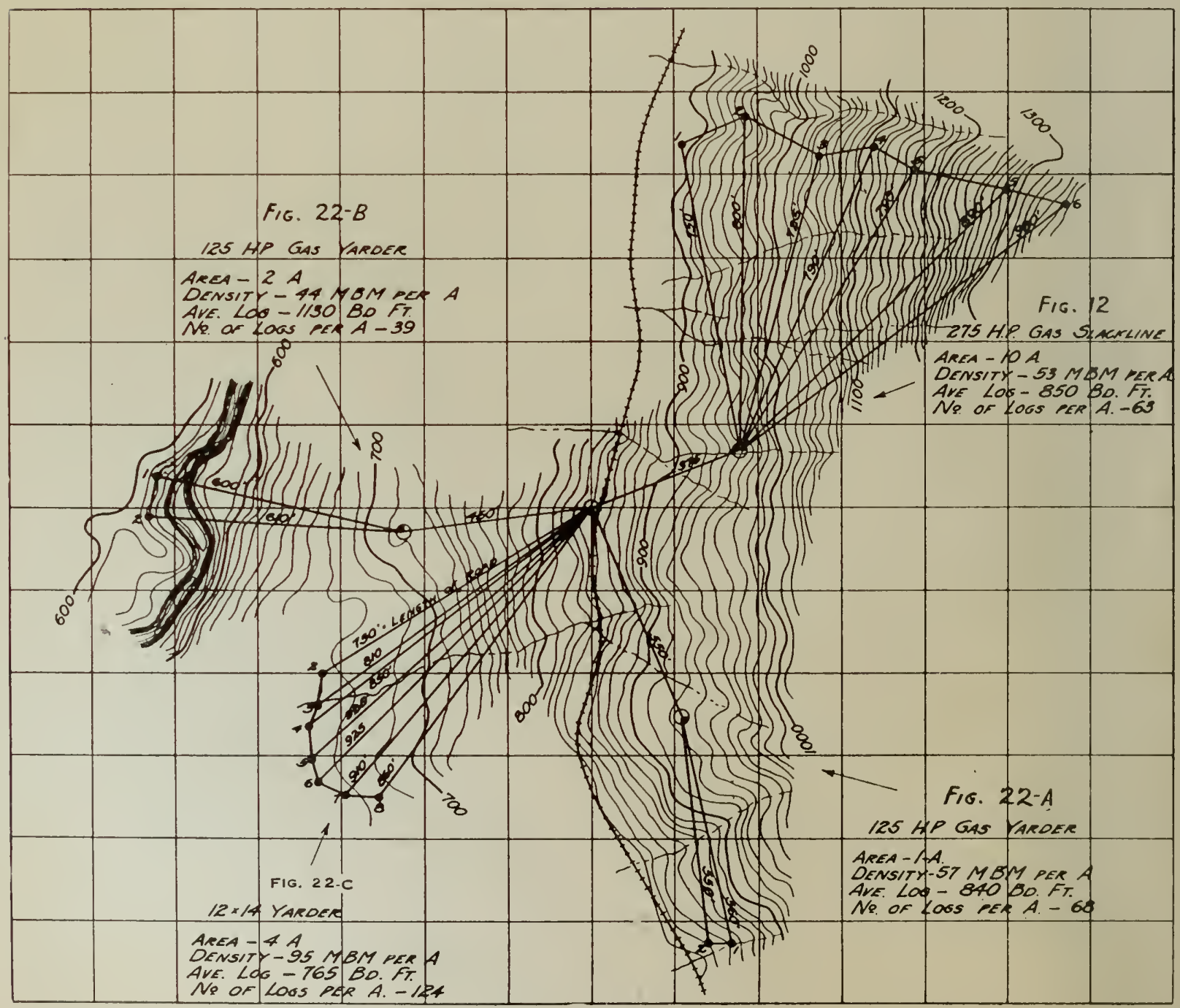

FIGS. 12 AND 22 
TABLE 13

Relution of volume of log and yurding distance to output and cost of yarding with $12 \times 14$ highlead yarder 1

I Rate of production in M ft.b.m. per 8-hour day2 for various actual yarding distances

$\begin{array}{crrrr}\text { Volume of } \log \text { ft.b.m. } & 300 & 500 & 700 & 900 \\ 100 & 38 & 34 & 29 & 26 \\ 200 & 75 & 66 & 57 & 49 \\ 400 & 141 & 123 & 105 & 90 \\ 800 & 248 & 216 & 185 & 158 \\ 1600 & 389 & 333 & 284 & 238 \\ 3200 & 486 & 417 & 343 & 299\end{array}$

II Yarding variable cost in dollars per M ft.b.m. ${ }^{3}$ for various actual yarding distances

$\begin{array}{rrrrr}100 & 3.06 & 3.47 & 4.00 & 4.66 \\ 200 & 1.56 & 1.78 & 2.06 & 2.41 \\ 400 & .83 & .96 & 1.11 & 1.30 \\ 800 & .47 & .54 & .63 & .7 .1 \\ 1600 & .30 & .35 & .41 & .49 \\ 3200 & .24 & .28 & .34 & .39\end{array}$

III Yarding variable cost in dollars per $M$ ft.b.m. ${ }^{3}$ for various external yarding distances

$\begin{array}{rrrrr}100 & 2.90 & 3.12 & 3.43 & 3.77 \\ 200 & 1.48 & 1.60 & 1.77 & 1.95 \\ 400 & .79 & .85 & .95 & 1.05 \\ 800 & .45 & .49 & .54 & .60 \\ 1600 & .29 & .31 & .35 & .40 \\ 3200 & .23 & .25 & .29 & .32\end{array}$

${ }^{1} \mathrm{Crew}, 10 \mathrm{mcn}$

"Deduct $18 \%$ for road changing.

${ }^{3} \mathrm{Add} \$ 0.18$ per $\mathrm{Ml}$ ft.b.m. for road changing (fixed per-acre cost) to get total yarding cost.

Busis of Cost: Operating costs per 8-hour day cousist of :

Item 1, 394.42 minutes actual yarding time at $\$ 0.243$ per minute

Item 2, 85.58 minutes road changing, etc., time at $\$ 0.198$ per minute

17.02

Total per day (full machine rate)

$\$ 112.76$

Item 1 termed "yarding variable" represents turn by turn cost in actual yarding.

Item 2 is "fixed per acre" costs averaging $\$ 8.80$ per acre, equivalent to $\$ 0.18$ per $M$ b.m. based on removal of $49 \mathrm{M}$ feet per acre. This does not include rigging ahead and moving costs which amount to $\$ 0.16$ per M b.m.

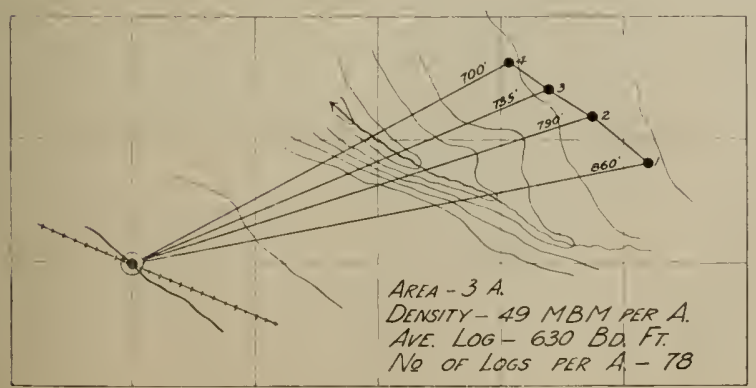

FIG. 13
TABLE 14

Kelation of volume of $\log$ and yarding distance to output and cost of yarding with $12 \times 14$ highlead yarder 1

I Rate of production in M ft.b.m. per 8-hour day2 for various actual yarding distances

Volume of $\log$ ft.b.m. $\quad 300 \quad 500 \quad 7.00$

$\begin{array}{rrrrr}100 & 33 & 29 & 24 & 19 \\ 200 & 64 & 56 & 47 & : 88 \\ 400 & 119 & 105 & 88 & 70 \\ 800 & 208 & 182 & 151 & 122 \\ 1600 & 338 & 292 & 241 & 191 \\ 3200 & 486 & 417 & 343 & 265\end{array}$

II Yarding variable cost in dollars per $\mathbf{M}$ ft.b.m. ${ }^{3}$ for various actual yarding distances

$\begin{array}{rrrrr}100 & 3.55 & 4.01 & 4.81 & 6.01 \\ 200 & 1.83 & 2.08 & 2.49 & 3.11 \\ 400 & .98 & 1.11 & 1.33 & 1.66 \\ 800 & .56 & .64 & .77 & .96 \\ 1600 & .35 & .40 & .48 & .61 \\ 3200 & .24 & .28 & .35 & .44\end{array}$

III Yarding variable cost in dollars per M fi.b.m. ${ }^{3}$ for various external yarding distances

$\begin{array}{rrrrr}100 & 3.38 & 3.63 & 4.01 & 4.57 \\ 200 & 1.74 & 1.88 & 2.08 & 2.36 \\ 400 & .93 & 1.00 & 1.11 & 1.26 \\ 800 & .53 & .58 & .64 & .73 \\ 1600 & .33 & .36 & .40 & .46 \\ 3200 & .23 & .25 & .28 & .33\end{array}$

'Crew, $10 \mathrm{mcn}$, excluding loading crew.

Deduct $10 \%$ for road changing.

Add $\$ 0.08$ per M ft.b.m. for road changing (fixed-per-acrc cost) to get total yarding cost.

Basis of Cost: Operating costs per 8-hour day consist of :

Item 1, 432.04 minutes actual yarding time at $\$ 0.243$ per minute

$\$ 104.98$

Item 2, 47.96 minutes road changing time at $\$ 0.198$ per minute $\quad 9.50$

Total per day (full machine rate) $\$ 114.48$

Item 1 headed "yarding variable" represents turn by turn cost in actual yarding.

Item 2 represents "fixed per acre" costs avelaging $\$ 6.00$ per acre, and is equivalent to $\$ 0.08$ per M b.m. based on the removal of 75 M feet per acre. Does not include rigging ahead and moving costs which amount to $\$ 0.13$ per M b.m.

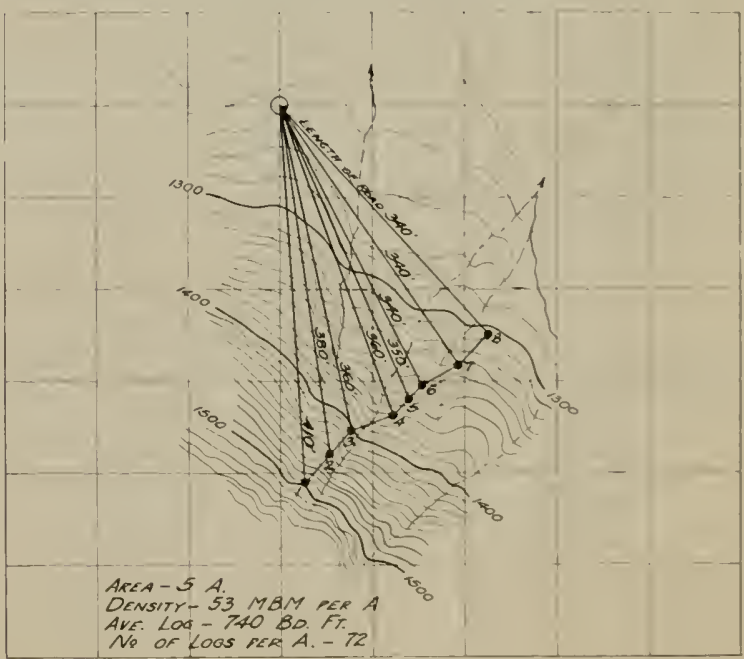

FIG. 14 
TABLE: 15

lirelation of rolume of loy and yardiny distaner to output and rost of yording with sol) h.p. alcetris highlead yurderi; 2 studie's

I Rate of production in M ft.b.m. per \&-hour day. for various actual yarding distances

Volume of logft.b.m. उon

$\begin{array}{rrrrr}100 & 20 & 1 ! & 17 & 15 \\ 200 & 10 & 37 & 33 & 23 \\ 100 & 80 & 73 & 130 & 57 \\ 800 & 158 & 145 & 131 & 113 \\ 1600 & 310 & 284 & 255 & 221 \\ 3000 & 571 & 522 & 162 & 100\end{array}$

II Varding variable cost in dollat's per M ft.b.u." for various actuol yarding distances

$\begin{array}{rrrrr}100 & 5.74 & 6.27 & 6.96 & 8.01 \\ 200 & 2.89 & 3.15 & 3.50 & 4.03 \\ 400 & 1.46 & 1.59 & 1.76 & 2.01 \\ 800 & .74 & .80 & .89 & 1.09 \\ 1600 & .38 & .41 & .46 & .53 \\ 3200 & .20 & .22 & .25 & .29\end{array}$

III Yarding variable cost in clollars per $\mathrm{M}$ ft.b.m.3 for various coternal yarding distances

$\begin{array}{rrrrr}100 & 5.48 & 5.82 & 6.21 & 6.71 \\ 200 & 2.75 & 2.92 & 3.12 & 3.38 \\ 400 & 1.39 & 1.48 & 1.57 & 1.71 \\ 800 & .71 & .74 & .79 & .86 \\ 1600 & .36 & .38 & .41 & .44 \\ 3200 & .19 & .20 & .22 & .24\end{array}$

Crew, 10 men.

2lerluct $12 \%$ for roisl changing.

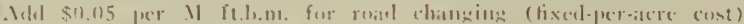
(1) get total varding cout

Liasis of Cost: Costs per 8-hour day consist of :

Item $1,421.42$ minutes actual yarding time at $\$ 0.243$ per minute

$\$ 102.40$

Item 2, 58.58 minutes road changing time at $\$ 0.198$ per minute

11.60

Total per day (full machine rate)

$\$ 114.00$

Item 1 termed "yarding variable" represents turn by turn costs in actual yarding.

Item 2 represents "fixed per acre" costs averaging $\$ 5.25$ per acre, equivalent to $\$ 0.05$ per M b.m., based on the removal of $105 \mathrm{M} \mathrm{b} . \mathrm{m}$. per acre. This does not cover rigging ahead ol muving costs for which add $\$ 0.17$ per M b.m.

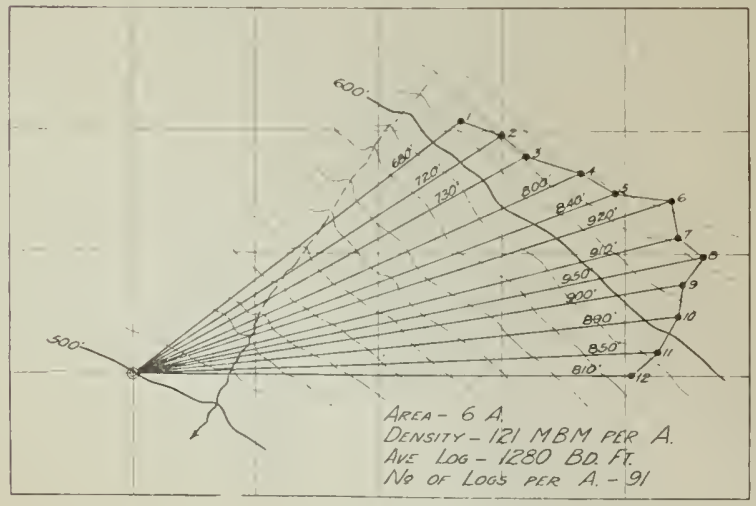

FIG. 15
TABLE 16

L'clation of volume of log and yording distance to ontmit and cost of yarding with 12014 highleud yarderl

I Rate of production in M ft.b.m. per 8-hour day ${ }^{2}$ for various actual yarding distances

\begin{tabular}{|c|c|c|c|c|}
\hline \multirow{2}{*}{ I'olume of logft.b.m. } & \multicolumn{4}{|c|}{ aralin } \\
\hline & 300 & 500 & $\pi 00$ & 001 \\
\hline 100 & 11 & 9 & 7 & \\
\hline 200 & 23 & 18 & 14 & 10 \\
\hline 400 & 45 & 36 & 27 & 20 \\
\hline 800 & 88 & 71 & $5: 3$ & 10 \\
\hline 1600 & 169 & 136 & 101 & 77 \\
\hline $32(10)$ & 307 & 243 & 100 & 139 \\
\hline
\end{tabular}

II Yarding varioble cost in dollars per M ft.b.m.3 for valious actual yarding distances

$\begin{array}{rrrrr}100 & 10.32 & 12.69 & 17.12 & 22.5 \% \\ 200 & 5.16 & 6.35 & 8.56 & 11.26 \\ 100 & 2.62 & 3.22 & 4.35 & 5.79 \\ 800 & 1.33 & 1.64 & 2.21 & 2.91 \\ 1600 & .69 & .86 & 1.16 & 1.52 \\ 3200 & .38 & .48 & .64 & .85\end{array}$

III Yarding variable cost in dollars per $\mathrm{M}$ ft.b.m.3 for various external yarding distances

$\begin{array}{rrrrr}100 & 9.32 & 10.74 & 12.75 & 15.57 \\ 200 & 4.66 & 5.37 & 6.37 & 7.79 \\ 400 & 2.37 & 2.73 & 3.24 & 3.95 \\ 800 & 1.20 & 1.39 & 1.65 & 2.01 \\ 1600 & .62 & .73 & .86 & 1.05 \\ 3200 & .34 & .41 & .48 & .58\end{array}$

'('rew. 111.5 men. exclusling loading crew.

"1) erluct $17 \%$ for roal changing.

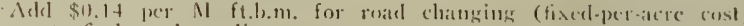
to fint total yatrling cost.

Busis of Cost: Operating costs per 8-hour day consist of :

Item 1, 398.11 minutes actual yalding time at $\$ 0.243$ per minute

$\$ 96.71$

Item 2, 81.89 minutes road changing time at $\$ 0.198$ per minute

16.23

Total per day (full machine rate)

$\$ 112.94$

Item 1 termed "yarding variable" represents turn by turn costs in actual yarding.

Item '2 represents "fixed per" acre" costs averaging $\$ 12.00$ per acre for the area equivalent to $\$ 0.14$ per M b.m. based on the removal of $84 \mathrm{M}$ feet per acre. This does not include rigging ahead and moving, for which add $\$ 0.11$ per $M$ b.m.

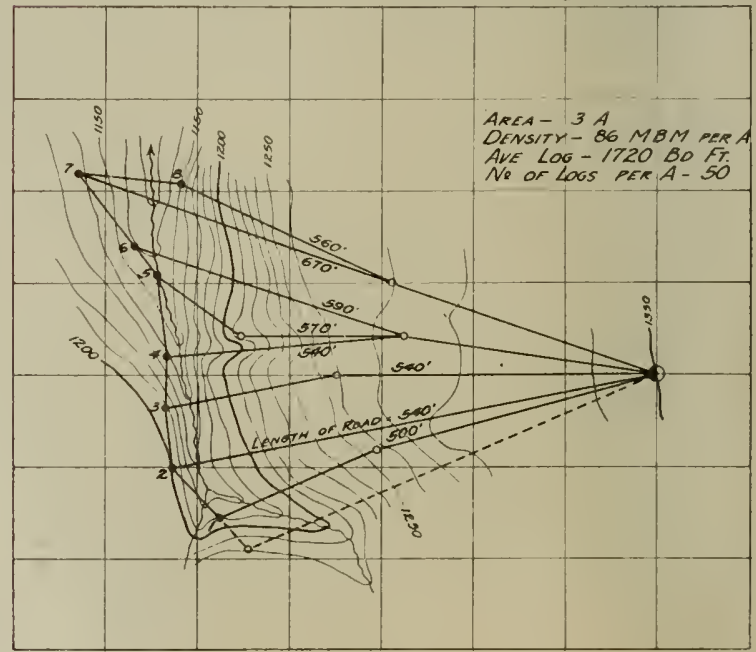

FIG. 16 
TABLE 17

Relation of volume of $\log$ and youdiny distance lo oulput and cost of yarding with $13 \times 14$ highlead yarder.1; 2 studies

I Rate of production in M ft.b.m. per 8-hour day ${ }^{2}$ for various actual yarding distances

$\begin{array}{rrrrr}800 & 85 & 56 & 38 & 28 \\ 1600 & 169 & 112 & 75 & 55 \\ 3200 & 336 & 222 & 148 & 109\end{array}$

II Yarding variable cost in dollars per $\mathrm{M}$ ft.b.m." for various uctual yarding distances

$\begin{array}{rrrrr}800 & 1.37 & 2.08 & 3.12 & 4.20 \\ 1600 & .69 & 1.04 & 1.56 & 2.11 \\ 3200 & .35 & .53 & .80 & 1.06\end{array}$

III Yarding variable cost in dollar's per $\mathrm{M} \mathrm{ft} . \mathrm{b} . \mathrm{m} .{ }^{3}$ for various external yarding distances

$\begin{array}{rrrrr}800 & 1.13 & 1.49 & 2.05 & 2.68 \\ 1600 & .57 & .74 & 1.03 & 1.35 \\ 3200 & .29 & .38 & .53 & .68\end{array}$

(irew, 10.5 men.

"Deduct $20 \%$ for road changing.

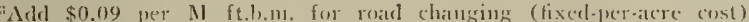
to get total yareling cost.

Basis of Cost: Operating cost per 8-hour day consists of :

Item 1, 382.24 minutes actual yarding time at $\$ 0.243$ per minute

$\$ 92.82$

Item 2, 97.76 minutes road changing time at $\$ 0.198$ per minute

19.40

Total per day (full machinc rate)

$\$ 112.22$

Item 1 termed "yarding variable" represents turn by turn costs in actual yarding.

Item 2 represents "fixed per acre" costs averaging $\$ 6.80$ per acre, equivalent to $\$ 0.09$ per $M$ based on the removal of $75 \mathrm{M}$ feet per acre. This does not cover rigging ahead or moving costs for which add $\$ 0.08$ per M.
TABLE: 18

Relation of volume of log and yarding distrnce to output und cost of yarding with $12 \times 14$ highlead yarder 1

I Rate of production in M ft.b.m. per 8-hour day" for various actual yarding clistances

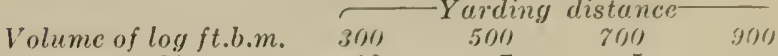

$\begin{array}{rrrr}100 & 10 & 7 & 5 \\ 200 & 20 & 14 & 10 \\ 400 & 40 & 27 & 20 \\ 800 & 80 & 51 & 40 \\ 1600 & 158 & 106 & 78 \\ 3200 & 307 & 205 & 151\end{array}$

iI Yarding variable cost in dollar's per II ft.b.m."3 for various acturel yarding distances

$\begin{array}{rrrr}100 & 11.52 & 17.20 & 23.33 \\ 200 & 5.77 & 8.63 & 11.69 \\ 400 & 2.90 & 4.33 & 5.87 \\ 800 & 1.46 & 2.18 & 2.95 \\ 1600 & .74 & 1.10 & 1.50 \\ 3200 & .38 & .57 & .77\end{array}$

III Yarding variable cost in dollar's per M ft.b.m." for various external yarding distances

$\begin{array}{rrrr}100 & 9.00 & 12.33 & 16.21 \\ 200 & 4.51 & 6.19 & 8.12 \\ 400 & 2.26 & 3.10 & 4.08 \\ 800 & 1.14 & 1.56 & 2.05 \\ 1600 & .58 & .79 & 1.04 \\ 3200 & .30 & .41 & .54\end{array}$

(rew, 10 men.

-1)educt $31 \%$ for roarl changing.

${ }^{3}$ Add $\$ 0.24$ per $M$ ft.l. m. for road changing (fixed per acre cos!) to get total yarding cost.

Busis of Cost: Operating cost per 8-hour dav consists of :

Item $1,331.82$ minutes of actual yarding time at 0.243 per minute

$\$ 80.68$

Item 2, 148.18 minutes of road changing time at 0.198 per minute

29.38

Total per day (full machine rate)

$\$ 110.06$

Item 1 termed "yarding variable" represents turn by turn time in actual yarding.

Item 2 represents "fixed per acre" costs, averaging $\$ 12.50$ per acre equivalent to $\$ 0.24$ per M b.m. based on the removal of $52 \mathrm{M}$ b.m. per acre. This does not cover moving and rigging ahead costs which amount to $\$ 0.15$ per M b.m.

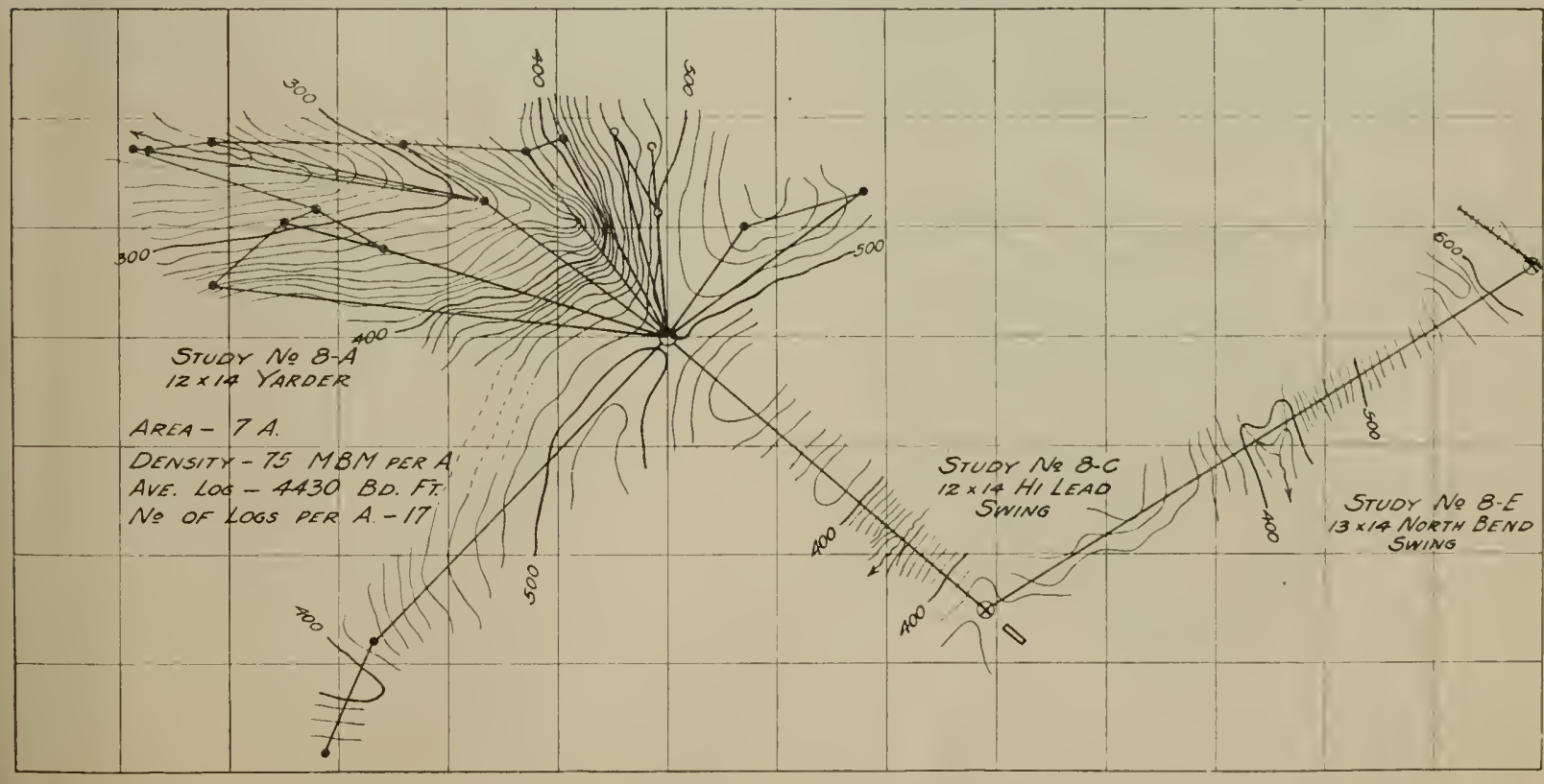

FIG. 17 
TABLE 19

Relution of volume of $\log$ and yardiug distunce to output and cost of yarding with 200 h.p. Diesel highlead yarderl

I Rate of production in M ft.b.m. per 8-hour day 2 for various actual yarding distances

\begin{tabular}{crrrr} 
& \multicolumn{4}{c}{ Yarding distance } \\
Volume of $\log$ ft.b.m. & 300 & 500 & 700 & 900 \\
100 & 19 & 15 & 12 & 10 \\
200 & 36 & 30 & 24 & 19 \\
400 & 71 & 58 & 47 & 38 \\
800 & 133 & 109 & 87 & 70 \\
1600 & 236 & 190 & 152 & 122 \\
3200 & 369 & 294 & 234 & 187
\end{tabular}

II Yarding variable cost in dollars per M ft.b.m. ${ }^{3}$ for various actual yarding distances

$\begin{array}{rrrrr}100 & 5.06 & 6.11 & 7.57 & 9.41 \\ 200 & 2.58 & 3.12 & 3.87 & 4.81 \\ 400 & 1.33 & 1.61 & 2.00 & 2.49 \\ 800 & .70 & .86 & 1.08 & 1.34 \\ 1600 & .40 & .49 & .62 & .77 \\ 3200 & .25 & .32 & .40 & .50\end{array}$

III Yarding variable cost in dollars per $\mathrm{M}$ ft.b.m.3 for various cotcrnal yarding distances

$\begin{array}{rrrrr}100 & 4.72 & 5.29 & 6.05 & 7.09 \\ 200 & 2.40 & 2.69 & 3.09 & 3.59 \\ 400 & 1.24 & 1.39 & 1.60 & 1.85 \\ 800 & .63 & .73 & .85 & .96 \\ 1600 & .37 & .41 & .49 & .57 \\ 3200 & .22 & .26 & .31 & .36\end{array}$

Crew, 8 men.

Deduct $33 \%$ for road clanging

Aild $\$ 0.15$ per $11 \mathrm{ft}$ b.m. for roarl clauging (fixed per-acre cost) to get total yarding cost.

Busis of Cost: Cost per 8-hour day consists of :

Iten 1,375 minutes actual yarding time at $\$ 0.195$ per minute

Item 2, 105 minutes road changing time at $\$ 0.175$ per minute

Total per day (full machine rate)

18.38

Item 1 termed "yarding variable" represents turn by turn time in actual yarding.

Item 2 represents "fixed per acre" costs averaging $\$ 9.06$ per acre, equivalent to $\$ 0.15$ per $M$ based on the removal of 62 M feet per acre. This does not cover rigging ahead and moving costs for which add $\$ 0.21$ per M.

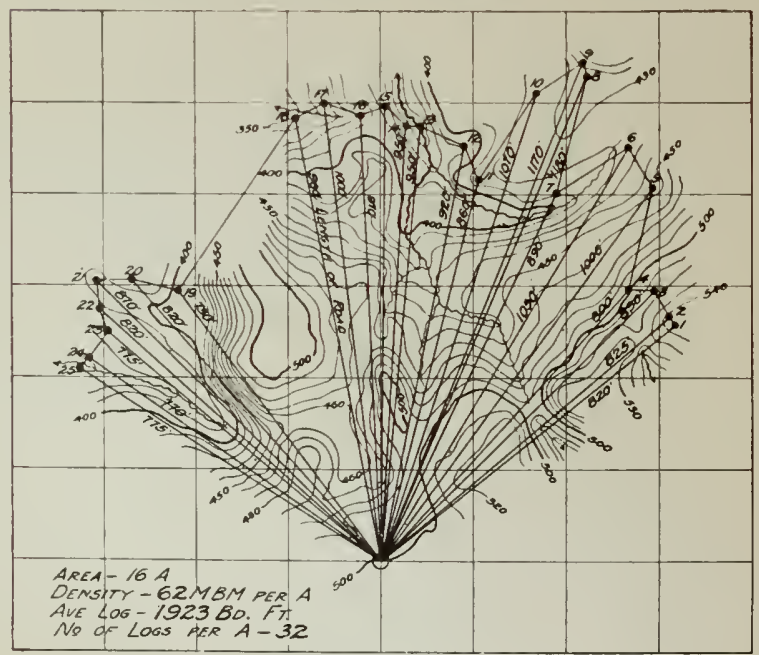

F1G. 19
TABLE 20

Relation of volume of $\log$ and yarding distunce to output and cost of yarding with 200 h.p. Diesel highlead yarderl

I Rate of production in $\mathrm{M}$ ft.b.m, per 8-hour day² for various actual yarding distances

Volume of $\log$ ft.b.m.
100
200
400
800
1600
3200

$\begin{array}{rrrr}300 & 500 & 700 & 900 \\ 14 & 12 & 10 & 8 \\ 27 & 23 & 20 & 17 \\ 52 & 45 & 38 & 32 \\ 98 & 86 & 72 & 60 \\ 173 & 150 & 124 & 103 \\ 254 & 216 & 178 & 146\end{array}$

II Yarding variable cost in dollar's per M ft.b.m.3 for various actual yarding distances

$\begin{array}{rrrrr}100 & 6.94 & 7.91 & 9.35 & 11.15 \\ 200 & 3.52 & 4.01 & 4.74 & 5.66 \\ 400 & 1.80 & 2.06 & 2.45 & 2.90 \\ 800 & .96 & 1.09 & 1.31 & 1.57 \\ 1600 & .54 & .63 & .76 & .91 \\ 3200 & .37 & .44 & .53 & .64\end{array}$

IJI Yarding variable cost in dollats per M ft.b.1m.3 for various cxterul yarding distances

$\begin{array}{rrrrr}100 & 6.64 & 7.13 & 7.86 & 8.81 \\ 200 & 3.42 & 3.63 & 4.00 & 4.47 \\ 400 & 1.72 & 1.85 & 2.05 & 2.30 \\ 800 & .93 & .99 & 1.09 & 1.23 \\ 1600 & .51 & .56 & .62 & .70 \\ 3200 & .35 & .38 & .43 & .49\end{array}$

Crew, 8.2 man.

- Deduct $29 \%$ for roal changing.

"Adel $\$ 0.31$ per $\mathrm{M}$ ft.b.m. for road changing (fixed per-acre costs) to find total yarding cost.

Busis of Cost: Cost per 8-hour day consists of:

Item $1,375.98$ minutes actual yarding time at $\$ 0.195$ per minute

Item 2, 140.40 minutes road changing time at $\$ 0.175$ per minute

Total per day (full machine rate)

$\$ 91.51$

Item 1 termed "yarding variable" represents turn by turn time in actual yairding.

Item 2 represents "fixed per acre" costs averaging, $\$ 8.75$ per acre equivalent to $\$ 0.31 \mathrm{per}^{\circ} \mathrm{M}$ based on the removal of $28 \mathrm{M}$ feet per acre. This does not cover rigging ahead and moving costs which amount to $\$ 0.21$ per $M$.

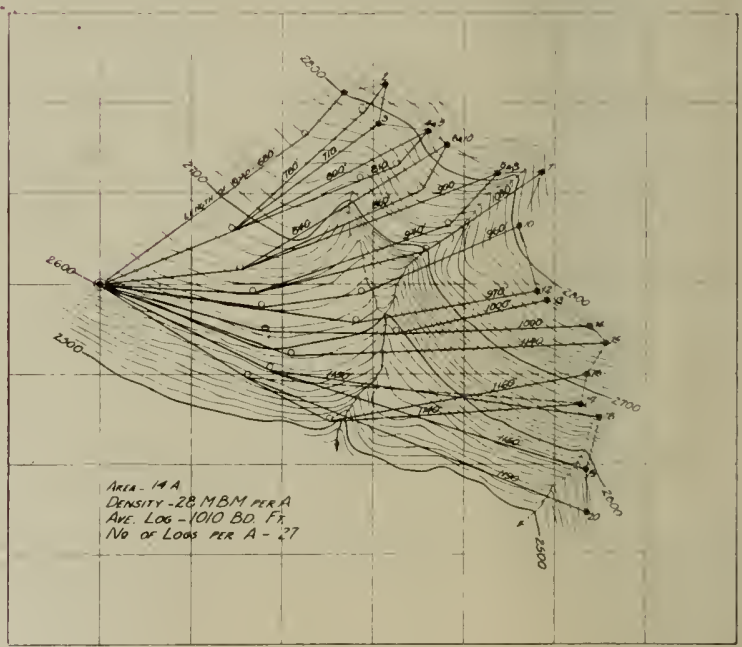

FIG. 20 
TABLE 21

Relation of volume of log and yarding distance to output and cost of yarding with 200 h.p. Diesel highlead yarder 1

I Rate of production in M ft.b.m. per 8-hour day² for various actual yarding distances

Volume of $\log$ ft.b.m. $300 \quad 500 \quad 700$

$\begin{array}{rrr}100 & 11 & 10 \\ 200 & 22 & 19 \\ 400 & 42 & 37 \\ 800 & 79 & 67 \\ 1600 & 145 & 123 \\ 3200 & 267 & 222\end{array}$

8

10

37

67

222

15)

29

51

92

II Yarding variable cost in dollars per $\mathrm{M}$ ft.b.m. various actual yarding distances

$\begin{array}{rrrr}100 & 8.44 & 9.66 & 12.40 \\ 200 & 4.31 & 4.95 & 6.37 \\ 400 & 2.22 & 2.56 & 3.33 \\ 800 & 1.19 & 1.39 & 1.83 \\ 1600 & .65 & .76 & 1.01 \\ 3200 & .35 & .42 & .56\end{array}$

III Yarding variable cost in dollars per M ft.b.m. ${ }^{3}$ for various external yarding distances

$\begin{array}{rrrr}100 & 8.19 & 8.72 & 9.84 \\ 200 & 4.11 & 4.38 & 5.00 \\ 400 & 2.12 & 2.29 & 2.60 \\ 800 & 1.12 & 1.23 & 1.41 \\ 1600 & .61 & .67 & .77 \\ 3200 & .33 & .36 & .43\end{array}$

'Crew, 8 men.

2Deduct $26 \%$ for road changing.

${ }^{3}$ Add $\$ 0.21$ per $M$ ft.b.m. for road changing (fixed per acre cost) to get total yarding cost.

Basis of Cost: Cost per 8-hour day consists of:

Item 1, 357 minutes actual yarding time at $\$ 0.195$ per minute $\$ 69.62$

Item 2, 123 minutes road changing time at $\$ 0.175$ per minute

21.52

Total per days (full machine rate) _..... \$91.14

Item 1 termed "yarding variable" represents turn by turn time in actual yarding.

Item 2 represents "fixed per acre" costs averaging $\$ 7.00$ per acre equivalent to $\$ 0.24$ per $M$ based on the removal of $29 \mathrm{M}$ feet per acre. This does not cover rigging ahead and moving costs for which add $\$ 0.21$ per $M$ ft.b.m.

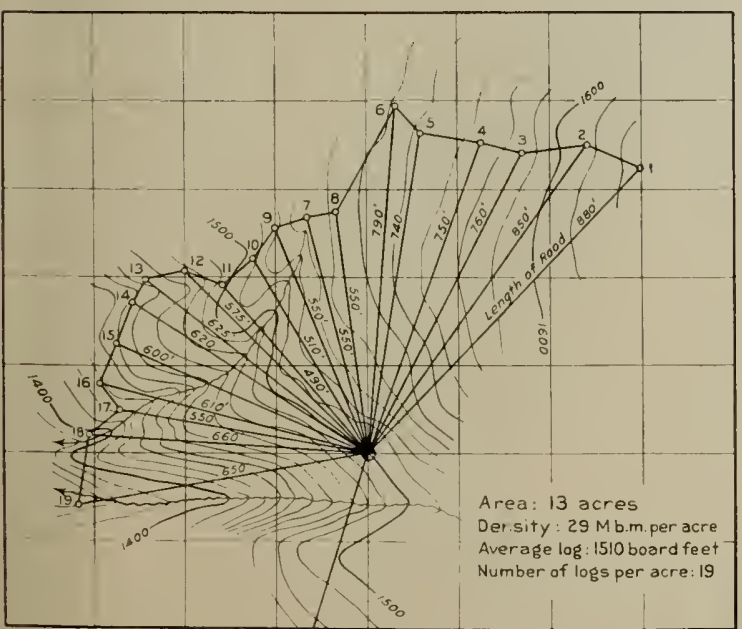

FIG. 21
TABLE 22

Relation of volume of $\log$ and yarding distance to output and cost of yarding with 125 h.p. gasoline highlead yarder ${ }^{-1}$

I Rate of production in M ft.b.m. per 8-hour day'2 for various actual yarding distances

$\begin{array}{crrrr}\text { Volume of } \log \text { ft.b.m. } & 300 & 400 & 500 & 600 \\ 100 & 21 & 17 & 14 & 12 \\ 200 & 40 & 33 & 28 & 23 \\ 400 & 77 & 63 & 53 & 45 \\ 800 & 143 & 119 & 98 & 84 \\ 1600 & 231 & 185 & 157 & 131 \\ 3200 & 330 & 273 & 225 & 185\end{array}$

II Yarding variable cost in dollars per $\mathrm{M}$ ft.b.m. ${ }^{3}$ for various retual yarding distances

$\begin{array}{rrrrr}100 & 3.05 & 3.69 & 4.38 & 5.11 \\ 200 & 1.57 & 1.90 & 2.25 & 2.63 \\ 400 & .82 & 1.00 & 1.19 & 1.39 \\ 800 & .44 & .53 & .64 & .75 \\ 1600 & .27 & .34 & .40 & .48 \\ 3200 & .19 & .24 & .29 & .34\end{array}$

III Yarding variable cost in dollars per $\mathrm{M}$ ft.b.m. ${ }^{3}$ for various external yarding distances

$\begin{array}{rrrrr}100 & 2.56 & 2.96 & 3.38 & 3.83 \\ 200 & 1.32 & 1.52 & 1.74 & 2.02 \\ 400 & .69 & .80 & .92 & 1.04 \\ 800 & .37 & .43 & .49 & .56 \\ 1600 & .23 & .27 & .31 & .36 \\ 3200 & .16 & .18 & .22 & .26\end{array}$

Crew, 7 men.

2 Deduct $6 \%$ for road changing.

${ }^{3}$ Add $\$ 0.02$ per $M$ ft.b.m. for road changing (fixed per acre costs) to get total yarding cost

Busis of Cost : Cost per 8-hour day consists of :

Item 1, 453.36 minutes actual yarding time at $\$ 0.131$ per minute

Item 2, 26.64 minutes road changing time at $\$ 0.118$ per minute

Total per day (full machine rate)

$\$ 62.55$

Item 1 termed "yarding variable" represents turn by turn time in actual yarding.

Item 2 represents "fixed per acre" costs averaging $\$ 1.20$ per acre and is equivalent to $\$ 0.02$ per M b.m. based on the removal of 50 M feet per acre. This does not include rigging ahead and moving, which amounts to $\$ 0.12$ per M b.m.

(for Fig. 22 see page 28). 
TABLE: 33

Relation of volume of $\log$ and yording distence to ontput and cost of yavding with 100 h.p. gasoline highlead yarder. 2 studies

I Rate of production in M ft.b.111. per 8-houl day" for various actual yarding distances

\begin{tabular}{crrrr} 
& \multicolumn{4}{c}{ Yarding distuncer } \\
Volume of $\log$ ft.b.m. & 300 & 500 & $\gamma 00$ & 900 \\
100 & 16 & 13 & 10 & 7 \\
200 & 31 & 25 & 18 & 13 \\
400 & 62 & 48 & 35 & 26 \\
800 & 117 & 89 & 64 & 46 \\
1600 & 209 & 150 & 105 & 75 \\
3200 & 325 & 217 & 143 & 101
\end{tabular}

II Yarding variable cost in dollars per $M$ ft.b.m." for various actual yarding distances

$\begin{array}{rrrrr}100 & 3.67 & 4.62 & 6.24 & 8.49 \\ 200 & 1.85 & 2.35 & 3.19 & 4.35 \\ 400 & .95 & 1.21 & 1.67 & 2.29 \\ 800 & .50 & .66 & .92 & 1.27 \\ 1600 & .28 & .39 & .56 & .78 \\ 3200 & .18 & .27 & .41 & .58\end{array}$

III Yarding variable cost in dollars per $\mathrm{M} \mathrm{ft.b.m."} \mathrm{for}$ various external yarding distances

$\begin{array}{rrrrr}100 & 3.22 & 3.76 & 4.51 & 5.59 \\ 200 & 1.67 & 1.96 & 2.37 & 2.94 \\ 400 & .85 & 1.01 & 1.23 & 1.54 \\ 800 & .45 & .55 & .68 & .85 \\ 1600 & .25 & .32 & .41 & .52 \\ 3200 & .16 & .22 & .30 & .39\end{array}$

'Crew, 6 mc11.

3Add $\$ 0.23 \mathrm{per}$ M ft.b.m. for road clianging (fixed per-acre cost) to get total yarding cost.

Basis of Cost: Cost per 8-hour day consists of :

Item 1, 378 minutes actual yarding time at

Iten 2,102 minutes road changing time at $\$ 0.10$ per minute

Total per day (full machine rate) ........ \$56.33

Item 1 termed "yarding variable" represents turn by turn costs in actual yarding.

Item 2 represents "fixed per acre" costs averaging $\$ 4.00$ per acre or $\$ 0.23$ per M b.m., based on the removal of $17.3 \mathrm{M}$ feet per acre. This does not include rigging ahead and moving costs which amount to $\$ 0.29$ per $M$ feet b.m.

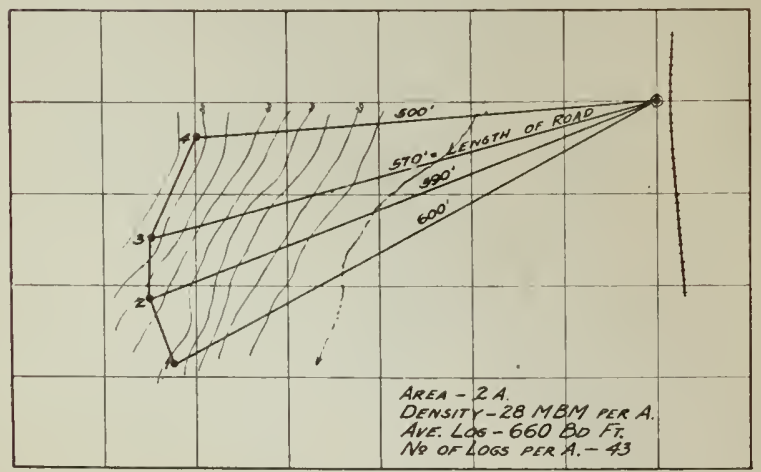

FIG. 23
TABLE 24

Relution of volume of $\log$ and yarding distance to output and cost of yarding with 35 h.p. yesoline highl'ad. yaider

I Rate of production in M ft.b.m. per 8-hour day" for various actual yarding distances

$\begin{array}{crrr}\text { Volume of } \log \text { ft.b.m. } & 200 & 400 & 600 \\ 100 & 11 & 7 & 5 \\ 200 & 21 & 14 & 10 \\ 400 & 42 & 27 & 19 \\ 800 & 84 & 53 & 37 \\ 1600 & 163 & 103 & 71\end{array}$

II Yarding variable cost in dollar's per $M$ ft.b.m.il for various cetual yarding distances

$\begin{array}{rrrr}100 & 2.52 & 3.93 & 5.61 \\ 200 & 1.26 & 1.97 & 2.81 \\ 400 & .63 & .99 & 1.43 \\ 800 & .32 & .51 & .73 \\ 1600 & .16 & .26 & .38\end{array}$

III Yarding variable cost in dollar's per M ft.b.m." for various cxterual yarding distances

$\begin{array}{rrrr}100 & 2.10 & 2.93 & 3.94 \\ 200 & 1.05 & 1.47 & 1.98 \\ 400 & .52 & .74 & 1.00 \\ 800 & .27 & .38 & .51 \\ 1600 & .13 & .19 & .27\end{array}$

'Crew, 4 men.

21)educt $32 \%$ for road changing cost.

"Add $\$ 0.11$ per $M$ ft.b.m. for road changing (fixcel per-acre cost) to get ental yarding cost.

Busis of Cost: Cost per 8-hour day consists of:

Item 1, 386 minutes actual yarding time at $\$ 0.056$ per minute

Item 2, 94 minutes road changing time at $\$ 0.046$ per minute

Total per day (full machine rate)

$\$ 26.00$

Item 1 termed "yarding variable represents" turn by turn costs in actual yarding.

Item 2 represents "fixed per acre" costs averaging $\$ 4.75$ per acre, equivalent to $\$ 0.11$ per M b.m. based on the removal of $43 \mathrm{M} \mathrm{b.m.} \mathrm{per} \mathrm{acre.}$ This does not include rigging ahead and moving costs which amount to $\$ 0.14$ per M b.m.

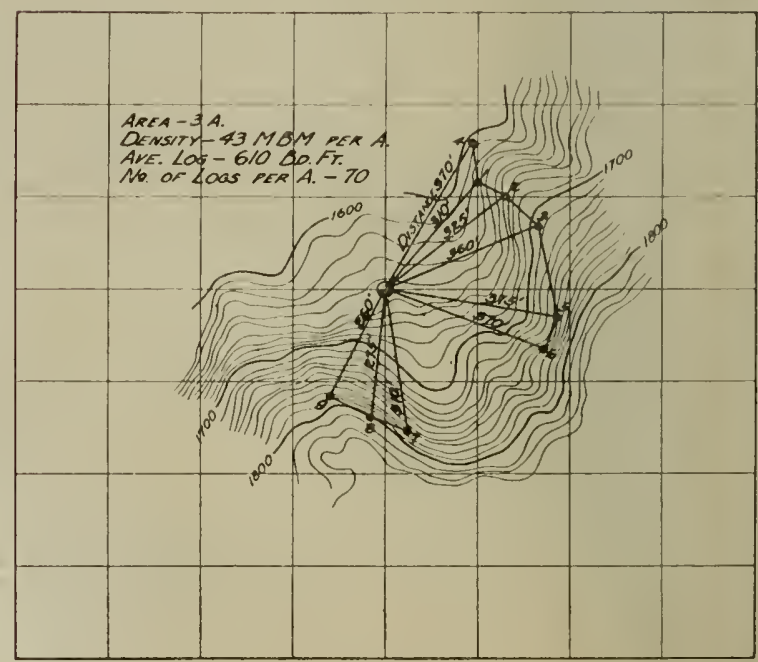

FIG. 24 
TABLE 25

Relation of volume of $\log$ and yarding distance to output and cost of yarding with 30 h.p. gasoline highlead yarder-1

I Rate of production in M ft.b.m. per 8-hour day? for various actual yarding distances

Volume of $\log$ ft.b.m. $\quad 200 \quad$ Yarding distance-

$\begin{array}{rrrr}100 & 19 & 7 & 4 \\ 200 & 37 & 14 & 8 \\ 400 & 66 & 24 & 14 \\ 800 & 116 & 43 & 24 \\ 1600 & 205 & 74 & 41\end{array}$

II Yarding variable cost in dollars per $M$ ft.b.m.3 for various actual yarding distances

$\begin{array}{rrrr}100 & 1.24 & 3.25 & 5.78 \\ 200 & .64 & 1.70 & 3.02 \\ 400 & .36 & .96 & 1.70 \\ 800 & .20 & .55 & 1.00 \\ 1600 & .11 & .32 & .58\end{array}$

III Yarding variable cost in dollars per M ft.b.m. ${ }^{3}$ for various external yarding distances

$\begin{array}{rrrr}100 & .90 & 1.74 & 3.28 \\ 200 & .46 & .91 & 1.72 \\ 400 & .26 & .51 & .97 \\ 800 & .15 & .29 & .57 \\ 1600 & .08 & .17 & .33\end{array}$

(Crew, 3 men.

"Deduct $29 \%$ for road changing. ${ }^{3}$ Add $\$ 0.15$ per $\mathrm{M} \mathrm{ft.b.m.}$. for road changing (fixed per-acre cost)
to get total yarding cost.

Basis of Cost: Operating cost per 8-hour day consists of :

Item 1, 343 minutes actual yarding time at $\$ 0.049$ per minute

Item 2, 137 minutes road changing time at $\$ 0.039$ per minute.

Total per day (full machine rate)

$\$ 22.00$

Item 1 termed "yarding variable" represents turn by turn costs in actual yarding.

Item 2 represents "fixed per acre" costs averaging $\$ 2.25$ per acre equivalent to $\$ 0.15$ per $\mathrm{M}$ b.m. based on the removal of $15 \mathrm{M}$ b.m. per acre. This does not include rigging ahead and moving costs which amount to $\$ 0.22 \mathrm{per}$ M b.m.

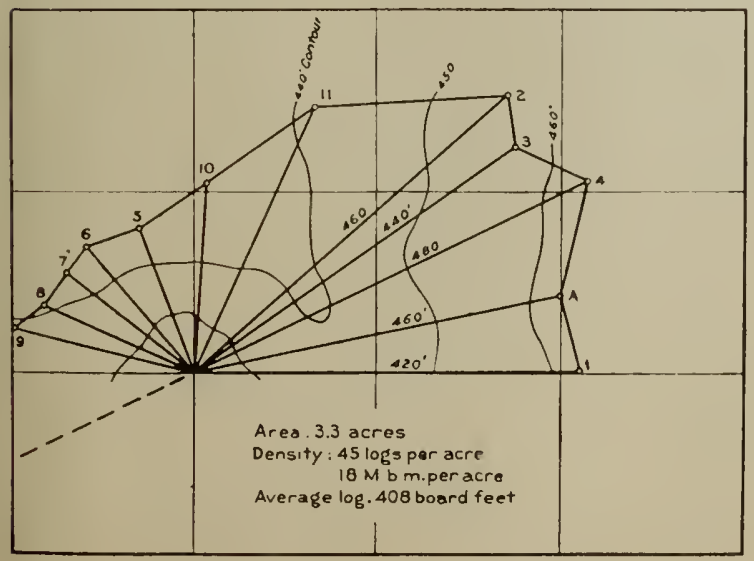

FIG. 23 - STUDY IA; 35 H.P. GAS YARDER
TABLE 26

Relation of volume of $\log$ and yarding distance to output and cost of yarding with 30 h.p. gosoline highlead yarder 1

I Rate of production in M ft.b.m. per 8-hour day2 for various actual yarding distances

Volume of $\log$ ft.b.m. $\quad 200 \quad 400 \quad 600$

$\begin{array}{rrr}100 & 9 & 6 \\ 200 & 18 & 11 \\ 400 & 33 & 21 \\ 800 & 59 & 36 \\ 1600 & 88 & 54\end{array}$

6
11

21
36

$54-21$

II Yarding variable cost in dollars per $\mathrm{M} \mathrm{ft} . \mathrm{b} . \mathrm{m}^{3}$ for various actual yarding distances

$\begin{array}{rrrr}100 & 2.08 & 3.23 & 5.22 \\ 200 & 1.07 & 1.68 & 2.73 \\ 400 & .57 & .91 & 1.51 \\ 800 & .32 & .52 & .88 \\ 1600 & .21 & .35 & .59\end{array}$

III Yarding variable cost in dollars per M ft.b.m. ${ }^{3}$ for various external yarding distances

$\begin{array}{rrrr}100 & 1.88 & 2.42 & 3.41 \\ 200 & .96 & 1.26 & 1.78 \\ 400 & .52 & .67 & .96 \\ 800 & .27 & .38 & .60 \\ 1600 & .18 & .25 & .37\end{array}$

'rew. 2 men.

"Deduct $17 \%$ for road changing.

3 Add $\$ 0.13$ per M ft.b.m. for road changing (fixed-per-acre cost) to get total yarding cost.

Basis of Cost: Cost per 8-hour day consists of :

Item 1, 399 minutes actual yarding time at $\$ 0.039$ per minute

Item 2, 91 minutes road changing time at $\$ 0.031$ per minute

Total per day (full machine rate) $\$ 18.00$

Item 1 termed "yarding variable" represents turn by turn costs in actual yarding.

Item 2 represents "fixed per acre" costs averaging $\$ 4.20$ per acre, equivalent to $\$ 0.13$ per MI b.m. based on the removal of $32 \mathrm{M}$ per acre.

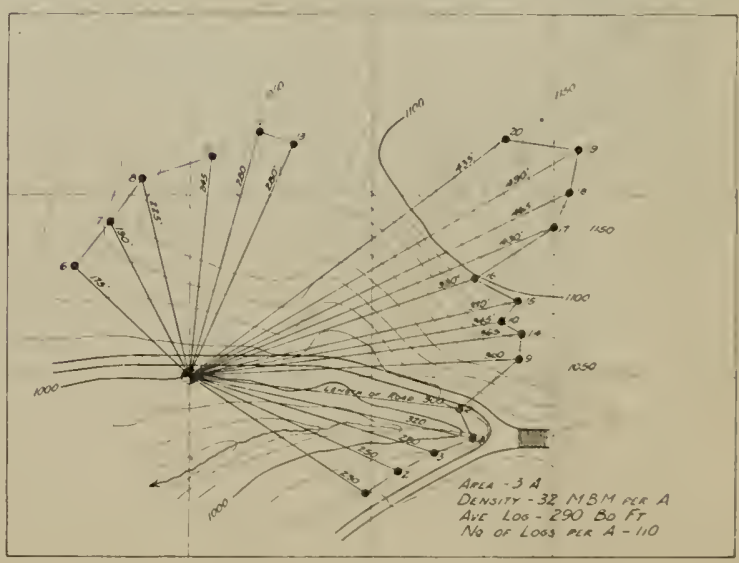

FIG. 26 
Relation of volume of $\log$ and yarding distance to output and cost of yarding with $35 \mathrm{~h} . \mathrm{l}$. gasoline highlead yarder.

I Rate of production in M ft.b.m. per 8-hour day ${ }^{2}$ for various actual yarding distances

$\begin{array}{crrrr}\text { Volume of } \log \text { ft.b.m. } & 100 & 200 & 300 & 400 \\ 100 & 13 & 10 & 8 & 6 \\ 200 & 25 & 19 & 15 & 12 \\ 400 & 47 & 36 & 27 & 22 \\ 800 & 92 & 67 & 50 & 40 \\ 1600 & 177 & 116 & 84 & 66\end{array}$

II Yarding variable cost in dollars per $M$ ft.b.m. ${ }^{3}$ for various actual yarding distances

$\begin{array}{rrrrr}100 & 2.20 & 2.78 & 3.61 & 4.38 \\ 200 & 1.10 & 1.42 & 1.83 & 2.26 \\ 400 & .56 & .74 & .97 & 1.20 \\ 800 & .29 & .40 & .53 & .67 \\ 1600 & .15 & .23 & .32 & .41\end{array}$

III Yarding variable cost in dollars per M ft.b.m.3 for various external yarding distances

$\begin{array}{rrrrr}100 & 2.01 & 2.37 & 2.82 & 3.33 \\ 200 & 1.01 & 1.20 & 1.43 & .7 .70 \\ 400 & .51 & .61 & .74 & .89 \\ 800 & .26 & .32 & .40 & .49 \\ 1600 & .13 & .18 & .23 & .29\end{array}$

'Crew, 4 men.

Deduct $12 \%$ for road changing.

${ }^{3}$ Add $\$ 0.05$ per M ft.b.m. for road changing (fixed per-acre cost) to get total yarding cost.

Basis of Cost: Operating cost per 8-hour day consists of :

Item 1, 434 minutes actual yarding timc at $\$ 0.056$ per minute ......... \$23.74

Item 2, 56 minutes road changing time at $\$ 0.046$ per minute

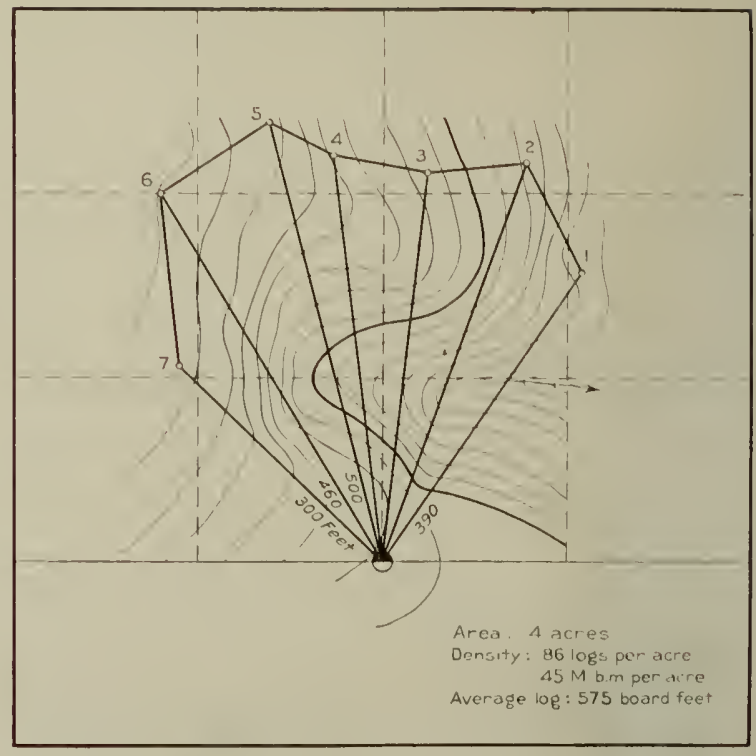

FIG. 27

Total per day (full machine rate) _.... \$ 26.32

Item 1 termed "yarding variable" represents turn by turn costs in actual yarding.

Item 2 represents "fixed per acre" costs averaging $\$ 2.45$ per acre, equivalent to $\$ 0.05$ per $M$ b.m. based on the removal of 49 M b.m. per acre. This does not include rigging ahead and moving costs which amount to $\$ 0.12$ per MI.

\section{COMPARISON OF YARDING COSTS FOR DIFFERENT TYPES OF MACHINERY AND METHODS}

23. Basis of Comparison. The comparison of the relative economic efficiency of various types of yarding machinery and methods is one of the major objectives of the yarding-cost studies. A good deal of attention in preceding chapters has been given to the basis on which such comparisons can be made, such as the determination of machine rates and the isolation of each of the principal factors which affect cost, namely, size of timber, yarding distance, density of stand, and topography; and a large amount of cost data so obtained have been presented.

A simple method of cost comparison would be to draw from each of the summary tables presented in the preceding chapter the cost data applying to any given log volume an yarding distance, or to extract from each c the tables an entire cost column applying to an given distance, and to group these data side $k$ side, classified by types of machinery and sort according to rising or falling costs, into a lary table. This method of comparison, howev $\epsilon$ would fail to give an adequate grasp of $t$ double relationships that are involved throu: variations both of distance and log volume. better visualize the cost relationships that ar both through variation of log size and yardi distances the accompanying chart (Figure 2 has been prepared to give a comparison yarding costs for five different groups of ya ing machinery. 

24. How to Read the Cost Comparison Chart.-

In explanation of this chart the following may be noted :

1. Line 8-8 at the top of the diagram headed " 200 foot log" represents a skidder study (Table 8 ). It shows the cost (as graduated along the left hand margin) of yarding $\operatorname{logs}$ of two hundred board foot volume within the external yarding distances noted along the bottom of the diagram; the data are taken from Table 8 and represent both yarding variable and road-changing costs. This study shows the highest cost of all studies in the skidder and steam slackline group.

2. Further down on the same diagram is shown a line marked 9-9, which represents the skidder study reported in Table 9 . This study gave the lowest costs for the studies in this group of machinery. The band between Line 8-8 and Line 9-9 embraces all skidder (and steam slackline) studies. The spread in this band shows the effect on costs of all the factors that in comparing one area or setting with another are not taken care of by sorting out specific log sizes and yarding distances; among these the most prominent are density and topography. Notations made show figure numbers to which the reader may turn for information on loging conditions responsible for the spread between high and low cost curves.

3. The heavy black line which runs approximately through the center of this band represents the average of the seven skidder studies that fall within the high-cost and low-cost curves. In calculating its position each study was given equal weight.

4. The same procedure has been repeated for each of four groups of yarding machinery, namely, large steam yarders, 100-125 h.p. gasoline yarders, 30-35 h.p. gasoline yarders and 60 h.p. tractors with fair-lead arch. The diagram thus consists of five bands of cost curves partly over-lapping each other each band representing a certain type of yarding machinery, and giving high, low, and average costs. The two other groups of machinery covered in this report, namely, 275-300 h.p. gasoline slackline yarders and 200 h.p. Diesel highlead yarders, have been left out of the diagram, partly because of unusual logging conditions met with in these studies, particularly in the Dieselyarder studies.

5. The procedure followed in constructing the diagram headed " 200 -foot log" has been repeated in the other four diagrams for the 400, 800, 1600 and 3200 -foot $\log$ sizes, respectively. Comparisons may thus be made over virtually the full range of log sizes ordinarily dealt with in logging.

25. Density of Timber, Efficiency of Crew, and Topography are Factors Affecting the Cost of Comparison.-It is obvious that the exact positions of the five average curves (heavy black lines) represent comparisons in which only those factors are fully considered that can be said to have been accurately measured, namely, size of $\log$ and yarding distance. Although these are on the whole the most potent, they are by no means the only factors affecting yarding costs. Some consideration must be given to density of timber, efficiency of crew and topography.
A comparison of density and volume of logs per acre is given below:

\begin{tabular}{|c|c|c|}
\hline Study gromep & $\begin{array}{l}\text { Log scule } \\
\text { me per acre } \\
\text { M.ft.b.m. }\end{array}$ & $\begin{array}{c}\text { Logs per acre } \\
\text { Number }\end{array}$ \\
\hline Skidder's & 52 & 63 \\
\hline team high-lead yalder.; & 70 & 61 \\
\hline 00-125 h.p. gasoline yarder's & 34 & 40 \\
\hline-35 h.p. gasoline yardel's & 35 & 78 \\
\hline 0 h.p. tractors & 13 & 38 \\
\hline
\end{tabular}

This shows on the face of it that the large skidders and high-lead yarders have received the best of the comparison in respect to density.

The light volume per acre noted for tractors is, however, no handicap at all because with this type of machinery there are no road-changing costs to reckon with (road-changing costs being the only item affected by volume per acre). For the gas yarders, the relatively low volume per acre creates a handicap of three and five cents per thousand board feet respectively in comparison with the steam high-lead group : while the skidder group by the same standard of comparison is handicapped by 9 cents per M. These corrections would evidently make relatively little difference in the position of the curves, except in the largest log sizes.

Density in terms of number of logs per acre is virtually equal for steam skidders and highlead yarders. The 30-35 h.p. gas high-lead, which relies entirely on one-log turns, is not aftected by this factor and may thus be considered equalized both with these groups and with the larger gas yarders and the tractors. The last mentioned groups, both of which rely on multiple log turns, are handicapped to an unknown extent by low density, which would tend to further strengthen their already very favorable position in relation to the curves representing the large machinery.

With regard to efficiency of crew, there is nothing definite to judge by in comparing one group of machinely with another; the only reasonable basis to go on is that a sufficient number of studies have been made in each of the five groups to strike as close to normal crew performance for one group as for another.

As to topography, an examination of the maps discloses that the skidder group, the large steam high-lead group, and the 30-35 h.p. gas high-lead group, each shows samples of all kinds of topographic conditions, bad, guod, and average. The 100-125 h.p. gasoline highlead group, on the other hand, is on the average favored in this respect, if compared with the afore-mentioned three groups, but this is also the group which is handicapped by low density, 
both in volume per acre and number of $\log s$ per acre. Finally there are the tractors for which the yarding studies here reported show comparatively little variation in topographic conditions, and which, furthermore, represent a method of yarding that is confined either to virtually level or to downhill topography.

In the above comments on topography the only factor's which are considered are the steepness and roughness of slopes with no account taken of such combinations of topographic features as are met with, for example, in Figure 10, which presents a forbidding picture for any method except skyline yarding, if the logs actually have to travel over the exact distance and route followed in that particular case, but which might give an entirely different impression if laid out for yarding with other methods.

26. Comparison of Yarding Variable Costs.With these various factors duly considered, the chart (Figure 28) can now speak for itself. The heavy lines, which represent the group averages, indicate a very striking superiority in the light and medium-sized machinery, particularly in the cases of high-lead yarders for short yarding distances and tractors for any yarding distance. In the latter case, the advantage is most evident for the longer distances, where tractors have no competition from highlead machinery and retain as well a handsome lead over the skidders. This becomes even more significant in view of the fact that in tractor yarding the distance may be extended indefinitely without incurring the relatively high cost incident to the double or triple handling which would usually occur in yarding with the other types of machnery. Further than this, there is virtually no rigging ahead and moving cost attached to the use of tractors. Finally, there is in the case of tractor yarding the indirect advantage of less breakage of timber in yarding, which, although here only casually referred to, may often overshadow all other considerations.

The above remarks are predicated mainly on the comparison of the group-average curves as shown in the chart. Looking next to the variations from the group averages, one finds that the large machinery is placed in a better position to compete provided that certain conditions are distinctly favorable to its use, the chief prerequisite being unusually dense or heavy stands of large timber. Under these conditions one finds, for example, that the curve for the large steam high-lead yarder (see low cost curve for steam high-lead group) inter- sects the curves for the light and medium-sized gasoline yarders at approximately 600-foot yarding distance and shows considerably better results for distances longer than this. However, it is probable that, had more studies been made in the 100-125 h.p. group, the resultant band of curves would have been considerably wider and, under equivalent density and topographic conditions, the intersection of the two low cost curves would not be quite so sharp.

\section{Rigging-Ahead Costs.-}

The comparison of yarding costs should be extended to include rigging-ahead costs in order to afford a full comparison of the yarding operation as a whole. This phase, however, did not receive much attention in the studies, except for the calculation from data furnished by the operators of the per M. feet b.m. and per-acre costs of settings covered in the yarding time-studies. These data are not very reliable, since they are based in many cases on rough estimates of direct-labor costs only; to which has been added another rough estimate of other costs. The average area per setting is also based on rough estimates. This is the reason for keeping these costs separate from the actual timestudy data on fixed per-acre costs incurred in changing of roads, although this item is identically of the same nature as rigging-ahead costs.

In the final comparison the basis should be the cost per acre. Below is a summary of average cost per acre for each of the seven groups of yarding machinery included in the studies. Average area per setting and cost per setting are also listed.

TABLE 28

\section{Comparison of rigging-ahead costs}

Cost Approx. Cost

\section{Type of machine}

per areaper per setting setting acre

Track settings: (including movDollars Acres Dollars ing and rigging ahead for loading rig)

$12 \times 14$ skidders (double track

landing) $\$ 300.00$ 312.00 60 32 $\$ 5.00$ Cold deck settings :

300 h.p. gasoline slack line 100.00 200 h.p. Diesel highlead yarder's

100-125 h.p. gasoline highlead yarders.

$30-35$ h.p. gasoline highlead yarders

108.00 21

yarth $42.00 \quad 4.5 \quad 4.75$ leck settings tractor corst would generally be negligille and is so assumed.

The high rigging-ahead costs shown for track landings, despite the relatively simple moving problem involved, derive largely from the construction of railroad sidings at the landing. In many cases (not encountered in these studies, however) when the steel-tower skidder is set up directly over the main track without special loading tracks, the rigging-ahead costs are much lower.

No data were obtained on the cost of riggingahead and moving for yarding with tractors. The moving expense involved in going from one landing to another would, however, generally be negligble. This would give the tractor an advantage of roughly $\$ 5$ per acre for cold-deck areas. For track settings the advantage, if any, may be more or less dependent upon loading method, track arrangements, cost of clearing landings, etc. 
The data can hardly be considered sufficient or reliable enough to justify definite comment on the relative standing of the other groups, except that the figures indicate that the small and medium-sized highlead machines hold their own in eomparison with the larger ones in spite of the small-sized seiting's and lequent moving that are involved in the short yarding echeme here followed.

28. Reasons for High Cost of Yarding with Large Machines.-In looking for basic reasons behind the generally poor showing made by the large machines, one finds from a study of the chart that they arc beaten before they start the actual transporting of the load. If yarding with the large machinery were entirely a process consisting of an uninterrupted movement of loads from stump to landing, the light machinery would lose its advantage. It is the departure from this working schedule that sets the large machinery back. The higher daily operating cost of large machinery is justified only during that portion of the working day when the hauling and haulbock lines are moving back and forth between the landing and the stump and provided then, of course, that their normal turn capacity is maintained. The higher cost of providing machinery and crew for nontransporting activities works against it. For example, hooking and unhooking a log of 1,000 board foot volume costs 41.4 cents in the skidder study reported in Table $9,31.3$ cents in the steam high-lead study (Table 14), 16.5 cents for the 125 h.p. gasoline yarder (Table 22), 18 cents (this covers hooking, unhookinghang-up, and "yarding" time in getting the log from stump to arch) for tractors (Table 5), and 5.4 cents for the 35 h.p. gasoline yarder reported in Table 25 . The examples taken represent in each case the study showing the lowest cost of hooking and unhooking in each group of studies.

Such a severe initial handicap against the large machines is not easily overcome by any possible economies in other phases of the work during that portion of the working day when loads are actually moving toward the landing. As shown graphically in Figure 29 only a relatively small portion of the working day of the large machinery is actually employed in hauling and haulback time; for example, at normal varding distances the large skidders and highlead yarders are actually working only about $25 \%$ of the time. In general, as the speed and power of the yarder increases the percentage of hauling and haulback time decreases. In other words, the nature of the yarding operation is such that as the power and speed of the machine is increased and the effective machine operating time is correspondingly decreased, the performance of those activities in which the machinery serves no useful function-setting chokers, changing roads, delays and waiting time-becomes costlier in approximate proportion to the higher total daily cost of operation of the machine as a whole. Within certain limits, ultimate efficiency as measured in cost per thousand board feet may be said to correspond roughly to the percentage of time devoted to the actual hauling and haulback operation.

29. Limitations of Small Yarding Machinery.From a practical point of view there are many questions to consider in weighing the significance of the data presented in Figure 28. These imply, for example, that the smaller the highlead yarder is, the lower becomes the cost of yarding (speaking here of external yarding distances of 400 to 700 feet.) But it is obvious that such a conclusion must recognize some definite limitations, which may depend upon:

1. Whether the power of the low-cost yarder is sufficient to handle the large logs on the yarding area, i.e., whether or not it can actually do the job as a whole.

2. Whether the yarding distances for which the relatively low cost is shown will serve, or advantageously can be made to serve, the needs of the area.

3. Whether the right volume of production can be secured at the loading point to permit of low cost loading and switching service.

4. Whether railroad construction and operation will be affected one way or the other.

The first of these questions may be answered at this point. The low costs shown for the 30-35 h.p. high-lead group apply (in the four studies reported) to logs under 2,000 board feet in volume. This type of yarder is no doubt limited largely to stands of small to mediumsized timber because logs scaling much over 2,000 feet generally cause trouble and logs over 4,000 board feet can probably not be handled by this set-up in any practical fashion. The 30-35 h.p. yarder's which figure so prominently in the chart (Figure 28) are thus after all impracticable for the general run of typical oldgrowth Douglas fir stands in which occur many $\operatorname{logs}$ of 3,000 to 6,000 board foot volume, with occasional logs still larger. To meet practical working requirements in stands of this character, a yarder of 60 to 80 h.p. operated by a crew of 3 to 5 men, would appear to be the best general choice. The cost curve for such a yarder may be reasoned to fall between the curves representing the $30-35$ and the $100-125$ 
h.p. groups. ${ }^{*}$ For external yarding distances of 400 to 700 feet, this type of yarder adds only slightly to the cost of yarding of small logs and provides, if properly designed, the necessary combination of power and ruggedness to successfully and cheaply bring in logs scaling as much as 4,000 to 5,000 board feet.

For larger logs the old fashioned art of hanging a block on the log may well be adopted. This may not appear an efficient method but as a matter of fact it may not as a rule be so essential to obtain high efficiency in yarding logs over 5,000 board feet in volume, at least not to the point of calling for specially designed machinery unless selective specialization can be practiced along the lines discussed in Chapters XX, XXI, and XXII. This is indicated by the fact that among about 20,000 study logs

+Compare cost of yarding with $60 \mathrm{~h}, \mathrm{p}$. tractor donkeys reported in Chapter XiN. taken at random in 14 different logging operations throughout the Douglas fir region, only 172 scaled over 5,000 board feet in volume, with the average volume striking very close to the recognized regional average of 800 to 1,000 board feet.

With these points duly considered, it may be concluded that there is scant opportunity for high-lead yarding machinery over 100 h.p. to justify itself. For yarding distances under 700 feet the Law of Diminishing Returns apparently goes into action at some point between 35 and 100 h.p. depending upon the general character of the timber. One may question, however, whether the power of the machine alone is as decisive a factor as has here been implied. The size of the rigging, the number of men in the crew and other factors may have

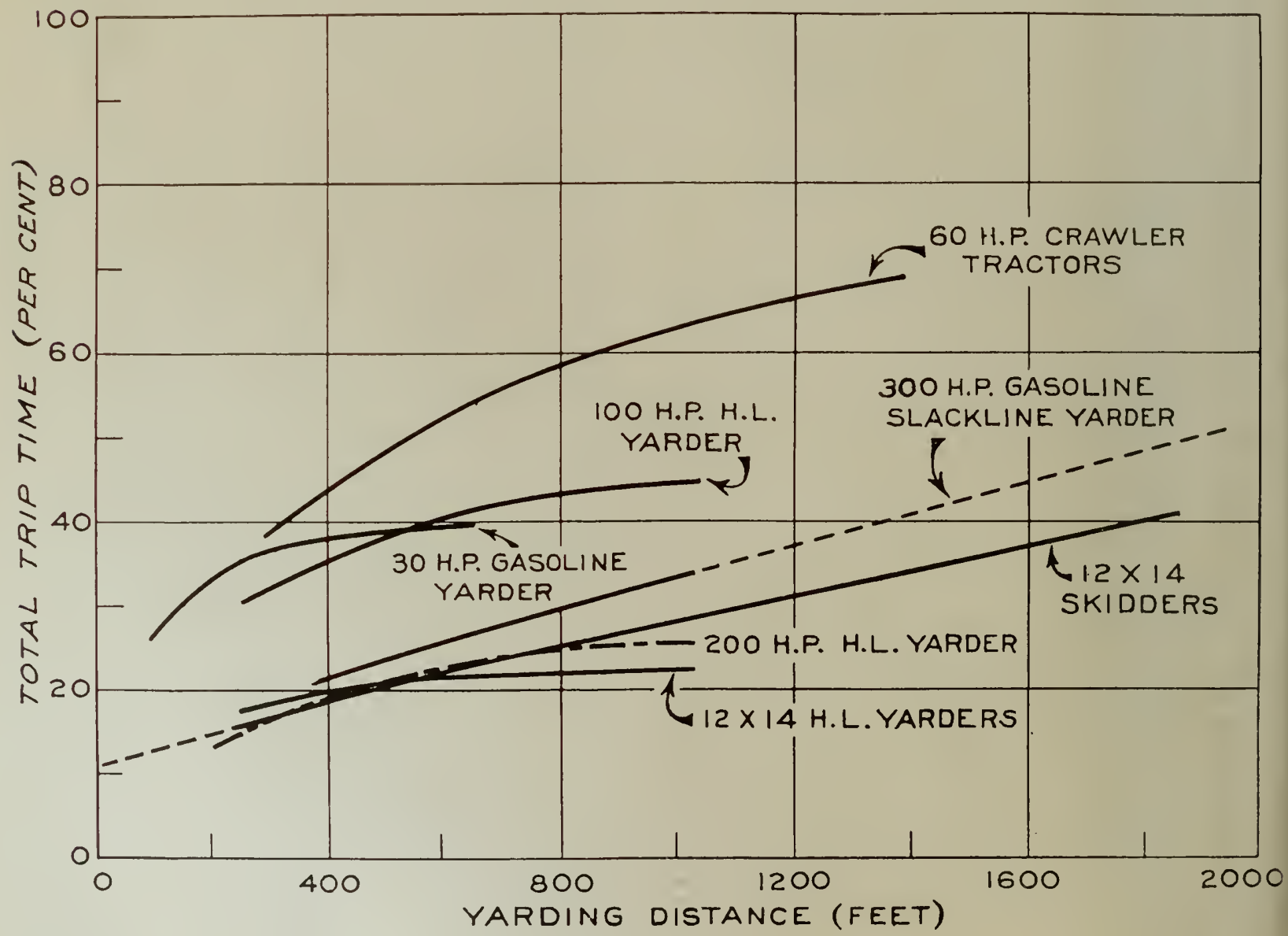

FIG. 29-HAULING AND HAULBACK TIME IN PER CENT OF PAYROLL TIME (LOG SIZE OF 1000 BOARD FEET) 
a good deal to do with the point at which a decline in efficiency will occur. It may well be that by being a little more liberal with the power of the machine, yet retaining the idea of a small crew and fairly light rigging, the use of somewhat larger machines than those suggested above can be justified in many cases.

These conclusions apply only to short distance high-lead yarding, with no implication at all at this point that it automatically would offer the right solution of yarding problems involving distances of 800 to 2,500 feet or more. Furthermore the considerations listed above under points 2,3 , and 4 cannot be ignored in estimating the practicability of yarders of this type in any given case. In short, then, all that has been defined above is the general type of high-lead yarders that may be expecterl to give the best combination of labor, supply, and investment costs for cold decking or similar yarding within the distances stated. This limitation, however does not necessarily restrict the use of this general type of machine to a narrow field, because its application may be widened through combination with other methods, as will be further discussed in Chapter VII and succeeding chapters.

\section{SKYLINE SWINGING STUDIES}

30. Scope of Studies.-Swinging studies were conducted along the same lines as the yarding studies and the results are presented in similar form excluding the maps. A total of about 6,000 logs scaling 5,400,000 board feet are covered in studies on which detailed results are presented in Tables 29 to 35 .

In any given swinging study, distance is a constant. However, the effect of distance on cost and output shows virtually a straight line relation in skyline swinging and may thus be calculated from data applying to two different distances. This has been done in Tables 29 to 34 which show costs and output for four different distances instead of only for the particular distance that happened to apply in any given case.

31. Swinging from Cold Decks Shows Higher Turn Volumes than Yarding.-The influence of density (number of logs per acre) naturally does not enter into swinging from a cold deck pile. Nevertheless, considerable differences appear in comparing different studies in regard to the make-up of the turn. Mixture of log sizes, size of the rigging, organization of the rigging crews, slopes, deflection problems, and relative over-capacity or under-capacity in regard to loading are contributing factors creating differences in turn volumes and turn-volume relations from study to study.

The swinging studies show, on the whole, considerably higher turn capacity for a given size of logs than the yarding studies. This is the logical result of the better density condition. No yarding studies were made in timber of exceptionally high density, but there is, of course, no reason why yarding should not yield as high turn volumes as in swinging from a cold deck if the logs lie close enough to permit gathering them with little or no delays.

\section{TABLE 29}

Relation of volume of log and swinging distance to output and cost of swinging from cold deck with 1 : $x 14$ North Bend skyline swingl

I Rate of production in M ft.b.m. per 8-hour day"

\begin{tabular}{|c|c|c|c|c|}
\hline \multirow[b]{2}{*}{ Volume of $\log$ ft.b.m. } & \multicolumn{4}{|c|}{ - Swinging distunces in feet } \\
\hline & 600 & 1000 & 1400 & 1800 \\
\hline 100 & 56 & 50 & 43 & 37 \\
\hline 200 & 106 & 93 & 80 & 68 \\
\hline 400 & 187 & 164 & 141 & 119 \\
\hline 800 & 274 & 240 & 206 & 173 \\
\hline 1600 & 417 & 362 & 307 & $25: 3$ \\
\hline 3200 & 572 & 491 & 410 & 331 \\
\hline Swinging variable & cost in & dollars & per $\mathrm{MI}$ & ft.b.m. ${ }^{3}$ \\
\hline 100 & 1.97 & 2.21 & 2.57 & 2.98 \\
\hline 200 & 1.04 & 1.19 & 1.38 & 1.62 \\
\hline 400 & .59 & .67 & .78 & .93 \\
\hline 800 & .40 & .46 & .54 & .64 \\
\hline 1600 & .26 & .30 & .36 & .44 \\
\hline 3200 & .19 & .22 & .27 & .33 \\
\hline
\end{tabular}

${ }^{1} \mathrm{Crew}$ of 8.5 men, excluding loading crew.

-Deduct $6.6 \%$ for road thanging and rigging tail trees.

${ }^{3}$ Add $\$ 0.05$ per $\mathrm{M}$ ft.b.nL fixed per acre cosi to get tosal swinging cost.

Basis of Cost : Opelating cost per 8-hour day consists of :

Item 1, 448.36 minutes actual tur'n by turn swinging time at $\$ 0.23$ per minute $\$ 103.12$

Item 2, 31.64 minutes road changing time at $\$ 0.18$ per minute.

Item 3, tail tree rigging labor

Total (full machine rate)

Item 1 represents swinging variable cost.

ltems 2 and 3 represent "fixed per acre" costs amounting to $\$ 0.05$ per M ft.b.m. (rigging ahead (head spar) and moving cost not included). 
Relution of volume of $\log$ and suinging distance to outmut and cost of swinging from cold deck with 12x14 North be nd sliyline swing

1 Rate of production in $\mathrm{M}$ ft.b.m. per 8-hour day" - Suinging distances in feet-

Folume of logft.b.m. 600 1000 $1400 \quad 1800$

$\begin{array}{rrrrr}100 & 5(i & 50 & 44 & 38 \\ 200 & 104 & 92 & 80 & 69 \\ 400 & 178 & 157 & 136 & 115 \\ 800 & 253 & 222 & 190 & 158 \\ 1600 & 420 & 339 & 276 & 233\end{array}$

II Swinging variable cost in dollars per M it.b.m.3

$\begin{array}{rrrrr}100 & 1.88 & 2.10 & 2.39 & 2.76 \\ 200 & 1.01 & 1.14 & 1.31 & 1.52 \\ 400 & .59 & .67 & .77 & .91 \\ 800 & .42 & .47 & .55 & .66 \\ 600 & .25 & .31 & .38 & .45\end{array}$

('rew of 9 men, excluding loading crew.

Nis road changing delays.

Arld \$1).10 per $1 /$ ft.h.m. for tail rigging to get total swinging cost.

Busis of Cost: Operating cost per 8-hour day consists of :

Item 1, 480 minutes actual turn by turn swinging time at $\$ 0.2188$ per minute. $\$ 105.00$

Item 2, tail tree rigging labor. 9.00

Total (full machine rate) $\$ 114.00$

Item 1 represents swinging variable costs.

Item 2 represents "fixed per acre" costs amounting to \$0.u8 per M b.m. (rigging ahear (head spar) and moving costs not inciuded).

\section{TABLE 31}

Relation of volume of $\log$ and swinging distance to out. put and cost of swinging from cold deck with 12x14 North Bend shyline swing 1

I Rate of production in M ft.b.m. per 8-hour day:

$\longrightarrow$ Swinging distances in feet

Volume of $\log \mathrm{ft} . \mathrm{b} . \mathrm{m} . \quad 600 \quad 1000 \quad 1400 \quad 1800$

$\begin{array}{rrrrr}100 & 41 & 35 & 30 & 27 \\ 200 & 78 & 66 & 57 & 51 \\ 400 & 137 & 117 & 101 & 90 \\ 800 & 217 & 184 & 160 & 139 \\ 1600 & 350 & 293 & 253 & 217 \\ 3200 & 543 & 452 & 388 & 339\end{array}$

II Swinging variable cost in dollar's per $\mathrm{M}$ ft.b.m.3

$\begin{array}{rrrrr}100 & 2.66 & 3.11 & 3.56 & 4.01 \\ 200 & 1.40 & 1.65 & 1.90 & 2.14 \\ 400 & .79 & .93 & 1.07 & 1.21 \\ 800 & .50 & .59 & .68 & .78 \\ 1600 & .31 & .37 & .43 & .50 \\ 3200 & .20 & .24 & .28 & .32\end{array}$

Crew of 8 men, exclucling loading crew.

1)erluct $3.3 \%$ for roal changing and rigging tail trees.

Adsl $\$ 0.08$ fer $\mathrm{Ml}[\mathrm{t} . \mathrm{H}, \mathrm{m}$. for rostl changing, etc., to get total swingittg cust.

Busis of Cost: Operating cost per 8-hour day consists of :

Item $1,464.2$ minutes of turn by turn swing-

ing time at $\$ 0.2262$ per minute.

$\$ 105.00$

Item 2, 15.8 minutes of road changing time at $\$ 0.18$ per minute

2.84

Item 3 , tail tree rigging

8.80

Total machine rate

$\$ 116.64$

Item 1 represents swinging variable costs.

Items 2 and 3 are "fixed per acre" costs, equivalent to $\$ 0.08$ per M b.m. (rigging ahead (head spar) and moving costs not included).
Relation of nolume of log and swinging distanee to ontbut und cost of swinging from cold deck with 12.01/ North Bend skyline swiugl

I Rate of production in M ft.b.m. per 8-hour dayz

Volume of log ft.b.m. $\overbrace{\text { Gon }}$ Swinging distarees in fect- 1000 1400

$\begin{array}{lllll}100 & 39 & 36 & 33 & 29 \\ 200 & 73 & 67 & 61 & 55\end{array}$

$\begin{array}{lllll}400 & 129 & 118 & 107 & 95\end{array}$

$\begin{array}{lllll}800 & 194 & 176 & 158 & 140\end{array}$

$\begin{array}{lllll}1600 & 270 & 242 & 214 & 187\end{array}$

II Swinging variable cost in dollars per $\mathrm{M}$ ft.b.m.3

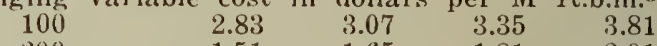

$\begin{array}{rrrrr}100 & 1.51 & 1.65 & 1.81 & 2.01 \\ 400 & .86 & .94 & 1.03 & 1.16\end{array}$

$\begin{array}{rrrrr}800 & .57 & .64 & 1.03 & 1.16 \\ 1600 & .41 & .40 & .50 & .59\end{array}$

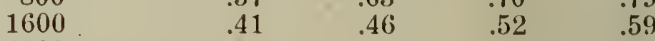

$\begin{array}{llll}3200 & .27 & .30 & .34\end{array}$

"rew 8.5 men ixcluding loading crew.

")educt to for roid changing.

shid \$0.04 per M it.b.m. for fixed per acre cost.

Basis of Cost: Operating cost per 8-hour day consists of :

Item 1, 460.30 minutes of turn by turn swing-

ing time at $\$ 0.23$ per minute.

$\$ 105.87$

Item 2, 19.70 minutes line changing time ar, $\$ 0.18$

$3.5 i$

Item 3, rigging of tail trees.

5.00

Total (full machine rate)

$\$ 114.42$

Item 1 represents swinging variable costs.

items 2 and 3 represent "fixed per acre" costs amounting to $\$ 0.04$ per M ft.b.m. (rig'ging ahead (head spar) and moving costs not included).

TABLE 33

Relation of volume of $\log$ and swinging distance to output and cost of swinging from cold deck with $13 \times 14$ Tyler skyline swing ${ }^{1}$

I Rate of production in M ft.b.m. per 8-hour day²

Volume of $\log$ ft.b.m. $\quad \overbrace{600}$ Swinging distances in feet-- $1000 \quad 1400 \quad 1800$

$\begin{array}{lllll}100 & 22 & 19 & 18 & 16\end{array}$

$\begin{array}{lllll}100 & 43 & 38 & 35 & 32\end{array}$

$\begin{array}{rrrrr}400 & 83 & 75 & 68 & 62\end{array}$

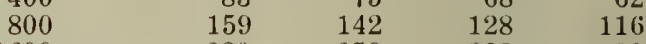

$\begin{array}{lllll}1600 & 280 & 250 & 222 & 199\end{array}$

$\begin{array}{lllll}3200 & 420 & 368 & 327 & 294\end{array}$

II Swinging variable cost in dollars per $M$ ft.b.m. ${ }^{3}$

$\begin{array}{lllll}.100 & 5.43 & 6.04 & 6.66 & 7.28 \\ 200 & 2.75 & 3.06 & 3.38 & 3.70\end{array}$

$\begin{array}{lllll}400 & 1.41 & 1.57 & 1.74 & 1.91\end{array}$

$\begin{array}{rrrrr}800 & .74 & .83 & .92 & 1.01\end{array}$

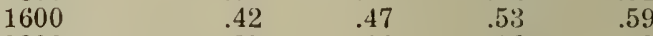

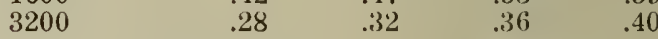

Crew 9 men, excluding loading crew.

"l leduct $10.7 \%$ for road changing.

"Acld $\$ 9.04$ jer $\mathrm{M}$ ft.b.m. for fixed-per-acre cost to get total swing. ing cost.

Basis of Cost: Operating cost per 8-hour day consists of :

Item $1,428.53$ minutes tur'n by tur'n swinging at $\$$ U. 245

$\$ 105.00$

Item 2, 51.47 minutes road changing time at $\$ 0.20$

Item 3 , other fixed per deck

6.50

Total (full machine rate)

$\$ 121.79$

Item 1 represents swinging variable costs.

Items 2 and 3 are "fixed per acre" costs amounting to $\$ 0.04$ per M b.n. (rigging ahead (head spar) and moving costs not included). 
TABLE 34

Relation of volume of $\log$ and swinging distance to output and cost of swinging from cold deck with $12 \times 1 / 4$ steum tower skidders' (4 studies)

I Rate of production in M ft.b.m. per 8-hour day"

Volume of $\log$ ft.b.m -Swinging distances in feet--

\section{0}

200

400

800

1600

3200

600

$10(0)$

1400

27

52

59

114

214

368

528

101

189

323

453

609

II Swinging variable cost in dollars per M ft.b.m.3 $\begin{array}{lllll}100 & 4.64 & 5.28 & 5.92 & 6.57\end{array}$

$\begin{array}{lllll}100 & 2.36 & 2.69 & 3.02 & 3.35\end{array}$

$\begin{array}{lllll}400 & 1.22 & 1.39 & 1.57 & 1.74\end{array}$

$\begin{array}{lllll}800 & .65 & .74 & .84 & .94\end{array}$

$\begin{array}{lllll}1600 & .37 & .43 & .49 & .55\end{array}$

3200

.26

.35

.55
${ }^{1}$ Average crew of 11 men, excluding loading crew.

Deduct $6 \%$ for road changing.

Add $\$ 0.06$ per MI ft.b.m. for road changing and tail tree rigging in get total swinging cost.

Basis of Cost: Operating cost per 8-hour day consists of :

Item 1, 451.21 minutes turn by turn swinging time at $\$ 0.33$ per min. $\$ 148.9 n$

Item 2, 28.79 minutes road changing time at $\$ 0.27$ per minute

Item 3 , tail tree rigging

Total (full machine rate)

$\$ 160.75$

Item 1 represents swinging variable costs.

ltems 2 and 3 represent "fixed per acre" costs amounting to $\$ 0.06$ per M ft.b.m. (rigging ahead (head spar) and moving costs not included).

TABLE 35

Relation of volume of log to output and cost of hot swinging with 12x17 slackline yarder-swinging distance 1,100 feet

Volume of $\log$ Rate of production Cost indollars feet b.m. per 8-hour day per $M$ ft.b.m.

$\begin{array}{rrr}100 & 12 & 10.00 \\ 200 & 24 & 5.00 \\ 400 & 45 & 2.67 \\ 800 & 83 & 1.44 \\ 1600 & 141 & .85 \\ 3200 & 229 & .52\end{array}$

'Based on estimaterl machine rate of $\$ 120.00$ for 6-man crew.

32. North Bend Swing Studies (Tables 29 to 32 Inclusive).-

Four studies were made, in all of which the swinging equipment( $12 \times 14$ steam yarders) and the organization of the crew were similar. The studies comprise about 3,000 Jogs. Detailed output and cost data are given in Tables 29 to 32 , inclusive. Slopes varied from slight uphill to steep downhill, but no logical effect of steepness or character of slope is brought to light from a comparison of haulback and hauling time, possibly because the contrasts between the studies in this respect are not sharp enough to make any particular difference.

\section{Tyler Swing Study (Table 33).-}

A total of 605 logs scaling $1,300,000$ board feet are comprised in this study. The cold-deck pile was large, not all of the logs in the pile being included in the study.
This study represents rough, uphill topngraphy. However, with the system used, no operating diff culties or loss of time occurred that can be traced to the character of the road, actual hauling time for a given load being relatively low compared with other swing studies. Hooking and delay time, however, relatively high, owing wimarily, it is believed, to the large size of the cold-deck pile-a detail that is further discussed in Section :37. Costs for log volumes under 800 board feet, as shown in Table 36 are relatively high, but this is not very signiflcant from the standpoint of averige costs, because the average loy volume in this case is very large (2160 board foot average) with only a small nercentage of total volume represented by logs under 800 board feet in volume.

34. Steam Skidder Swing Studies (Table 34).--

A total of 2,148 logs, scaling over two million feet are represented in the study presented in Table 34 . This table is derived from four studies, with all points of distinction between the different studies lost in the process of averaging the results.

35. Steam Slackline Swing Study (Table 35). -

This represents a "hot swing". From the standpoint of showing production capacity of the swing machine, hot swings are usually of no direct significance on account of being directly integrated with the yarding operation which sets the pace. The hot swing simply relays the logs brought in by the yarder. This table is presented only to demonstrate an exceptional case in which for a short period of time a. complete lack of synchronization of yarding and swinging capacity happened to raise costs beyond reason.

36. Comparison of Results.-All the skyline swinging studies here reported apply to machinery of approximately equal power, speed, operating radius, and general method of operation. Hence, no basis exists for comparison of large versus small machinery as was the case in the yarding studies. Nor is this a question which, if answered, would be likely to lead to conclusions similar to those drawn in connection with short distance high-lead yarding (Sec. 26), because swinging from cold decks creates optimum conditions for effective use of great power and speed, particularly in steep, uphill swinging for distances of 1,000 to 2,500 feet.

Table 36 gives a comparison of swinging costs for logs of various volumes at a swinging distance of 1,800 feet. The table brings attention to the following points:

1. For each of the six studies, variations of the volume of the log show a striking effect on cost, quite similar to that shown in the yarding cost tables.

2. From study to study, an apparent comnection exists between variations in the average volume of the $\operatorname{logs}$ and the relative spread of costs from small to large logs. The larger the average log volume, the greater is the relative spread in costs from the 200 to the 3,200 foot log volume. On the whole, the same is true of the yarding studies. 
3. The size of the cold-deck pile (total rolume) seems in a rough way to be a factor affecting the efficiency obtained in swinging. The larger the cold-deck pile, the higher is the cost per M ft.b.m. of swinging a $\log$ of a given volume. The comparison in this case should be confined to the first five studies (Tables 29 to 33) which represent similar machines operated at approximately equal daily machine rates.

Further discussion of points 1 and 2 follows in Chapter XI, in which a summary is given of cost relations for all yarding, swinging and loading studies.

TABLE 36

Comparison of costs for six studies of shyline swinging of $\operatorname{logs}$ of varions volumes-suringing distance 1,800 feet Approx. Folume total of iol. of logs arerags Type of in cold deit log saing il ft.b.m. lit.b.m. North Bend $490 \quad 700$ North Bend $150 \quad 360$ North Bend $360 \quad 350$ North Bend $1200 \quad 770$ Tyler $\quad 1750 \quad 2160$ Skidders $\quad 750^{1} \quad 960$ (4 studies)

'Estimated average volume per deck for four studics.

37. Large Cold Decks Cause Increase of Swinging Costs.-Loggers have commonly recognized that higher efficiency is obtained on the average in swinging from small or medium-sized cold decks than from large ones. Much depends, of course, upon how the logs are stacked and unstacked. However, large cold decks containing from one to two million board feet or more are usually difficult to handle, causing a good deal of delay and a general slowing up of the hooking-on operation. The findings made in the five studies of North Bend and Tyler swinging confirm common experience.

Tables 29, 30, and 31, grouped together to represent small cold decks (ranging from 150 to $490 \mathrm{M} \mathrm{ft}$. b.m. total volume), show an average cost of 77 cents for the 800 -foot $\log$ volume and 54 cents for the 1600 -foot log volume. The corresponding cost for the large cold decks (Tables 32 and 33) which total 1,200 and 1,750 M ft. b.m., respectively, averages 96 cents and 66 cents per $\mathbf{M}$ ft.b.m.; an increase of 25 per cent for the 800 board foot log volume and 22 per cent for the 1600 -foot volume. A part of this difference, however, arises through the higher machine rate applied in the Tyler study (on account of higher wire rope costs), the correction of which would lower the percentages of increase to 21 and 18 per cent respectively. A similar comparison for the smallest and largest $\log$ sizes would not be very significant since the 200-foot volume class virtually drops out of Tables 32 and 33 while the 3200 -foot class is scarce in the other studies.

In tracing the source of this increase the following data on the time elements, as read from the original time-study tables, are significant:

The small cold decks show for the 800 foot $\log$ (1) average turn volume of 2,443 board feet; (2) hauling, haulback, and hang-up time, aggregating on the average 4.55 minutes per turn (1800-foot distance); (3) hook and unhook, and delay time, aggregating on the average 2.95 minutes per turn; (4) total turn time, averaging 7.50 minutes.

The large cold decks show for the same items (1) 2,300 board feet, (2) 4.04 minutes, (3) 4.51 minutes, (4) 8.55 minutes, respectively.

Thus, although the turn volume in large cold decks shows a decrease of slightly over 5 per cent, the total turn time increases 14 per cent. The increase in turn time is due entirely to increase of hooking-unhooking and delay time, items which logically should be affected by size of pile (except unhooking, which is a small item). Hauling, haulback, and hang-up time, which items have nothing to do with the size of the cold deck, show on the other hand a lower average time per turn for the larger cold decks than for the small ones.

A similar comparison for the 1600 -foot log volume shows a decrease of 7 per cent of turn volume, and an increase of 11 per cent of total turn time. For shorter swinging distances the relative increase in turn time is greater.

In previous time studies of swinging from two cold decks, one comprising about 450 M ft.b.m., the other 1,500 M ft.b.m., both cold decks being located on one swing road and swung by the same crew and machine, it was found that production in swinging from the large pile (1400-foot swing distance) dropped 11 per cent in addition to the drop accounted for through increase of distance. 
The co'd-elecking cost for Line $\mathbf{F}-\mathrm{F}$ is similarly inter polated between the curve representing the 100 125 h.p. group and the curve tor the large steam high-lead group.

In addition to the lines representing swinging costs and combined swinging and cold-decking costs there have been entered in $\mathrm{Figure} 30$ two lines representing the cost of direct yarding (skidding) with $12 \times 14$ steam skidders. Line C-C represents the study (Table 9) which wave the lowest cost of direct skidding. Line E-E represents the slidder study showing the highest cost. These lines are the same as the top and bottom line of the "skidder band" shown in Figure 28, except that Figure 30 is based on exiernal yalding distance, while Figure 28 represents actual distance as heretofore defined in Section 20 .

Neither the skidder costs (C-C and E-E) nor the swinging costs include rigging ahead and moving costs inculred at the track landing. No adjustment has been made for swinging distanees although it might reasonably be expected that cold decking would on the average tend to bring the logs closer to the track spar, thus roducing the swinging distance. As matters stand, cold decking is considered a process of assembling the logs. and not transporting them toward the landing.

The right hand side of Figure 30 represents identically the same costs as the left hand side except that the cost of loading has been added. With loading costs included, the cold deck system gains some additional ground in competition with direct skidding. This is due to more effective use of loading facilities through increase of and/or steadier pace of production under the cold-deck system. By the same token it may be inierred that further conomies may follow through nore effective use of railyoad operating facilities and general overhead-a point on which the advocates of the swinging-cold-decking system lay particular stress.

39. One Problem-Many Solutions.-A glance at the right hand side of Figure 30 shows that, as far as these studies indicate, any kind of an answer can be given to the general question as to which of the two systems will generally give the best result, although the logging conditions to which the different answers would sefer are identical. Fol example:

40. Size of Cold Deck is Controlling Factor.All shades of opinion regarding the relative merits of the cold deck versus the direct yarding or skidding system can thus be supported by cost data and operating experience, but with each one giving an entirely different solution of an identical problem, the answer depending largely upon the size of cold deck that is being considered. The large cold deck as a product of the large cold-deck yarder and relatively long yarding distances brings (1) high cold-decking costs, (2) high swinging costs, (3) high breakage loss, and (4) high fire risk. In contrast to this the small cold deck as the product of the small yarder, small crew, and short yarding distances brings low cold-decking costs, low swinging costs, and overcomes to a large extent the objections in regard to breakage and fire risk.
41. Effect of Volume of Log on Comparative Costs.-The comparison made above is based on logs of 800 board foot volume. A similar comparison of the 1,600-foot class shows that the relative positions of the three systems are virtually the same. For logs of 3,000 board foot volume some ground is lost by the small cold deck, and reason would suggest that this trend will be accelerated in the 4,000 and 5,000 foot classes. For logs under 600 board feet, on the other hand, the small cold deck shows additional gains, which increase substantially with decrease of $\log$ size.

42. Objections to Foregoing Conclusions.-On the strength of the study data, the small colddeck system has on the average a decided advantage, since it meets serious competition and occasional defeat only from the direct skidding system and then only when operating in medium-sized or large-sized timber in good shows, i.e., under conditions which bring about such a low cost average per M. feet b.m. that the winning and the losing systems are only a few cents apart.

However, looking beyond the cost findings made in these particular studies, it is obvious that some exceptions must be made to the sweeping conclusions here implied.

(1) In the first place it might be argued that better skidder shows than that represented by Line C-C are often found and that Line C-C therefore might not represent the average of good performance in the best shows. This argument, however, would also apply to the competing system though perhaps not quite in equal degree. To whatever extent the argument is valid, it would tend to give direct skidding a clearer title to the really good shows.

(2) Cost of tail tree rigging and line changing for small cold decks will go considerably higher than in the study cases, if the skyline must be set up for only one cold deck (compare system explained in Section 43). For very small cold decks these costs may become rather excessive.

(3) On long slopes, too steep for suitable cold-deck landings, the small short-yarding colddeck system may become entirely impracticable. In direct skidding a suitable landing is required only at the head spar; in the cold-deck system some sort of a landing must be provided for each deck, although the requirements in this respect are rather moderate for the small decks. Extremely steep long slopes lacking the necessary landing places may therefore require direct yarding irrespective of the 
character of the timber. Whatever the swing system that is used as a part of the cold-deck system, whether it be a North Bend, Tyler. skidder, or slack line system, situations of this character can be met by putting the swing to direct yarding or skidding whenever necessary.

\section{Example Showing Adaptability of Cold.} Deck System to Rough Topography.-

The wide range of adaptability possessed by the cold-deck system is illustrated in Figure 31 . The map here reproduced is a duplicate of Figure 8 , which is selected among Figures 5 to 27 as representing the roughest topography encountered in this series of studies with the exception of that shown in Figure 17. It represents a skidder setting, with the skidder placed at the point marked "head spar", the area shown having been logged uncler the direct skidding system according to the plan indicated by the location of the roads radiating from the head spar to the tail spars, numbered from 1 to 8 . Superimposed on this map is the plan of the short-yarding cold-deck system represented by the dot and dash lines indicating setting boundaries and circles showing spar tree locations for cold-deck areas $A$ to $H$. Under the cold-deck system the skvline roads to tail spars 2,3 , and 7 are retained as swing roads, serving all cold-deck settings, except Setting E which is swung without setting up a skyline. The area between E, D, and the head spar need not, of course, be cold decked. The eight cold decks average about $300 \mathrm{M}$. feet b.m. each, while each skyline rwing road taps an average of $700 \mathrm{M}$. feet b.m.

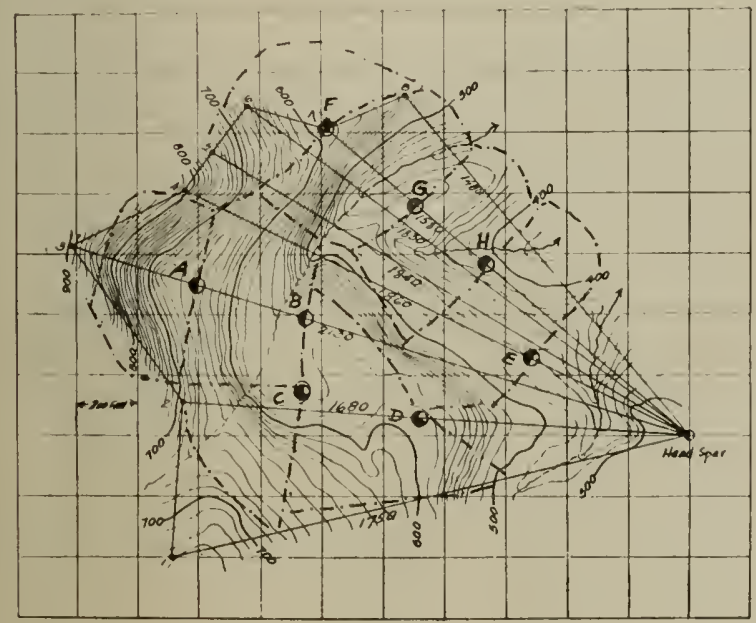

FIG. 3 :

A special feature of the small cold-deck system worked out by many loggers is the use of two or morc landings lined up to be tapped by one skyline road as shown in Figure 31 , thus reducing the per $M$ b.m. cost o $i$ rigging up skylines. To this end the problem of finding suitable spar trees is greatly simplified because, if necessary, almost any tree above 30 inches in diameter will serve for yarding with these small machines and for short yarding distances. The feasibility of this system, however, depends generally upon whether suitable landings can be found in the right locations.

The cold deck areas as planned in Figure 31 are nearly all laid out as half settings with yarding distances kept down generally to 400-500 feet or less.
While this adrs to the number of trees to be rigued, it actually simplifies the problem of moving the donkey (by eliminating moving around the pile to change sides), helps to keep the piles small, and gives the yarder engineer a better chance to watch the turns come in.

A study of the area as laid out for cold decking shows that the tonographic difficulties that strike the eye in looking at the area as a whole will largely disappear one by one when the area is subdivided into small independent units of area. Areas such as cold deck settings $A, B$, and $C$, are steep but involve really rough yarding unly when combined with the surround ing areas. A, B, and C, considered by themselves, are all good short-distance high-lead shows, possessing much the same advantage for this type of yarding as the area illustrated in Figure 24, which gave the lowest cost to logs yarded with $30-35$ h.p. gas yarder: thanks to just the tyne of topography that is shown on these areas. But if combined with other areas into larger high-lead settings, difficult yarding problems may arise. For example, the three relatively easy shows representerl by areas $B, G$, and $H$, if combined into one large high-lead cold deck with the spar lo cated at or near $\mathrm{H}$, make a difficult yarding show. Another striking example of how two types of favorable topography combine through long yarding into one large high-lead cold leck with the spar loFigure 16, on which area yarding costs were twice as high as on the areas represerted in Figures 13 and 15 for no other reason than that the wrong combination of easy high-lead topography resulted in a difficul ground-yarding show. The point in all this is that topography that appears rough ard difficult un der long-yarding methods may become very favorable tor shori-yarding, provided that suitable landings are found.

A study of the areas in Figures 7 to 27 in which enough area is shown to permit of judging the yarding problem as a whole, indicates that the small colddeck scheme can, as far as topography is concerned, be worked out in all cases. The co!d-deck system, therefore, does not appear to be limited to any specific type of topography, but may as a rule be applied to any area on which direct yarding or skidding is feasible, excluding long, steep slopes on which no suitable landings can be found.

44. Significance of Foregoing Findings.-The combination of the small cold deck with conventional swinging methods provides a system of logging that can be applied to a wide rariety of conditions. It is on the average more economical than direct yarding with the large cquipment; and much more flexible. The conventional type of high-speed, high-puwer machinery still remains an important part of the picture, but remains no longer in a position to dictate how the $\log$ s shall start out on their journey to the pond. Therein lies the significance of this system from the broad point of riew of sound timber management as a problem apart from the direct promotion of lowcost logging methods. Low-cost logging is demonstrated here does not favor the removal of the timber by large units of yarding area. Yarder settings here embrace generally 3 to 6 acres of area instead of 50 to 100 acres. Thus, on the area shown in Figure 31 one fourth of 
an acre or one eighth of an acre becomes the unit of area embraced by each yarding road, planned under direct skidding.

The resultant flexibility, giving the timber owner a relatively free hand in what timber to take and what to leave, is obviously a most important step toward intensive forest management.

This first step toward lower costs and greater flexibility is not necessarily the final step. It might be only a beginning. The small, flexible rarder drives the large, long-yarding machinery, so to speak, "out of the woods," and puts it to work on the swing roads, which gives to each of these types of machinery a better opportunity to justify itself. But the small, flexible high-lead yarder, in competition with the still more flexible tractor, can not retain all the territory it has conquered. The tractor has a better claim than the small highlead yarder (compare Figure 27) to the areas comprised largely by cold-deck settings B, C, $\mathrm{D}, \mathrm{E}, \mathrm{H}$, and part of $\mathrm{G}$, by underbidding the small high-lead yarder by about 15 per cent ( $\$ 0.10$ per M. feet b.m., the saving arising largely through elimination of rigging ahead and moving costs) and offering an indirect saving that might amount to several times that much through reduction of breakage. The results of experiments reported in Chapter XXI support this view most emphatically. The interesting point to emphasize at this stage of the discussion is that low-cost logging is promoted by greater flexibility in equipment, which may be expressed in the substitution of light flexible gas yarders for the large, highpower, high-speed yarding machinery, or better still, displacing the light gas yarder with the highly flexible tractor which in the case at hand takes over more than half of the yarding area shown in Figure 31 . This trend toward greater flexibility and lower cost extends also to the swinging operation as will be brought out in the following study of "roading" with tractors; in typical cases, it leads in the end to important changes all through the logging operation from railroad construction to felling and bucking. Final conclusions as to the significance of these cost findings must therefore await the unfolding of the logging picture as a whole.

\section{TRACTOR ROADING STUDIES}

45. Distinction Between Roading, Swinging, and Yarding with Tractors.-In the studies reported in Section 21, Chapter IV, tractors drawing fair-lead arches were used for direct yarding without special preparation of roads and without special effort made to build up standard loads. The tractors made their own roads as best they could in the course of the yarding operations. In the operation reported in this chapter, the same type of equipment was used for swinging from a cold deck to a track landing over a road that had been prepared in advance; and special attention was given to the building up of large loads. In the operation reported in Chapter XXI the same type of equipment was used again for hauling over roads prepared in advance, but with the logs yarded directly by the tractor. The term "roading" is used in both of these cases to denote the hauling of large loads of logs over roads prepared in advance, irrespectve of whether it represents a swinging or a direct yarding operation.

46. Scope of Study.-In the operation studied, roading was carried on over a distance of 6,600 feet (horizontal distance) with grades varying from 9 per cent against the load to 31 per cent in favor of the load. The total difference in elevation from the landing at the railroad track to the cold deck at the end of the road is 750 feet. The accompanying profile (Figure 32) gives further details on gradients.

Performance and cost records covering roading operations involving a large volume of $\operatorname{logs}$ were made available by the operator, rendering it unnecessary to undertake a comprehensive study insofar as a reliable cost average is concerned. Only a brief time study was made to throw light on the effect of slope on hauling and haulback time and to determine the load capacity applicable to downhill roading.

Actual detailed timing was applied to 14 round trips. The average load scaled 4,256 board feet, gross $\log$ scale; the volume of the average log was 1,124 board feet; and the average trip time, 68.7 minutes. According to the operator's recolds, based on over a month's operation on this road, the average load scaled about 3,600 board feet net log scale, with seven trips constituting the average performance for a full 8-hour day. This is equivalent to 68.6 minutes per trip, assuming the full 8-hour day represents a working period of exactly 480 minutes. This record, then, indicates that long-time performance agrees very closely with the time study results for the twodav period.

These results, however, apply only to roading in dry weather. The combination of rain, clay soil and steep grades proved too much for the return haul with tractor and arch. 


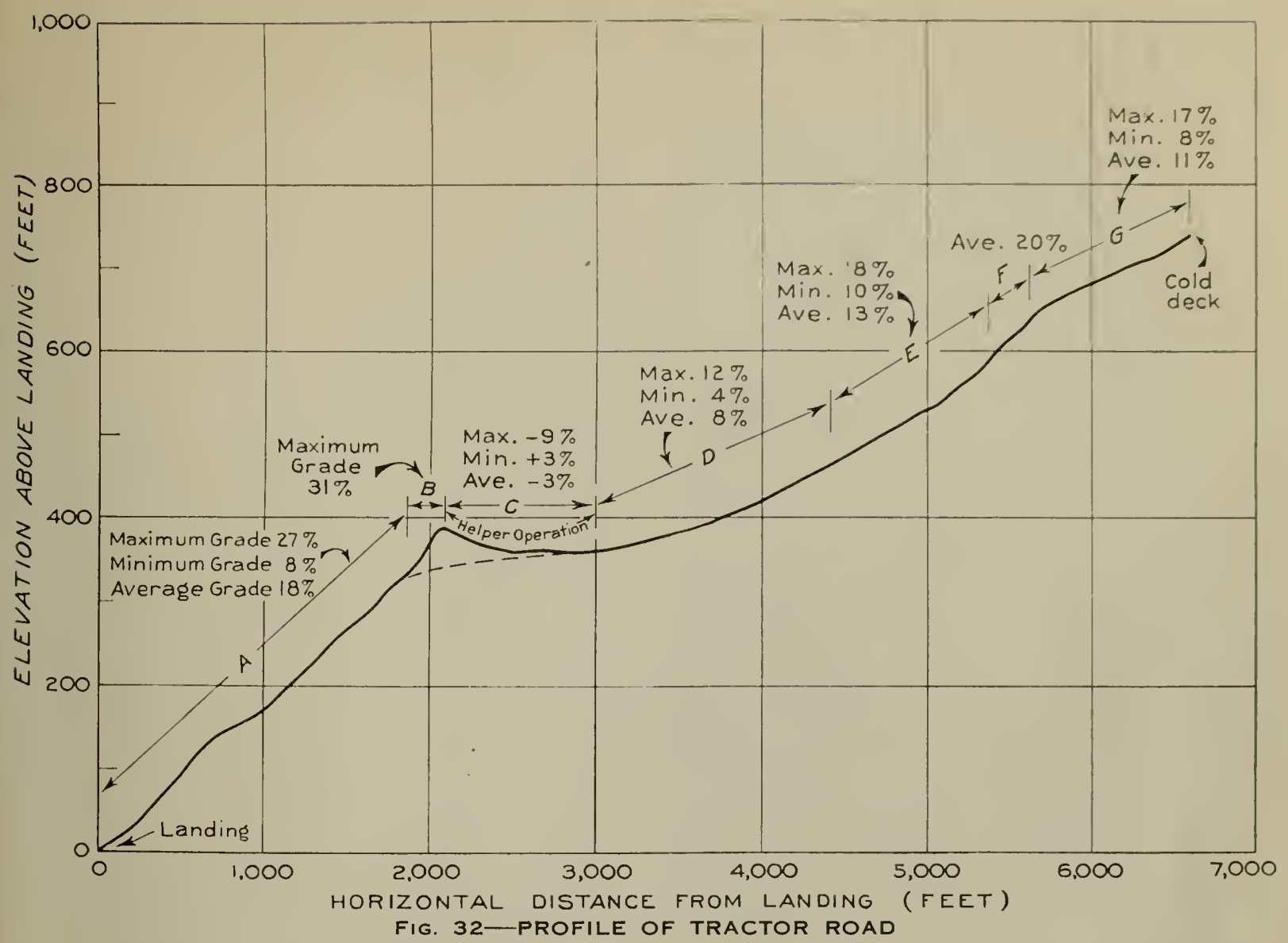

47. Tabulation of Results.-

Time and cost per trip are arranged in the order of increasing load volumes in Table 37. Note that 82 per cent (Columns 2, 3, and 6) of total operating time is spent in actual travel, of which the larger share (43.6 per cent) is accounted for as haulback time. Hooking and unhooking consumes slightly over 10 per cent.

TABLE 37

Time and cost of rouding loads of different volumes with $60 \mathrm{~h} . \mathrm{p}$. tractor and fairlead arch6,600 foot roading distance

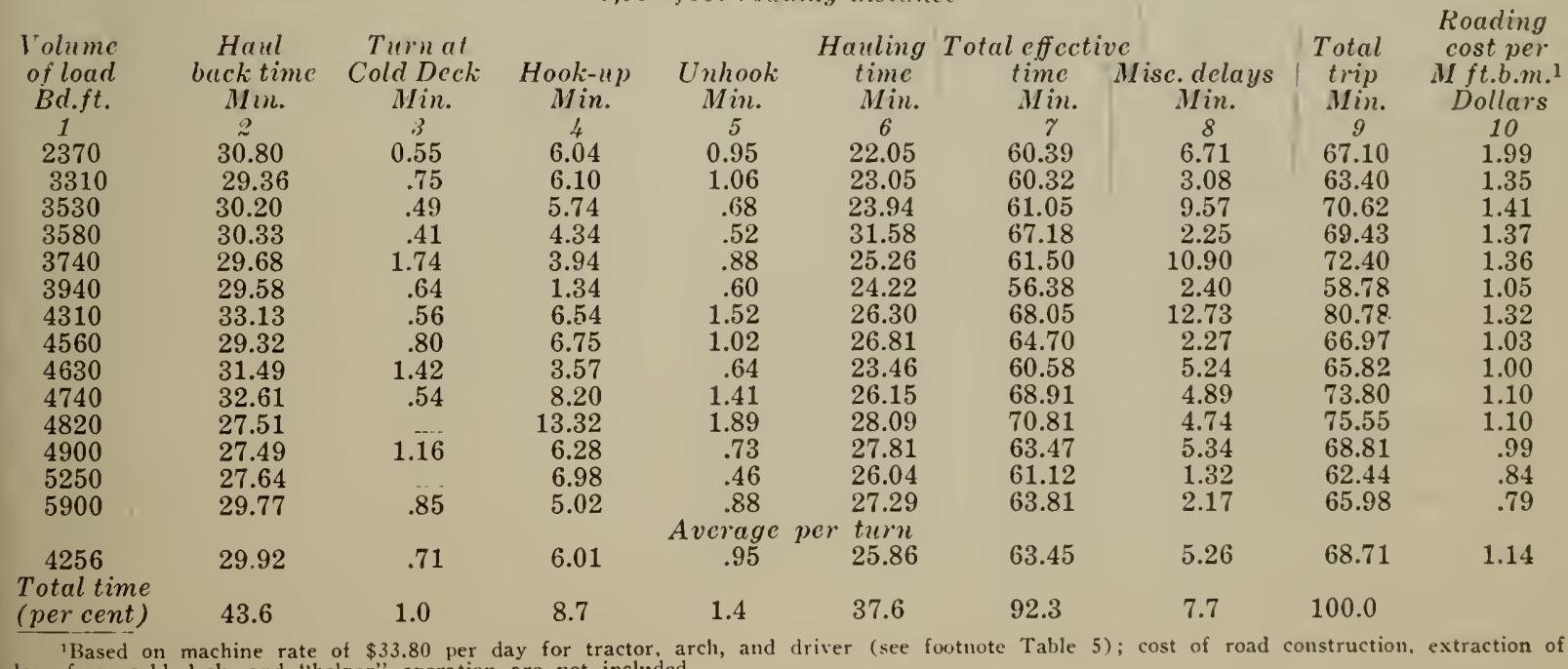
logs from cold deck, and "helper" operation are not included. 
48. Importance of Favorable Grades in Tractor Roading.-

The delay time noted enters mainly as a result of the helper operation introduced to boost the loads over the adverse grade shown in Figure 32 at distance $2,000-2,500$. At this point the adverse grade (up to 0.3 per cent adverse) could not be negotiated directly by the loaded tractor. A gasoline donkey had been installed to pull the loads over this grade. Delays incident to this operation amounted to 3.56 mimutes per trip, while all other delays such as waiting for the otler tractor to pass, minor repair work, etc. amounted to 1.70 minutes per trip.

The time lost on account of the helper operation, in addition to the added expense thereof, calls attention to the importance of avoiding long adverse grades in roading heavy loads. The same situation was noted in comnection with the windfall yarding study reported in Section 21 in which adverse slopes of as high as 14 per cent were encountered. In the tractor yarding study, however, it was found that with the liglit loads involved in direct yarding of generally small logs (average turn 1,360 board feet compared with 4,256 in roading), short adverse grades of as high as 10 per cent slope had relatively negligible effect on total results; but in that case only a small part of the total distance was involved. The tractor either succeeded in climbing such slopes at reduced speed without dropping its load, or else overcame the handicap by letting the load down and winding it in with the drum after reaching the top of the hill. This procedure, however, is not practicable in connection with very long adver'se grades, especially with such heavy loads as are involved in roading.

In dealing with this study for the purpose of determining the performance of tractors in downhill roading, the effect of the adverse grade may be eliminated by disregarding the added cost of the helper operation and by reducing the trip time from 68.71 to 65.14 minutes (deducting 3.57 minutes helper delays). The latter figure represents, then, the performance of the tractor over favorable grades of not less than 3 per cent, as indicated in Figure 32 by the dotted line.

49. Effect of Slope on Hauling and Haulback (Return) Time.-In order to determine the effect of steepness of slope on hauling and haulback time the traveling speed of the tractor was timed over measured distances featuring different degrees of slope. The road was divided into seven sections (A to $\mathrm{G}$ in Figure 32), each featuring different average slopes, but with considerable spread in grades within each section as shown in Figure 32. Hauling and haulback time were taken for each section and translated into time in minutes required to cover 1,000 feet of hauling distance. The results, listed by uniform grade per cent intervals, are given in Table 38 .

According to Table 38 maximum efficiency in roading occurs on a grade of 8 per cent. On this grade the round trip time (actual traveling time only) over 1,000 feet of roading distance is only 7.51 minutes compared with 8.65 minutes on level ground. Furthermore, on level ground the maximum load that the tractor can haul without undue delays is about 4,000 board feet while approximately 6,000 board feet is
TABLE 38

Relation of slope to traveling time in roading with 60 h.p. tractor with fairlead arch, per 1,000 feet of hauling distance; average lond 4,256 feet b.m. (Based on 14 trips)

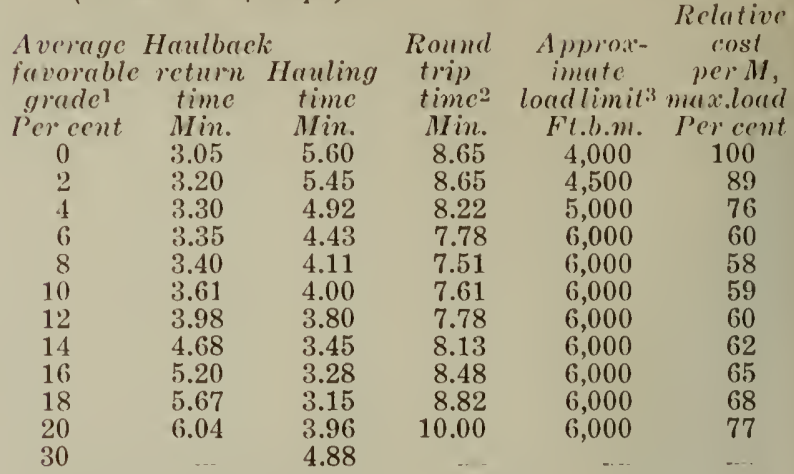

Original table values are hased in consiclerable variations in gradc. Fixcludes hooking, delays, etc.

"Harge logs.

indicated in this study as being the practical maximum load on grades over 8 per cent (Table 37 ). The practical maximum load on grades over 8 per cent is probably determined by the capacity of the arch rather than by what the tractor can haul. Theoretically, therefore, the cost of operating on an 8 per cent grade, based on the largest possible load, is only 58 per cent of corresponding cost on level ground. And, as shown in the last column to the right in Table 38, the cost of operating under maximum loads on a tractor road with grades varying from 8 per cent to 18 per cent is only about 60 per cent of the operating cost on level ground.

With this type of roading equipment, the high efficiency in hauling maximum loads on grades from 8 per cent and up is of practical significance only in connection with fairly large logs because only large logs offer an opportunity to build up maximum load volumes. Obviously, most of the potential advantage of downhill grades is lost if the load volume is not kept at or near the maximum. (See Column 10, Table 37).

No data were obtained on haulback time on grades over 20 per cent due to the fact that the ascending tractor detoured around the steepest portion of the grade in order to avoid meeting the descending loaded tractor. It is interesting to note, however, that on grades of 12 per cent and more, haulback time increases nearly as fast as the increase in percentage of grade. In other words, in operating on grades above 12 per cent, it takes about the same length of time to gain a given elevation irrespective of the steepness and length of the road. Thus it requires 3.31 minutes to climb 100 feet in elevation when operating on 12 per cent grade; 3.25 minutes on a 16 per cent 
grade; and 3.02 minutes on a 20 per cent grade. According to this, it would be rather immaterial as far as the time required for the return haul is concerned, whether in operating between two points of different elevation the shortest or the longest possible route were followed, provided that the grade were kept above 12 per cent. From a practical standpoint, speaking here of tractor roads on soil that becomes slippery when wet, the longest route might be the best route, because a tractor drawing a fair-lead arch can operate over grades of 12 per cent to 18 per cent under rather unfavorable road conditions, whereas on grades of 20 per cent to 30 per cent a light shower might forcc the closing down of the operation until the road becomes dry. In bringing down the load, on the other hand, the shortest route is undoubtedly the proper one to choose, with the limiting grade probably held down to about 45 per cent. The ideal arrangement of a roading operation on very steep ground would thus be to have the most direct route-with grades up to 45 per cent-for the loads to come out, and a return haul over grades ranging generally from 12 to 20 per cent. By providing a separate road for the return haul it becomes feasible to operata any number of tractors without causing the delays incident to tractors meeting on the road, thus promoting high efficiency in the roading operation and permitting any volume of production to be attained at the track landing. This question is further discussed in Chapters XXI and XXII.

\section{Relation of Distance to Costs.-}

The effect of distance on roading time and costs will naturally show a straight line relation provided that both load and slope, or combination of slopes, are fixed.

From the data presented in Table 37 it is found that the average "still" time per trip is 9.37 minutes, while the distance variable time amounts to 8.45 minutes per round trip for each thousand feet of hauling distance. On the basis of $\$ 0.0704$ per operating minute (\$33.80 yer day, covering tractor, arch, and driver) applied to the average load of 4,256 board feet, there results the following table of roading costs :

Roading distance

$\begin{array}{cr}\text { gross log } \\ 0 & \$ 0.15 \\ 2,000 & .43 \\ 4,000 & .71 \\ 6,000 & .99 \\ 8,000 & 1.27 \\ 10,000 & 1.55\end{array}$

The cost interval is $\$ 0.14$ per 1,000 feet of distance, with $\$ 0.15$ fixed costs at zero distance.

51. Effect of Volume of Load on Total Trip Time

Direct inspection of Column 9. Table 37 shows that the volume of the load has relatively little effect on time per trip. The first seven turns which range from 2,370 to 4,310 board feet (average 3,540 board feet) consume on the average 68.93 minutes per trip. The last seven turns which average 4,971 board feet (from 4.560 to 5,900 ) in volume consume on the average 68.48 minutes per trip ${ }^{i}$. An analysis of the detailed time study elements shows that by eliminating variations in elements of time which have nothing to do with the volume of load, the large loads consume slightly more time than the small ones, but the difference is negligible.

\section{Roading Cost Table.-}

Due to insufficiency of data on the effect of volume of $\log$ on load capacity, a valid basis is here lacking for the construction of tables similar to those presented in the yarding and swinging studies. In the absence of these data, it is nevertheless possible to gain a reasonable understanding of the full range of variation in roading costs by using volume of load as the index of performance instead of the volume of the log. Following is a table of costs and outputs for different load volumes and roading distances, based on the assumption that total trip time at any distance is fixed irrespective of variation in total load volume as discussed in the preceding paragraph.

${ }^{6}$ The same situation is noted in the cxperiments reported in Chapter Xxi.

TABLE 39

Relation of volume of load and roading distance to roading cost, and daily outputs60 h.p. crawler tractor with fairlead arch!

Downhill roading costs-per $M$ ft.b.m.:

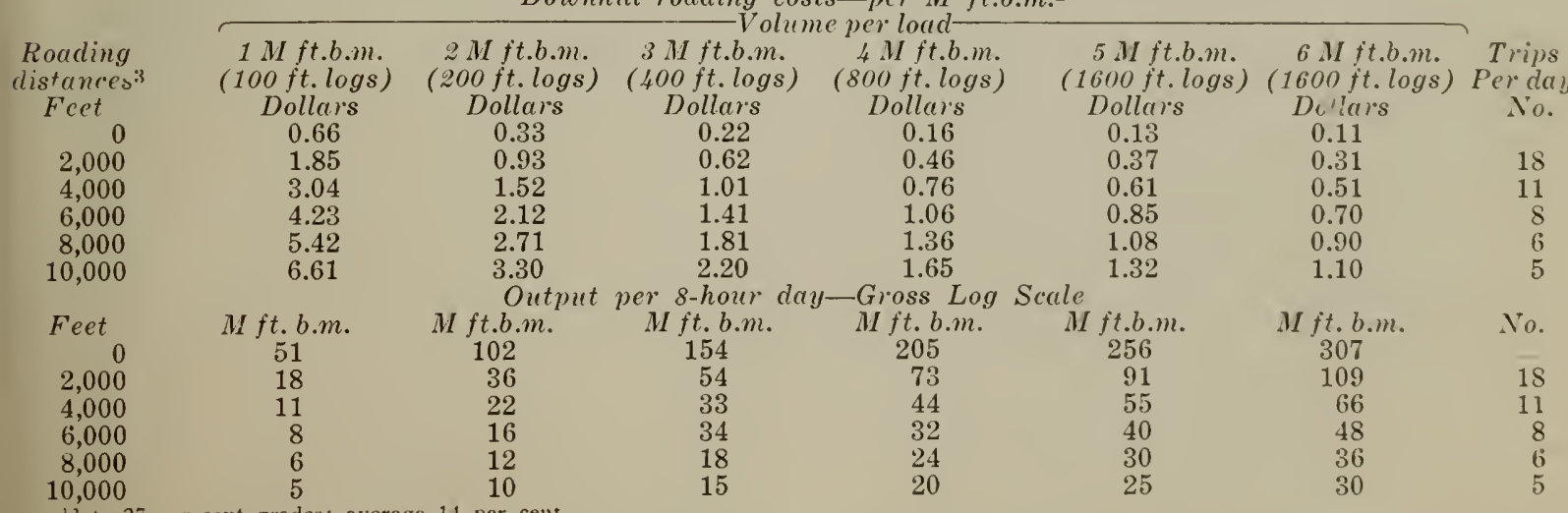

3 to 27 per cent grades; average 14 per cent.

s?he values shown for zero distance represent the "terminal" cost (hooking, delays, etc.) involved in the assembling and discharging of the load. 
53. Relation of Load Volume to Log Volume.-

While Table 39 is based on load volume as the index to cost (or output) there is given in each heading an alternative index based on volume of log. The study itself did not yield sufficient data to throw much light on this question. The log volume index was arrived at by translating the log to load relationships shown in the tractor yarding study (Table 5) for distance 3,000 (at which distance a good deal of care was used in building up loads) to the greater carrying capacity and better facilities for gathering together a full load under conditions applying to downhill roading. Thus, in the roading study the grand average log volume of 1,124 board feet produced an average load of 4,256 board feet as compared to a load of 2,411 board feet for the same log volume in the yarding study. The ratio is 1.77 and this has been applied to other load volumes up to the limit of a 6,000-foot load and rounded off to the $\log$ volumes listed. The results agree roughly with the roading study data for the 800-foot, 1,600-foot, and larger log sizes. For the small log sizes the results should be considered applicable only to timber of generally small and fairly uniform size such as was dealt with in the tractor yarding study.

There is, no doubt, considerable room for improvement in the design of equipment that will permit larger load volumes of small logs than is possible with the present types of roading arches or other forms of trailers. About ten logs is believed to be the average maximum that can be carried with the small fairlead arch, even if the logs are only 10 to 14 inches in diameter. It should be possible to devise equipment and methods that will enable hauling as great a load (in weight) of small logs as of large ones. Even then the board foot log scale of a load of small logs will be considerably less than for large ones due to differential in weight per board foot (see Section 73).

54. Large Load Volume is Essential to Low Cost of Downhill Roading.-The key to high efficiency in downhill roading is to build up just as large a load as it is practicable to carry. In the operation here reported, closer attention than is usual was paid to this problem. The operator required that each load be scaled in order to avoid carelessness that might result in dispatching undersized loads. A load of 3,500 board feet was set up as a standard to aim at. Only one tur'n scaled below 3,000 board feet and this occurred as a result of two logs dropping off the load after starting for the landing. As shown in Table 37 no loss of time occurred by taking loads of 4,000 to 6,000 board feet volume whenever the available $\log$ sizes rendered it practicable to get that large a load under the arch.

The importance of getting a large load volume is quite obvious in this long-distance roading study. It takes over an hour to make a round trip. Only a small percentage of the time goes to hooking on and unhooking; most of the time goes to traveling, the speed of which is not affected noticeably by variation in the volume of the load. If it does take a few minutes longer or even two or three times longer to get together a large load, it is clearly evident that those few minutes are by far the most profitable moments in the day's work. The basic idea in downhill roading, then, should not center on making a quick get-away with the load, but rather on not attempting to get away at all until the practical maximum in load value has been attained. In short-distance roading the building up of - large loads becomes relatively somewhat less important but not enough so to be neglected. From general production figures obtained from short-distance roading operations during the last summer it appears that closer attention must be paid to the load volume in order to attain the degree of efficiency that is represented in Table 39.

\section{COMPARISON OF TRACTOR ROADING WITH SKYLINE SWINGING}

55. Basis of Comparison.-The foregoing results of tractor roading might appear to be based on an insufficient number of studies and insufficient data to support a reliable comparison with skyline swinging costs. However, the results here obtained agree very closely with results obtained in short-distance roading studies conducted in the summer of 1932 , the only important source of variation being the volume of the load; a variation caused in part by the fact that the study here reported represents logs not exceeding 40 feet in length while in the 1932 studies log lengths varied up to 64 feet. The results of the latter studies, which are presented in Chapter XXI, have been drawn upon in this chapter in connection with tractor road construction. The data on roading costs proper, however, are entirely from the longdistance roading study reported above.

56. Explanation of Graph (Fig. 33):

In Figure 33 is shown a comparison of roading and swinging costs for logs of 800 board feet volume over various distances. Roading is represented by lines 1,2 and 3; skyline swinging by lines 4 and 5 .

In using three different lines to represent roading costs the aim has been to specify various conditions which have a decisive effect on costs.

Line 1 thus represents the cost of strictly downhill roading with no allowance for road construction. It has been plotted from data given in Table 39 , with 1.0 per cent added to cover the cost of hooking and unhooking, which items are not included in the $\$ 33.80$ daily machine rate on which Table 39 is based. 


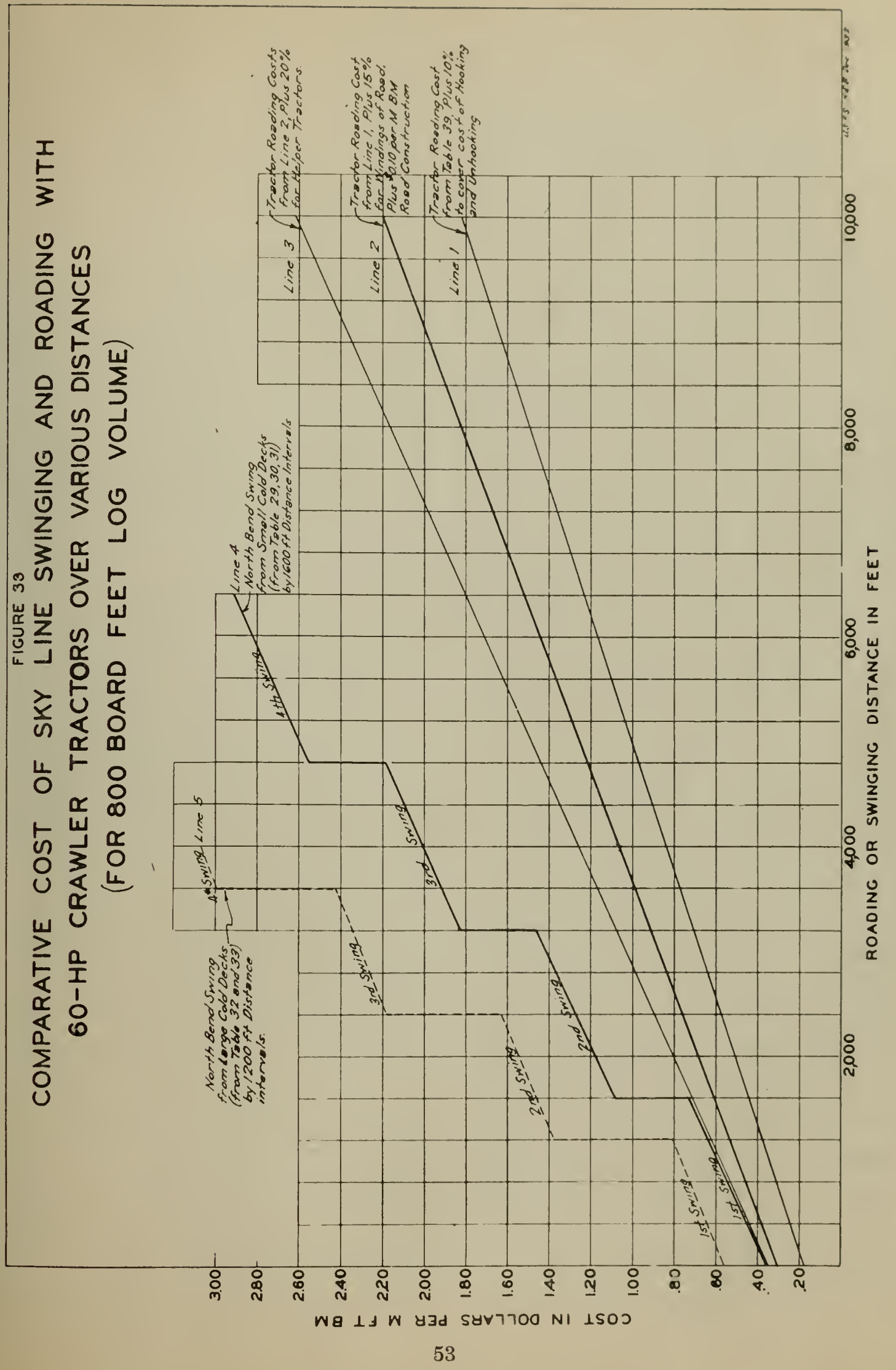


In plotting line 2 there have been added to costs represented by line 1 :

(a) Ten per cent to cover the difference between roading distance and swinging distance as represented by straight-line swing roads versus winding tractor roads;

(b) Five per cent for time lost on account of occasional flat stretches or very short adverse grades in the road of a character that does not require the use of helper tractors but that does cause a considerable increase of hauling time;

(c) $\$ 0.10 \mathrm{per}$ M feet b.m. to cover the difference between the cost of the tractor road construction compared with the cost of rigging ahead and moving under the skyline-swinging system.

Line 3 represents the same costs as line 2 with an additional allowance of 20 per cent to cover the cost of operating one helper tractor for each three roading tractors, to overcome long adverse grades in the road such as that shown in Figure 37.7

The three lines thus represent, respectively, roading costs under ideal conditions, under handicaps such as may occur under typical conditions, and under a set of conditions which approaches the point at which roading may become impracticable on account of steep adverse grades.

Skyline swinging costs in line 4 are the same as those represented by line A-A in Figure 30 , being based on Tables 29, 30 and 31. They represent swinging (North Bend system) from small cold decks, which as heretofore discussed gave the lowest swinging costs obtained in this series of studies. It is assumed arbitrarily that swinging is limited on the average to a distance of 1,600 feet, and that each 1,600 feet of distance requires an additional set-up of skyline and swing donkey, and hence the transfer of logs from one to another. Hence the step-up effect shown in line 4 in which a perpendicular rise of 36 cents per $M$ ft. b.m. represents these transfer costs, while 37 cents represents the cost of swinging while the lines are in motion over the 1,600-foot distance. Rigging ahead and moving costs are not included, but have been credited to tractor roading as an item off-setting a part of road construction costs.

Line 5 is the same as line B-B in Figure 30, based on an average swinging distance of 1,200 feet.

\section{Roading from Large Cold Decks Introduces} Additional Costs:

Swinging costs under various conditions will thus fall generally between lines 4 and 5 , while roading costs fall between lines 1 and 3 . A still wider spread in roading might be pictured, however, in connection with roading trom large cold decks under conditions requiring a special crew and/or donkey for extracting the logs from the pile. This was the situation in the study heretofore reported, but represents as here viewed only the transition stage from old methods to new ones. The adoption of the roading system would inevitably tend toward the elimination of cold decks entirely or toward their reduction in size toward a point where no serious difficulties arise in getting the logs out of the deck. They might be eliminated either by (1) resorting to short distance yarding to the tractor roads with tractors, either ground skidding or using pans or fairlead arches, etc.; or (2) by hot yarding with small highlead donkeys or ground yarding with donkeys; or (3) by constructing so dense a network of tractor roads as to render it practicable to yard directly to the roading tractors using the fairlead line. If, however, the large cold deck happens to represent the only practical answer to a given roading problem, then it becomes necessary, of course, to include as a part of roading costs the extra cost incurred ${ }^{2}$ The cost of operating a helper tractor is here estimated at only
$\$ 22.00$ per day, while a roading tractor outfit cosis $\$ 37.18$ per day. in getting the logs out of the deck-a cost which often might amount to twenty or thirty cents per $M$ feet b.m. In this case it is obvious that the corresponding skyline swinging cost would tend to move toward line 5 in Figure 33 since this line represents swinging from large cold decks, while line 4 represents the small decks. That is to say, skyline swinging is handicapped by large cold decks similarly to tractor roading and possibly to about the same extent. When the question of large cold decks is eliminated, the comparison should be focused on line 4 as representative of skyline swinging, and lines 1 to 3 as representative of tractor roading.

58. Comparison of Results. - Innumerable comparisons of swinging and roading costs can be read off directly from the graph (Figure 33). The most striking feature is the growing superiority of the roading system with increase in distance. For example, in roading under conditions represented by line 3 , costs are nearly identical with skyline swinging costs for distances reached by the first skyline swing; but the roading curve leaps forward rapidly when the comparison is extended to the second, third, or fourth swing. Thus the same cost $(\$ 2.00$ per $\mathrm{M}$ ft. b.m.) that brings in a log of 800 board feet volume over a distance of 4,000 feet under the skyline swing system (line 4 ) reaches out to a distance of 7,300 feet on line 3 ; to 9,000 feet on line 2 ; and to 11,000 feet on line 1 ; and, to complete the contrast, will cover only 2,400 feet if three swings are made under conditions represented by line 5 !

59. Significance of Low Cost of Long Distance Roading.-To the logging operator it might appear at first blush that the real importance of the cost comparison in Figure 33 hinges largely on how the two systems compare for distances ordinarily covered by the first skyline swing, because, through the present lay-out of railroad spurs, stump to track transportation is confined usually to relatively short distances. Double skyline swings are thus resorted to only occasionally; and triple swings are used only under exceptional conditions.

On further thought, however, it will become apparent that the importance of the increasing superiority of the tractor roading system at longer distances should not be minimized on account of possible lack of application under the present general railroad scheme. Unless the railroad system is already built the adoption of the tractor roading system will affect the location and spacing of railroad spurs. Each major system of stump to track transportation creates its own standard of distances over which the bulk of the timber will be transported. The relatively low cost of long-distance tractor roading upsets radically the relation 
between yarding and swinging distances and railroad construction and operating costs; and in so doing throws open the whole problem of log transportation a much broader inquiry than that followed in the preceding discussions. In reestablishing the economic balance for the roading system it will be found that roading distances of $4,000,6,000$, or even 10,000 feet will become no more exceptional than are swinging distances of 1,200 to 3,000 feet under the present general plan of operation. In this situation it is easy to see possibilities arising that are likely to have a far-reaching effect, not only on questions dealing with efficiency in logging, but also on more basic questions of forest management. Through the skeletonizing of the railroad system drastic reduction can be effected in the opening-up costs incurred in the development of virgin timber areas; and through the flexibility and cheapness of tractor road construction a highly flexible system can be evolved admirably adapted to the solution of problems of selection in logging-whether by small subdivisions of area or by individual trees.

60. Reduction of Breakage Is Important Factor.-Reduction of breakage is, perhaps, on tha average as important an advantage of the roading system as is the reduction of costs. To many loggers this will appear as the principal advantage, the cost advantage being subject to exceptions. In roading with tractors the logs are handled like glassware, arriving at the landing without the well-known blemishes-broken, broomed, and split ends; bark and ends impregnated with rocks, and covered with mud; broken slabs, etc.- which frequently distinguish the more or less battle-scarred "donkey $\operatorname{logs}$ " at the end of their eventful journey.

Obviously, if the bottom of line 4 (and 5) in Figure 33 were raised to allow for breakage losses that might range generally from $\$ 0.25$ to $\$ 2.00$ per $\mathrm{M}$ ft. b.m., the superiority of the tractor roading system would become most striking, no matter what distance might be under consideration.

61. Construction of Tractor Roads Broadens the Use of Tractors in the Douglas Fir Region.-The conclusion reached in Section 53 with regard to yarding, that the small, flexible equipment underbids the large, high-power and high-speed machinery, may now be extended to swinging. Thus, if selection of equipment is governed strictly by principles of efficiency and economy on such an area as that shown in Figure 31 , which was discussed in connection with swinging and cold decking, it becomes evident that the crawler tractor will take over the functions of the skyline swing and that there will be a relocation of the railroad and shifting of the landing to permit a downhill tractor road system. It will also take over the yarding on more than half of the area, leaving the remainder to small, short-distance highlead yarders, preferably tractor-mounted donkeys (Fig. 3), to facilitate moving over the tractor roads. Logs from steep slopes that are inaccessible to the tractor's can thus be donkey-yarded at relatively low cost to the tractor roads. Through this combination of small, flexible donkeys with roading tractcrs, it is evident that the roading system as a whole can penetrate successfully into rough and steep territory which would not ordinarily be considered suitable for tractor logging. It is readily seen, also, that areas which in their virgin state might not be fit for direct travel with tractors, owing to rough ground detail, can be made over through the construction of tractor roads to better fit the requirements of the tractor. The recent development of the tractor-mounted, so-called "bulldozer" (see Fig. 45, Chapter XXI) - a large adjustable blade mounted in front of the tractor-has brought about a remarkable reduction in the cost of constructing roads of the character needed for tractor roading, as will be further discussed in Chapter XXI.

62. Limitations of the Tractor Roading System.Within certain limits rough and steep topography, as exemplified in Figure 31 , and in general in Figures 7 to 27 inclusive, is not necessarily a severer handicap to the tractor roading system than against other systems. The roading system thrives on slopes, provided that they are not excessively steep along the route that is followed by the road itself, and provided that the slope is downhill toward the track landing.

Roading over uphill grades is impracticable, with some minor but very important exceptions to which attention was called above in explaining the basis of the spread between line 1 and line 3 in Figure 33 . Uphill roading in the broader sense is, of course, out of the question. The whole scheme of railroad location under tractor logging would, however, tend to revert to that of the bull-team days when railroads or skidroads were confined as far as practicable to the low elevations, giving the law of gravity as wide a play as possible in helping the logs 
along toward the track. On this basis the field for uphill skyline swinging as an adjunct to the general tractor roading scheme would become much narrower than under the present railroad scheme. On the other hand, if railroads are located primarily for donkey logging the skyline system regains title to much territory that would otherwise be claimed by the roading system.

On downhill slopes the roading system is not disabled so easily. On slopes ranging up to about 40 per cent, tractor roads need not meander excessively in order to reach their objectives. An allowance of 10 per cent was made for this item in establishing line 2 in Figure 33. This is believed sufficient on areas where roads can be located without any special account being taken of general topography. Costs naturally will rise on steeper slopes, where the roads must be built along side hills with much loss in distance and increase in road construction cost. However, in view of the wide space between line 2 and line 4 (Figure 33), further widened by making a proper allowance for reduction of breakage, it seems that the road. ing system can stand a good deal of loss of distance and increase in road construction costs before roading costs will exceed skyline swinging costs. Then, too, it should be pointed out that the tractor and heavy trailer (fairlead arch) might not be the right combination of equipment to use except where slopes are reasonably moderate. On consistently steep slopes ranging from 20 to 50 per cent the tractor might do better with a pan or by direct ground skidding, taking into account increased hill climbing ability and the elimination of side-hill road construction; or, in this mechanical age, it is not so far fetched to assume that if the need were voiced by the industry for a more practical hauling unit for overcoming the handicap of steep grades, such a unit would soon be produced.

The point will be reached, however, at which the roading system does become impracticable. Long slopes of 50 per cent and over are probably handled cheaper by skyline swings, bearing in mind, however, that steep slopes, whether uphill or downhill, on areas tributary to tractor roads, do not interfere with the roading system if the tractor roads do not traverse the slopes, since donkeys can be used in getting the logs to the roads.

Roading may also become impracticable because of rock formations that make cheap tractor-road construction impossible. These, however, are generally associated with excessively steep topography, which in itself renders roading impracticable. Grade and alinement specifications for tractor-road construction are sufficiently flexible to allow for most difficulties of this character on slopes on which roading is at all practicable.

Further handicaps arise against the roading system in that in many logging operations in this region it may have to be confined to the dry season, a period of about 6 months with intermittent wet periods of short duration. Tractor operations on gravelly or well-drained soil may not be seriously handicapped by the winter rains, but the large majority of logging operations in this region are on clay soil, upon which under a heavy rainfall the present type of roading equipment is virtually helpless, particularly on steep slopes. This is probably the most important general handicap to tractor roading in this region.

Because of these handicaps certain situations arise which call for various solutions, such as:

(1) On some operations tractor logging is feasible and the most practical system the year round.

(2) On other operations the topography is such that tractors alone or tractors in combination with small tractor donkeys, etc., although confined to the dry season, can solve all logging problems to better advantage than the more conventional methods.

(3) On some operations a practical solution to both topographic and weather problems would be to combine dry-weather tractor roading with wet-weather skyline swinging into a year-round operation.

(4) On some operations the tractor would enter in in varying degree as an adjunct to the present system; or may be entirely impractical.

Both (1) and (4) are exceptional cases. The broadest general solutions applicable to a wide variety of conditions come under (2) and (3). In the latter case the skyline system would function not only as a wet season expedient but would also during the wet season dispose of the logging problems passed up by the tractor-roading system or, occasionally, during the diry season might be combined with the tractor roading system, where difficult topography recommended such a solution. The only major duplication of equipment under this general system arises in providing, a skyline donkey to substitute for the roading tractors during the wet season-other equipment being interchangeable. 


\section{LOADING STUDIES}

63. Relation of Loading to Yarding and Railroad Transportation.-From a practical standpoint, cost relations in loading in typical donkey operations lose their significance when yarding capacity, whether by choice or circumstance, is normally lower than loading capacity. Loading does not then function as a pace-setting or independent activity, but simply serves to relay the logs that are yarded or swung to the landing. This situation applies largely to 7 of the 13 studies reported in Table 40. In these cases, loading is properly to be dealt with as a part of the yarding or swinging operation. However, for the purpose at hand these studies have been analyzed as representing loading as an independent activity.

Of the remaining six studies, two represent cases in which loading is virtually independent of yarding, while in four studies loading was found to be the pace-setting activity during the greater portion of the working day, reacting accordingly on the effective costs and cost relations in yarding or swinging.

These three groups of loading studies represent different theories and practices in the management of logging operations.

According to the first of these, yarding is looked upon as the principal part of the operation and loading and railroad operation as merely subsidiary functions serving the yarding operation according to its needs.

According to a second plan of operation yarding and loading are independent of each other, neither activity being allowed to interfere with the efficient performance of the other. This ideal system probably is not attainable when loading and yarding are carried on concurrently, except through a scheme of yarding similar to that described in Section 21 in connection with tractors, and providing then, of course, that conditions allow their use. How yarding and loading may be kept entirely independent of each other in a large scale operation is discussed in Chapter XXII.

According to a third school of thought, the loading operation is set up as the regulator of production, setting the pace both for yarding and railroad transportation. In this system the yarding or swinging operation aims to contin- ually crowd the loading operation. It relies, generally, upon cold decking to create favorable conditions for high production where nature has failed to do so of its own accord. It may, in many cases, voluntarily assume an increase in the cost of transporting the logs from the stump to the track landing, if by doing so production can be kept up to the full capacity of the loader, keeping loading costs at a minimum and also, and usually more important, bringing about lower unit costs in railroad transportation and in general overhead expense.

A modification in any one of these methods of regulating production arises when the main emphasis is placed on producing a fixed number of car loads per day. This may work hand in glove with the other systems if the timber is uniform in size and other conditions are favorable for uniform output, or it may seriously lipset the normal course of events if the timber and logging conditions are variable.

\section{Scope of Studies.-}

A total of $14,016 \operatorname{logs}$ scaling 12,345 M feet b.m. are represented in the thirteen loading studies herewith reported.

Figure 34 gives an example of the detailed analysis of these studies showing the relation of volume of $\log$ to the various time elements of the loading operation and also the relation of volume of $\log$ to cost and output. It represents loading with the McGiffert loader shown in Figure 6, Chapter II. Similar analyses were made of the other twelve studies covering four different types of loading machinery. The results of these are briefed in Table 40 which shows costs only. Corresponding output rates may be computed by dividing the daily machine rate listed at the foot of the table by the cost per M feet b.m.

\section{Factors Affecting the Cost of Loading.-}

In all loading studies the following major subdivisions of time apply:

1. Direct Loading Time, or the time spent on the actual loading process, $\log$ by $\log$.

2. Car Spotting Time, or the time elapsing from the moment the last $\log$ has been loaded on one car until loading is begun on the next; with waiting delays excluded. (See item 4.)

3. Miscellaneous Loading Delays, or time lest in shifting of logs already loaded to nake better room for other logs, sorting of logs on the landing, etc.

4. Waiting Delays, or time out on account of lack of logs on the landing, waiting for empty cars, etc.

In the loading operation, logs are handled one by one; the distance of travel is equal for all logs, or may 
be so considered in dealing with a large number of them. Conditions are, as a whole, standardized. The only measurable variable which affects cost relations is the size of the log.

Size of log affects direct loading time per log in that, generally, the heavior the log the greater is the time required in loading. It further affects car spotting time per $\log$ because the larger the log the smaller is the number of logs that can be loaded on the car, and hence, the more frequent the repetition of the car spotting operation. This factor has been determined from car-loading studies which were conducted in connection with the loading studies and which are reported in Section 75 .

The third item, loading delays, is not affected by the size of the log. It has been morated per log in all studies.

The fourth item, waiting delays, has nothing to do with cost relations in the loading operation as an independent activity. It represents the lack of synchronization between yarding, loading, and railroad transportation. Cost relations in loading as an independent operation are determined on the strength of items 1, 2 and 3. Item 4 has, then, the effect of adding to costs by whatever percentage of the day is lost in waiting.

The costs listed in Table 40 represent only items 1 , 2 and 3 Total loading cost may be computed by multiplying these costs by the multiplying factors entered at the foot of each column. These represent the increase in costs caused by waiting delays.

66. Comparison of Costs.-A glance at Table 40 shows that loading costs are practically identical for studies No. 2 to 6 inclusive. These studies are on a fairly equal basis in regard to the pressure under which the loading crews were working. Study No. 2 represents the operation described in Section 21, where a fleet of tractors supplied a steady flow of $\log$ s to the loader with no lost time segregated as waiting delays. The other four studies represent conventional donkey operations in which yarding or swinging capacity is normally greater than loading capacity, although, as indicated by the multiplying factors shown, considerable waiting delays occur as a result of time lost in changing blocks and lines and other delays in the yarding operations as well as in switching cars at the landing. Nevertheless, when loading was being done the loading crew was working under fairly constant pressure to keep the landing from filling up with logs.

In studies No. 7 to 13 it will be noticed that the cost level as a whole is considerably higher and waiting delays considerably greater than for identical machines among the studies discussed above. Yarding capacity here lags behind loading capacity and as a result the load- ing crew is not working under the same pressure as in the previous studies. The higher cost level indicates that the loading crew simply adjusts its pace to fit the needs of the occasion, working faster when the landing is constantly well supplied with $\log s$, and slower when the $\log$ supply is low or intermittent.

\section{Adaptation of Equipment to Log Size Brings} Reduction of Cost.-Of special interest in the comparison of costs given in Table 40 is the relatively low cost shown for study No. 1 . This represents loading with a 30 h.p. gas donkey which was used alternately for highlead yarding and loading; a few hours would be spent in yarding until the landing was filled, then the rigging was changed for loading, then back again to yarding, etc.

The low costs here shown apply with particular force to small logs. It costs, for example, about 70 cents less per $M$ feet b.m. to load logs of 100 board-feet volume with this loader than with conventional 100 h.p. steam loaders as represented by the five most efficient operations shown in Table 40. No saving, however, is shown for logs of 1,600 board foot volume, and the indications are that for still larger logs this operation drops behind in the race with the others.

Nevertheless, the comparison emphasizes the opportunities for drastic reductions in the cost of loading small logs through special adaptation of machinery to $\log$ size. Performance records in other regions, where the problem of efficient loading of small logs has been more generally recognized, will afford a better illustration of this than the present study. Timestudy data compiled by Garver ${ }^{8}$ covering loblolly and shortleaf pine operations in Arkansas show that in loading logs from trees ranging from 8 to 27 inches in diameter on staked cars, using a steam jammer operated at a cost of $\$ 50.00$ per 8-hour day, the loading time per log averages only about 40 per cent of corresponding time per log as represented by the five most efficient operations shown in Table 40, which represent loading machinery in the same general class as far as operating cost per day is concerned, allowing for differences in wage levels.

Data ubtained from R. 1). (iarver, Senior Forester, Forest Pro. ducts Laboratory, Madison, Wisc. 


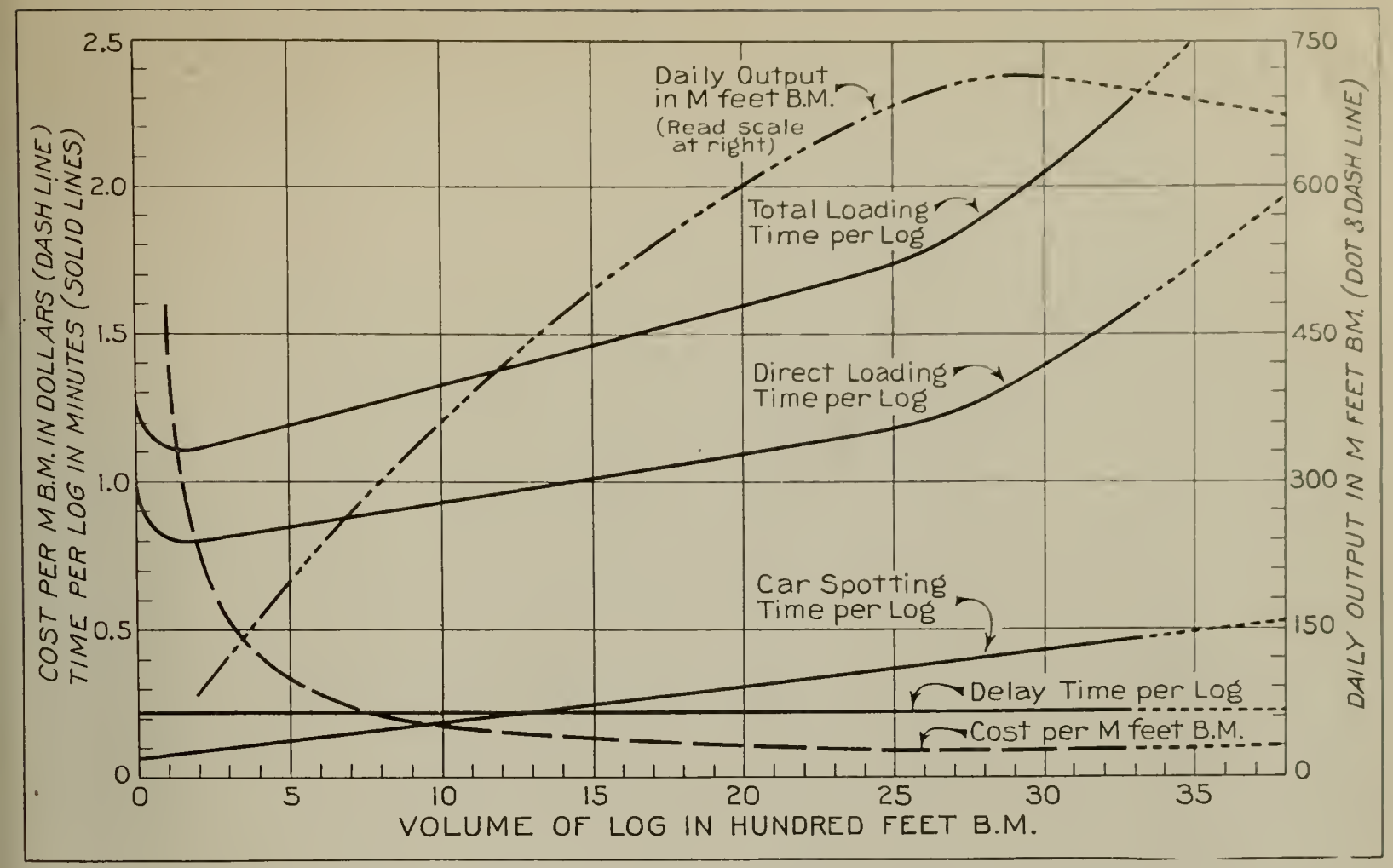

FIG. 34-EFFECT OF SIZE OF LOG ON TIME, COST, AND OUTPUT IN LOADING BASED ON 4325 LOGS

TABLE 40

Cost of loading logs of various sizes in dollars per $M$ feet b.m., under different relations of loading to yarding13 studies

Loading independent of Loading controls yarding

Volume 30 h.p. Jam- Heel McLean McLean of log Crotchline mer boom boom boom Duplex ift.b.m. 1 2$$
100
$$$$
100
$$

300

500

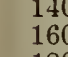$$
{ }_{1800}
$$$$
\begin{aligned}
& 180 \\
& 200 \\
& 250
\end{aligned}
$$$$
3000
$$$$
4000
$$

5000

6000

Multiplying

factors 1

Machine rate

8-hr.day $\$ 20.00 \quad \$ 59.4$

2

$$
3
$$

$\$ 1.43$

.48

.37

.30

.25

.20

.17

.14

.13

.12

.11

.11

4

$\$ 1.31$

.66

.66

.33

.27

.23

.18

.15

.13

.11

.10

.09

.11

5

$\$ 1.47$
.73

.73
.49
.37

.37

.29

.25

.19

.16

.13

.11

.10

.11
.27

.23

.18

.15

.13

.11

.11

.10

.10

$\begin{array}{llll}1.00 & 1.40 & 1.32 & 1.39\end{array}$
.72
.48

Yarding

\section{controls loading}

Heel Heel McLean McLecn

boom boom boom bom Duplex Diplex Inplex $\begin{array}{llllllll}6 & \text { \% } & 8 & 9 & 10 & 11 & 12 & 1.3\end{array}$

$\begin{array}{llllllll}\$ 1.33 & \$ 3.06 & \$ 2.13 & \$ 2.57 & \$ 3.15 & \$ 2.63 & \$ 2.35 & \$ 2.35\end{array}$

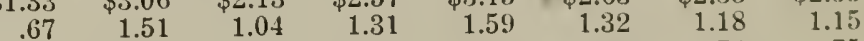

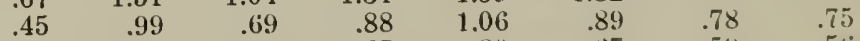

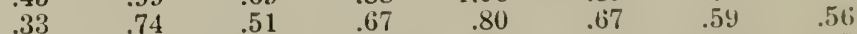

.74
.59

$.49 \quad .33$

$\begin{array}{ll}.37 & .35 \\ .25\end{array}$

$.29 \quad .20$

.25

.22

.20

.18

.17
.14

.12

.10

.09

$\begin{array}{lll}\ldots & & . \\ \cdots & 09\end{array}$

.17

.14

.12

.12

.10
.09

.09

.08

.54

.46

.35

.29 .

.25

.21

.19

.17

.16

.13

.11

.09

.65

.54

.41

.34

.29

.25

.23

.21

.19

.16

.14

.11

.08

.10
.09

.54
.45

.34

.28

.20

.18

.17

.16

.14

.13

.47

.40

.30

.25

.18

.15

.14

.1

.11

.10

.45
.38

.24

.24

.20

.18

.14

.13

.12

.11

.10

.10

1.58

1.90

4.23

1.47

1.74

1.98

1.56

$55.00 \quad \$ 52.50 \quad \$ 52.50 \quad \$ 52.50 \quad \$ 52.50 \quad 52.50$

'Multiplying factor times cost listed in same column gives loading cust inclusive of waiting time. 
Under the clear-cutting system practiced in the Northwest, there is scant opportunity for reducing the cost of loading small logs through specialized methods and machinery. Since logs of all sizes arrive at the landing and the mal- chinery must be designed for fairly efficient loading of large logs, the cost of loading small logs becomes excessively high. This is an argument against the clear-cutting system to which further attention is given later in this report.

\section{COMPARISON OF COST RELATIONS IN TRANSPORT FROM STUMP TO CAR}

68. The Effect of Volume of Log on Yarding Variable Cost.-The striking feature in all the studies of yarding, swinging, roading and loading methods is the marked influence of factors which are easily measured-namely, log size and distance, which for any given type of timber, method, or machine act somewhat the same in all cases, no matter how far apart actual costs may be.

The effect of volume of log on yarding variable costs is summarized in Figure 35 by means of a series of curves, each numbered to correspond with the table from which the data are taken. They represent cost relations for only that portion of total yarding costs that has been termed "the yarding variable," heretofore defined, i.e., they exclude fixed road-changing costs. In each study the cost of yarding logs of 3,000 board-foot volume is arbitrarily assumed as unity, irrespective of how much actual costs might differ from study to study; with costs for other volumes rising as shown by reading the graduations on the ordinate at the point where the curves and graduations on the abscissa intersect. The spread between any two curves does not, then, represent differences in costs between the studies but shows differences in the relative rate at which costs change with decrease in $\log$ size.

The cost relations have been determined from time data in the time-study tables for a yarding distance of 500 feet in the case of highlead studies and 1,000 feet for tractor and skyline yarding studies. Other distances exhibit the same relationships except in the case of tractors, which, as previously noted, display considerable variation at different distances.

Exceptions to the use of the 3,000 boardfoot volume as unity had to be made for 30 to 35 h.p. gasoline yarders, because no data were obtainable for logs of that size. In these cases cost for the 2,000 board-foot log volume is assumed as unity. It is believed that for these low-power machines minimum costs are reached at about 2,000 board-foot log volume, and may be expected to rise again in approach- ing 3,000 feet, except in steep downhill yarding in which case the decline in costs may continue well past the 3,000 -foot point.

In many of the studies the decline in costs with increase in the volume of the log continues well past the 3,000 board-foot point. With few exceptions, however, this decline is not very pronounced. Furthermore, at some point near the 3,000-foot size one may seriously question the reality of any substantial decline that is predicated on the translation of time cost into money cost on the basis of applying a fixed cost per yarding-minute to logs of any size. The point will be reached at some log volume at which the cost per yarding-minute will commence to show a noticeable increase due to more frequent overloading of both machinery and rigging with consequent increase in the cost of operation. This would apply more specifically to operations having generally small or medium-sized timber and which are organized and equipped for that type of timber.

Figure 35 shows that the curves, except Curve 5, which represents tractors, form a rather closely spaced band of virtually parallel lines, but with a considerable spread from high to low. The upper six curves are shown in dot and dash line. Their position at the top of the "band" indicates that the rate of increase in costs with decrease in log volume is more rapid than for the other curves. They represent in all cases high-power yarding machinery working under conditions and operating practices which bring about high relative costs of yarding small logs. The three upper-most curves represent $12^{\prime \prime} \times 14^{\prime \prime}$ and 13"x14" steam highlead yarder studies in which only one choker was carried, with the result that the increase in cost is virtually inversely proportional to the size of the log. The next three curves represent a maximum of either one or two chokers. With one exception all six curves represent scattered large timber combined with difficuit topography. In all six cases the percentage (by volume) of small logs is very low; that is, a compelling reason for paying close attention to 


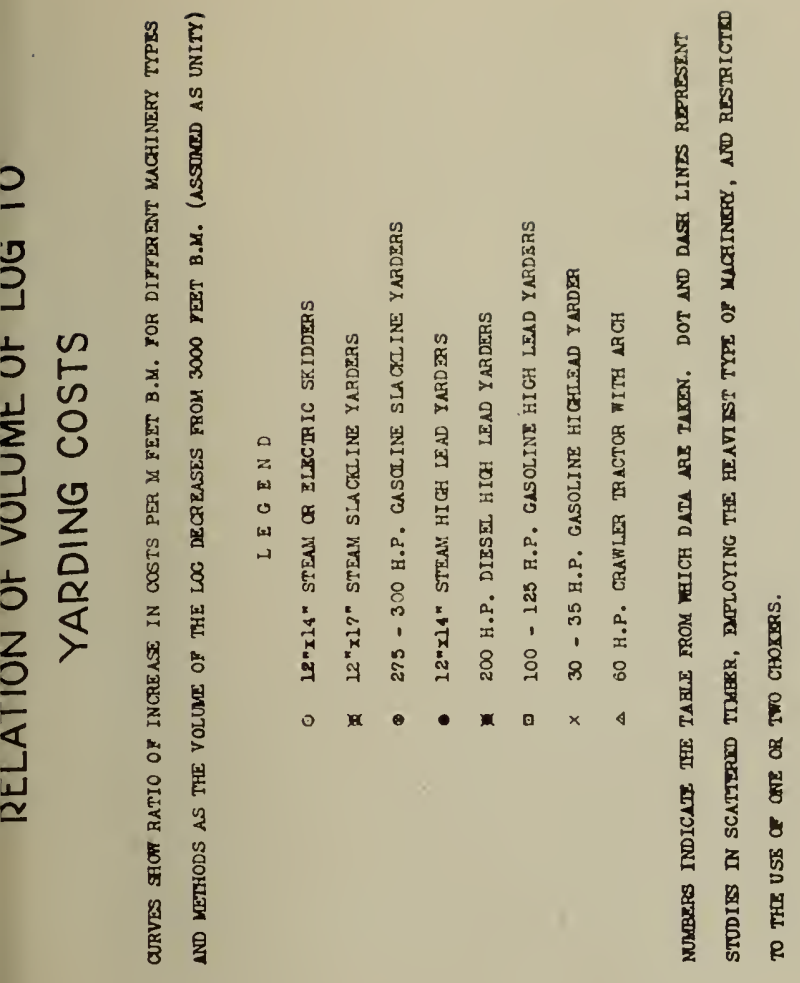

क

శి

ผ

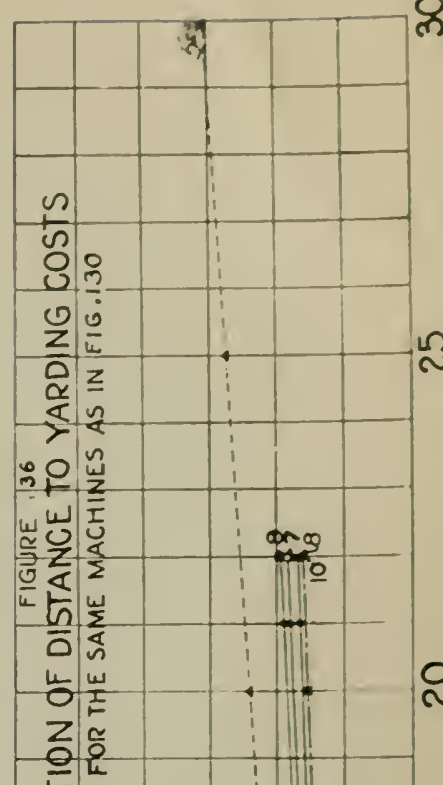

$\stackrel{\sim}{\sim}$



으

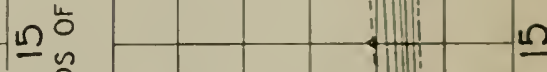

几

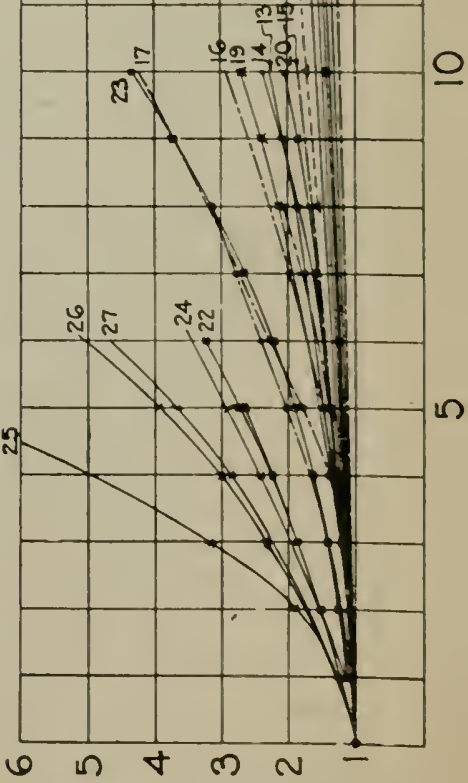

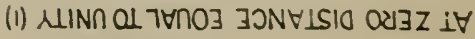

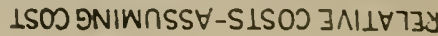


the cost of handling small $\operatorname{logs}$ is almost entirely lacking.

The dot and dash lines in Figure 35 might be described as being steeper than the other curves. The ter"m "steeper" thus denotes relatively more rapid rate of increase in costs with decrease in volume of $\log$, and will be used henceforth in this sense.

Curves shown in solid lines represent more normal working conditions and operating practices. They represent both highlead and skyline yarding machinery of all sizes.

The curves representing 30 to 35 h.p. gasoline yarders fall quite closely in line with the general trend for the larger machines. However, the effect of power on the steepness of the yarding cost curves is indicated by comparing them with the three dot and dash curves at the top of the band which, like the small machines, represent only one-log turns. This relation between power and the steepness of the curves is further emphasized by the fact that Curve 24, which represents steep downhill yarding (hence relatively less demand on pulling pow(1) departs noticeably from Curves 25, 26, and 27 , which represent relatively level or uphill yarding. The same thing is again shown by the spread between Curve 1.1 and Curve 12, both representing equal pulling power, but one representing steep uphill yarding, the other, downhill.

69. Volume of the Average Log as an Index to Steepness of Cost Curves.-Curve 17 is the steepest curve in Figure 35 and represents also the operation with the largest average log $(4,430$ feet average log). Next in the order of steepness and also in the order of average log size is Curve 18 which represents an average $\log$ of 2,340 board feet. At the bottom of the band are Curves 5 and 25 which represent $\log$ averages of 360 and 400 board feet, respectively - cperations showing the smallest average log and also the flattest curves. Between these extremes are other operations in which the average log ranges from 500 to 2,000 board feet. The order of decreasing steepness and the order of decreasing average log size do not coincide exactly in all cases but there is on the whole fairly close agreement between them. This is shown below by segregating the curves into four groups, with the mean average log volume computed for each group. The first group represents the six steepest curves while the second, third, and fourth group, arranged in the order of decreasing steepness, each comprises five curves.

Group
Curves 17 to 21 $\quad \begin{gathered}\text { Mean average log volume } \\ \text { Curves } 12 \text { to } 20\end{gathered} \quad \begin{array}{r}2,200 \text { board feet } \\ \text { Curves } 7 \text { to } 11\end{array}$

These data are the basis for the figures that are entered diagonally across the widest portion of the band in Figure 35. Here the graduation at the figure 3,000 , for example, shows the predicted position of a curve representing an operation having an average log of 3,000 board feet; while the 500 foot mark shows the position of a curve representing an average log of 500 board feet; and by interpolating between any two figures the normal position of a curve representing any given log average may be determined.

In using this band of curves as a basis for selective cost appraisal as discussed in Chapter XVI, it can readily be seen that from the known average size of the timber as this varies from setting to setting or from tract to tract, curves may be selected that are most likely to fit various types of timber, provided, of course, that the timber is to be clear cut in conventional fashion using conventional types of donkeys. The chance for serious error in thus "spotting" a curve to fit a given case is relatively small.

The reason why the average $\log$ size is a fairly reliable index to the steepness of the curves is that it generally reflects the influence of a number of factors which control the relation between size of log and yarding cost. A very large average $\mathrm{log}$, for example, almost invariably goes hand in hand with scattered timber, i.e., with fewer logs per acre than in stands with a small average log. It usually also goes hand in hand with heavier lines, chokers and machinery and with the practice of flying fewer chokers than in small timber. These conditions combine to place the small log of a largetimber stand at a relatively greater disadvantage than the small $\log$ in a small-timber stand, i.e., they produce a steeper cost curve.

70. The Effect of Distance on Yarding Variable Costs.-In Figure 36 the cost index at zero distance represents the time required solely for hooking, unhooking, and delays; the distance yarded adds to these costs as indicated by the curves. The studies represented are identical with those shown in Figure 35 and are numbered to correspond. These show:

(1) Erratic results occur in connection with high-lead yarding; consistent results in skyline yarding. The reason for this is, of course, that traveling conditions are under better control in skyline yarding. 
(2) Skyline studies show virtually straight line relations. High-lead studies show curved relations. The reason for this is that hang-up delay is generally an important factor in highlead yarding and increases much more rapidly than the increase in distance, while in skyline yarding, hang-up time is not related to distance out.

(3) Superficially, the greater the speed of the machine, the less is the effect of distance. The curves for 30 to 35 h.p. gasoline yarders are thus much deeper than for the 100 to 125 h.p. yarders. These in turn are steeper than curves representing larger machines, etc. Speed and power alone, however, are not deciding factors in these relations. Traveling speed in relation to the "fixed" time spent on hooking, unhooking, and delays will actually determine the steepness of the curves which show cost ratios based on both traveling and "still" time. This explains why distance has only a relatively moderate effect on tractor yarding costs in spite of the low traveling speed of these machines.

In the case of highlead yarding the increasing steepness of the distance curves with decrease in the size of the machinery will be found to offset approximately the combined effect of the generally steeper volume-relation curves (in Fig. 35) and the longer external yarding distances ordinarily used in connection with the larger machines. For the sam? range in $\log$ sizes and for distances typical of the type of yarder used the total relative spread in costs based on both log size and yarding distance is thus approximately the same in all casses.

71. The Effect of Volume of Log on Swinging Variable Costs.-Figure 37 represents the effect of volume of $\log$ on swinging costs in seven different studies. The relation between the average volume per $\log$ and the steepness of the curves was brought out in Table 36, and discussed in Section 36. Not enough studies were obtained to warrant a definite gradation of the band based on specific log averages such as was done in Figure 35 for the yarding studies. However, the four lower curves represent $\log$ averages from 350 to 770 ; the three upper from 960 to 2,160 , thus embracing virtually all log averages that are likely to be encountered in swinging from cold decks, and giving a rough guide for predicting where any curve representing a given log average should fall.
72. The Effect of Volume of Log on Loading Costs.-Figure 38 gives a comparison of cost relations in loading logs of different volumes. for different types of loading machinery and methods. The data are taken from Table 40 and are translated into parcentage costs the same as in Figures 35, 36, and 37. As in preceding percentage diagrams the spread in the band of curves does not indicate differences in costs from study to study, but signifies only differences in cost relations in various studies. The six solid-line curves represent studies in which loading was carried on independently of the yarding operation or in which yarding capacity normally was greater than loading capacity. The dotted lines represent studies in which the yarding capacity normally fell behind loading capacity.

Curve No. 11 departs strikingly from the others. This is accounted for by the fact that (1) it represents a machine of low power (a 30 h.p. gasoline loader, compared with 100 h.p. or more for the other studies), (2) it represents loading of small trucks of limited carrying capacity (11/2-ton truck, 3 -ton trailer) thus giving large logs only a relatively minor advantage in spotting time per $M$ feet b.m. when compared with loading or railroad cars, (3) the prorated time per $\log$ is a neglible factor which tends to further flatten the trend of the curve.

A comparison of Figure 38 with Figure 35 shows striking resemblances-in fact, the two series of curves virtually coincide with the exception of the three highest curves in Figure 35. Imaginary center lines drawn through the two "bands" produce virtually identical curves. This nearly perfect agreement is apt to be somewhat misleading. The position of the dotted-line curves would indicate that the greater the volume of the average log the steeper becomes the loading cost curve, the same as for the yarding and swinging operations, although. there is no reason that would explain why it should be, and no indication that this correlation holds in connection with the solid line curves. It is believed, therefore, that the cost relations in the dotted-line curves reflect yarding relations rather than loading relationsyarding being the pace-setting activity in these cases. The loading crew in cases of this kind probably strikes a relatively slower pace in loading the small logs than is normal for the loading operation as an independent activity because there is no need of crowding the loaciing as long as yarding is continually lagging 
behind. For this reason cost relations of loading are here assumed to be represented only by the solid line curves. These show a slightly flatter trend than the yarding curves but the difference is rather small.

It has already been pointed out that in the combined yarding and loading operation the ultimate significance of cost relations applying to each activity will depend upon which activity controls the output. If yarding controls, which is the case when yarding capacity is normally lower than loading capacity, then cost relations in loading are of no significance. Loading is then simply a part of the yarding operation. If loading controls, as is the case when yarding (or swinging) capacity is normally greater than loading capacity, then cost relations in yarding or swinging lose their significance be- caluse these activities represent then only the tail end of the loading operation.

The question of how to provide for a case where neither yarding nor loading is definitely in control, or where the control may shift back and forth from loading to yarding according to variations in the yarding show, now appears relatively less important than one might anticipate in view of the close agreement in cost relations shown in Figures 35 and 38. This applies, however, only to the specific combinations of loading and yarding machinery here dealt with. It does not apply, for example, to a combination of "jammer" loading and tractor yarding, and probably would not apply in many other cases in which yarding and loading machinery is not mechanically synchronized in the first place.

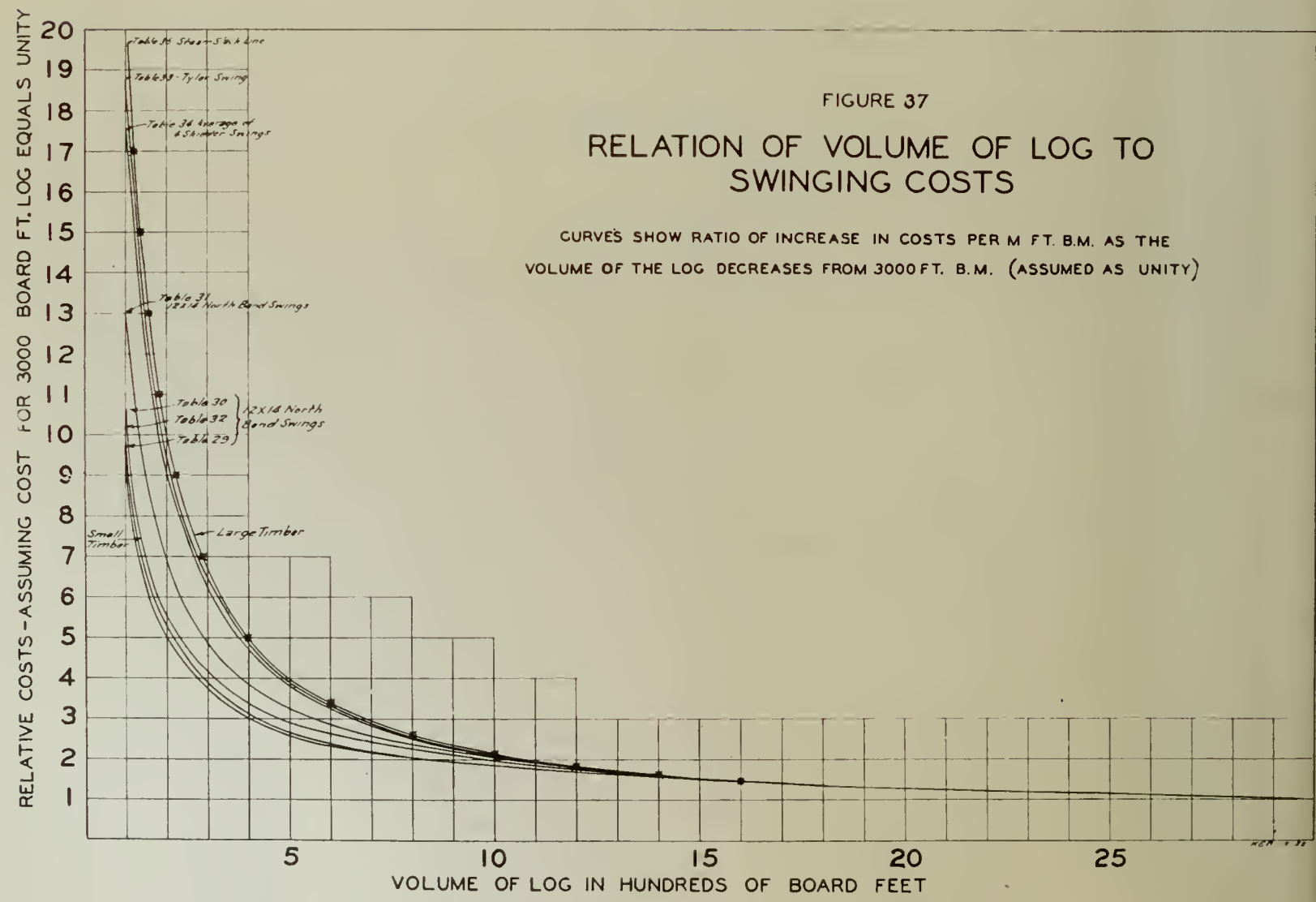




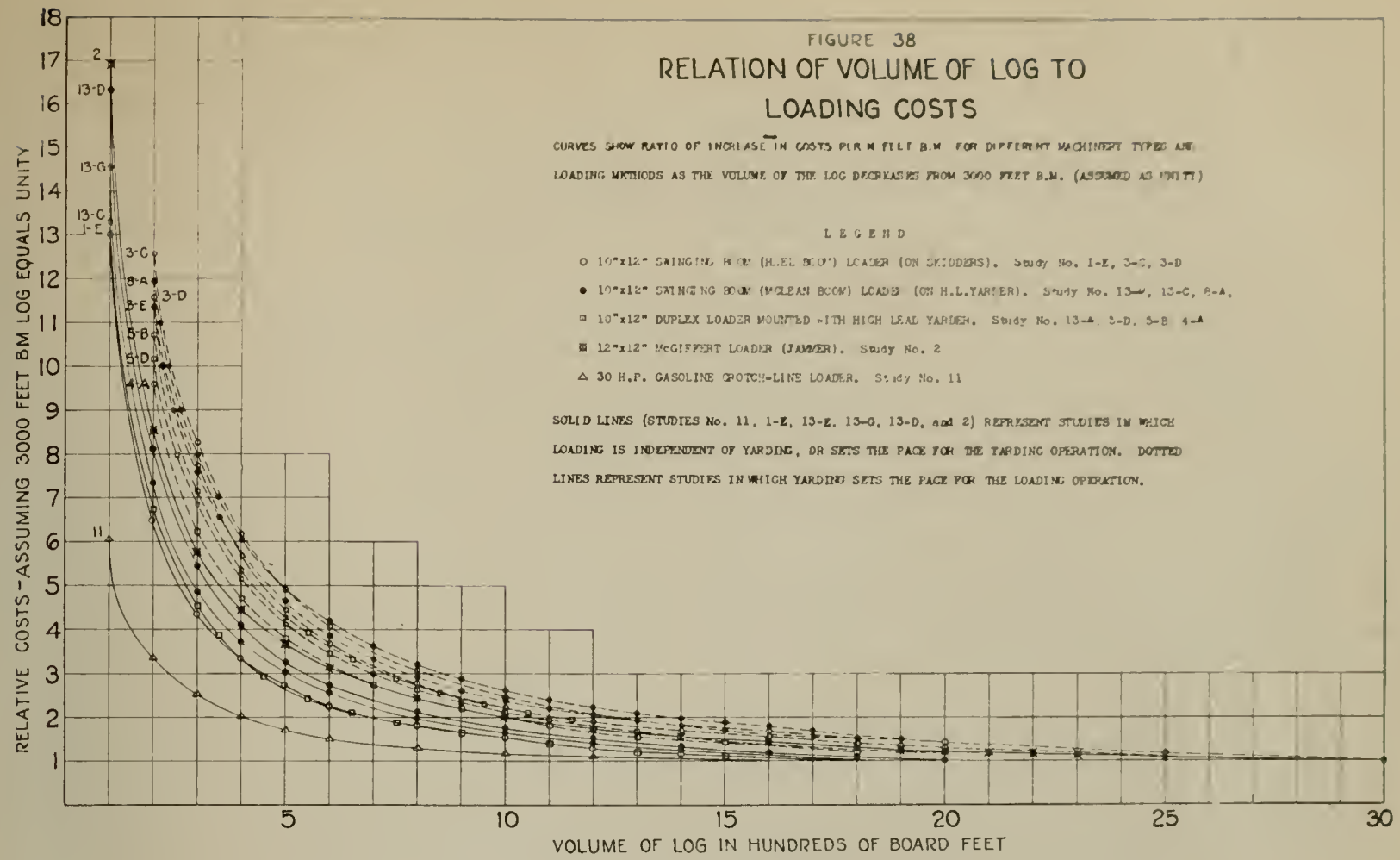

73. Summary Graph-Comparison of Typical Cost Relations Covering All Phases of Logging.In Figure 39 are shown a few representative curves which bring out the main points of the foregoing.

Curve 1, representing cost relations in yarding under typical conditions, in typical timber, using conventional logging machinery, coincides with Curve 9 in Figure 35, and represents an average log volume of 900 board feet ${ }^{3}$ as interpolated on the average log scale shown in Figure 35. The departures of other yarding curves from Curve 1 as governed by differences in average log volume and other factors are discussed in detail in Sections 68 and 69.

Curve II, representing cost relations in loading with conventional types of loading engines (100 h.p.) is in effect a center line drawn through the band of solid line curves in Figure 38.

Curve III (swinging from cold decks) represents a center line projected through the band of curves shown in Figure 37. It is comparable with Curves I and II in that it represents approximately the same average log volume (900 board feet).

\footnotetext{
"An average $\log$ of 900 board feet is approximately the grand aver age log volume dealt with in these studies, and is also approximately the regional srand average log volume.
}

Curve IV, for yarding with tractors, is identical with Curve $\mathrm{V}$ in Figure 35 . It represents (1) a log average of 360 board feet, (2) at distance of 1,000 feet, (3) very scattered timber. Other curves representing this method of yarding would be steeper in large timber, but would tend to flatten under better density conditions and at longer distances. If density conditions are good and if operating practice centers on the idea of building up maximum load rolumes. the yarding curve may swing dow toward or past Curve V.

Curve $\mathrm{V}$ represents downhill roading with tractors. This is only an assumed curve, the basis of which was discussed in Section 53. This curve virtually parallels Curve II in Figure 38 , which latter represents loading of logs on small auto trucks using a 30 h.p. gasoline hoist.

Curve VI represents the relative increase in the number of cubic feet per M feet b.m. that takes place as the log size decreases from three thousand board feet, based on 32-foot logs and a taper of one inch per 10 feet in length. This curve is introduced merely to show the absolute line of limitation, a limitation based on actual volume, and presumably, then, on weight, below which the relative cost of handling small logs can not be expected to go under any circumstances. It represents the initial basic handicap 


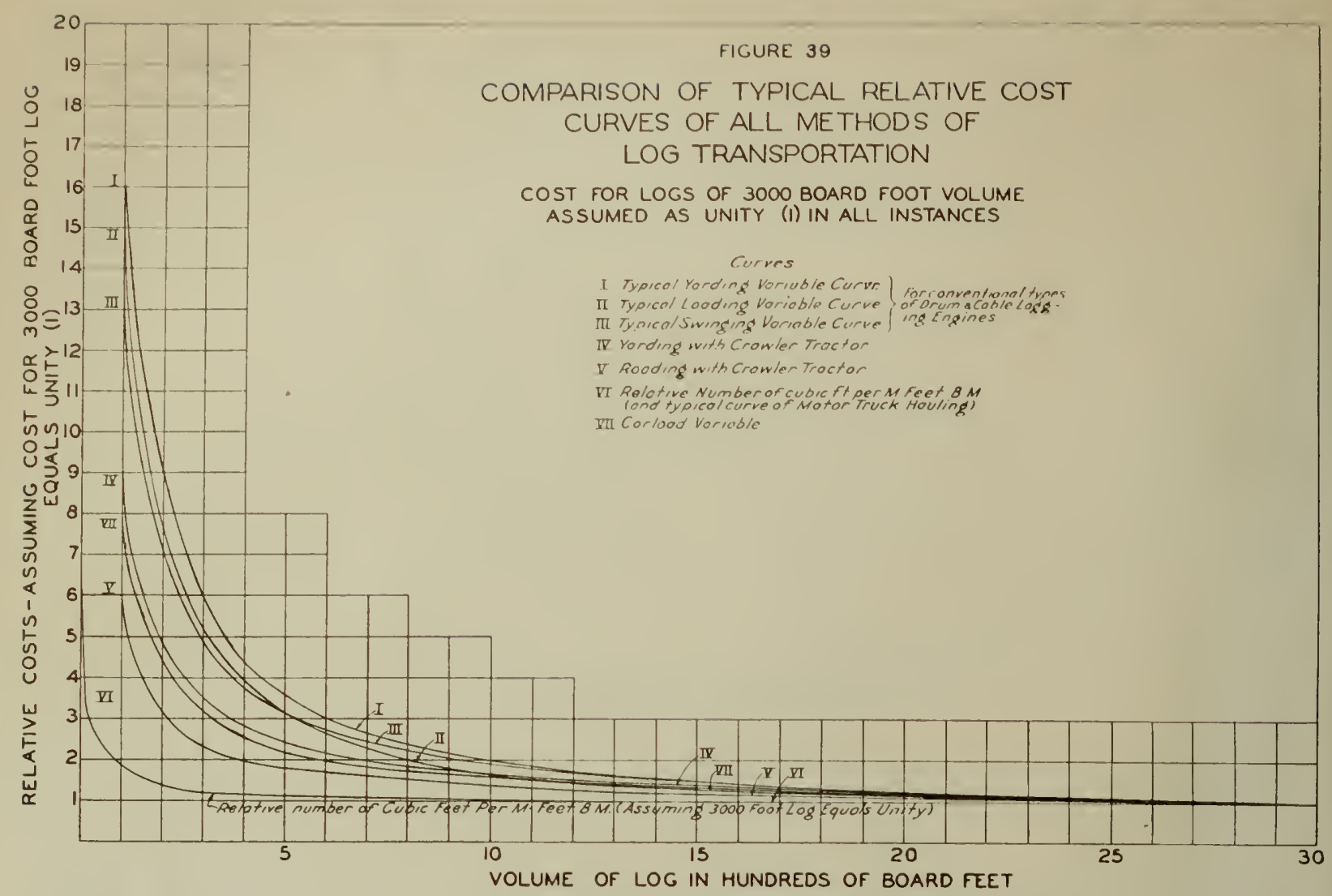

against the small $\log _{s}$ when measured in board feet based on Scribner Decimal C log rule. While a part of this initial handicap is due to the "unfairness" of the log rule itself in that it gives a much greater percentage of mill "overrun" in small logs than in large logs, it is nevertheless as real a handicap as any, if both

logging costs and log values, fairly arrived at, are based on the same arbitrary unit of measure.

The application of relative costs as represented by these curves to analysis of actual costs is taken up in detail in Chapter XVI.

\section{RAILROAD TRANSPORTATION}

74. General.-Railroad transportation is a very important element of cost in logging as carried on in the Douglas fir region. It often exceeds the current cost of yarding and loading; and represents, generally, the greater portion of the capital invested in the logging operation (timber excluded).

In a general way transportation costs are affected by variations in the size of bodies of timber, topography, density, gradients, length of haul, ground conditions, and by many other factors, too obvious for specific mention, which enter either as a part of construction or operating costs. Variations in the cost of transport- ing the average $\mathrm{M}$ foot unit of logs may, therefore, be very great in comparing one logging operation with another, and great variations may also occur in the cost averages applying to bodies of timber tributary to different spurs within a given tract.

No effort has been made in this series of studies to delve into the details behind such variations in cost along the lines followed in the foregoing studies of transportation from stump to car. The investigation is here confined to the determination of relative costs of hauling $\operatorname{logs}$ of different sizes and, later, to certain questions dealing with the allocation of so- 
called fixed costs and their bearing on different plans of operating a timber property. Other aspects of railroad transportation costs are all subject to proper solution in the hands of the logging engineer, and need not be gone into here as they have no particular bearing on the problems at hand. For information on transportation costs one may turn either to engineers' cost estimates or, in the case of a going logging operation, to actual cost records and analyze these for proper allocation of cost against the $\log$, tree, or area of timber.

75. Carload Capacity Studies.-In allocating certain items of railroad transportation costs the cost per carload enters as the basic unit of measure. It follows that the cost per $\mathrm{M}$ feet b.m. must then vary in inverse proportion to variations in the volume per load. The size of the $\log$ is the controlling factor in such variations. It becomes important, therefore, to determine the relation of size of $\log$ to volume of load (carload capacity) to provide a measuring stick for allocating costs to logs and trees of different sizes. This relationship between log size and carload capacity, and consequently between log size and cost per $M$ feet b.m. will be referred to as "the carload variable."

To throw light on these relationships a total of nine studies of carload capacity were made. the results of which are graphed in Figure 40. These are all based on gross scale per load against gross scale of the average $\log ^{10}$ in the load, except in the case of the study represented by Curve II in Figure 40-A which is based on net commercial scale. The data in the last mentioned case were obtained from scale records kept by a logging operator and cover 7,567 carloads from 54 different settings.

Four studies, the results of which are shown in Figure 40-A represent log lengths varying from 24 to 40 feet. The equipment consists of 42 -foot standard skeleton log cars. Four studies (Figures 40-B and C) represent long log operations, with logs ranging up to 108 feet in length; the equipment consists of "disconnected" steel trucks.

Much irregularity is shown in the plotted data, particularly in the case of the curves representing long log operations (Figures 40-B and $\mathrm{C}$ ). The most pronounced breaks in the trends of these curves coincide largely with variations in log lengths. The three studies in which occur carloads averaging over 3,000

"The distinction between "average log" and "individual log" has been disregarded in the carload studies. board feet per log show sharp breaks in passing from the 3,000 to the 4,000 -foot log volume, because at this point the increase in log size represents a somewhat abrupt change from long logs obtained from medium-sized trees to a greater proportion of short butt logs of large diameter. However, a break in the trend of the curves may be expected in the large log sizes whether or not variation in log lengths enters the case. The reason for this is that the increase in carload capacity represents a rather gradual stepping down in the number of logs per car until the "six-log load" has been reached, after which a somewhat sudden drop to the "three$\log$ load" will take place. This break in the trend of the curves in passing from 3,000 to 4,000-board foot log volume is in sharp contrast to the uniform straight line trend that follows in the still larger sizes. These straight lines represent "three-log loads." They point directly toward zero.

A comparison of the smoothed curves is given in Figure 40-D. A rather wide spread is noted in carload volumes for studies representing log lengths from 24 to 40 feet, although the same type of equipment (42-foot skeleton cars) is used in each case. This spread is due primarily to differences in (1) average log lengths, (2) taper and roughness of the logs, (3) the care with which loads are built up.

76. Relative Costs for Logs of Various Sizes.In Table 41 are shown relative costs of hauling logs of various sizes, derived from corresponding variations in carload capacity. The cost per car is assumed to be fixed; hence, costs will vary in inverse proportion to variations in load volume. In each study the cost of hauling logs of 1,000 board foot volume is rated at 100 ; costs for other log volumes being expressed as percentages of the assumed base of 100 .

Relatively little variation frorii one operation to another is noted in the percentage costs so derived; that is to say, variation in $\log$ size has virtually the same relative effect on costs in all cases, although actual load volumes differ widely from one operation to another.

In the last columns to the right in Tabie 41 are shown average cost percentages for the six columns listed. These percentages recalculated to a base cost of unity for the 3,000 board foot $\log$ size, have been used in plotting the carload variable curve (Curve VII) in Figure 39. 


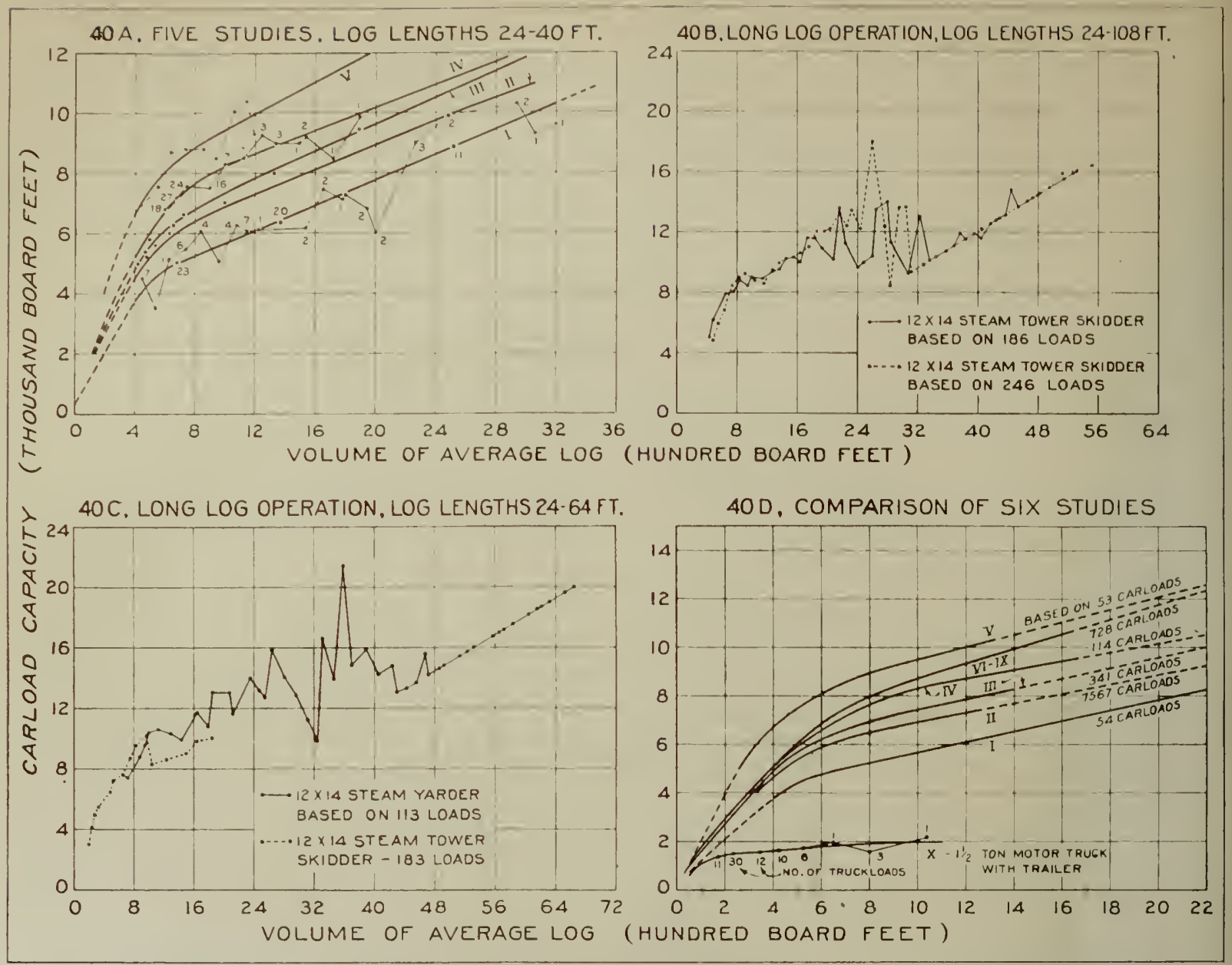

FIG. 40-RELATION OF VOLUME OF LOG TO CARLOAD CAPACITY. A. STUDIES OF LOG LENGTHS $24.4 O$ FEET. 42 FOOT SKELETON CARS. B. STUDIES OF LOG LENGTHS 24 TO 108 FEET, DISCONNECTED TRUCKS. C. STUDIES OF LOG LENGTHS, 24 TO 64 FEET, DISCONNECTED TRUCKS. D. SMOOTHED CURVES, ALL STUDIES.

\section{TABLE 41}

Relative costs of transporting logs of various volume assuming cost for 1,000 board foot log equals 100;

based on nine opcrations using unstaked cars

Volume Relative Costs Per Cent-

of Loglengths from 24-40 feet Long Average

average ${ }_{42-f o o t}$ cars-5 studies- $\longrightarrow \log \mathrm{s}^{2}$ of

log Curve Curve Curve Curve Curve Curve Curves

boardft. $I^{1} \quad I^{1} \quad I I I^{1} \quad I^{1} \quad V^{1} \quad V I^{1} \quad I-T^{1}$

$\begin{array}{rrrrrrrr}3,000 & 56 & 64 & 62 & 66 & 64 & 59 & 62 \\ 2,500 & 63 & 70 & 69 & 72 & 70 & 65 & 68 \\ 2,000 & 72 & 78 & 77 & 79 & 78 & 74 & 76 \\ 1,600 & 81 & 86 & 85 & 87 & 85 & 82 & 84 \\ 1,200 & 92 & 95 & 95 & 95 & 94 & 94 & 94 \\ 1,000 & 100 & 100 & 100 & 100 & 100 & 100 & 100 \\ 800 & 108 & 106 & 107 & 109 & 106 & 109 & 108 \\ 600 & 119 & 119 & 121 & 126 & 115 & 128 & 121 \\ 500 & 130 & 130 & 132 & 141 & 125 & 143 & 134 \\ 400 & 151 & 150 & 154 & 166 & 140 & 174 & 156 \\ 300 & 187 & 192 & 195 & 202 & 174 & 218 & 195 \\ 200 & 267 & 265 & 274 & 277 & 241 & 311 & 272 \\ 100 & 467 & 431 & 462 & 488 & 448 & 544 & 473\end{array}$

${ }^{2}$ Curve numbers refer to Figure 40-D.

${ }^{2}$ Average of four studies.

\section{Effect of Volume of Load on Cost per Car-} load.-

The cost relations derived in Table 41 rely on the assumption that variations in the volume of the load have no effect on the cost per carload, excepting loads which exceed a fixed maximum volume. In cases involving adverse grades, this assumption may be considerably in error. Three general cases might be recognized:

(1) Hauling on grades favorable to the load;

(2) Hauling on virtually level grades;

(3) Hauling on adverse grades.

In the first case, which is the most typical one for operations in this region, the volume of the load has obviously no practical effect on cost per car, since the hauling capacity or traveling speed of the locomotive is not controlled by the load factor.

In the second case one would expect that variation in load volume will have a more noticeable effect on hauling speed or on the number of cars which a locomotive can haul. Actually, however, the effect is "ather slight, because as the weight of the pay load increases the rolling resistance (which is the only factor to overcome on level grade) per ton of gross weight decreases substantially. In a recent article 11 it

"Bulletin issued April, 1932 by The Pacific Northwest Advisory Board, American Railway Association, Car Service Division. 
is thus disclosed that according to tests made by common carrier railroads, freight cars loaded to a gross weight of 70 tons per car gave a rolling resistance of only 4.53 pounds per ton, compared with 8.04 pounds per ton when reduced to 30 tons; and that a locomotive capable of moving 4,200 tons gross train load on a level track with cars loaded to 70 tons would move only 2,370 tons gross train load if the cars were loaded to only 30 tons gross weight per car.

In the third case, gravity resistance causes a more pronounced increase in cost per car with increase in weight of pay load. This, however, is not in direct proportion to the weight of pay load because the dead weight of the car is a constant, and reduced rolling resistance again favors increasing pay load weight. Furthermore, increase in pay-load weight is less rapid than increase in board-foot volume because volume translates into weight on a sliding scale represented by the cubic-foot to board-foot variable as shown in Figure 60 (Curve VI). If adverse grades are confined to short hauls on spurs and do not affect the length of trains subsequently handled in mainline hauls on favorable grades, pay-load volume may not be a very important factor; but on adverse grades that are steep enough and long enough to influence the hauling capacity or speed of the locomotive, the cost per car is materially influenced by volume of pay-load.

It may be concluded that a carload variable curve predicated on a fixed cost per car irrespective of load volume, needs no correction if grades are favorable. A very slight downward swing of the curve, perhaps not over 10 per cent at the 100-board-foot log size, will take care of an operation having virtually all roads on level grades $\mathrm{or}^{*}$ an operation having mostly favorable grades on the main roads with adverse grades confined largely to spurs. A more substantial adjustment of the curve would be in order if the mainline haul is largely over adverse grades. It may be computed from data in load weight and hauling capacity of locomotive.

78. Items of Cost Which Are Governed by the Carload Variable.-The importance of the carload variable curve depends largely upon what portion of transportation costs properly should be classified under this heading. Among items of cost which most clearly belong to the carload variable are:

(1) Common carrier freight costs, based on a flat rate per carload ${ }^{12}$.

Flat rates per carload paid for "running rights" over common carrier tracks obviously fall in the same category, except that the volume of the load may affect operating cost per car as discussed in the foregoing section.

(2) Car maintenance costs.

Other items of railroad operating costs may be more or less directly related to the carload depending upon the extent to which they are dependent on variations in the number of cars loaded out each working day at the landing. Among such items are:

(3) Train-operating costs, other than car maintenance.

12Since the log carriers in this region recently changed the rate basis from a fixed cost per II feet b.m. to a fixed cost per car, this item has become a most important part of carload variable costs in opera. tions which ship by common carrier railroads.
(4) Road-bed maintenance other than that caused by weather and time.

(5) Unloading costs.

(6) "Incline" operating costs.

The cost of operating a logging incline where each trip consists of lowering one carload of logs would be a good example of an item of cost that should faithfully reflect the carload variable curves, provided that the trip by trip schedule is not upset by the effect of the yarding variable. The same thing would apply to train operation, road maintenance, and unloading, provided that each trainload consists of a fixed number of cars. Train operation over logging mainlines may often approach this situation.

79. Variations in Yarding Costs May Control Variations in Railroad Transportation Costs.-As a rule, operation of a logging railroad is not an independent activity. It is set up to serve the varying needs of the yarding-swinging-loading operation and cost relations may be affected accordingly. A comparison shows that the effect of increasing log size on the yarding-swingingloading output is not taken care of fully by the corresponding increase in carload capacity; therefore, as the size of the log increases, there results not only an increase in volume per carload, but also an increase in number of carloads produced per day. With this, there follows a reduction in the cost per carload, because railroad operating facilities and capacity, which ordinarily are designed to take care of regularly recurring high production days are utilized most efficiently when high production is obtained.

The extreme case occurs if railroad operating costs (excluding car maintenance) are fixed per working day irrespective of daily variations in the number of carloads. In this case the carload variable is obviously wiped out entirely, being superseded by the yarding-swinging-loading variable. The cost of operating a switching locomotive on spurs is quite often of this character. In some logging operations the same thing may apply for all practical purposes to railroad operating costs as a whole. In other operations a split-up of the carload variable may be in order. The question of which items of cost, or what percentages of such items of cost should be shifted from the carload variable to the yarding variable must, of course, be decided separately for each case. 
80. Staked Cars Show Increased Load Capacity for Small Logs.-The prevailing practice in this region in logging operations which operate over their own railroads to pond or market is to transport the $\operatorname{logs}$ on cars without side stakes, while in many other regions the use of stakes is standard practice. The above data on carload capacity and relative costs apply to unstaked car's.

In using staked cars the height and width of the load becomes fixed irrespective of variations in $\log$ size. Through the use of unstaked cars, on the other hand, there results a gradual decline in the height and width of the loads with decreasing size of logs. This is an important factor which contributes to the relatively sharp decline in carload capacity with decrease in the size of the logs. Other contributing factors, which are common to both staked and unstaked car's, are that as the size of the log decreases (1) cubic volume increases in relation to board foot scale, (2) the relative amount of wasted space within the load increases owing to increasing effect of knots, crooks, and other irregularities which multiply with decreasing size and increasing number of pieces in the load.

In these studies no data pertaining to cost relations as applicable to staked cars have been collected. They may, however, be assumed to fall at some point near the half-way mark between the cubic foot to board foot and the carload variable curves (see Figure 39 ).
81. Use of Staked Cars is Impracticable Under Clear-Cutting System.-In timber typical of this region the use of staked cars for small logs is generally impracticable under the present system of donkcy logging. Logs of all sizes arrive at the landing, and most of them can be transported most economically on unstaked cals. Intermittent staking (by hand) and "wiring" of cars under these conditions may interfere with the yarding operations, calls for a great deal of sorting of logs on the landing, and may not bring any noticeable reduction in daily train operating costs because the latter generally can not be adjusted from day to day in direct response to variations in the number of cars produced. The really profitable use of staked cars for small logs in this region requires uniformity in $\log$ size over long enough periods of time to allow the proper balancing of railroad transportation facilities and capacity with yarding capacity; or else an expensive haul to pond or market, as, for example, in the case of operators who ship their logs over common carrier railroads.

It is important in this connection to recognize clearly that the practicability of using staked cars for small logs in this region hinges largely upon the method of cutting that is used; although impracticable in most cases under the clear-cutting system, it will not necessarily remain so under a selective system of cutting that creates uniformity in $\log$ sizes irrespective of the range in log sizes in the stand as a whole. To this question further attention is given in Chapter XX.

\section{MOTOR TRUCK TRANSPORTATION}

82. Relation of Log Size to Load Volume and Hauling Cost.-In this series of studies only one study was made of relative truck load capacity for logs of different sizes. The results (Figure $40-\mathrm{D}$, Curve $\mathrm{X}$ ) indicate that the increase in board-foot volume of the load with increasing $\log$ size corresponds roughly to the decreasing ratio between cubic feet and board feet. That is to say, the cubic foot contents and hence the weight of a load of small logs is about the same as for larger logs. The same condition is noted by Rapraeger from whose report ${ }^{13}$ Table 42 is taken.

\footnotetext{
${ }^{13} \mathrm{E}$. F. Rapraeger, "Motor Truck Log Hauling in Oregon and Washington," The Timberman, Vol. XXX1V, Nos. \& to 11, 1933.
}

TABLE 42

Relation between the number of logs per auto-truck load and their volume expressed in board feet and cubic fect ${ }^{1}$

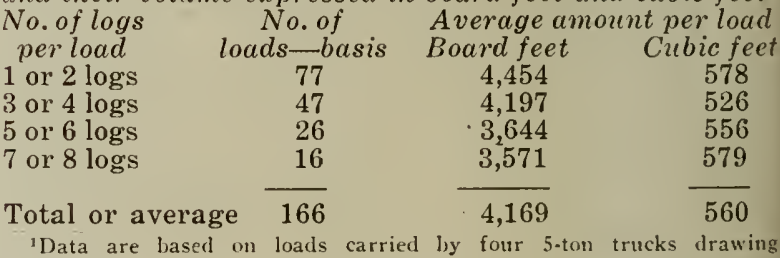

${ }^{1}$ Data are based on loads carried by four 5-ton trucks drawin railers.

This is the only method of log transportation covered in these studies in which the relative cost of transporting small logs reaches the theoretically attainable minimum as represented by Curve VI in Figure 39. 
The reason is obvious. Motor trucks equipped with log bunks and trailers usually provide sufficient room for as heavy a load as the truck can be and generally is made to carry, even if the logs are very small. The weight of the load can be judged reasonably close by "sizing up" the $\operatorname{logs}$, or by watching the deflection of the springs on truck and trailer. When large logs are loaded the dimensions of the load are smaller. This is the reverse of the practice followed in loading unstaked railroad cars, where large logs producs wider and higher loads than small $\log s$.

83. Truck Hauling Costs for Various Distances.-From the above-quoted report by Rapraeger is taken Table 43 showing hauling cost for various lengths of haul up to 30 miles. The data apply to 3 -ton trucks with trailers and are based on a machine rate covering truck and driver varýng from $\$ 15.22$ per day for a daily travel of 40 miles to $\$ 25.96$ for a daily travel of 100 miles.

TABLE 43

Cost of hauling over various distances, ${ }^{1}$ expressed in dollars per thousand board feet ${ }^{2}$

Number of (3-ton motor truck drawing trailer)

\begin{tabular}{|c|c|c|c|c|c|c|c|c|}
\hline trips per & 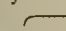 & & -Lens & $h$ of & $a u l i$ & miles & & \\
\hline $8-h r \cdot d a y$ & 2 & 4 & 6 & 8 & 12 & 16 & 20 & 30 \\
\hline 11 & 0.45 & $\ldots$ & .... & ....... & ....... & & $\ldots$ & \\
\hline 10 & .47 & & .... & ........ & $\ldots .$. & ....... & $\ldots$ & -- \\
\hline 9 & .49 & 0.71 & & & & & & \\
\hline 8 & .58 & .75 & 0.97 & & & $\ldots$ & ...... & $\ldots$ \\
\hline 7 & .57 & .79 & 1.01 & 1.23 & & ....... & $\ldots$ & . \\
\hline 6 & . & .85 & 1.07 & 1.29 & & & & \\
\hline 5 & & .93 & 1.15 & 1.37 & 1.81 & 2.25 & & \\
\hline 4 & -...... & $\ldots$ & 1.28 & 1.50 & 1.94 & 2.38 & 2.82 & \\
\hline 3 & ....... & ...... & ........ & 1.70 & 2.14 & 2.58 & 3.02 & 4.12 \\
\hline 2 & -..... & ........ & -..--. & $\ldots$ & $-\ldots .$. & 3.00 & 3.44 & 4.54 \\
\hline 1 & $\ldots$ & $\ldots$ & ..-..- & $\ldots$ & $-\ldots . .$. & -.. & $\ldots .$. & 5.77 \\
\hline
\end{tabular}

The ttalic figures indicate normal costs.

The above data apply to hauling on good roads, principally on public highways. Hauling costs, based on eleven operations hauling over poor and/or steep, privately built roads, with lengths of haul varying from two to six miles, average roughly as follows:

$$
\begin{aligned}
& \text { 2-mile haul- } \$ 1.00 \text { per } \mathrm{M} \\
& \text { 4-mile haul- } \$ 1.50 \text { per } \mathrm{M} \\
& 6 \text {-mile haul- } \$ 2.00 \text { per } \mathrm{M}
\end{aligned}
$$

All cost data exclude road building and maintenance costs.

84. Comparison with Tractor Roading and Railroad Transportation.-About 7 per cent of the log output of this region is at the present time hauled directly to mill or market by truck. Hauls of 20 to 30 miles are not uncommon. One instance is recorded where logs are trucked over a distance of 56 miles. The average haul is approximately 11 miles.
Convenient access to public highways is in most cases a prerequisite to profitable truck haul over these relatively long distances, because in spite of the rapid development of motor trucks, the typical logging railroad operation when operating at normal capacity is still far in the lead as far as actual hauling efficiency is concerned. This is indicated roughly by the comparative costs listed in Table 49 , Chapter XVIII, which show that hauling by rail, disregarding road amortization costs, amounts to only from one-half to one-fourth of corresponding costs for motor trucks. In most cases, therefore, it is only through drastic reduction of road amortization and maintenance costs that the motor truck can compete successfully with the logging railroad. This saving is exemplified best, of course, by public highways, for the use of which a nominal fee is paid, but even where logging truck roads must be built it may in many cases be attained, though in less striking fashion, through lowered construction costs and reduced distance of haul owing to the greater flexibility in grades and alinement permissible in truck roads.

The total volume of timber to be hauled, daily volume of production, and distance of haul are obviously controlling factors in any comparison between the two methods. High efficiency in motor truck operations can often be attained best in cases in which the required daily output is relatively small while high operating efficiency in railroad operations generally presupposes a high daily output, below which operating efficiency generally decreases quite rapidly.

The use of motor trucks as feeders to a railroad operation, instead of as a complete substitute therefore, has many possibilities that come to the fore particularly in conection with the proposed tractor roading system heretofore discussed. Compared on the basis of hauling costs (as distinct from hauling and road construction costs combined) the motor truck, as shown in Table 49 , is relatively as far ahead of the crawler tractor as the railroad is ahead of the truck. In both cases, however, that method of hauling which offers lower operating costs is accompanied by higher construction costs and is furthermore restricted by more exacting specifications as to grades and curvature. Harling by motor truck, compared with roading by tractor. is furthermore handicapped by the cost of loading; a handicap that is usually severe enough to exclude it from consideration for distances of less than one mile. For roading distances 
over one mile, however, there would seem to be considerable opportunity to substitute trucks for tractors: and in cases in which such substitution is feasible the operating radius of this method may, if desired, very well be extended to several miles, since the cost of hauling for each additional mile is relatively low (about $\$ 0.25$ per M feet b. m.per mile on rough or steep loads compared with about $\$ 0.95$ for roading with tractors). This is an important point to baar in mind in devising operating methods that will provide maximum freedom of selection in logging without sacrifice of operating economy. To this end it is obviously advantageous to develop methods which tend to reduce road construction and similar costs which are "fixed" against the area developed. The tractorroading system by providing low-cost long-distance yarding, was shown to be an important step in this direction, since it calls directly for a drastic sleletonization of the railroad system. The motor truck carries the same idea into distances far beyond the point where the tractor loading method ceases to be effective. The significance of this may not be so great for carrying on the present clear-cut system of logging as for carrying on the lighter cuttings demandcd under sustained yield management in a selection forest.

\section{WATER TRANSPORTATION}

85. Low Cost of Water Haul.-Stream driving is a neglected art in the Douglas fir region, but towing on lakes, rivers, and protected bodies of salt water is common. The items properly included in this type of transportation are booming and rafting, boomstick expense, towing, and depreciation of equipment. Folowing are the costs in a typical operation which tows varying distances up to about 30 miles.

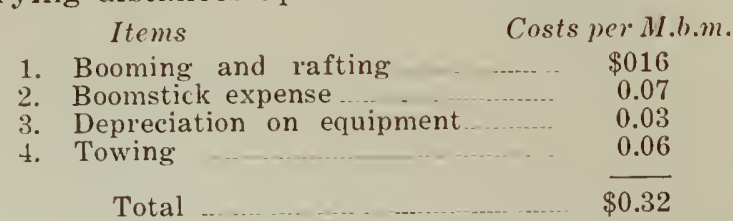

These figures confirm the well known fact that water transportation is by far the cheapest method of transport. Comparison of methods in Table 49 shows cost relative to other methods.

86. The Relation of Volume of Log to Cost of Booming and Rafting.-No field studies have been made of cost relations applicable to booming and rafting, but general evidence indicates that the carload variable will roughly apply to a large portion of these costs, except as superseded by the yarding variable in the same manner as the loading and railrcad hauling variables heretofore discussed.

In support of this assumption it may ba pointed out that most of the costs involved in booming and rafting (as an independent operation) are to a large extent fixed per raft (or section of raft), which represents one layer of logs spread over an area of fixed width and length, with depth varying with the diameter of the individual log. With costs fixed per raft, the costs chargeable against individual logs of different sizes will vary with variations in log scale per unit of surface area in the raft. The diameter of the $\log$ is the controlling factor here.

According to this one finds, for example, that a $\log$ nine inches in diameter yields approximately 3 board feet per square foot of log surface area in the raft; for a $l o g$ of thirteeninch diameter, this rises to 5 board feet; at 21 inches, to 10 board feet; at 26 inches, to 14 board feet; for 37 inches, to 20 board feet; for 46 inches, to 25 board feet; etc.; all based on $\operatorname{logs} 32$ feet long with an allowance of one inch taper per ten feet of length. Expressed as a percentile cost, this shows approximately the same trend as the carload variable curve shown in Figure 39. Allowing further that the percentage of waste space in a raft will increase with decrease in the size of the log, the trend of the "booming and rafting variable" would become still steeper. In view of this it seems reasonable to assume that booming and rafting costs follow the carload variable.

The cost of towing may or may not conform to the same approximate laws of variation. If rafts were towed only over short distances, or moved down stream or with favorable tides, there would be little reason for distinction between towing costs and booming and rafting costs insofar as cost relations are concerned. On the other hand in the case of long-distance towing upstream, or in still water, towing costs will undoubtedly be affected by the size of the logs in the raft. Cost relations would tend to approach the cubic foot to board foot variable. 
87. Relation of Diameter of Tree to Felling ad Bucking Costs.-Felling and bucking are imortant phases of any logging operation, not nly because they comprise a considerable porion of the cost of logging, but because the way n which the timber is handled controls to a onsiderable degree the profitableness of the peration.

The cost of log making varies with the size $f$ the timber, as was shown by Rapraeger and pelman ${ }^{14}$. They found the cost of making a housand board feet of logs from 20-inch Dougas fir trees was double that for 58-inch trees. 'rees smaller than 20 inches would have a still igher production cost as evidenced by the rate f change of the curves in Figure 41, which are eproduced from the published report. Graph 1 of Figure 41 is based on stop-watch obserations of the felling and bucking of 300 ouglas fir trees and Graph B of 211 western iemlocks.

In the Douglas fir region felling and bucking done in many cases under a piece-rate system t a flat rate per thousand board feet. Super-

${ }^{14} \mathrm{E}$. F. Rapraeger and Howard R. Spelman, 1931, "The Effect of ree and Log Size on Felling and Bucking Costs in the Douglas Fir egion." U'est Coast Lumberman 58 (13):20-23, illus, ficially this system would seem to disregard the effect of $\log$ or tree diametor on cost. Actually, however, it implies balancing low production from small trees with high production from larger trees so that on the average tha contract fellers and buckers can earn a satisfactory wage. If fair balance between high and low production trees were not maintained, th 3 rate per thousand would be changed, since it is derived in the first place by dividing the average wage desired by average output in average timber The high cost of small trees and low cost of large trees are therefore implicitly reflected in the rate itself just as if a sliding scale of pay were used in which each tree or log size were to be paid for at a different rate, according to tha variations shown, for example, in Figure 41. But instead of actually so showing it on the books when computing the earnings of the workmen, these variations are all taken care of in the field by relying on the law of averages and bull-bucker to see that each man or crew gets a fair sampling of large trees and small trees or of difficult conditions and easy conditions so that the flat rate will work out fairly in the long run.
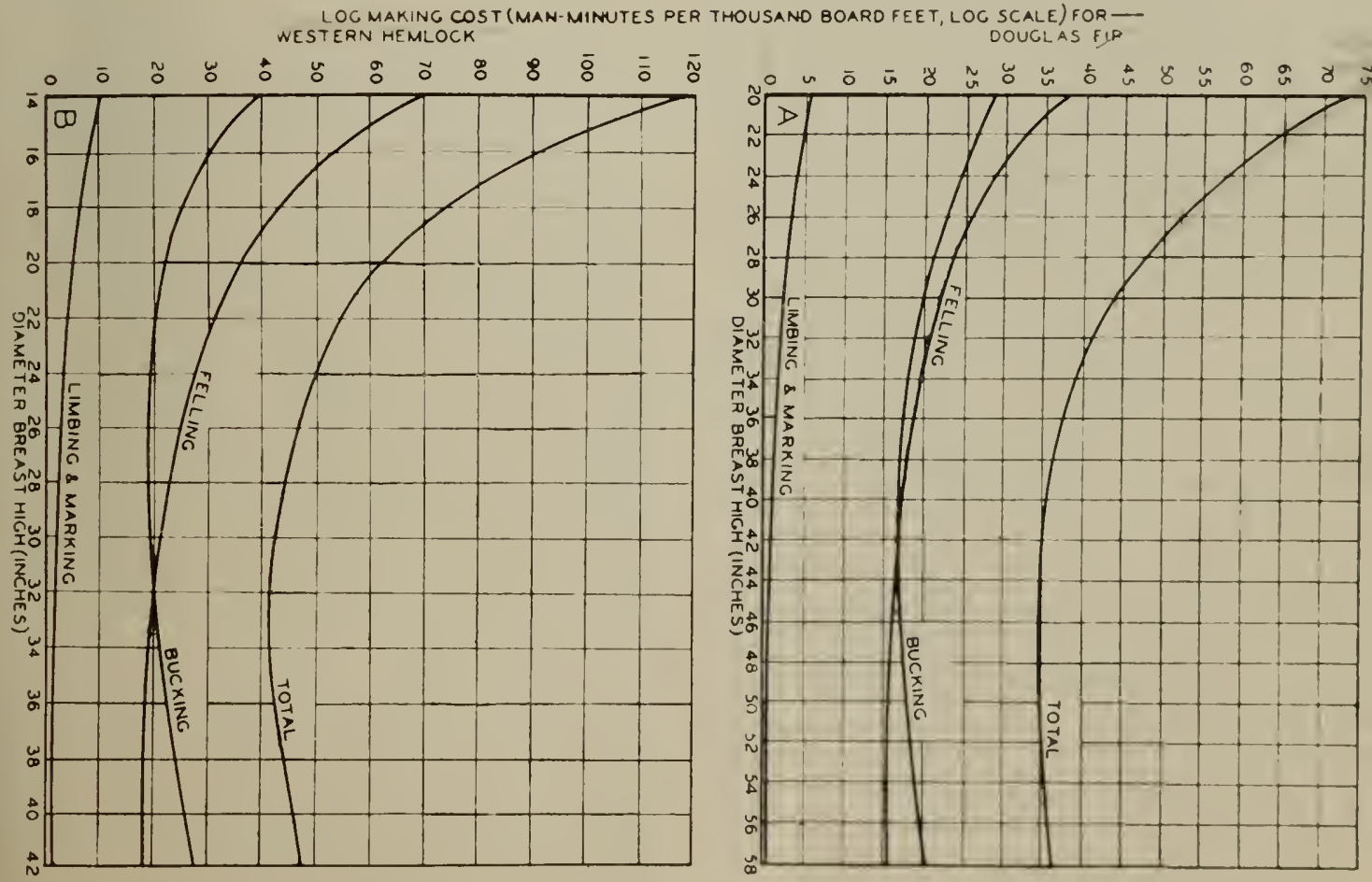
88. Consistency Shown in the Relations of Log and Tree Size to Logging Cost.-In the foregoing it has been shown that in any given logging operation there are certain elements of cost which are fixed and others which are variable. The principal variables governed by size of timber, which is by far the most potent factor affecting costs, are the felling and bucking variable, the carload variable, and the yarding (loading, swinging, roading) variable. Of these, the felling and bucking variable is subject to only slight changes which may be predicted from data on tree form and log lengths. The carload variable, as demonstrated in Table 41 , is likewise subject to only slight changes for any given type of equipment, and may be analyzed from itme to time from carloading records. Even in the case of the yarding variable, which shows a distinctly different trend for tractors from that for drum and cable machinery, and a considerable variation with different types of drum and cable machinery and different yarding shows, the results obtained in different studies agree closely, if a rough classification is made of average size of timber and general type of machinery (see Figure 35 ). The conclusion is eminent, therefore, that in any given logging operation, where conventronal clear cutting is practiced, and where machinery and size of timber are known factors, the variables once established for that particular operation may subsequently be applied with a fair degree of assurance that they are not likely to fluctuate very widely from the established trends. They are, as demonstrated by the great number of studies here reported, consistent enough so that if intelligently interpreted, and modified as needed to meet current changes in the logging show, they may be used as the final word in the allocation of costs, not in the belief that they are instruments of precision, but because they represent as close an approximation as it is practicable to make.

89. Application of Relative Costs to Complete Cost Analysis of Operating or Non-operating Timber Properties.-With the variable accepted as representing basic cost relations the next step is to translate these into costs. In the yarding timestudy tables this was done by setting up machine rates for purposes which have been explained. The machine-rate method, however, becomes very cumbersome, if applied to every phase of the logging operation, and does not readily lend itself to current analysis of a log- ging operation as a whole. A simpler and more effective method is to turn directly to cost averages as dealt with in the ordinary form of logging cost statements (Table 49), and by proper segregation of cost items determine the averages applicable to each cost variable, as well as to fixed costs. Whether it be a case of analyzing costs in a going operation or of estimating costs for a non-operating timber property, one may thus deal with the actual cost level in the same identical manner as in present timber appraisal practice. One deals first with the cost averages as determined in present practice and second, with the cost variables for the purpose of allocating costs to logs or trees of various sizes.

90. Analysis of a Logging Cost Statement.-An example will best serve to show the method of cost analysis that may be applied to a going operation, where authentic cost records are available. The cost statement in Table 44 applies (with a few minor changes in classification) to one of the operations in which carloading, yarding, and loading studies were conducted.

It is further ascertained that:

(1) The log freight of $\$ 0.583$ is a derived cost, actually based on a flat carload cost.

(2) The average log scales 850 board feet net scale; 3 per cent average defect deduction.

(3) The investment tied up in the operation groups as follows:

$\begin{array}{llr}\text { 1. Logging machinery } & \$ 100,000 \\ \text { 2. Locomotives and rolling stock } & 120,000 \\ \text { 3. Unamortized mainline construction } & 40,000 \\ \text { 4. Steel rails for spurs } & 25,000 \\ \text { 5. Camp buildings, machine shop. } & 20,000 \\ \text { 6. Liquid working capital } & \end{array}$

The above cost statement carries sufficiently detailed cost segregations to allow a fairly complete analysis to be made. To do so, however. requires a re-classification of the various cost items whereby items identified with variable and fixed cost activities may be brought together into the proper groups. This is shown in the following table (Table 45).

A reclassification of costs from a company' cost statement is often rather difficult to make. Often detail is lacking or the segregations used apply to more than one of the re-classified groups without anything to guide in making a clear cut distribution. Most of the items listed in Table 44, however, are in this case so labeled as to be easily identified with one or the other 
of the five groups listed in Table 45. A few items, namely, industrial insurance, equipment insurance, supervision, machine shop, and fire protection, belong to more than one group and so appear more than once in Table 45 . In addition to this a split-up has to be made of costs identified with yarding and loading in order to segregate yarding-variable costs from roadchanging costs. The allocation of 84 per cent to the yarding variable and 16 per cent to fixed per acre costs (Item 37) is based on data secured through time studies.

\section{TABLE 44}

Detailed Stutement of Logging Costs per M Feet b.m. Jamuary-June, 1.931

(Interest and Taxes not Included)

Woods Costs

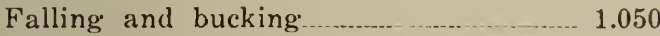

Spur construction …...................... 1.050

Rigging ahead .131

Yarding and loading ........................ 1.390

Wire rope 298

Fuel and supplies .181

Total woods costs

$\$ 4.100$

Camp Overhead

Foreman and clerks _........ 0.054

Maintenance camp buildings _............. 0.034

Camp shop

0.042

Total camp overhead

0.130

Railroad operation

Speeder operation-hauling crew__ 0.052

Maintenance, main lines.

0.082

Maintenance, spurs

0.018

Maintenance, logging cars

0.180

Depreciation, main line

0.304

Train operation, main line

0.400

0.242

Woods train operation

0.082

Total R. R. operation

Geemeal Logging Extpense

0.074

Engineering

0.190

Office Expense

0.050

Check scaling

0.064

Sales scaling

0.018

Industrial insurance

0.157

0.040

Insurance-equipment

0.128

Fire protection

0.063

ues and subscriptions

0.583

0.025

Unloading

0.168

Depreciation, logging equipment

0.180

Headquarters shop
TABLE 45

Re-cluseificution of Costs from Tuble 4t.

(Interest and Taxes Not Included)

Gromp I.-Fixed jeer W feet h.m.

1. Dues and subscriptions

(1).0fi:?

Group, II-The Carloud Varioble

A. Current Costs

2. Sales scaiing

0.018

3. Check scaling

0.064

4. Unloading

5. Log freights

0.025

0.58 .

7. Mainline maintenance 0.082

8. Maintenance of logging cars. $\quad 0.180$

9. Maintenance of spurs ... 0.018

10. Headquarters shop $(50 \%)$

11. Prorated industrial insurance $\quad 0.020$

B. Annual Costs

12. Depreciation of equipment 0.082

13. Insurance of equipment $\quad 0.015$

Group total

Group III-The Yarding Variable

A. Current Costs

14. Yarding and loading _.... . $\quad 1.390$

15. Wire rope and rigging 0.298

16. Fuel and supplies 0.180

17. Camp shop 0.042

18. Woods foreman and clerk 0.054

19. Speeder operation (crew) $\quad 0.052$

20. Woods superintendent $(50 \%) \ldots 0.037$

21. Woods train operation 0.242

22. Fire protection (30\%) 0.038

23. Office expense $\quad 0.050$

24. Headquarter's shop $(50 \%) \ldots 0.090$

25. Prorated industrial insurance .. 0.067

B. Annual Costs

26. Depreciation of equipment_a.... 0.168

¿7. Insurance of equipment _...... 0.025

28. Maintenance camp buildings 0.034

$\begin{array}{rr}\text { Group total } & 2.767 \\ \text { 29. Less } 16 \% \text { to Group V } & 0.443\end{array}$

Net Total

Goues IV-Felling and Bucking I'ariable

30. Felling and bucking ....__ 1.050

31. Prorated industrial insurance $\quad 0.035$

Group total $\quad-1.085$

Group V-Fixed P(') Acre Costs

32. Mainline depreciation

0.301

33. Engineering $\quad 0.190$

34. Spur construction $\quad 1.050$

35. Fire protection $(70 \%) \quad \ldots .0 .090$

36. Rigging ahead .... 0.130

37. Road changing- $16 \%$ of Group III $0.443^{1}$

38. Woods superintendent $\left(500_{0}^{\circ}\right) \ldots 0.037$

39. Prorated industrial insurance _- 0.035

Group total _... 2.276 
The cost averages applying to the three variables, Groups II, III, and IV, represent the weighted averagc cost of handling logs of different sizes, the average volume of which is 850 board feet. The weighted average cost applying to two distinctly different size classes of logs does not coincide preciscly with the cost applicable to the corresponding "sorted" log size; and the farther two log sizes are apart, the greater becomes the difference between the "sorted" cost and the weighted average cost. The reason for this is that the weighted average derived from points located on a curve falls inside the curve. The sharpness of the curve and the percentage distribution of log sizes spreading on either side of the average size, will determine in this case the actual position of weighted average cost in relation to the cost corresponding to the sorted log size, the latter cost being a point located on the curve. In order to translate the weighted average cost to "sorted" costs for different tree or log sizes, it is necessary, therefore, first, to determine the quantities or percentages of total rolume, in each size class, and then to multiply these by the relative costs read from the cost relation curve applicable to the particular operation that is being considered. To take a simple example:

In a certain operation it is found that the average cost of felling and bucking is one dollar per $M$, and that $5 \mathrm{per}$ cent of the total volume is found in trees from 16 to 24 inches d.b.h. (average, 20 inches), (by eight inch diameter groups) $10 \mathrm{per}^{\circ}$ cent in the group averaging 28 inches, 15 per cent in the 36 -inch group, 20 per cent in the 44 -inch group, 25 per cent in the 36 -inch group, 15 per cent in the 60 -inch group, and 10 per eent in the 68 -inch group. By referring to the felling and bucking curve (Figure 41-A) it is found that the relative cost for 20 -inch trees is 72 (man minutes); for 28-inch, 48; for 36-inch, 37; for 44 -inch, 35 ; for 52 -inch, 35 ; for 60 -inch, 37 ; and for 68 -inch (by extending the curve), 40. Now, let $\mathrm{X}$ represent the cost per man-minute which, when multiplied by the volume percentages and number of man minutes, will give a weighted average cost of one dollar per M. The following equation will then result:

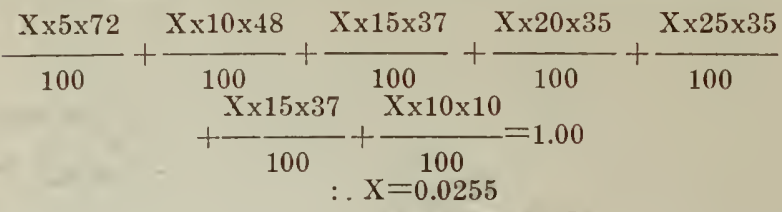

For 20 -inch trees the cost is $72 \times 0.0255$ or $\$ 1.84$ per M. By similarly multiplying man minutes by the value of $\mathrm{X}$ the following table is derived:

$\begin{array}{cc}\begin{array}{c}\text { Diameter class } \\ \text { inches }\end{array} & \begin{array}{c}\text { Cost per } M \\ \text { dollars }\end{array} \\ 20 & 1.84 \\ 28 & 1.22 \\ 36 & .94 \\ 44 & .89 \\ 52 & .89 \\ 60 & .94 \\ 68 & 1.02\end{array}$

By plotting these values a eurve is obtained from which "sorted" costs for any other diameter can be read. In this case the "sorted" cost for the average tree, which measures about 44 inches in diameter, is only $\$ 0.89$ compared with a weighted average of $\$ 1.00$ per M, a difference of over 10 per cent. Pronounced differences like this are characteristic of the felling and bucking curve owing to its sharpness and the fact that it reaches its lowest point for medium size trees and then rises again for larger trees. In the case of the yarding and carload variable the curves do not turn upward for the larger trees. The differences betweeen the cost for the "sorted" average log size and the weighted average cost are, therefore, relatively slight, seldom exceeding 3 per cent. If, in a given case, the volume distribution by size classes is not known it would be a fairly safe guess to deduct 2 per cent from the weighted cost averages of the carload and yarding variable and 10 per cent from the felling and bucking variable. The remainder represents then, in each case, the "sorted" cost of the average size log or tree, from which cost for other sizes can be derived by proportions read from the cost curve.

By applying the above method of computation to the cost relation curves and volume percentages by size classes that are applicable to the operation covered in Table 45 and by correcting for the 3 per cent allowed for defect deductions, the following table is derived (Table 46), showing costs allocated to logs and trees of different sizes. Here it will be noted that the total of fixed and variable costs for the average log comes to $\$ 6.90(\$ 4.69+\$ 2.21)$ compared with a weighted average cost of $\$ 7.33$ (Table 45). Half of the difference between these two values is accounted for by the correction for 3 per cent defect deductions, while the remaining difference represents the departure of the weighted average cost from the corresponding points on the cost curves.

TABLE 46

Allocation of costs from pond to stump to logs and trees of various sizes (Fixed-per-acre cost of $\$ 2.21$ per $M$ feet b.m. not included)

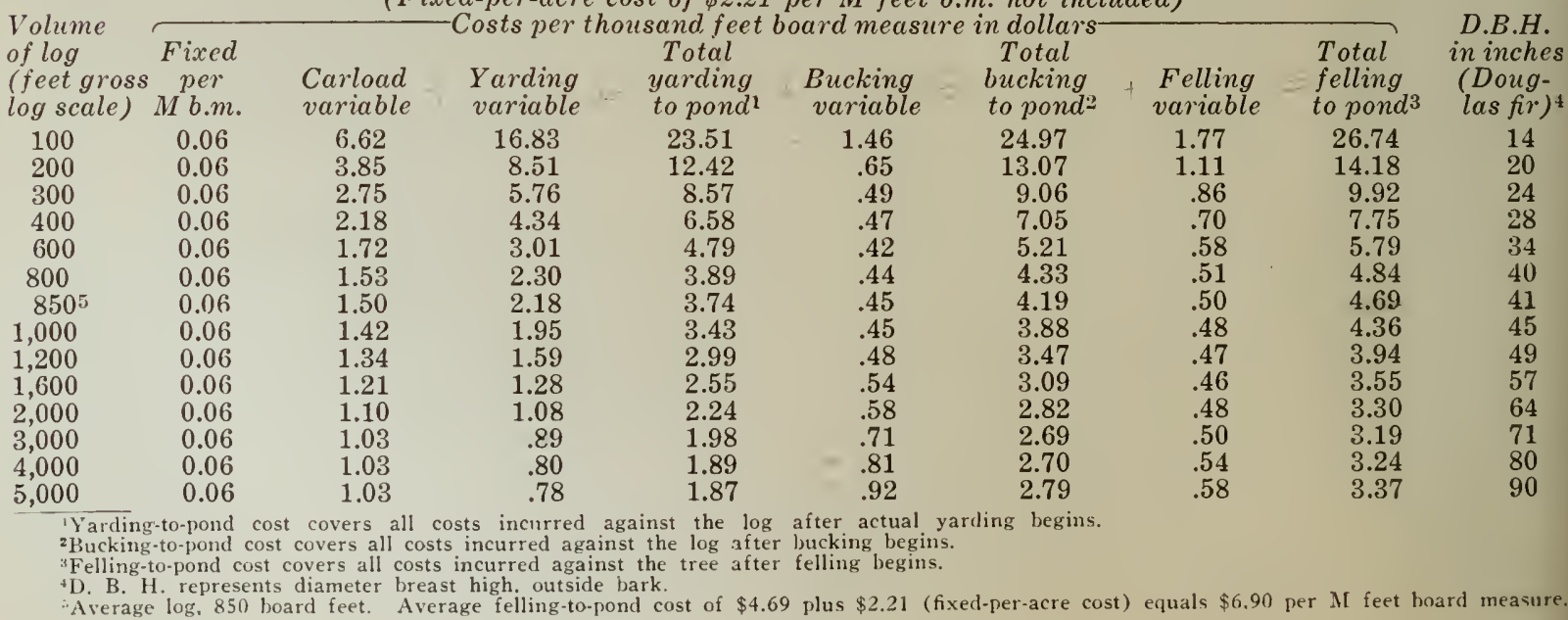


The following points should be noted:

(1) For defective logs of gross scale as listed, corresponding costs against net scale may be computed (and if desired defect cost tables constructed) by dividing the costs in Table 46 by the percentage of sound volume and multiplying by 100 .

(2) Further segregations may be made of yarding variable costs to show the effect of yarding distance on costs, provided that the average distance, to which the cost average applies, is known.

(3) For logging operations resorting largely to cold-decking, two cost tables should be set up; one for cold-deck areas, and one for direct yarding areas.

Instead of following the progress of the log from stump to pond, Table 46 presents cost accumulation in the reverse direction. This "backing-up" process permits deflation of ascertainable log values in the pond step by step to find the true conversion value at any desired point. For example, if the conversion value of a 300 foot log is $\$ 8.50$ per $M$ at the pond, it is evident that no value remains after deducting costs subsequent to bucking (fixed per M, carload, and yarding variable costs). Likewise, if a Douglas fir tree of 24-inch diameter yields logs which are worth $\$ 10$ per $M$ in the pond, one finds that all of this value (except 8 cents) drops out after deducting costs incurred from the moment the fallers begin their work. By segregating felling from felling and bucking costs it is further possible to determine cost chargeable against the individual log from the point where bucking begins until the log reaches the pond. By splitting up fixed per acre costs, light is thrown on costs chargeable against different areas of timber at different stages in the process of converting timber into cash. These are steps $^{15}$ involved in selective appraisal, which underlies the practice of selective logging.

91. Adaptation of Cost Averages to Specific Operating Conditions.-The data in Table 46 are derived from cost averages which are based on actual performance in logging a certain portion of a tract of timber. It is obvious that in applying these data to future operations on individual settings or other specific portions of the tract, various adjustments in the cost averages may be in order.

${ }^{15} \mathrm{~A}$ clear exposition of the steps involved in selective appraisals is given in an article by David T. Mason in The Timberman, issue of October, 1929.
As a rule it may be assumed that fixed per M, carload variable, and felling and bucking variable costs (Groups I, II, and IV) are fairly stable, except as influenced by basic changes, is in the rise or fall of wages, or in the distance of rail haul.

The cost level in the yarding-variable column, on the other hand, may vary considerably from one setting or area of timber to another, because these costs are keenly responsive to a number of factors, such as density, topography, etc., not influenced by size of timber alone. However, adjusting the values to fit sush specific conditions cannot be gone into in very fine detail in actual appraisal practice.

Some of the problems involved in timber appraisal, such as that of $\log$ and tree selection within an operating area that has already been developed with roads, deal only with costs incurred subsequent to assumption of fixed peracre costs. In the solution of such problems, then, the only costs that generally require frequent adjustments to meet changing operating conditions are those connected with the yarding variable.

92. Allocation of Fixed Per Acre Costs.-Fixed per-acre costs, made up of costs incident to road construction, engineering, fire protection, rigging ahead, and road changing, are in each case incurred against a certain area of timber and are not chargeable specifically against the individual $\log$ or tree. Mainline depreciation charges, Item 32 , Table 45 , thus represent a fixed lump-sum cost against the entire tract while spur construction (Item 34) represents in the case of each spur a lump sum against some specific area of timber within the tract; and so on down to road changing cost which in the case of each individual road applies to a very small subdivision of arei. Leaving out mainline amortization charges which apply to the entire tract, it is obvious that the remaining items of fixed per-acre costs may create important differentials in per thousand costs from area to area, and this in turn reacts on the net conversion value of the timber. Some areas may thus escape spur construction costs entirely, or call for only a very moderate outlay, while for other areas these costs may be very high. The proper allocation of these costs is of great importance in the solution of those problems in timber appraisal and planning of the logging operation which involve the determination of recovery values existing prior to the assumption of fixed per acre costs. 
For purposes of preliminary appraisal prior to formulation of detailed operating plans, such items of cost as fire protection, rigging ahead, and road changing may properly be treated as varying with the density (volume per acre) of the timber. In the case at hand, as detailed in Table 45, these items total $\$ 0.66 \mathrm{per}^{\circ} \mathrm{M}$ on the basis of an average stand density of $75 \mathrm{M}$ feet b.m. per acre. For stands of various densities, then, the following costs result:

$$
\begin{aligned}
& \text { Density: Fect } \\
& \text { b.m. per acrec } \\
& 25,000 \\
& 50,000 \\
& 75,000 \text { average } \\
& 100,000 \\
& 125,000 \\
& 150,000
\end{aligned}
$$$$
\begin{aligned}
& \text { Cost per thousand } \\
& \text { feet b.m. } \\
& 1.98 \\
& .99 \\
& 66 \text { average } \\
& .50 \\
& .40 \\
& .33
\end{aligned}
$$

Were topography and ground conditions less variable than is typical of this region, it would in a large sense be proper to deal with spur construction costs and all other items of fixed per-acre costs in a similar manner. However, under existing conditions of rough topography and other physical problems, they had better be considered a special appraisal problem in each particular case.

An examination of cost records for several years back in the operation dealt with in Table 46 shows spur construction costs to vary from 40 cents to $\$ 2.60$ per M spur by spur, and from nothing to $\$ 3.50$ per $M$ setting by setting. In conjunction with the density variable costs tabulated above, it is thus evident that variation in fixed-per-acre costs from one area to another is a very important factor in the differentiation of net conversion values within large tracts of timber. Instead of representing a flat charge per thousand board feet as shown in Table 46, they become important "variables" in allocating costs from setting to setting and from spur to spur.

93. Allocation of Capital Charges.-Costs in Tables 44,45 , and 46 do not include interest, taxes, and uninsured risks on the $\$ 425,000$ investment as detailed in Section 104. Depreciation and fire insurance, on the other hand, are included. The latter two items account for $\$ 0.38$ in the grand total cost average of $\$ 7.33$ per thousand board feet, leaving a net of $\$ 6.95$ as total current operating costs. Interest, taxes, and risk, as dealt with in Tables 2 and 3 in Chapter III would amount to approximately $\$ 0.70$ per thousand, bringing total logging costs to $\$ 8.03$, inclusive of all capital charges. The difference between $\$ 6.95$ and $\$ 8.03$ represents. then, annual capital charges expressed as a perthousand cost.

In allocating capital charges, as well as other fixed annual costs, if any, various cases may arise als follows:

(1) They may be treated as a part of current operating costs in the same manner as shown in Table 45 , in which items $12,13,26,27,28$, and $\$ 0.035$ of item 37 (depreciation and insurance costs) are grouped with the activities through which they are incurred;

(2) They may be treated as fixed per thousand costs ;

(3) They may be ignored entirely or in part.

The first case is based on the premises that logging is carried on steadily with a fixed layout without restrictions with respect to annual output. At the time the operation is first started a rough idea of prospective rate of daily production may be established as a basis for deeiding what type and size of equipment to get; but after operating facilities have once been acquired, production will be carried on without any definite limitations in the rise or fall of annual output. The working season may be limited by weather conditions or intermittent glutting of the log or lumber market, but not by filling a fixed quota as far as any given operation is concerned. The ups and downs in daily, weekly, monthly, etc., outputs, as governed by the variables heretofore discussed, will in this case be reflected in corresponding variations in capital charges per thousand board feet.

Under normal business conditions this situation is typical of a good many operatons in this region. Both the independent logger who sells his logs on the open market, and the logger-mill-owner whose mill is conveniently located on tidewater where logs may be bought or sold, are in a position to give the logging operation free rein in regard to annual output when profitable markets are available steadily or with brief interruptions. Less or no freedom in this respect may obtain in the case of a logging operation supplying a sawmill of limited capacity or limited outlet for its products.

The allocation of capital charges in the yarding-time studies is premised upon the above assumption that the length of the working season is not affected by variations in output.

In the second case, annual charges are considered fixed per thousand board feet. This applies to some or all items of capital costs in case the annual output is fixed. It will in that cas? invariably apply to those items of cost which 
re incident to fixed investments such as, for xample, the logging main line. It may or may ot apply to capital charges incident to investrents in logging machinery or rolling stock, epending upon whether or not such facilities re fixed irrespective of variations in the outut. In the typical self-contained logging operion, most of these facilities are usually fixed. In short then, capital charges per thousand ard feet become fixed when both the annual itput and the investment in operating facilies are fixed. Decreasing or increasing rate of aily, weekly, or monthly production will in iis case reflect itself in a corresponding ngthening or shortening of the working seaon without affecting capital charges per thousad board feet at the end of the operating year. In the third case annual capital charges are nored entirely or in part. In this treatment ie problem centers on a post mortem analysis : irretrievable investments. Operators who in lese trying times find it impossible to recover ll ownership costs as originally anticipated when the investments were made, continue to operate in spite of it, because it is more profitable to operate than to shut down, until the point is reached where ownership costs are wiped out entirely"i. Even in more normal times the marginal producer who lacks opportunity to employ profitably the capital invested in operating facilities may be thus compelled to carry on at a luss. Under these conditions, the capital engaged in the enterprise is being unavoidably dissipated. It is obvious, however, that as long as opportunity exists for recovery of capital charges they should be insisted u'pon as a part of current costs. Timber that can stand paying these costs in full has first call upon the use of operating facilities. Deeply involved in this question are other problems of internal value movements between different classes of stumpage, which in this period of €conomic upheaval are exceedingly difficult to answer.

${ }^{10}$ See articie by C. A. Lyford on "Nature of Stumpage Values" in the American Lumberman, issue of Oct. 17, 1931.

\section{FURTHER EXAMPLES OF SELECTIVE COST ANALYSIS OF TYPICAL OPERATIONS}

94. Case Studies-Basis of Comparison.-Folwing a procedure similar to that described Sections 89 and 90 , and as embodied in Table , five additional logging operations have been alyzed. A comparison of the results is given Tables 47 and 48 . The variation of costs and st relations as controlled by variations of the ze of logs and trees under different conditions ad methods of logging are thus brought out de by side.

These analyses are termed "case studies," imbered from 1 to 6 . They represent in each ise a selective analysis of costs for a going gging operation. In a later report (Part II) ese studies will be followed up by the introction of corresponding data on values of ees and logs of various sizes, from which net umpage returns may be derived as the basis ir economic selection in logging.

As discussed in the preceding chapter the acking-up" process of tracing costs from the nd back into the woods allows the determinaon of costs yet to be incurred at the moment e log or tree arrives at any given point in the nversion process from stump to mili, exclud$g$ all costs previously incurred, (such as umpage, road construction, etc.) The princi- pal points at which the determination of future costs is of practical significance in arriving at decisions in logging and timber management policy are represented by the designations "yarding-to-pond," " bucking-to-pond," and "felling-to-pond" costs and are defined in the footnotes in Tables 46,47 , and 48 .

The data given in Table 47 represent yarding-to-pond costs for logs of various volumes, while Table 48 covers felling-to-pond costs for trees of various diameters. In both cases this grouping of costs brings together two or more of the independent variables (yarding, carloading, felling, etc.) dealt with in Table 46 and previous discussions.

In addition to presenting the results in terms of actual cost in dollars per $M$ feet board measure, the tables also give a comparison of relative (percentile) costs as governed by variations of $\log$ and tree sizes within each study, disregarding cost differentials from study to study. These cost relatives may, of course, be re-computed against a base of $100 \mathrm{for}^{\circ}$ any log or tree size other than those selected here, and may also be translated into any set of monetary values that from time to time may be found to better fit a given case. 
TABLE 47

Comparison of yarding-to-pond costs for logs of various volumes based on studies in sire different logging aperations

Aetual Costs in Dollurs per .I Feet B.M.

lolume

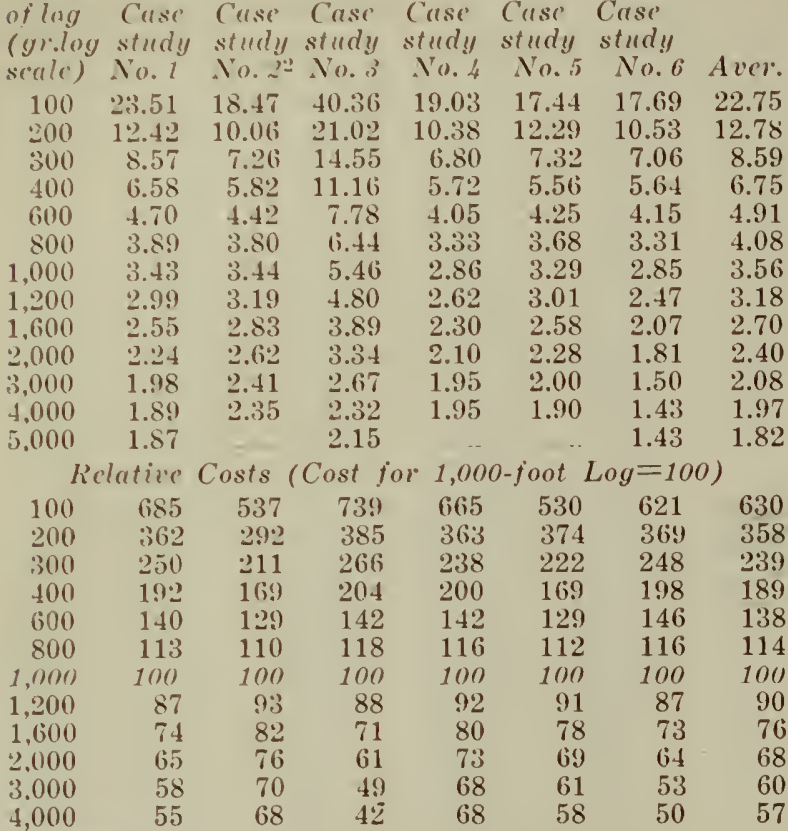

1) arding-to-vond costs cover all costs which are incurred against the log after yarling begins. All costs incurred against the area (construction, rigging ahead. line changing, etc.) as well as stumpage and felling and bucking costs are excludel. Interest and taxes not included.

Ease Study . No. 2 represents yarding with tractors; the other five studies represent conventional high-lead, skidder and slackline operations.

95. Small Logs and Trees Show Relatively High Costs.-The comparisons given in Table 47 and 48 again call attention to a fact that has been frequently referred to in preceding pages, viz., that under present clear-cutting practice variations in size of $\operatorname{logs}$ and trees have a strikingly potent effect on the cost of logging. Each logging operation is, true enough, a case by itself in which the ccmposite effect of all the various factors heretofore discussed produce different cost levels and different cost trends from those found in any other logging operation. This situation is demonstrated in the tables by contrasting, for example, Case Study No. 2 with Case Study No. 3 (see upper sections of the tables), the former representing an operation using tractors for yarding, while the latter represents a conventional donkey operation. But, looking at the situation in a broader way with attention given only to the cost relations shown within each study, the story of the effect of log or tree size on logging costs reads about the same in all cases. This is brought out best by comparing the data in the last column to the right in the lower section of the tables, which represents average cost relations based on six studies, with the corresponding data of each individual study. These case studies, it should be noted, while confined to conventional railroad type logging operations, thus leaving out, for example, the small motor truck operations, apply to operations which were selected for the purpose of bringing out fairly sharp contrasts in types of yarding machinery, logging methods, timber types and general logging conditions-yet comparison with individual studies shows no very radical departure from the average percentile trend.

Speaking in broad terms of the typical logging operation of this region, it is thus seen that it costs on the average nearly twice as much per $M$ feet $\log$ scale to handle a $\log$ of 400 board feet volume, three and a half times for a $\log$ of 200 board feet volume, and six

\section{TABLE 48}

Compurison of felling-to-pond costs for trees of varions diameters based on studies in six different logging operations

\begin{tabular}{|c|c|c|c|c|c|c|c|}
\hline $\begin{array}{l}\text { diam. } \\
\text { b.h. in } \\
\text { inches } 2\end{array}$ & $\begin{array}{l}\text { Case } \\
\text { study } \\
\text { No. } 1\end{array}$ & $\begin{array}{l}\text { Case } \\
\text { study } \\
\text { No.2 }\end{array}$ & $\begin{array}{l}\text { Case } \\
\text { study } \\
\text { No. } 3\end{array}$ & $\begin{array}{l}\text { Case } \\
\text { study } \\
\text { No. } 4\end{array}$ & $\begin{array}{l}\text { Case } \\
\text { strudy } \\
\text { No. } 5\end{array}$ & $\begin{array}{l}\text { Case } \\
\text { study } \\
\text { No. } 6\end{array}$ & Aver \\
\hline 16 & 22.05 & 17.35 & 27.40 & 17.40 & 22.54 & 19.60 & 21.0 \\
\hline$\therefore 0$ & 14.20 & 11.60 & 18.70 & 13.20 & 16.10 & 12.34 & 14. \\
\hline 24 & 10.00 & 8.52 & 13.30 & 10.00 & 11.29 & 8.45 & 10.2 \\
\hline 28 & 7.82 & 6.80 & 10.40 & 7.90 & 8.22 & 6.85 & 8.0 \\
\hline 32 & 6.40 & 5.72 & 8.65 & 6.30 & 6.35 & 5.58 & 6.5 \\
\hline 36 & 5.44 & 4.86 & 7.60 & 5.22 & 5.29 & 4.80 & 5.5 \\
\hline 40 & 4.85 & 4.50 & 6.70 & 4.40 & 4.68 & 4.25 & \\
\hline 44 & 4.40 & 4.15 & 6.00 & 3.75 & 4.28 & 3.80 & \\
\hline 48 & 4.02 & 3.95 & 5.40 & 3.25 & 3.96 & 3.50 & \\
\hline 52 & 3.80 & 3.80 & 4.90 & 3.00 & 3.69 & 3.27 & 3.7 \\
\hline 56 & 3.60 & 3.65 & 4.45 & 2.85 & 3.43 & 3.10 & 3.5 \\
\hline 60 & 3.40 & 3.55 & 4.10 & 2.80 & 3.25 & 3.00 & \\
\hline 80 & 3.20 & 3.25 & 3.60 & 2.75 & 2.88 & 2.80 & \\
\hline \multicolumn{8}{|c|}{ Relative $C$} \\
\hline 16 & 549 & 439 & 507 & 535 & 569 & 560 & 52 \\
\hline 20 & 353 & 294 & 346 & 406 & 407 & 353 & \\
\hline 24 & 249 & 216 & 246 & 308 & 285 & 241 & 25 \\
\hline 88 & 195 & 172 & 193 & 243 & 208 & 196 & 20 \\
\hline 32 & 159 & 145 & 160 & 194 & 160 & 148 & \\
\hline 36 & 135 & 123 & 141 & 161 & 134 & 137 & 13 \\
\hline 40 & 121 & 114 & 124 & 135 & 118 & 121 & \\
\hline 44 & 109 & 105 & 111 & 115 & 108 & 109 & 11 \\
\hline 48 & 100 & 100 & 100 & 100 & 100 & 100 & 10 \\
\hline 52 & 95 & 96 & 91 & 92 & 93 & 93 & \\
\hline 56 & 90 & 92 & 82 & 88 & 87 & 89 & \\
\hline 60 & 85 & 90 & 76 & 86 & 82 & 86 & \\
\hline 80 & 80 & 82 & 67 & 85 & 73 & 80 & \\
\hline
\end{tabular}

Felling-to-pond cost represents all costs which are incurred against the tree after felling begins. Fixed-per-acre costs, or costs incurred against the area, (road construction, rigging ahead, line changing, etc.) and stumpage costs are excluded. Interest and taxes not included.

"Diameter breast high outside bark.

Fired-per-Acre Costs

$\begin{array}{cccc}\text { Case Study } & \text { No. } & 1-\$ 2.21 \\ \text { “ } & \text { “ } & \text { " } & 2-0.65 \\ \text { " } & \text { “ } & \text { “ } & 1.40 \\ \text { " } & \text { " } & \text { ". } & 5-1.15 \\ & & & 6-50\end{array}$


times as much for a $\log$ of 100 board feet volume-tying the comparison in each case to the yarding-to-pond cost shown for a $\log$ of 1,000 board feet volume. Extending this comparison all the way from the 100 to the 4,000 board feet log volume shows further that it costs eleven times as much for the small $\log$ as for the large one. Another way of picturing these relations is to say that it costs about as much to handle four logs in the 100-foot class as one $\log$ in the 5,000-foot class.

Similarly the data in Table 48 shows that in comparison with a tree of 48 -inch diameter it costs twice as much per M feet log scale to log a tree of 28-inch diameter and five times as much for a 16-inch tree; and that costs multiply seven times in going all the way from an 80 -inch to a 16-inch tree.

96. Present Clear Cutting Practice Penalizes the Small Log or Tree.-It is important to bear in mind that the foregoing data on size-to-cost relations represent the relations which arise within any given unit of yarding area and under the present clear cutting system of logging. Trees of all sizes are felled and bucked before actual yarding begins. Logs of all sizes are yarded, swung, and loaded etc., in whatever order they happen to come and are all handled alike. The result is that the machinery and equipment, designed to handle large logs with a fair degree of efficiency, fails utterly to respond to the requirements for equal cost efficiency in the handling of small logs, resulting in a rather steep upward trend in costs with decreasing size of log or tree. This becomes particularly noticeable for logs under 600 board feet in volume and for trees under 32 inches in diameter, and has, indeed, a withering effect on the net conversion value of the small $\log$ or tree, in view of the well known fact that small trees and logs are worth less than the large ones.

To successfully remedy this situation, once the disability of the small $\log$ is fully recognized-and at the same time to stipulate that the small log must be logged and that the present general scheme and methods of logging be retained-is not an easy matter. On the whole there does not seem, and can not be reasoned to be, a practical escape from relatively high cost for small logs under a system of donkey logging which requires for any given area that logs of all sizes-particularly with a spread in sizes as great as in typical operations of this region and with equipment adapted primarily for the large $\log \mathrm{s}$ - shall be removed in one operation and with only one set of equipment.

To more effectively remedy this situation by revising present operating methods or by adopting new methods, or more particularly, by adopting a system of selective specialization in logging is quite another phase of the question. To these questions further attention is given in the following chapters.

\section{GENERAL SUMMARY AND COMPARISON OF LOG TRANSPORTATION COSTS}

In a sense, the chief elements of logging cost are transportation items or capital and overhead accompanying them. The most important exception is felling and bucking, which in this region rarely exceeds 15 per cent of total logging costs, and even this is performed usually in a manner to facilitate transportation. Low cost logging consists, then, largely in combining the different forms of transportation which usually are necessary in the most judicious proportions. It is of interest to compare the relative cost of transporting 1,000 feet b.m. of logs per mile of distance as well as over distances most commonly involved in each of the different forms of transportation available to the logger, starting from the stump. Such a comparison is given in Table 49 .
The cost data for Items 1 to 7 in Table 49 have been read from Figures 28, 30, and 33 , and represent a log volume of 800 board feet. The remaining items are based on general cost averages from various sources.

These costs are of an exceedingly complex nature when it comes to juggling with different distances, $\log$ sizes, and other variable and fixed items of cost. They serve, however, to give a bird's-eye view of costs representative of different methods and serve to center attention on conclusions heretofore arrived at in discussion of various methods or combinations of methods of stump to track transportation, the main points of which are re-examined briefly in the next chapter. 
A. larding

Method of trunsportution

1. Large steam skidders and slackline yarder (12x14")-exter'nal yarding distance of 1,800 feet; average specific distance 1,200 feet

2. Large steam high-lead yarders (12-14") - external yarding distance 900 feet; average specific distance 600 feet

3. 30 to 125 h.p. gasoline high-lead varder's-external yarding distance 600 feet; avelage specific distance 400 feet

4. 30 to 125 h.p. gasoline high-lead yarders-external yarding distance 450 feet; average specific distance 300 feet

5. $60 \mathrm{~h}$.p. crawler tractors drawing fair-lead arch-external yarding distance 3,000 feet; average specific distance 2,000 feet

Cost for

distance

B. Swinging or Roading

6. North bend skyline swing from sma!l cold decks-average distance 1,600 feet

7. Downhill tractor roading-average distance 1 mile

C. General Transportation

8. Motor trucks hauling on poor or steep roads-average hauling distance 3 miles

9. Motor truck hauling on good roads (public fighways)-average hauling distance 10 miles

10. Logging railroad spur transportation (landing to make-up track) average haul 3 miles; $5-15$ million feet of timber ner mile of road; cost per mile $\$ 8,000.00$

11. Logging main line-average haul 20 miles; 20 to 60 million feet of timber per mile of road; cost per mile $\$ 12.000$

12. Joint tariff common carrier roads of western Washington-distance of haul 40 miles

13. Water transportation-average towing distance 50 miles noted

Dollars

1.60

1.40

0.70

0.55

0.85

Approximute Fixed rate perene permile rosts Dollars Dollur's

$7.00^{1}$

$0.10^{2}$

$12.00^{1}$

$0.10^{2}$

$9.25^{1}$

$0.10^{2}$

$9.50^{1}$

$0.10^{2}$

1.60

$0-0.10^{2}$

0.72

1.05

$2.40^{1}$

$0.10=$

1.05

$0-0.30^{3}$

0.40

0.18

0.10

$0.50-1.50^{3}$

0.04

$0.20-0.60^{3}$

0.06

2.50

0.60

'Relay basis. 'Rigging ahcad. 'Road construction. 'No data.

\section{POSSIBILITIES OF COST REDUCTION THROUGH ADAPTATION OF}

\section{MACHINERY AND METHODS UNDER CLEAR CUTTING}

98. Planning of Logging Operations for Low Cost Methods.-The logging operator wishing to reduce costs through changes in mechanical equipment or modifications of logging methods and plans will consider first the possible adaptation of his existing layout. Possibilities along these lines can be demonstrated best by comparing the layout of an existing operation with that necessary if methods disclosed in these studies as most effective are to be employed.

As briefly told in Table 49, and as previously discussed in Chapters V, VII and IX, the greatest opportunities toward efficient, low-cost logging enter through the use of the crawler tractor, either for direct yarding or for roading with or without previously prepared roads, in combination-where uphill, rough country, or wet weather logging is involved-with the small sledded or tractormounted high-lead yarder or the conventional skyline swing system.

In using these methods or combinations of methods, the operations should be planned primarily for tractor logging with the more nxpensive methods figured in only where un- avcidable; and with reliance on railroad spurs continuous and effective transportation.

The first step is to so skeletonize the railroad system that the balance between yarding or roading on the one hand and railroad spur construction and operation on the other gives every advantage to the cheaper method. Since the chief strength of the tractor system, when compared with conventional donkey logging, lies in downhill roading or yarding over relatively long distances this usually means that railroads should be located at low altitudes and water grades with main branches as needed but with spur construction to the extent now common, eliminated.

Just how far the skeletonizing of the railroad system may go will depend upon a number of factors which must be evaluated separately in each case. The reduction of railroad-spur mileage, it should be noted, is not only a question of reduced construction costs, but in balancing against the cost of tractor roading, involves as well the cost of railroad maintenance and train operation, and affects capital investm $n$ ts in railroad operating facilities. 
Comparison of operating costs as uctually incurred and as possible under revised methods

Group I-Muinline transportation, booming, etc.

$\begin{array}{cc} & \text { Costs ijlow-cost } \\ \text { Costs } & \text { methods covered } \\ \text { actually } & \text { by this study } \\ \text { incurred } & \text { uereapllied } \\ \text { Dollars } & \text { Dollurs } \\ \text { per Hb.m. } & \text { per.Mb.m. }\end{array}$

(a) Depreciation and maintenance including trackage and rolling stock (15.6

miles main line)

(b) Mainline operation

(d) Mainline depreciation of equipment

(e) Unloading, booming, rafting, towing, scaling, etc.

Total Group I

$\begin{array}{ll}.57 & .57 \\ .30 & .30 \\ .10 & .10 \\ .25 & .25 \\ .26 & .26 \\ 1.48 & \frac{.25}{1.48}\end{array}$

Group $I I-S p u r$ Transportation

(a) Railroad spur construction and engineering

(b) Maintenance of spur track, speeder operation

(c) Switching and spur transportation

Total Group II

\section{.95 \\ .20 \\ .22}

.30

.05

Group III-Louding (totul)
Group II-Swinging or rocding
(a) Rigging ahead
(b) Swinging (skidders or donkeys) $\$ 0.80 \mathrm{per} \mathrm{M} \mathrm{ft}$. on $70 \%$ of logs prorated
(c) Roading (tractors) $\$ 1.25$ per $\mathrm{M} \mathrm{ft}$ on $80 \%$ of logs prorated to all logs
(includes $\$ 0.25$ for road construction)

Group III-Louding (totul)
Group II-Swinging or rocding
(a) Rigging ahead
(b) Swinging (skidders or donkeys) $\$ 0.80 \mathrm{per} \mathrm{M} \mathrm{ft}$. on $70 \%$ of logs prorated
(c) Roading (tractors) $\$ 1.25$ per $\mathrm{M} \mathrm{ft}$ on $80 \%$ of logs prorated to all logs
(includes $\$ 0.25$ for road construction)

Group III-Louding (totul)
Group II-Swinging or rocding
(a) Rigging ahead
(b) Swinging (skidders or donkeys) $\$ 0.80 \mathrm{per} \mathrm{M} \mathrm{ft}$. on $70 \%$ of logs prorated
(c) Roading (tractors) $\$ 1.25$ per $\mathrm{M} \mathrm{ft}$ on $80 \%$ of logs prorated to all logs
(includes $\$ 0.25$ for road construction)

Group III-Louding (totul)
Group II-Swinging or rocding
(a) Rigging ahead
(b) Swinging (skidders or donkeys) $\$ 0.80 \mathrm{per} \mathrm{M} \mathrm{ft}$. on $70 \%$ of logs prorated
(c) Roading (tractors) $\$ 1.25$ per $\mathrm{M} \mathrm{ft}$ on $80 \%$ of logs prorated to all logs
(includes $\$ 0.25$ for road construction)

Total Group IV
1.00

$\overline{1.00}$

Group V-Yarding or cold decking

(a) Rigging ahead

(b) Yarding

Total Group V

Group VII-Administration and Fire Protection

(a) Salaries and overhead.

(b) Industrial insurance

(c) Other insurance

(d) Fire protection

Total Group VII

$$
\begin{aligned}
& .49 \\
& .11 \\
& .06 \\
& .10 \\
& \hline .76
\end{aligned}
$$

7.18

.57

.30

25

26

(1)

148

Total comparative logging costs

99. Example - Comparison of Present with Proposed Methods.-To demonstrate the principles involved and that may follow the proposed changes in logging methods, it is well to consider a representative area (Figure 42) that has been nearly completely logged by present methods. Cost of railroad mainline and spurs is, therefore, definitely known, as well as the entire logging costs. Mainlines aggregating 17.2 miles and spurs 24.3 miles, inclusive of sidings and landing tracks are shown on Figure 42 by two symbols, one indicating mainline and branches that would be retained under tractor logging, the other showing spurs needed only for the present method. To these are added the main

tractor roads necessary to take the same timber out. A comparison of the itemized costs by each method is shown in Table 50, with some minor adjustments of orerhead and insurance cost disregarded. The costs in the first two columns (highlead and slack line logging) are actual costs for the first six months of 1931 as to total, redistributed in a few items to fit the classification here adopted. The last two columns retain the same costs where they apply as in mainline railroad transportation, and utilize costs ascertained by this study for gas yarders and tractors. A similar comparison of capital investments under the two systems is given in Table 51. 
Mainline railload (17.2 miles) total cost $\$ 2: 23,390$

Railroad spurs ( 24.3 miles) total cost $\$ 234,390$; average in use

Railroad steel, average in use

Locomotives

Log car's

Oil tank cars and oil storage tanks

Construction equipment

Camp and camp equipment (including; shop and $\log$ dump)

Highlead unit including North Bend skyline equipment

Gasoline highlead varder

Slackline gasoline yarder

Locomotive crane or jammer

3 ( $60-80$ h.p.) gas yarders (1 sledded; 2 tractor mounted)

(i (60 h.p.) crawler tractors with arches

Miscellaneous

Liquid working capital

Total comparative investment
Average investment in dollars

Present System

$\$ 111,695$

46,858

40,000

30,000

28,800

6,000

10,000

15,000

15,000

5,000

12,000

Proposed System

$\$ 111,695$

34,000

18,000

24,480

8,000

15,000

12,000

12,000

12,000

25,000

3,000

40,000

50,000

$\$ 373,353$

$\$ 315,175$
100. Elimination of Spur Construction Leads to Important Economies.- To the informed reader the indicated saving of $\$ 1.98$ per M feet b.m. in operating costs (Table 50) accompanied by a reduction of about 15 per cent in capital investments (Table 51) may seem unduly optimistic. Analysis of the origin of the savings, however, leaves little doubt of their actuality.

On this tract of only $300,000 \mathrm{M}$ feet of timber, 24.3 miles of expensive railroad spur construction, estimated to cost $\$ 234,290.00$ could have been eliminated by the revised method of logging. The spur transportation costs (construction and operation) averaged, for the first six months of 1931, $\$ 1.37$ per M feet b.m.; the yarding, cold decking, swinging, and rigging ahead, part and parcel of this method, amounted to $\$ 2.31$ per $\mathrm{M}$ or a total of $\$ 3.68$. The proposed method substitutes for these items $\$ 1.00$ for tractor roading and $\$ 0.70$ for short yarding with tractors or gas donkeys, a total of $\$ 1.70$.

The reduction in capital investments springs mainly from the elimination of spur construction ${ }^{17}$ together with transportation facilities which are associated therewith or of other operating facilities affected by the proposed changes in operating methods; and from reduced requirements for liquid working capital that follows reduced operating costs. The investment in machinery employed in bringing the logs from stump to car, on the other hand, is about doubled.

${ }^{1 i}$ The corresponding cest of tractor road construction is here treated as a part of current logging cost the same as rigging ahead costs under the present system of logging.
101. Substitution of Skyline Swinging for Tractor Roading Offers Practical Solution of Difficult Problems.-A part of the increased investment in yarding machinery in Table 51 covers a skyline swinging outfit, although no account of this is given in Table 50. In this discrepancy lies the answer to many pertinent questions that might be asked such as how practicable the proposed plan might be, or how much costs might rise if, on further detailed investigation, it be shown that conditions do not actually permit the use of tractors to the full extent indicated in Figure 42. Suppose it were found that some of the timber on areas lying below the railroad level could not be roaded by tractors as proposed on the map and that some of the steepest downhill logging was also beyond the practical range of the tractor system. Suppose further that the tractor system, disabled in the winter time on account of heavy rains coupled with unfavorable soil conditions could only be relied upon for six months production per year, although eight to ten months of production was essential for fulltime production. Such problems can be solved with very little rise in costs by substituting the skyline swing outfit for the roading tractors for distances within reach of the skyline siving (compare Figure 33).

A detailed study of a large-scale map of the area shown in Figure 42 shows that, if it were necessary to provide year-round logging, it would be feasible to allocate to the skyline swing about one half of the timber (about 40 per cent of the area) without moving the sky- 


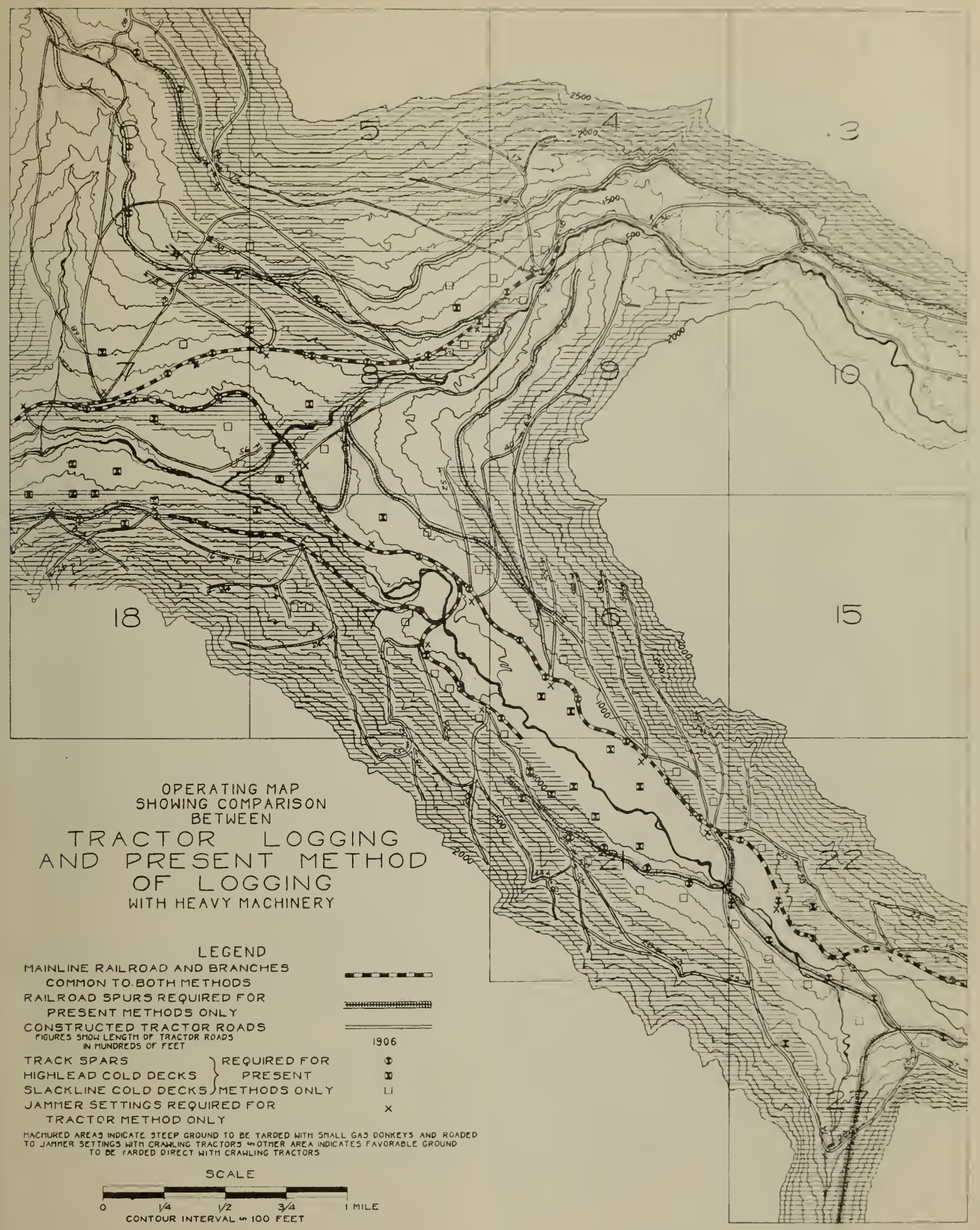

FIG. 42-REPRESENTATIVE LOGGED OVER AREA: SHOWING OPERATING PLAN FOR ACTUAL LOGGING WITH HEAVY MACHINERY AND THAT REQUIRED FOR TRACTOR LOGGING 
line donkey away from the track. Under this plan, then, that half of the timber beyond the reach of the skyline swing would be logged during the dry seasons, using the tractor roading system, combined as needed with short distance highlead yarding with small drum units. When the wet season arrived, the skyline swing would be brought into operation on areas adjacent to the railroad tracks, using the same cold decking and loading cquipment as used in connection with the tractor roading system. The costs presented in Table 50 would thereby be increased less than ton cents per M feet b.m.

Looking beyond costs into the question of timber breakage and selectivity in logging there is, however, every reason to believe that it would be advantageous to confine skyline swinging to a much smaller portion of the area than suggested above. A study of this question gives the following tentative allocation of timber:

(1) Fifty per cent to the tractor roading system, comprising timber beyond the reach of a single skyline swing. This will be operated only during the dry season.

(2) Twenty per cent to the skyline swing system, comprising areas within reach of a single skyline swing which offer topographic difficulties that may render the tractor system either entirely impracticable or costlier than the skyline system. This is allocated exclusively to the skyline system except as this may be modified to some extent by possibilities to reduce breakage through the use of tractors; and excepting also that some of the timber within about a 400 -foot yarding distance of the track may be allocated to the small highlead cold deck units without the use of the swing donkey. Operations in this timber, as here planned, are to be confined to the wet season.

(3) Thirty per cent of optional territory, all of which comes within reach of a single skyline swing.

This area should be allocated to the tractor system by reason of (a) lower costs and/or (b) reduction of breakage and/or (c) the slectivity offered by the flexible tractor system. Furthermore, portions of this area become in any case the corridors through which the tractor road system will extend into the exclusive tractor territory mentioned above. Allocation to skyline swinging of any of this area is justified only if the advantages or necessity of a longer operating season offset the advantages obtainable with the dry weather tractor roading system. In the case at hand it is believed that the proper balance of all factors calls for the allocation of 70 per cent of the annual cut to the dry weather tractor roading system, and 30 per cent to the wet season skyline system, giving an operating season of 8 to 10 months per year as under the present system of logging. This modification of the tractor plan proposed in Figure 42 does not materially change the cost comparison given in Table 50 .

102. Further Modification to Solve Special Problems.-Many combinations can be made of short-distance highlead yarding, tractor roading, and skyline swinging, although in the case at hand the use of such combinations does not appear necessary beyond the use of short-distance highlead cold decking for "feeding" either the tractor or the skyline as heretofore discussed. The chief importance of other combinations may be to permit of a practical solution of some particularly difficult logging problem. For example a dry-weather combination may be effected whereby the skyline swing, located at the track, relays the logs from the end of a tractor road system; or, vice versa, the skyline swing outfit may be used for yarding out of a steep canyon located, for example, half a mile away from the track, while the tractors are used to "road" the same logs to a track landing. By means of such combinations almost any problem can be solved; but costs will then naturally rise above those claimed in Table 50 . The low costs here claimed for the tractor roading system are based entirely on the direct movement of logs from stump to track, except that provision has been made for strictly shortdistance cold decking where needed. To substitute for this a system of relaying the logs, with one operation tied up with another, may make an entirely different story as far as costs are concerned. But it is significant, nevertheless, that combinations can be devised for solving difficult logging problems that otherwise might make it impracticable to carry out the general scheme of a skeletonized railroad system balanced against low-cost long-distance roading.

103. Hauling by Motor Truck May Eliminate Some Long Distance Roading.-Still further modification of the tractor roading plan outlined in Figure 42 may be suggested. For example, substitution of motor trucks in the place of roading tractors might be suggested for that timber in Sections 6, 3, and 10 which lies more than one mile from the track landing. Gradients of roads needed to reach this timber can be kept within the requirements of $15 \%$ for reasonably successful truck haul. On the strength of 
the data presented in Chapter XIII for hauling cver rough and steep roads and allowing a reascnable cost for loading, the motor truck should show a fair saving for the timber located one to two miles from the railroad track; provided that strictly dry weather hauling can be arranged with little extra cost for road maintenance and construction over that required in tractor roading or, if such extra costs have to be incurred, that hauling cost may be correspordingly reduced to compensate therefor. Since truck haulirg of logs is usually performed by independent truck owners who hire out or contract their services for short or seasonal jobs, the occasional or seasonal introduction of trucks does not raise the objections usually attached to the acquisition of operating facilities to meet special and temporary problems.

Aside from the possibilities of some reduction of costs for the distances involved in this particular case, the introduction of the motor truck into the picture is of interest in that it permits further skeletonization of the railroad system even to the extent of involving stumpto-track hauls of several miles.

104. Some General Points Established from Foregoing Comparisons.-The initial scheme of roading as proposed in Figure 42 may thus undergo many changes and modifications without any serious consequences to the success of the general plan. Its details may be changed, but its broad features remain; and its striking superiority over the present system remains substantially as shown in Tables 50 and 51 in spite of the fact that in the final carrying out of the plan the role played by tractor yarding or roading may be restricted to a much narrower field than at first contemplated.

In order to see clearly where the bulk of the savings originates, attention is again called to the striking economies that follow the skeletonization of the railroad system. A more intimate glimpse of the transportation picture shows that under the proposed plan this area is amply served by a total of about 16 miles of railroads including the main line outside the logging area proper; by one locomotive; by an average distance of haul of about 8 miles on roads with fairly easy grades, good road bed and good alinement. Under the present system of logging, on the other hand, there are added to this a good many, and very costly, "extras." The construction of an additional 24 miles (including landing tracks and sidings) of railroad spurs with generally steep grades, sharp curves and very high cost construction is thus a major itcm of cost which more than doubles total road amortization charges. It, in turn, calls for bringing in a second locomotive for handling the added traffic created through the expansion of the road system. The extra traffic created consists not only of the added distance of haul. which in this case amounts on the average to only about two miles, but of a costlier type of haul due to extra switching and break-up of trains in going from main lines to spurs. Extra traffic is also created both on mainlines and spurs through the hauling of ties, steel, timbers, ballast, etc., needed for the adcied spur construction and is further augmented by extra moving of logging machinery and by many cther minor chores connected either with the increased construction or the increased number of track landings required under the present systcm. There follows the added cost of road maintenance, added wear and tear of the rolling stock; also, the added investments represented by an extra locomotive, extra steel, ties, rolling stock, road construction machinery and other facilities connected with the construction of the roads. In the end the accumulation of all these "extras" means just about a doubling of railroad transportation costs as a whole. The proposed plan eliminates this excess of railroad transportation and still retains the simplicity of direct movement of logs from stump to track, as renclered possible by the strikingly low costs of relatively long distance roading with tractors. In this combination of utmost simplicity in the railroad set-up, coupled with equal simplicity and directness in the stump to track operations, lies, then, the strength of the proposed plan.

It is not here argued that the average operaticn nor even that very many logging operations in this region would necessarily offer to the proposed plan as striking an opportunity for reduction of costs as that set out in the example cited above. It may be a rather extreme case. At the other extreme may be pictured the type of operation in which, for example, the economies represented in the elimination of spurs may be negligible; the type of operation where construction costs are low; where long "switch-back" spurs are seldom required, and where instead, spurs can be built to branch out herring-bone fashion from the main stems without adding perceptibly to the distance or cost of rail haul; and where, perhaps, only a relatively small amount of steel rails and other track supplies need be kept on hand for "relay" 
branch-road construction. Between this type of flat country operations, seldom encountered in this region, and the type of operation shown in Figure 42, there is probably to be found the type of logging operation that most truly represents this region insofar as the question of logging railroad economy in general is concerned.

The example cited above, whether extreme or not, serves to focus attention on some of the vulnerable features of the present highly complicated system of logging. It brings to attention the fact that under the present system the cost of transporting the logs from stump to main spur sidings-a function that in effect is performed in one continuous operation under the tractor system-may often be pyramided to excessive heights and still escape detection by inadvertently disguising a wide array of miscellaneous items of costs under an equally wide variety of confusing or misleading names and titles. Finally, it brings to attention that in the long run, if not from day to day, the logging operator pays, so to speak, the "full machine rate" cost, as heretofore dcfined, for each additional foot-pound of energy required in the production of logs, because such additional costs crop up ultimately and on the average in all the various forms into which costs may be subdivided, whether they be a part of current operating cost, general ovcrhead, or capital investment cost.

105. Comparison Based on Clear Cutting is not Final.-The comparisons made above have proceered on the implied assumption that it is the function of logging to remove and convert into logs all the so-called "merchantable" timber on an area; and to do so all at once. In other words the assumption here is that the present general practice of wholesale clear cutting is the mode to follow. In accepting this mode the criterion of what is good and what is not so good in logging procedure must necessarily be based, by and large, on the general thesis that that method of clear-cut logging is best which costs the least; with some modifications arising, for example, by recognizing the importance of timber breakage as affected by different methods of logging.

On this basis of comparison the proposed system, as demonstrated in the above example, offers a substantial reduction of logging costs as a whole. An interesting and important feature of these savings is that in the final analysis they are reflected to a large extent in the re- duction of fixed-per-acre costs rather than in the reduction of those items of cost which vary with the size of and are chargeable to individual trees and logs. This leaves the yarding-topond, the bucking-to-pond, and the felling-topond costs, as defined in Chapters XVI and XVII, much the same as under the conventional donkey logging system. The cost level of the variable item may, of course, be reduced to some extent and the size-to-cost relations may not show quite so steep a trend as under conventional donkey logging, but the contrast is not likely to be much more striking than that shown in Tables 47 and 48 (Chapter XVII) in comparing Case Study No. 2, which represents a tractor operation, with the other five case studies which represent ordinary donkey operations The opportunities for further cost reduction by seriously attacking the problem of overcoming the unreasonably high costs shown for small $\operatorname{logs}$ and trees (Tables 47 and 48) still remain virtually untouched.

With this and other factors yet to consider, it will be seen that a clear understanding of the function of logging, of the principles of selective appraisal of timber, of the opportunities for reduction of costs through selective specialization, and of the objectives of sound timber management is required in order to establish a really sound basis for rating the relative merits of different types of logging machinery, logging methods, and logging practice. $\mathrm{Ob}$ viously if the objectives sought in logging are changed, so also the methods of logging will be changed. In the following chapters, it will beccme more and more apparent that selective logging, in one form or another, and usually in several forms together, is a basic requirement to effective and intelligent logging practice both from the standpoint of operating efficiency and from that of sound timber management. This, in turn, means that other considerations than the cost of clear-cut logging enter into the equation that the logger must solve in charting his course through the woods; in deciding upon what types of machinery and methods of logging to use, and in deciding upon what timber to cut and what not to cut. For these reasons the comparison of logging costs drawn in the preceding discussions should not be considered closed by simply striking the balance on the basis of clear cutting, but must be left open for further consideration in the light of further study of what the logger should strive to accomplish. 
106. Specialization Reduces Cost of Small-timber Logging in General.-It can readily be reasoned that the size-to-cost relationships, shown in Tables 47 and 48 , Chapter XVII, which apply in each case to trees and logs within an operating area that is logged in wholesale clear cutt.ng fashion as discussed in Section 96, probably do not apply from one operating area to another, particularly if different equipment or methods are used. In fact it is commonly recognized that the cost of logging small timber, particularly timber of fairly uniform size, using an operating layout, methods, and plan of organization specially designed for small-timber logging, does not as a rule compare very unfavorably with the cost of logging large timber; at least not enough so to suggest any such relationships as are indicated in Tables 47 and 48. And it is not reasonable that it should, since the basis of comparison is not the same.

The term "specialization" will here be used to denote the adaptation of machinery, equipment, methods, etc., to more closely fit the requirements of different size classes of timber. It will often go a long way toward the equalization of logging costs. Its potency in this respect, however, is often overrated, due to the fact that specialization is frequently only one, though on the average the most important one, of several factors which together operate to place the cost of small-timber logging in general in a very favorable light in comparison with the large timber. If these other factors are eliminated, a truer and more reasonable picture may be obtained.

As an example, consider the case of small-timber versus large-timber logging in this region. General cost data can be compiled to show that the smalltimber, and more particularly the second-growth, operations as a group have a lower logging cost than certain large-timber operations. But a most important factor in this situation is that the small-timber operations as a group are situated in more favorable locations, closer to the market and/or are operating in denser stands or on more favorable logging ground. ${ }^{18}$ Further than this, the pressure of competition operates to force them into greater efficiency, and/or forces the adoption of a lower wage scale or other measures to accomplish the same purpose. Together with the benefits actually gained through specialization these and other factors combine to place a select number of small-timber operations in a very favorable light in comparing costs with large-timber logging. But where the comparison through lack of natural ad-

${ }^{18}$ This in a large measure is the logical result of the broad selective program of the industry as a whole, whereby only areas of large and choice timber in good locations were logged in the early days. while in later years small-timber and second-growth areas in good while in later years small-timber and second-growth areas in good
locations have been brought into production in competition with large timber from less favored areas and locations. vantages, etc., would fail to be favorable tos the smalltimber operations, these are as a rule kept out, or forced out, of production. The lower log values which ordinarily go hand in hand with smaller timber simnly prohibit carrying on opesations on at much higher levei of costs than in large timber with which it must compete for a market.

General cost data are thus apt to be misleading. The comparisons are thrown askew through the presence of factors which have nothing to do with the point at issue and which by the very nature of the question tend to hide the basic disability of the small timber from a direct and clear view. In extending the comparison to other regions, for example, the picture goes out of focus through differentials in wage levels, which, when other measures fail and provided that necessity demands, are adjusted to keep the nominal cost of small-timber logging at a comparatively low level.

Nevertheless, specialization in the broad scnse here discussed is a potent enough factor to keep the cost of small-timber logging from rising very far above that of large-timber logging. It is to a large extent through specialization that, for example, the operator in Case Study No. 4 is able to show nearly as low a cost for a 600 board foot $\log$ as the operator in Case Study No. 3 for a 1,600 board foot log. Specialization in this case has been applied to the tract as a whole, operating facilities and methods having been adapted through all steps from stump to pond to fit the requirements of a fairly uniform type of timber of medium size. Many similar cases may be cited. And there are many instances where specialization along somewhat similar lines is applied to individual settings within any given logging operation, though quite often, then, with relatively less success on account of the difficulty under the present scheme of logging of applying it to all steps of the operation; the initial yarding operation frequently being the only activity to benefit in full.

107. Selective Specialization is Needed in this Region.-Specialization, broadly applied from region to region, tract to tract, or setting to setting along the lines discussed above, is a part of the general operating policy of the industry as a whole. This is specialization in its broadest form. As such it shows in a general way what specialization tends to do. Many instances might be cited to prove its effectiveness. With specialization out of the picture some mighty important upheavals in the line-up of the lumber industry would no doubt occur. 
But specialization along these broad, general lines, if followed up by the present system of clear cutting as practiced in this region, does not rally carry the idea of specialization into the woods. It reaches to the outskirts of the timber but does not enter. It fails to cater to the specific needs of the individual $\log$ or tree. ol, in a more practical sense, to specific size classes of logs or trees which occur within any given unit of opsrating area. Specialization in the latter sense shall hereinafter be termed "selective specialization," since it obviously wculd call for the selective removal of various size groups of timber occupying the same site, with each group to be logged in a manner that befits its size and style.

In principle, the need for selective specialization to fit the specific requirements of various size classes of logs or trees within an operating area is, obviously, just as great as the need to fit the same requirements from stand to stand, from tract to tract, or from region to region. If the spread in log or tree sizes within the area is large, the potential opportunities for selective specialization become correspondingly large. They disappear only if the differentials in size disappeax; a situation which from a practical point of view would arise, for example, in a second-growth stand of evenaged timber in which the diameters of the merchantable trees vary within comparatively narrow limits. As a general rule, then, specialization as applied to a stand as a whole does not do a complete job unless, in the practical sense, the timber happens to be exceptionally uniform in size.

In virgin timber areas typical of this region th s range in size is generally very wide. Even in so-called uniform even-aged stands of medium size virgin timber the merchantable trees will commonly be found to range from 16 to 60 inches in diameter; and logs from 100 to 4,000 board feet in volume with a sprinkling of other sizes both above and below. It is against this general background of sharp contrasts in log and tree sizes that a real opportunity is created for successful application of selective specialization.

A representative picture of the cost problem that selective specialization should aim to solve may be obtained by referring back to Tables 47 and 48 in Chapter XVII. In these tables the data represent six different logging operations -or, for purposes of illustration, they may also be considered as six different settings within a given timber property-each one representing a different type of timber. The average log from study to study varies from 400 to 1,600 board feet; the total spread in $\log$ size within each study, generally from 100 to 4,000 board feet or more. A certain degree of specialization has been attained in each case to fit the general character of the timber. The small-timber operations for this and other reasons show lower costs for a given size of $\operatorname{logs}$ or trees, particularly for the smallest size classes. But compared with the large-timber operations they suffer instead from having a much greater percentage of the total volume of timber in the mallest size classes. Their particular small log problem, therefore, has simply shifted its center of gravity toward a smaller log along with the decline in the size of the average $\log$; and remains just as acute a problem as in the higher-cost large-timber operations. In this sense a $\log$ of 300 board feet volume might occupy the same relative cost position in a large timber operation as a 100 board foot $\log$ in a smallt.mber operation; a "small" log being only a relative term to fit various types of timber.

108. An Estimate of Potential Possibilities for Cost Reduction Through Selective Specialization.To better visualize what specialization might do in these particular types of stands, the following table (Table 52.) has been set up in which (in the upper section of the table) yarding-to-pond costs for six different log sizes, as r.ad from the last column to the right in Table 47 , are contrasted with the cost theoretically attainable if specialization can be applied to the $n$th degree and successfully enough to remove all handicaps against the small log except that of increasing weight and bulk per board foot $\log$ scale. This trend then, is that of the changing cubic-foot-to-board-foot ratio, as read from Curve VI, Figure 39.19 In the lower section of the table the same comparison is given covering falling-to-pond costs for trees of various diameters. The trend of felling and bucking costs is here assumed to be the same for selective specialization as for present logging practice (Figure 41). This gives a slightly different composite trend of felling-to-pond costs for trees than of yarding-to-pond costs for logs.

19Cosis, if expressed in terms of dollars per cubic foot (or per cord, etc.) instead of per board foot. log scale, would on this basis remain constant for all $\log$ sizes. 
TABLE 52

Comparison of relation of size of $\log$ and tree to logging $\operatorname{cost}^{1}$-conventional logging practice versus selective specialization:

Cost in dollars per M ft., gr. log scale (Scribner Deeimal C)

Conventional Selective

clear-cutting specialization

Log or tree size

Volume, ft.b.m.

100

200

400

800

1,600

3,200 (base)

Inches-D.B.H.

16
20
24
32
40

60 (base)

to the nth degree

-Logs : Yarding-to-pond-costs $22.75 \quad 3.80$

$\begin{array}{ll}12.78 & 2.90\end{array}$

$\begin{array}{ll}6.75 & 2.47\end{array}$

$4.08 \quad 2.22$

$\begin{array}{ll}2.70 & 2.10\end{array}$

$2.06 \quad 2.06$

Trees: Felling-to-pond costs

$21.06 \quad 6.80$

$14.36 \quad 5.00$

$10.26-4.25$

$6.43 \quad 3.72$
$4.90-3.40$

$4.90-3.40$

3.35

3.35

"Excludes "fixed per acre costs" (such as road construction, riggin ahead, etc.).

${ }^{2}$ Based on assumptions stated in text.

Here, then, are two entirely different views of the relation of size of log or tree to logging costs; both show the same logs and trees on the same area, one showing the relations which arise if the timber is logged in wholesale clear cutting fashion using methods and machinery typical of this region, the other, the relations which may arise under the most intensive system of specialization, using methods and operating facilities best adapted for each particular size class of logs and trees.

The inherent weakness of the present wholesaie clear cutting system as practiced in this region and as applied to the type of timber that is characteristic of this region is here sharply exposed in principle. It shuts the door on specialization, and proceeds instead on the theory that what is good for one $\log$-and this, by the very nature of the system so created, must necessarily mean a large $\log$-is good enough for another. As a result, costs are relatively high except for the particular size class of logs for which the system has been designed to give its maximum degree of efficiency. They rise, as shown in the table, to unreasonable heights, heading rapidly for infinity if extended very far beyond the 100 board feet log size. At this point one can readily see that by enlisting the aid of the "pole man," the "tie hack," the "pulpwcod cutter" and their allies in the small log business costs can again be restored to a reasonable level. In other words, the idea of selective specialization can no longer be suppressed, when the present system finally gets so far out cf bounds that one is forced to recognize, with or without the aid of selective cost analysis, that the peavy or horse rather than the conventional types of logging machinery is the key to efficiency in the woods operations; the staked car, the flat car, or the wood car, the key to efficiency in the railroad operations. The present system often yields to these particular forms of selective specialization, but, surely, not quite so generally as would be the case if the unreasonably high cost of handling small logs under the present system were clearly recognized; and, in principle, surely not so generally as might be the case if a planned system of selective specialization for each major size group of timber could be worked out in a practical manner in laying out and organizing the operation as a whole.

It must be recognized, of course, that the real trend of costs under selective specialization can not very well be held down in practice, and hardly even in theory, to quite so slow a rise as that shown in Table 52. There the assumption, as stated, goes all the way to the $n$th degree. It assumes that between the "one-horse outfit" and the present types of large logging machinery, and between the box car and the unstaked disconnected steel trucks the logger will be able to select or devise the correct type of operating layouts to so fit the requirements cf each size group of logs as to wipe out all differentials in cost except the basic weight, bulk, and $\log$ making differentials as heretofore discussed. This assumption is quite reasonable in connection with some phases of the logging operation, but not so reasonable for cthers. It can be made to apply very closely, for example, to the railroad operations, since it is only a question of car length, bunk width, side stakes, etc., to so adapt the railroad cars that they will carry as great a weight of a size group of small logs as of large ones; or eren in the form of cordwood, pulp chips, or other forms of wood products. The same thing is true of motor truck or tractor hauling, or any form of transport that can be adapted for hauling of logs in some form of standardized "unit loads." But in other activities of the logging operation, where logs have to be handled piece by piece, or where it is impracticable to build up standardized unit loads as, for example, in direct yarding with donkeys the small logs are at a disadvantage. This, however. might not be a very serious handicap if the "unit load" system can be carried back close to the stump, thus making a minor task (such as a low-cost "bunching" job) of the initial yard- 
ing operations. These are the general lines along which the small-log regions have worked out their small-log problems. They appear to be applicable to this region under the conditions and plans discussed in the next chapter.

109. Flexibility in the Yarding Operation is Essential.-In Chapter XXII the question of applying and adapting the principles here discussed to the operating problems and physical conditions that are a part of the general logging picture of this region will be touched upon in the light of the operating plans followed and the results obtained in a recent series of selective logging experiments reported in Chapter XXI. There it will be shown that under the plan followed and under the conditions given, theory may be translated into practice without losing much of the strength claimed in Table 52.

The general procedure in a plan of selective specialization, as here invisaged, is to classify the trees into diameter or tree volume groups. Three major size groups-a large, medium and small-timber group-may be sufficient in the typical operation in virgin timber. Each of these groups is treated as if it were a separate stand, with only one thing in common with the other groups, namely, the road system. Each group, then, is logged separately, using an operating layout that is specially adapted for it all the way from stump to pond; different types of railroad cars, different types of loading machinery and different types of yarding machinery. Further specialization may be applied in the initial yarding or bunching operations within each major size group. The three major size groups may be logged one after another in rapid succession if the stand is to be clear cut at once. Or, better yet, from many viewpoints, they may be logged years apart if the stand is to be selectively cut and managed.

In this program of selective removal of various size groups of timber, the stump-to-car operations must necessarily be performed with the most mobile types of machinery, using the most flexible methods of operation. Horses, motor trucks, small tractors, large tractors, and tractor-mounted "donkeys"' (designed for short distance "ground lead" or "semi-highlead" yarding) all free to shift about over a closely spaced network of cheaply constructed "tractor roads" with virtually no moving and riggingahead costs to reckon with, are the most promising answers to this demand for mobility and selectivity. To what extent and under what con- ditions they are also the answer to low costs even if selection were not to be considered at all has heretofore been discussed, and is again demonstrated in the logging experiment reported in the following pages.

The conventional system of high-power donkey yarding does not fit in with this scheme of operation. It is not designed for mobility of the kind demanded here. It is not designed for reaching into a stand of timber to remove a certain size group of trees and to leave the others; and then to repeat this performance three or four times in succession by moving in other donkeys to remove other size groups of timber. Nor is it designed for first clear cutting a stand of timber and then attempting to pick out first one size group of logs and then another.

110. Clear Cutting Leads to Inefficiency in all Phases of Operation.-The method of yarding, then, is a controlling factor in deciding what can be done with the theory of selective specialization. Donkey logging of the conventional style goes out of the picture when selective specialization comes in; and vice versa.

This leads to an interesting question: How much may selective specialization be worth for raising the efficiency of activities other than the initial yarding operation? And how much may this add to the true, comparative cost of a yarding method that precludes the possibility of applying selective specialization in comparison with a method that makes it practicable to apply it?

Consider the railroad operations, for example. Log cars or trucks used in the operations covered in carloading studies reported in Chapter XII are rated generally at 80,000 pounds load carrying capacity. According to rough calculations, the average load of large logs, taking loads averaging 1,200 board feet and larger per log, weighed approximately 80,000 pounds. That is to say, this group of large logs (or trees) made on the average full use of the normal capacity of the cars on which it was carried. But in the same studies the average car, taking in all log sizes, carried only slightly over 50,000 pounds of logs. This is the situation created by providing facilities for large $\operatorname{logs}$ and then using them also for small logs. Under selective specialization, this type of cars would be used only for the large size class of timber, while staked cars, wider, longer, or lighter cars would be used for the smaller $\log s$ so that for each major size group it would be possible to utilize approximately the 
full normal carrying capacity of the cars. This means, roughly, that in transporting the logs produced in the average logging operation covered in these studies the present system requires about 50 per cent more log cars, 50 per cent more locomotives, and 50 per cent more "car miles" and "locomotive miles" of travel than would be required to transport the same total volume of logs under selective specialization. Since these added investments and operating costs are brought about as the result of the present indiscriminate system of yarding and lack of selective policy, they, for purposes of comparing a different plan of yarding, must be considered a part of the present yarding layout and costs rather than a part of railroad transportation.

The same line of thought should be applied in re-examining, for example, the booming and sorting operation, the loading operation (see Table 40 ), or other activities which are similarly affected by lack of standardization in log size. By thus going over the whole operation from the pond back toward the stump and charging the rost of this particular type of basic inefficiency to the yarding operation whence it originates, a more realistic view will be had of how much the initial yarding operation actually costs and what the relative merits may be of two entirely different plans of operation using entirely different methods of yarding.

\section{AN EXPERIMENT IN TRACTOR LOGGING AND TREE SELECTION POINTS THE}

\section{WAY TO A NEW LOGGING PLAN}

111. Experiment Needed to Verify Conclusions Reached in Studies.-The findings in the reported time and cost studies when first analyzed left many questions to be answered, doubts to be solved, and possibilities to be looked into. The greatest opportunities for increased efficiency and for increased flexibility which would facilitate intensive tree selection appeared to lie in the use of tractors. For these a far greater usefulness than they have had in the past in this region could be envisaged through the construction of a dense network of cheaply built tractor roads. By this means the best features found in the previously reported roading study - namely, a high degree of efficiency and applicability to difficult terrain-could be obtained and at the same time provide selectivity in logging at a low cost, eliminating, as far as possible, cold deck donkeys through extremely close spacing of tractor roads.

But, where the greatest possibilities seemed to lie, there was a lack of fundamental information which was badly needed. No reliable information existed as to what the approximate average cost might be of constructing serviceable tractor roads in forest areas typical of this region-a most pertinent question, of course, in a general plan calling for so vast a number of roads. The data on roading costs were furthermore rather meager. And no information existed as to what might happen to yarding efficiency and size-to-cost relations under a scheme of intensive selection.

Actual logging experiments were needed whereby new logging methods could be tried and the results recorded and analyzed. Credit for venturing into this line of experimentation belongs to the management of one of the largest logging operations of this region. They unhesitatingly closed down their well equipped steam logging operations and started instead to test equipment, methods, and ideas which heretofore have been considered impracticable for the type of timber and logging conditions with which they have to deal. This not only gave the desired information, but proved to be a gratifyingly profitable venture even while in the experimental stage.

Some of the more general conclusions and findings reached in these experiments have already been incorporated in preceding discussions of the possibilities and general applicability of the tractor roading system. In the following pages, however, is given a more direct and detailed discussion of the logging conditions, the yarding technic dertloped, and what the results have disclosed.

Mr. John E. Liersch, studying under a fellowship granted by the Charles Lathrop Pack Forest Education Board, and working in cooperation with the author, followed this project through from beginning to end, compiled the data and analyzed the results. It is from his report=0 that most of the following cost data, photographs, map, and direct quotations are taken.

2"I.iersch, John k.: lepport on Selective I.ogging Experiments Inpublished manuscript. 


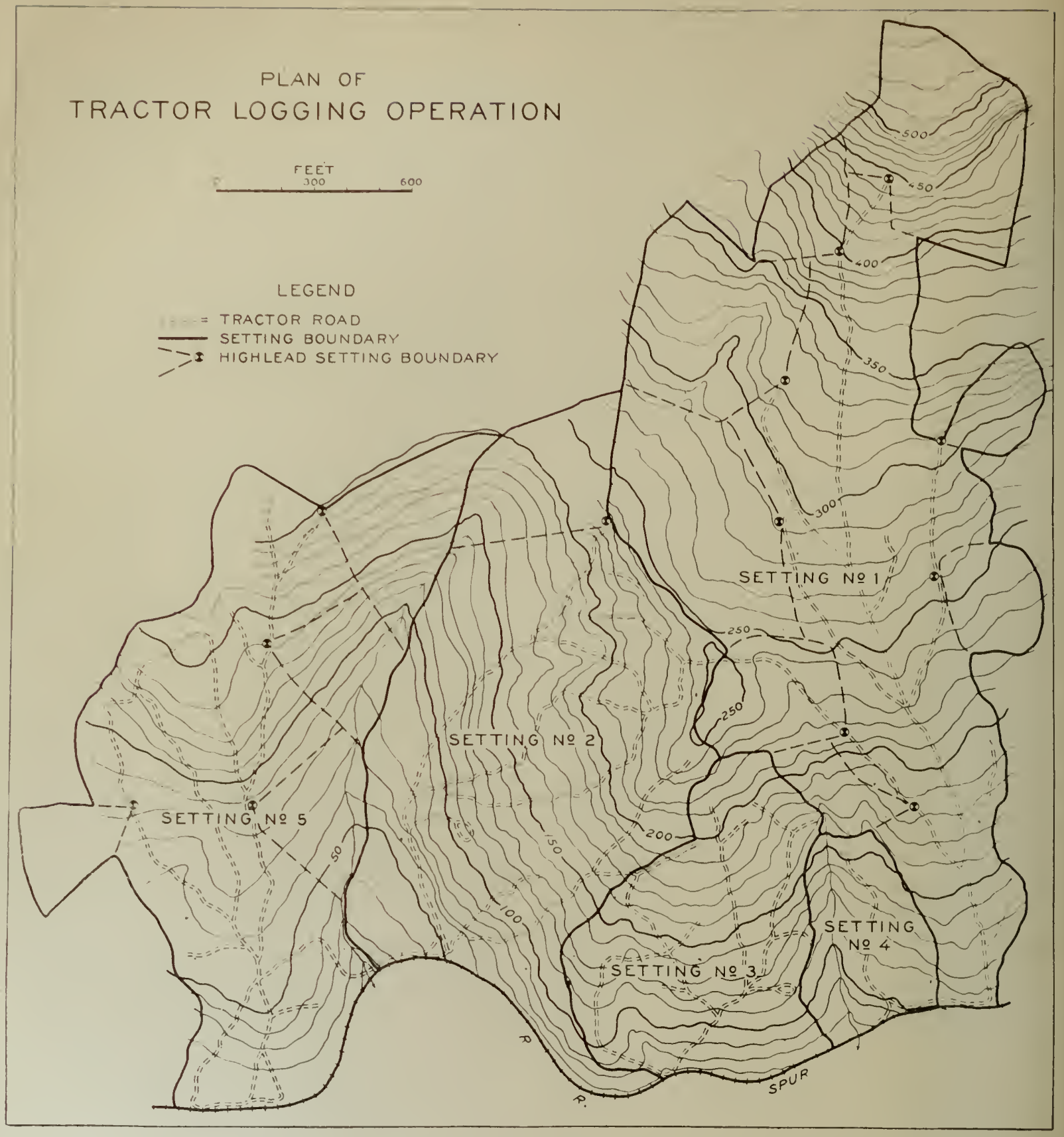

FIG. 43-PLAN OF EXPERIMENTAL TRACTOR LOGGING OPERATION

112. Description of Study Area and Logging Conditions.-The experiments were conducted in a typical stand of spruce-hemlock-fir which is found throughout the coastal fog belt of this region. The experimental area as shown by the accompanying map (Fig. 43) comprises about 200 acres. It is representative in all respects of the type of timber, ground conditions, and topography on which donkey logging had been conducted; some of the adjoining areas had already been so logged and the experimental area would have been next in line had the tractor logging experiment not disrupted previous plans.

Liersch describes the study area and experiments as follows:

"In general the soil consists of a top layer of duff and clay loam about 12 inches thick under which a 
stratum of pure clay of varying depth is found. It is this type of soil which makes it practically impossible to operate tractor's after heavy rains. Small patches of 'blue clay' are frequently encountered which have to be scrupulously avoided in building roads, as they form permanent 'soft spots' which make roading extremely difficult.

"The ground surface was rough, the windfalls few, and the underbrush dense, consisting of vine maple, salmon ber'ry, alder, and willow.

"Slopes as shown in Figure 43 varied generally from level to 40 per cent, except for a few short steeper stretches.

"The stand of timber" averaged slightly over 40,000 board feet per acre, and by 10 -acre subdivisions varicd from 30,000 to 60,000 board feet per acre. It consisted of veteran spruce trees and occasional Douglas firs ranging generally from 5 to 10 feet in diameter breast high with an understory of hemlock, white fir, and spruce up to 5 feet in diameter. The average log cut on the area scaled about 1,400 board feet.

\section{General Logging Plan and Methods:}

"The map of the logging plan is shown in Figure 43. The railroad spur shown in the lower boundary of the map had been located for donkey logging and therefore failed to provide as advantageous locations for tractor landings as might otherwise have been the case. Along this spur, landings (Figure 44) were constructed, each landing serving a setting as shown on the map.

"Tractor roads were built before any of the timber was cut, and in genaral were located at approximately right angles to the contours. They followed the undulations of the ground without attempting to secure uniform grades by balancing cuts and fills as is done in railroad construction. Roads were constructed with c. tractor equipped with a 'bull-dozer' (Figure 45), and the ground was simply cleared and leveled to a width of about fourteen feet. Grades varied from 5 per cent adverse to 30 per cent favorable, steeper grades being aroided by detouring.

"After the roads were built the trees were felled and bucked. Two 60 h.p. tractors drawing fair-lead arches were then used for roading the logs to the landing where they were loaded on car's with a locomotive crane (Figure 44). Logs within a reasonable distance of the tractor roads were direct-yarded either by taking the fair-lead line to the logs, or where conditions permitted, by backing the tractor and arch off the road to get closer to the logs."

"Where the area was not adequately served by closely spaced roads, a double drum unit mounted on a 60 h.p. tractor (Figure 3, Chapter II) was used for high-leading the logs to the roads from which they were roaded to the landing with the roading tractors. For the yarding, spar trees were rigged with four guy lines, the high-lead block being usually hung at an elevation of 100 feet or higher. Logs scaling over 4,000 feet frequently required a block purchase, but otherwise did not cause any difficulties. Yarding distances rarely exceeded 500 feet and the average setting embraced about 4 to 5 acres as is shown on the accompanying map (Figure 43 ).

"The first area to be logged was the upper half of Setting No. 1, which was followed in turn by the lower half and then by the other settings in the order of their numbering on the map. At first, roads were built as straight as possible and any obstacles in the way were blasted, the total cost of construction being about $\$ 400.00$ per mile. As logging progressed alinement standards were gradually modified and the roads more frequently detoured around stumps to avoid blasting. It was possible to haul logs up to 64 feet in length without a noticeable loss in travel time in following the windings of the road. As the 'bull-dozer' operator became more accustomed to his work the cost of rosed building was considerably redueed and the winding roads of Setting 5 cost only $\$ 26(0.00)=1$ per mile as compared to $\$ 400$ for the roads in Setting 1 . As the cost of construction was reduced, more roarls were built, and as logging progressed from Settings 1 to 5 these were spaced more closely as is shown by the map (F'igure 43)."

114. Reduction in Road Construction Cost Leads to a Denser Network of Tractor Roads:

It will be seen from the map (Figure 4is) that where the dense road systems are built (as in Settings 3 and 4 , and on most of the area embraced by Sêttings 2 and 5), high-lead yarding is entirely dispensed with, and the logs are direct-yarded with the roading tractors. On these areas an average of about 250 feet of roads was built per acre or at the rate of about 30 miles per section of timber. If uniformly spaced and lined up parallel to each other, these roads would be only 176 feet apart and the average distance from center of stump to center of nearest road only 44 feet. Allowing for branching and winding of the roads, the average actual distance from the stump to ihe nearest road is less than 60 feet. It was the policy in locating the roads, particularly the short branch roads, to have them pass by the larger trees so that these could be felled across the road in such a way that it would be easy to get the fair-lead arch close to the logs, and thereby climinate the problem of ground-leading the heavy logs, some of which scaled over 6,000 board feet (see Figure 46). Trees of small or medium size, on the other hand, were usually felled quartering away from the road so that the heavy brush and tops would be clear of the yarding operations. Logs from these trees offered as a rule no difficulties in ground-leading with the fair-lead line over distances up to about 100 feet. As a result of this policy, it was found that on the average it required no more time to make up a tur'n of logs in direct-roading than in roading from the high-lead cold decks.

This leads to an interesting comparison between the intensive roading system as exemplified, for instance, by setting No. 3 and the less intensive system represented by a large portion of Setting 1. Placing the cost of road construction at $\$ 200$ per mile and the stand : olume at $40 \mathrm{M}$ feet b.m. per acre it costs only $\$ 0.25$ per $M$ to provide an intensive road system of 250 feet

"This cost includes all items commected with the bull dozer oper ation, based on a "full marhine rate" of $\$ 33.37$ per $\$$-hour day tor tractor and two men. and mcludes l. lasting of stumbs, surveving of roads, and roal maincuance as well as some time spent ou helping the roading tractors to loost heavy loads over adverse gratles. 

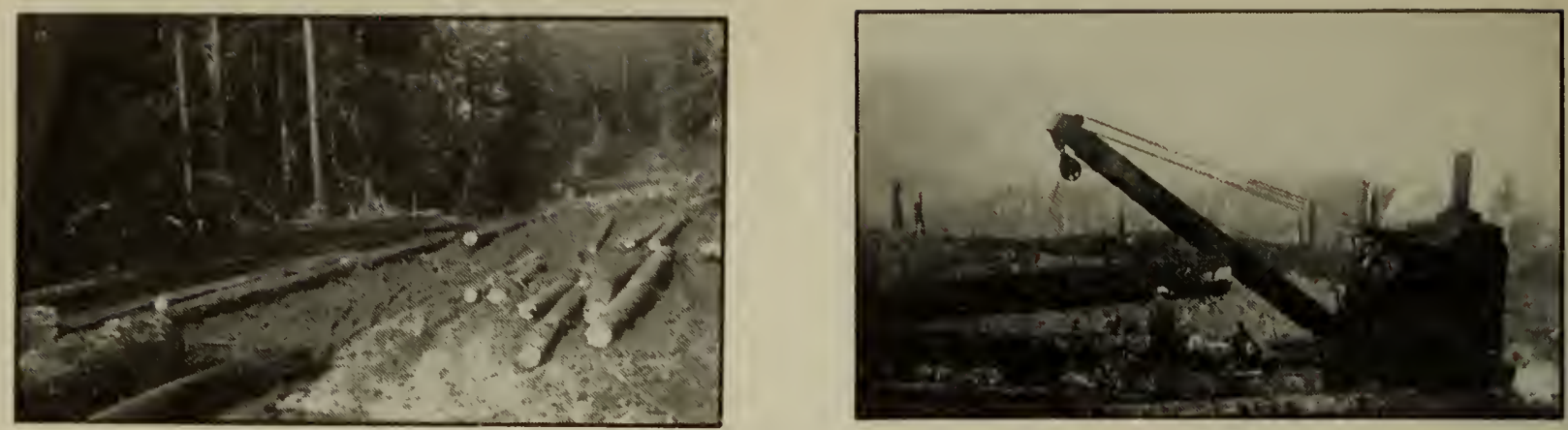

FIG. 44-(LEFT) A WELL LEVELED, ROOMY LANDING TO WHICH THE TRACTORS DELIVER THE LOGS: (RIGHT) LOCOMOTIVE CRANE WITH HEAD BOOM LOADING LOGS FROM TRACTOR LANDING

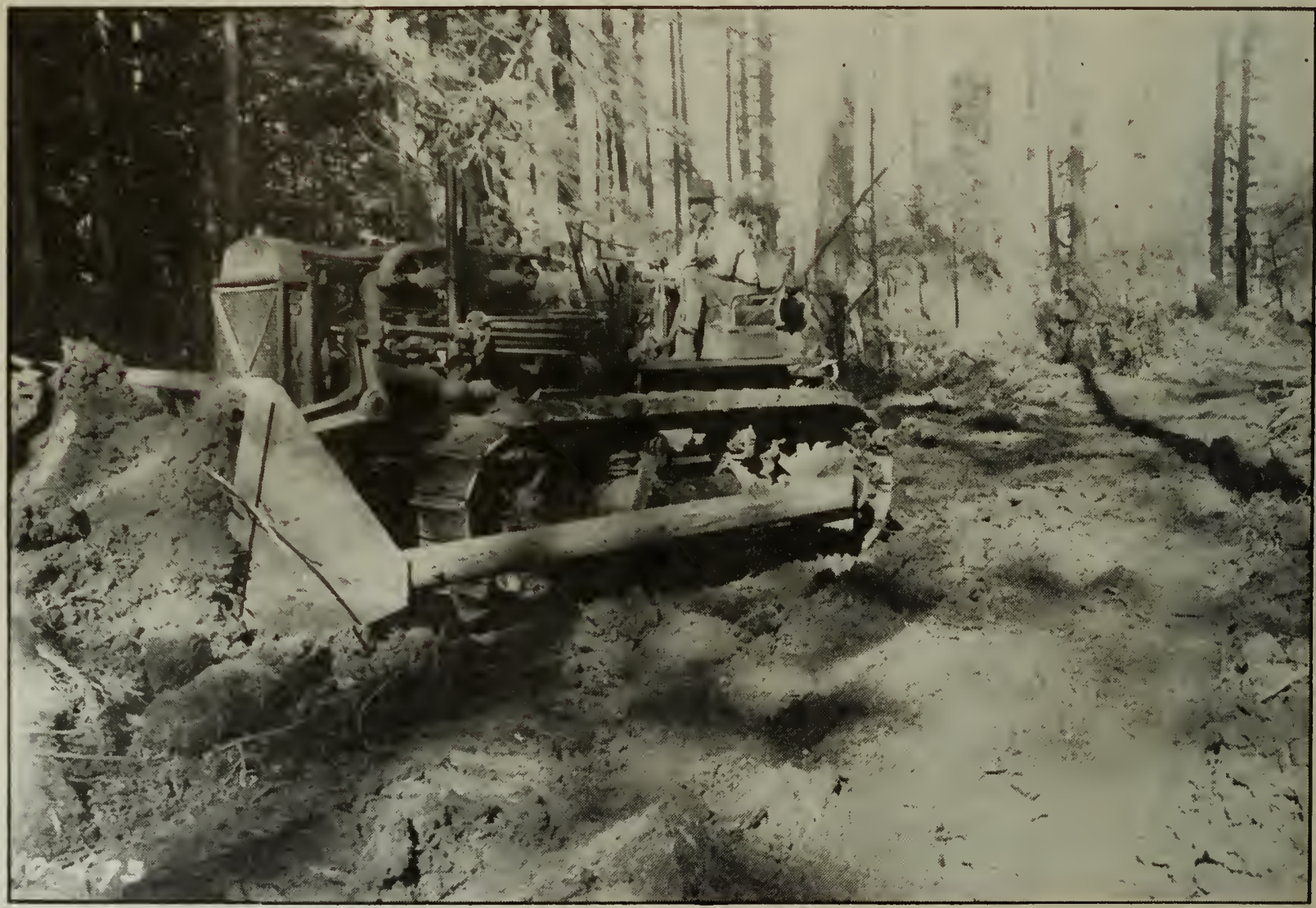

\section{FIG. 45-THE "BULL.DOZER" AT WORK. GRADING IS PERFORMED MOST EFFICIENTLY BY WORKING DOWNHILL}

of roads per acre (i.e., sufficient roads to give as high a degree of efficiency in the directroading operation as in roading from the highlead landings). In contrast to this the cost of high-leading the logs to the tractor roads was $\$ 0.65$ per $\mathrm{M}$, a difference of $\$ 0.40$ in favor of the intensive roading system. An examination of the map shows that roads can be built into the high-lead areas just about as easily as into the direct roading areas, there being no topographic or other difficulties to prevent this. This situation was not recognized until after 

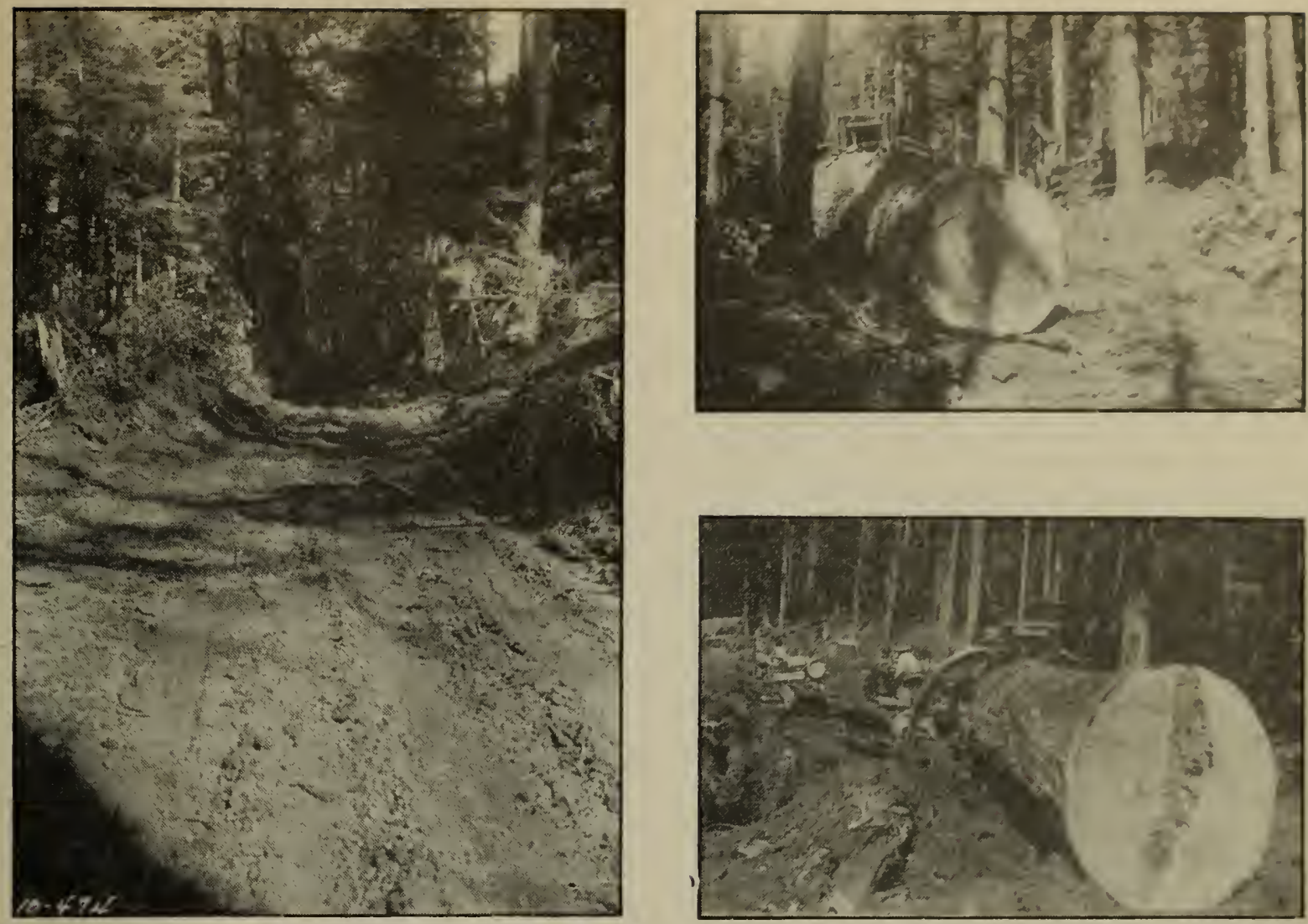

FIG. 46-(LEFT) TRACTOR ROAD CONSTRUCTED WITH "BULL-DOZER" AT A COST OF S2OO A MILE (UPPER RIGHT) HAULING A 5.6 M FT.E.M. LOG 1,100 FEET TO THE LANDING AT A COST OF 22 CENTS PER M: (LOWER RIGHT) ROADING A 6.2 M FT.B.M. LOG WITH THE AID OF A HELPER TRACTOR 48 HOURS AFTER A HEAVY RA!N
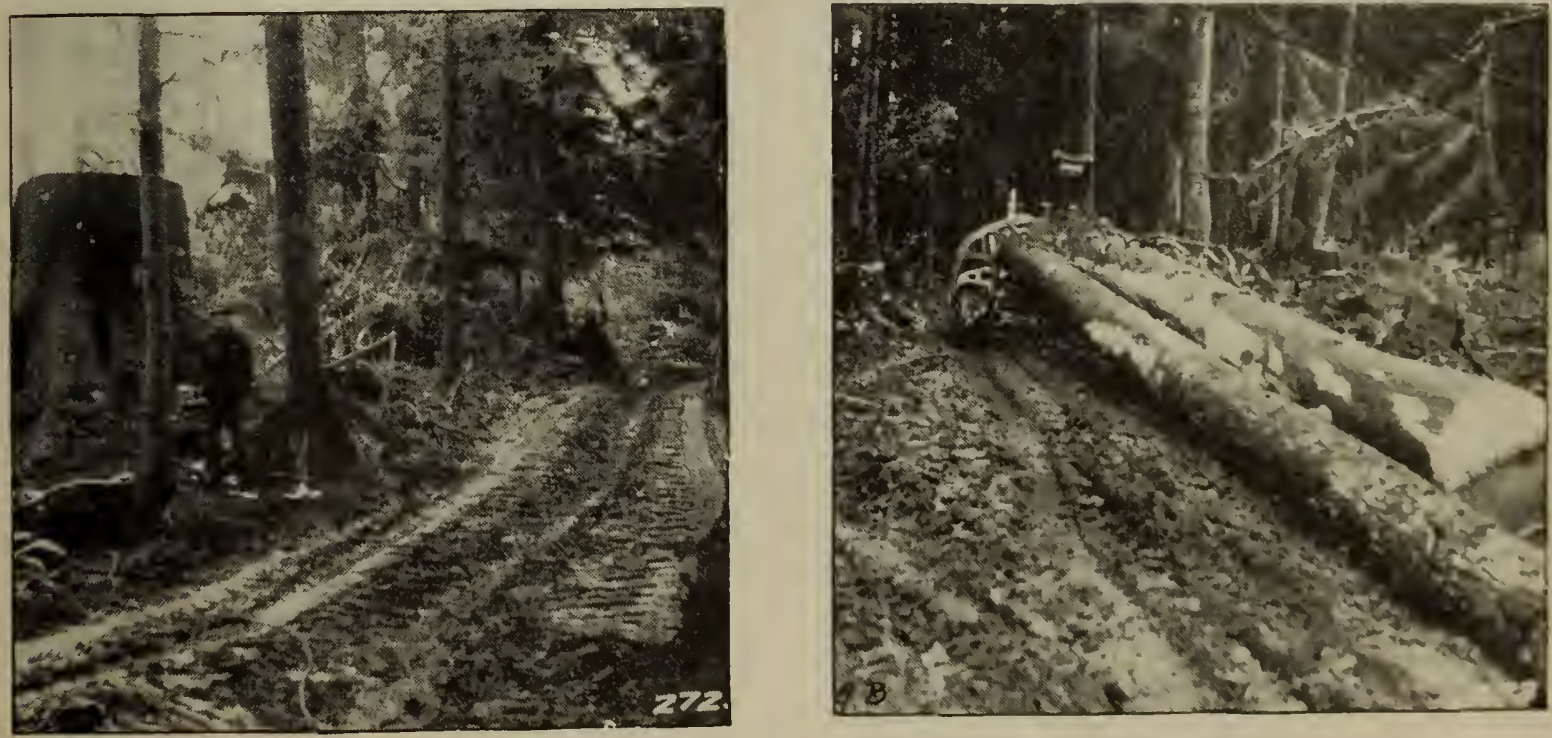

FIG 47-(LEFT) WINDING TRACTOR ROAD ON 20 PER CENT GRADE: (RIGHT) BUTT LOGS FROM TREES UNDER FIVE FEET IN DIAMETER WERE USUALLY TAKEN IN 56 OR O 4 FOOT LENGTHS 
the whole area had been logged and the cost data had been assembled and compared. At the beginning of the experiments high-lead yarding was accepted as a necessary part of the proposed system, in fact as the rery key to the practicability thereof, because it was confidently exepected that, although the direct roading scheme might fit certain portions of the area, it would not fit all of it. Were the job to be done over again, the high-lead could very well be eliminated with the intensive roading system making a clean sweep of the whole area. The logging plan shown in Figure 43 should therefore be looked upon merely as a record of the evolution of the roading system, beginning with the combination of roading. first, with highlead cold decking, second, with high-lead hot yarding, and as a climax, direct-roading. The high-lead, of course, may reenter the picture on steeper or rougher areas than those shown in the map.

115. Object and Plan of Tree Selection Experiments.-After the first general experimenting with road construction and yarding methods had established the practicability and led to the adoption of the intensive roading system as illustrated by Setting No. 3 in Figure 43, the experiment was directed toward the question of intensive tree selection. Here it was desired to determine the feasibility of logging the timber in several successive cuts and what increase or decrease of cost, if any, results from such a procedure.

To throw light on this question three represcntative areas comprising a total of 54 acres were laid out for careful study. Detailed reports on Study Plots Nos. 1 and 2 as reported by Liersch are briefed as follows:

"Study Plot No. 1 comprises 6.8 acres, with a volume of 411,680 board feet, or about 60,000 board feet per acre. It is located in Setting No. 3.

"Study Plot No. 2 amounts to 11.4 acres, with a stand volume of 410,530 board feet, or 36,000 board feet per acre. It is located in the center of Setting No. 5, comprising the entire area enclosed within the double loop of tractor roads shown on the topographic map. The stand volumes given represent volumes actually removed. On both study plots the distribution of stems was fairly uniform throughout.

"The trees on the study plots were first classified and marked for three separate cuts. The first cut included all trees above 40 inches in diameter breast high; the second, trees between 30 and 40 inches; and the third, trees below 30 inches, the minimum di. ameter reaching 18 inches for trees that were well shaped enough to yield a fairly good 56-foot or 64-foot log.

"The fallers were instructed to fell only the trees which were marked for the particular felling on which they were working. In felling the first cut, there was little leeway in choosing the felling direction because of the size of the timber. In a few cases the situation would therefore arise where certain trees marked for a subsequent cut would be in the way of larger trees, which made it necessary to fell them along with the first cut.

"After a portion of the first eut had been felled and bucked, the yarding-roading operation was started and all logs from the first cut were removed; the second and third cuts were subsequently logged in the same manner. Portions of the stand within each study plot were set aside as check plots for logging of all three size groups in one cut (i.e. for ordinary clear cutting) so as to obtain a basis for comparison of the cost of clear-cutting with selective cutting."

116. Results Show Advantages of Tree Selec. tion.-Detailed time and cost studies were kept on every turn taken from the plots, together with information as to the number and volume

TABLE 53

Comparison of clear cutting with selective cutting for various sizes of trees and logs Plot No. 1-Average roading distance, 650 fert

\begin{tabular}{|c|c|c|c|c|c|c|c|c|c|c|c|c|c|}
\hline \multirow{7}{*}{$\begin{array}{l}\text { Size class } \\
\text { d.b.h. } \\
\text { Inches } \\
40 \text { and over... } \\
30-40 \\
18-30 \\
\text { Weighted av. } \\
\text { all sizes... } \\
\text { Mixed cut } \\
\text { all sizes. }\end{array}$} & \multirow{5}{*}{\multicolumn{3}{|c|}{ 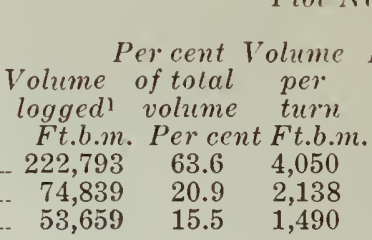 }} & \multirow{5}{*}{$\begin{array}{l}\text { Logs } \\
\text { per } \\
\text { turn } \\
\text { No. } \\
1.13 \\
2.06 \\
2.47\end{array}$} & \multirow{5}{*}{$\begin{array}{c}\text { Average } \\
\text { log } \\
\text { Ft.b.m. } \\
3,593 \\
1,040 \\
617\end{array}$} & \multirow{5}{*}{\multicolumn{2}{|c|}{$\begin{array}{cc}\text { Haul } & \text { Hook- } \\
\text { back } & u p \\
\text { Min. } & \text { Min. } \\
3.46 & 3.68 \\
3.46 & 5.47 \\
3.46 & 5.97\end{array}$}} & \multirow{2}{*}{\multicolumn{3}{|c|}{$\begin{array}{l}\text {-Time per turn- } \\
\text { Haul- Un- }\end{array}$}} & \multicolumn{2}{|c|}{ Output } & \\
\hline & & & & & & & & & & & & & $\begin{array}{l}\text { Cost per } \\
\text { Ift.b.m.2 }\end{array}$ \\
\hline & & & & & & & & & & & & & lars \\
\hline & & & & & & & & & & & & & \\
\hline & & & & & & & & & & & & & \\
\hline & 351,291 & 100.0 & 2,788 & 1.90 & 1,466 & 3.46 & 4.41 & 3.14 & 0.67 & 1.5 & 13.22 & 101 & $0.2^{\circ}$ \\
\hline &, 262 & 3 & & & & & & & & & & 75 & 0.48 \\
\hline & & $\begin{array}{l}55.8 \\
32.8 \\
11.4\end{array}$ & $\begin{array}{l}3,8 \\
2,3 \\
1,6\end{array}$ & $\begin{array}{l}1.18 \\
2.19 \\
2.59\end{array}$ & $\begin{array}{r}3,25 \\
1,07 \\
61\end{array}$ & & & & & & & & \\
\hline & 379,336 & 100.0 & 2,810 & 1.94 & 1,445 & & & & & & & & \\
\hline & & 3 & 2,022 & 2.12 & 951 & 4.73 & 5.78 & 4.32 & 0.82 & 1.54 & 17.19 & 56 & 0.64 \\
\hline
\end{tabular}

${ }^{1}$ Spaulding Log Scale. ${ }^{2}$ Costs are based on full machine rate of $\$ 36.04$ per 8 -hour day for tractor, arch and crew.

${ }^{3}$ The mixed cut shows the following percentage distribution of volume: (1) Plot 1: First cut, 35.6 per cent; second cut, 39.0 per cent; thisd cut, 25.4 per cent. 
of $\log$ s per turn and distance of haul. The results are tabulated in Table 53. The data for the mixed cut represents the check plots that were clear cut.

The table shows that the cost relation between the three separate cuts are approximately in the ratio of $1: 2: 3$ on both plots. Thus cin Plot 1 the large-timber cut cost $\$ 0.23$ per $M$; ihe medium timber, $\$ 0.50$; and the small timber, $\$ 0.73$. On Plot 2 the three cuts cost $\$ 0.32$, $\$ 0.55$ and $\$ 0.77$, respectively. These relations are practically identical with the relations shown for the same distances and log sizes in the tractor yarding study reporter in Table 5, Chapter IV. Table 5 represents costs allocated to "sorted" log sizes, while Table 53 is based on average log sizes of the three separate cuts.

Probably the most interesting result of the experiment was that it is possible to practice tree selection by removing timber in successive cuts and to do so at a cost below that of clear cutting. On Plot 1 , according to Table 53, the average cost of logging trees 18 inches in diameter and over was 36 cents per M b.m. and for clear cutting (mixed cutting) 48 cents. This same advantage of the three-cut method is shown by Plot 2 where the respective costs are 45 cents and 64 cents.

In laying out the plots a conscious effort was made to have the portion which was selectively cut of the same character and size classes as the check plots which were clear cut. Unfortunately, however, analysis of the data showed that the clear cut areas had a smaller representation of the larger size classes and consequently a higher logging cost. To obtain a very precise comparison between selective cutting and clear cutting, a recapitulation was made for the portion of each plot that was clear cut. To do this the percentage of each size class making up the total volume (footnote 3 , Table 53) was multiplied by the cost for each size class when logged selectively and the cost compared with that actually obtained in the clear cutting experiment. The result showed that the clear cut portion of Plot 1 could have been logged in three cuts for 46 cents per M whereas it actually cost 48 cents. On Plot 2 the saving would have been still greater, the cost by the three-cut method being 55 cents per $\mathrm{M}$ and by the mixed cut 64 cents.

In other words on Plot 1, after adjusting for difference in log size, the cost was two cents per $M$ less than if the same logs had all been logged together and on Plot 2, nine cents lessa saving of 4 and 16 per cent, respectively. The savings are probably due to the opportunities offered in selection to standardize the work and to have the size of the rigging and the size of the crew in harmony with the size of the logs. When logs of all sizes are mixed a one-log turn will require only one choker while a turn of small logs will require five or six. Under these conditions, the hooker will often be short of chokers and at other times have more than necessary. Large logs and small logs, long logs and short logs do not mix well in the loads and the hooker's judgment of what constitutes a good load is less reliable when uniformity in log size is lacking.

Another point of importance to the operator is that some of the problems in felling and bucking are simplified. Experienced fallers can be selected for felling the large valuable trees while the mediocre fallers can be assigned to the smaller trees in the secord and third cuts. Besides reducing breakage, criss-crossing of timber will be avoided and the work of the buckers will be greatly simplified. Felling need be done only a day or two ahead of the roading and less money is tied up in felled and bucked timber; the fire risk also will be small because the felled trees are scattered about in the shade of the forest.

The flexibility of the roading system, it was further found, could be carried considerably beyond the general scheme of removing the timber in three cuts. The woods superintendent thus discovered that he could stay at the landing and to a certain extent direct intensive selecion of $\log$ s to serve whatever purpose he had in mind. If he temporarily wanted more of a certain type of logs for bunk loads, he would give orders to that effect to the tractor drivers and $\operatorname{logs}$ of the type desired would soon begin to arrive at the landing; and if he wanted some particular type of $\operatorname{logs}$ to "top off" the loads. he would so order and it would be so done. In cther words, a high degree of selective control could be obtained, particularly in removing the "first cut" where practically every $\log$ is a separate load and, therefore, can be dealt with individually.

"All this evidence points to the conclusion that even if an operator plans to clear cut an area, it will be an advantage to fell and $\log$ the timber in several suc. cessive cuts. Not only can the yarding-roading be done more cheaply, but under the three-cut method the breakage is considerably less.

"An important fact to be bol"ne in mind in planning several separate fellings on an area is to see that no one felling is so sparse that the roading tractor must travel considerable distances up and down the roat: in order to pick lip a full turn. This situation would not be encountered in the larger size classes, where one or two logs generally make up a full turn, 
but only in the second and third cuts where a greater number of logs make up each separate load. This difticulty can easily be avoided by proper marking of the timbel to be felled." ".:

117. Large Timber is No Handicap to Tractor Logging.-Individual trees on the study area measured as much as 10 feet in cliameter. Logs from the very largest trees were cut shorter than they might have been cut for donkey logging; generally not to exceed much over 5,000 and rarely over 6,000 board feet in volume. The largest $\log$ removed from the experimental plots, for example, scaled 6,500 board feet. These are large logs for any type of equipment and in many operations $\operatorname{logs}$ of this size are extremely rare if encountered at all. They were found to be the most ideal type of $\log$ for down hill tractor roading, as may be gathered in part from an examination of costs and outputs listed in Table 53. There it is shown that unbelievably high outputs and low costs result from keeping the tractors busy with the large logs. The output thus averages 154 M board feet per 8-hour day in logging the first cut in Plot 1, and $114 \mathrm{M}$ in Plot 2, with an average $\log$ scaling about 3,600 and 3,300 board feet, respectively. The first day of logging the large-timber cut in Plot 2, when specially large logs were selected, showed an output of $138 \mathrm{M}$, with an average $\log$ volume of slightly over 4,000; surely an unusually high output for a two-man outfit gathering in logs scattered all the way from 500 to 2,000 feet from the track. Yet, it represents, according to the time data, only normal performance supported by an abnormally large average log.

Back of these figures are the advantages gained through down hill logging. On level ground a 4,000 board foot log is about the practical limit of the "one-tractor" haul; while larger logs require a "two-tractor" hook-upwith consequent increase of costs.

It is believed that in the large timber here encountered more powerful tractors might be used to great advantage. If 80 or 100 h.p. tractors had been used it would have been possible in this operation to cut many logs up to 8,000 board feet in volume. With the virtually unlimited flexibility that is obtained under the selective plan of operation it can readily be seen that real economy might result by assigning this type of tractor to specialize, if logging down hill, primarily on one- and two-log turns made up of $\operatorname{logs}$ scaling generally from 2,000 to 8,000 feet in volume (i.e., on taking out a "first cut" of trees ranging generally above

\footnotetext{
${ }^{22}$ This problem of density of stand can also be solved by using
} specialized outfits for bucking small logs as discussed in Chapter XXII. six feet in diameter). Or, on level ground it would permit cutting logs of 5,000 to 6,000 board feet volume without resorting to a twotractor hook-up. It might also be assigned to hauling over adverse grades, or other special tasks, whereby the extra power may be utilized to good advantage. However, if not so utilized for large-timber or other heavy duty roading, it, like the "over-size" donkeys, might casily become a liability instead of an asset because much of the logging can be done at lower cost with a smaller tractor. Through selective specialization which is made possible by tree selection, the misapplication of specialized machinery can be avoided.

118. Comparison with Conventional Donkey Logging.-It is shown in Table 53 that the weighted average cost of roading the three cuts on Plot No. 2 amounts to $\$ 0.45 \mathrm{per}^{*} \mathrm{M}$ feet b.m. This applies to distances from 500 to 2,000 feet, the weighted average distance being 1,100 feet and the average $\log 1,445$ board feet. The cost represents the "full machine rate" (\$36.04 per day per tractor outfit) covering all items connected with the yardingroading operations proper. The only remaining item to consider is road construction which in this particular case, according to data collected by Liersch, amounts to $\$ 0.22$ per M. Total stump-to-track costs (roading and road building) thus amounts to $\$ 0.67$ per $\mathrm{M}$.

Direct skidding for the same timber on the same area, using conventional steam logging equipment and including the cost of rigging ahead, is estimated to cost $\$ 1.30$ per M b.m. based on time and cost study data obtained on the same operation during the previous year, with costs adjusted for wage decreases, etc.. from the year 1931 to 1932 . The lowest estimate of combined short distance cold decking and skyline swinging shows a cost of about $\$ 1.20 .: 3$ In other words, the reduction in costs under the direct roading system is about 50 per cent.

Disregarding capital charges - interest, taxes, and depreciation-on the investment in the steam logging machinery on the principle that it has already been paid for anyway, it is found that the cost of direct skidding drops to $\$ 1.10$ and that of cold decking (short distance) and swinging to $\$ 1.02$. These costs represent, then, the current out-of-pocket costs of operation, covering labor, maintenance, fuel, wire rope, etc. Even on this basis the intensive roading system, although carrying all capital

${ }^{23}$ For large cold-deck donkeys and longer yarding distances the corresponding cost is estimated at about $\$ 1.50$ per $M$. 
charges, shows nearly 40 per cent reduction when compared with the competing system.

It is significant that this situation applies to the timber within direct skidding or swinging distance from the track landings. It has heretofore been pointed out that the most pronounced advantages of the tractor system apply to timber beyond the direct reach of the "first skyline swing"-a fact that is shown most strikingly in Figure 33 (Chapter IX). The results of this experiment, however, prove that the intensive roading system-by entirely eliminating the cold decking operations-has a very substantial advantage even for timber close to the track landing.

In extending the comparison to the 200 -acre area as a whole it is found that the average cost under the intensive roading system would amount to about $\$ 0.80$ per M (including capital charges and tractor road construction), while the corresponding cost under donkey logging would amount to about $\$ 1.50$ (with capital charges excluded). The latter figure allows that under the donkey system all the timber that is located more than 1,600 feet from the track wculd on the average have to stand either the cost of relaying or else the cost of switch back spur construction which had been planned under the original donkey logging plan for shortening the stump-to-track distance of the outlying timber on this and adjoining areas.

This relatively low cost, it should be remembered, applies only to the intensive-roading tree-selection system. The average logging cost for the entire 200-acre area was actually higher than this because various experiments made (cold decking, clear cutting, and higher cost of road construction at the beginning of the job) brought considerably higher costs for approximately 60 per cent of the area logged.

119. Closer Attention to Load Volume Will Bring Further Savings.-It is believed that these strikingly low costs can be reduced still fur- ther by developing the roading proredure along the lines emphasized in Section 54. There it was pointed out that the key to high efficiency in long distance down hill roading is to build up large loads and it was suggested that the same policy should be carried out in short distance roading. This point was not emphasized so much in carrying out the experiments on Plots 1 and 2, its full significance having escaped attention until a comparison could be made of results obtained under different operating policies. On Plot 1 in particular many turns were hauled only a few hundred feet and the idea of building up large loads did not seem of much importance. That it is important, how ever, even in short distance roading, is indicated by the data given in Table 54 .

As shown in Table 54 the average load volume in the short distance roading studies (Column 3) is 2,800 board feet. The average log here scales 1,455 board feet. In the direct-yarding study reported in Column 2 the corresponding load volume for the same log volume and distance is 2,250 board feet. In the long distance roading study (Column 4 ) the load volume is 4,256 board feet-this being the average load volume for an average log of 1,120 board feet and here assumed applicable also to a $\log$ size of 1,450 board feet.

An examination of the time data in Table 54 shows that the large load volume in the long distance roading study is not attained accidentally but represents a definite policy of devoting plenty of time to the hooking-up operation. Comparison with the other studies shows that there is a definite correlation between hook-up, unhook and delay time with increasing load volume. Equally consistent, but pointing in the opposite direction, are the striking contrasts shown in cost per $M$ feet.

The quick get-away with the load and the resultant high cost as illustrated by the short distance yarding study (Column 2) represent a policy of indifference toward maximum load

TABLE 54

Comparison of time elements, turn volumes, and cost in three different tractor studies

\begin{tabular}{|c|c|c|c|}
\hline & $\begin{array}{c}\text { Short distance } \\
\text { yarding } \\
\text { from Table } 5\end{array}$ & $\begin{array}{c}\text { Short dsitance } \\
\text { roading } \\
\text { from Table } 53\end{array}$ & $\begin{array}{l}\text { Long distance } \\
\text { roading from } \\
\text { Tables } 3 \text { \& } 39\end{array}$ \\
\hline board feet & 2,250 & 2,800 & 4,256 \\
\hline ook and unhook time per turn-minutes & 3.41 & 5.40 & 6.96 \\
\hline $\begin{array}{l}\text { per turn-minutes } \\
\text { nd haul-back time per } 1,000 \text { feet of hauling dis- }\end{array}$ & 1.27 & 1.54 & 1.70 \\
\hline -minutes & $\begin{array}{l}9.54^{2} \\
0.62\end{array}$ & $\begin{array}{l}8.79 \\
0.42\end{array}$ & 8.45 \\
\hline adjusted to comparable machine rates, 1932 basi & 0.54 & 0.42 & 0.30 \\
\hline
\end{tabular}

1. Load volume in board feet

2. Average hook and unhook time per turn-minutes

3. Delay time per turn-minutes

4. Hauling and haul-back time per 1,000 feet of hauling distance-minutes

5. Cost per $M$ feet b.m. at 1,000-foot hauling distance-dollars

6. Cost per $\mathbf{M}$ adjusted to comparable machine rates, 1932 basis dollars

'Average of plots 1 and 2.
"Level grades. 
volumes. In the long distance roading study, on the other hand, a more serious view is taken of the importance of securing large load volumes; the hooker uses a scale stick to supplement his judgment and takes whatever time may be needed to build up to or beyond a fixed minimum load. The short distance roading studies in Plots 1 and 2 stand intermediate between these two extremes both in the policy followed and in the results obtained.

In the light of these data the conclusion is inescapable that the policy of building up large loads should be adopted without compromise even in short distance roading. It is plainly shown that the efliciency attained in the short distance roading studies is virtually identical with the long distance study in regard to traveling and delay time and is substantially in harmony in regard to hook-on time if allowance is made for the difference in load volumes. All that is lacking in order to obtain the same ultimate cost efficiency (as in the long-distance study) is stricter attention to large load volumes. For the short distances involved in Plots 1 and 2, this means only a few cents per M, but in extending the view to long-distance roading it becomes more important. For example, the long distance roading study shows a.cost of $\$ 1.14$ per M at a distance of 6.600 feet, while the extension of the results obtained in the short distance studies to the same distance indicates a cost of $\$ 1.74$.

120. Reduction of Breakage, Another Advantage of Tractor Method.-The reduction of breakage in logging with tractors is an important factor in increasing the cash returns from an area. The company's records on this operation show that when conventional steam logging methods are used, the commercial water scale is 82 per cent of the woods scale and for tractors 88 per cent. Using $\$ 9.70$ per M b.m. as an average log value, the saving resulting from the use of tractors amounts to $\$ 0.71$ per M.

Based on log values obtained in 1931 the corresponding net saving would amount to about one dollar per thousand. This may be considered a fairer figure to use since all cost data previously dealt with in the reports are based on 1931 costs. Even the $\$ 36.04$ tractor machine rate that has been applied to the 1932 experiments comes within about a dollar of the corresponding machine rate for 1931 , and therefore need not be adjusted in going back to the 1931 base.
121. Summary and Conclusions of Logging Experiment.-The experiments reported above were eminently successful. The intensive roading system and the intensive tree selection plan are here shown to work hand in hand to give a logging method which not only is practicable but, in all important respects, strikingly superior to present methods. Three principal advantages may be noted:

1. A striking reduction of cost amounting to about $40 \%$ of corresponding donkey logging costs for the distances involved in the experiment. Further savings would result by utilizing this low cost method for longer distance of haul, resulting in the skeletonization and simplification of the entire railroad network and transportation set-up along the lines discussed in Chapter XIX. In the final analysis this rebalancing of the operating scheme as a whole operates, as heretofore shown, to take a large share of the reduction of costs in the form of lowered railroad construction and other "fixed-per-acre" costs and capital investments therein, rather than to take all of the reduction in the form of lower "yarding variable" costs -a shifting of the source and character of cost reductions which is extremely important in utilizing these methods to promote intensive timber management.

2. A striking reduction of breakage, which is about sufficient in this particular case to pay for the entire cost of roading and road construction.

3. A high degree of selectivity which, through selective specialization, may be utilized further to obtain important economies in other phases of the logging operations (loading, railroad transportation, etc.) and which is invaluable for promoting the intensive application of sound principles of forest management and for many other purposes.

of these three advantages, the first two have been definitely appraised in dollars and cents. The third has been discussed so far only on the strength of general principles, but will be considered again in the following chapter.

\section{Weather Difficulties Detract from Advantages}

Against these important advantages the most serious disadvantage applicable to the case at hand is the problem of wet weather logging. The results reported apply exclusively to dry veather logging. Wet weather in this particular operation means the shut down of the tractor operation. To secure year-round production (or an operating season of 8 to 10 months) as is 
possible with present methods of donkey logging, a plan similar to that discussed in Chayter XIX may be adopted. The main feature of this plan, it will be recalled, is that the tractor rcading system is moved out to cover the areas beyond the reach of direct skyline swinging from the track, while donkey methods are used during the wet season for logging a large portion of the timber close to the track.

On the basis of the results obtained in the experiment, however, skyline swinging would bring a substantial increase of costs as well as added loss through timber breakage. This will greatly widen the gap between skyline swinging and tractor roading shown in Figure 33, Chapter IX. To fit the case at hand, the skyline swinging costs represented by lines 4 and is in Figure 33 should be raised by $\$ 0.50$ to $\$ 1.00$ per $\mathrm{M}$ on account of added breakage losses and an additional $\$ 0.50$ in adjusting for the elimination of cold decking through direct-roading. This suggests that skyline swinging should bo used very sparingly and only on areas where the tractor roading system may be absolutely impracticable on account of topography, and that the problem of year-round logging on areas adapted only for dry weather roading should be solved, if possible, without falling back on the conventional donkey systems. To this problem further attention is given in the next chapter.

\section{APPLICATION OF FINDINGS FROM LOGGING STUDIES AND EXPERIMENT}

122. Conclusions Reached in Studies of Various Phases of Logging Suggest Complete Logging Plan.At various points in the foregoing discussion summaries have been presented of the findings reached in the detailed time and cost studies. In the preceding four chapters the more important conclusions concerning the relative efficiency of various logging methods point the way to lower costs and better selective control of the timber property in the planning of logging operations. In Chapter XIX, the advantages of low-cost, long-distance tractor roading and motor truck hauling are discussed with no change proposed in the present scheme of clear cutting and many other features of conventional donkey operations. In Chapter XX, attention is directed toward the opportunities offered-in principle-by selective specialization, but without any direct evidence of how this may be successfuliy applied under logging conditions typical of the region. In Chapter $\mathrm{XXI}$, the experiments with intensive tractor roading and tree selection not only bring additional support to previous conclusions regarding the correct application of the tractor roading and allied systems, but give also a detailed yarding procedure that, with a few logical changes in other phases of the operation, might easily be adapted to selective specialization. But a comprehensive view of how this may work out in practice is lacking. In the following pages these possibilities are re-examined by means of a complete logging plan outlined for a large-scale Douglas fir operation. In this are incorporated the most important conclusions reached in the cost studies in regard to efficiency, selectivity, and specialization in all phases of logging.

The object is to show how flexibility, selectivity, and specialization go hand in hand with low costs and how they may all be combined into a practicable, all-weather system of logging of rather wide applicability.

Owing to contrasting conditions in the Douglas fir region, no rigid plan of operation will fit all cases. The following, therefore, is submitted as an example which may require many modifications in adapting it to varied conditions. It should be recognized too that it may not work at all in some operations and in many others may not fit certain portions of the operating areas. Where this is due to excessive ruggedness or other peculiarities of topography the conclusions of the studies in regard to efficient yarding methods in Chapter VII may be considered, together with the conclusions in regard to relative cost for various $\log$ and tree sizes in Chapter XVII.

The physical background for the operations hereinafter pictured may be visualized, first. by examining that portion of the area shown in Figure 43 (Chapter XXI) which is covered with an intensive network of tractor sads: second, by picturing the extension of this network to cover the whole 200 -acre area and beyond to a distance of generally one to two miles from the railroad track; third, by assuming the relocation and skeletonization of the rail- 
road system along the lines discussed in Chapter XIX. In briet, the details of the short-distance roading system as developed in the tractor experiments are to be combined with the larger features and operating economies of the long-distance roading system as a whole, as cutlined in the exannple cited in Chapter XIX. The area to be considered in some detail comprises 10,000 acres with a stand of about half a billion feet of timber.

123. The Construction Program.-With a few miles of well located, widely spaced railroad spurs and a relatively immense mileage of closely spaced, cheaply constructed tractor roads, large quantities of timber are opened แр. This area of 10,000 acres is opened up with only about 15 miles of spurs, giving an average of 30 to 40 million board feet per mile of road compared with 8 to 12 million feet under the conventional system of donkey logging.

The main settings are large, extending generally two or three times as far from the landings as those shown in Figure 43, embracing as a rule 100 to 300 acres in area, and containing 5 to 15 million board feet of timber. Fifty large settings, containing 500 million feet of timber, are strung out along 15 miles of railroad spurs. In addition to these, 50 small settings, like settings Nos. 3 and 4 in Figure 43, are wedged here and there between the large ones to save hauling distance to the landings or to meet topographic problems. These small settings contain an additional 50 million feet of timber.

The logging spurs are located with a view to obtaining large and favorably located landings. The opportunity to accomplish this is enhanced by the fact that railroads need not be extended into every 40 -acre subdivision of area as is the tendency under the intensive railroad scheme followed in logging with donkeys. They may here be located with relatively little attention paid to how far the back end of the settings may extend from the landings, and for this general type of topography this gives a good opportunity to select favorable ground for the location of railroad grades and landings.

The landings for the large settings generally vary from 300 to 800 feet in length and 50 to 100 feet in width (depending upon topography and stump clearing problems) and comprise on the average one acre per landing. The construction of landings consists for the most part of clearing the area of stumps and debris and smoothing the surface with a bulldozer (see Figure 44 B, Chapter XXI), but may frequently also call for moving a couple of thousand yards of earth in order to give the desired slopes. An average cost of $\$ 500$ per landing (per acre) or five cents per $\mathrm{M}$ ft. b.m., will be spent on the construction of landings. Paralleling the full length of the landing is a railroad siding for a self-propelling loader to travel over. Under the conventional donkey system of logging the requirements for sidings or other "landing tracks" is about the same per mile of spur as is here proposed so that no special allowance for the cost of these sidings need be made.

The landings for the small settings are built to a generally lower standard and are not provided with side tracks but are made as roomy as possible, averaging one-third of an acre in area. The 50 large landings plus the 50 small cnes will thus give a total of about 65 acres of landing space.

The logging of this 10,000 -acre area will require eight years, assuming that all the timber must be liquidated in that period of time irrespective of whether or not this represents the best management policy. Under the operating plan here contemplated, however, logging will not begin until virtually the whole construction program is finished. The construction of railroad spurs, sidings, and landings is thus completed before actual logging begins. A large portion of the tractor road system is also built and connecting tote roads are constructed from setting to setting or from landing to landing (as shown in Figure 43), so that the whole area is tied together both with railroads and tractor roads. Out of a total of 500 miles of tractor roads, costing $\$ 200$ per mile (or 20 cents per M), about 250 miles will be completed before logging starts. The remaining 250 miles, consisting mainly of short branch roads or of roads on areas that may not be touched during the first year or two after logging begins will be built as needed. Under the cutting program to be followed some roads may not be constructed for several years.

This initial construction program is not so costly as conventional road-building programs. Under the usual donkey logging plan, this area would be developed in the course of eight years with 50 to 60 miles of railroad spurs at an assumed cost of one dollar per thousand (1931 basis) or a total of $\$ 580,000$. Under the proposed plan, a two-year spur construction program, based on the same costs and speed of construction, would see the completion of 15 miles of spurs for about 30 cents per thousand or a total of $\$ 174,000$ for railroads. At the same 
time, landings and tractor roads would be constructed at a cost of about 15 cents per thousand or $\$ 87,000$, leaving 10 cents per thousand, or a total of $\$ 58,000$, for deferred tractor-road construction that will be spread over several years. The total construction cost under the proposed plan would be $\$ 319,000$.

The above construction program does not include the main line logging railroad outside of the operating area proper, which obviously wculd be the same under any scheme of railroad logging.

124. General Logging Plan.-CThe idea behind the road construction plan outlined above is to make it possible (1) to decentralize the stumpto-rail operations and to keep them independent of the loading; (2) to obtain year-round production from the tractor operation and yet confine the actual roading to the dry weather; (3) to standardize the roading, loading, and railroad hauling; and (4) to obtain complete selective control of the timber property.

To this end the 10,000-acre area will be divided into 10 operating units or "sides" to each of which will be assigned one tractor roading outfit. On the average each side will embrace an area of 1,000 acres, and with its five large settings and five small ones will front on about 1.5 miles of track. With interconnecting tractor roads from landing to landing in addition to the railroad connection, each side will in effect be as easily managed as if it consisted of only one setting and one landing. For each side, or perhaps for each two sides, a small camp will be established to accommodate the roading and felling and bucking crew, while all other activities may be carried on from a central camp serving all sides. The side camps will be located with a view to having all the landings within an easy walking distance of the camp. Loading and train service (for logging purposes only) will be furnished to each side when needed, other necessary contact being maintained by track speeders or automobiles and trucks. In the latter case it would not, of course, be so important to provide handily located side camps, since the men could travel back and forth by automobile.

125. The Logging Program for the Large-Timber Cuts.-The operations will be planned for intensive tree selection with the first cuts over the area to consist of the large timber, to be followed in turn by the medium and small timber cuts.
The Large-Timber Stand

The large-timber cuts consist of trees over four feet in diameter which total 220 million board feet or 40 per cent of the total volume of standing timber of all sizes above 20 inches in diameter. In addition there will be about 30 million feet of merchantable windfalls and about 10 million feet of small or medium-size trces that an 2 felled because they are in the way of the large timber. The total volume in the large timber cuts is thus 260 million feet. The average $\log$ scales 2,500 and the average tree about 8,000 board feet. Only a negligible percentage of the total volume will consist of logs scaling less than 1,000 board feet and only occasionally will they exceed 6,000 feet. On the average there are about three large trees per acre, and about 25 of all sizes above 20 inches in diameter. These large trees frequently occur in groups, with fairly large areas on which practically none occur.

\section{General Roading and Loading Procedure}

With the initial construction completed the stage is set for the logging. Tiactor roads, which so far have been built primarily for the large timber, are easily accessible; generally it is only a few steps from road to tree.

The procedure in roading the large timber will be identical with that followed in the tree selection experiments reported in the preceding chapter; i.e., the $\log _{\mathrm{S}}$ will be direct-roaded from stump to landing. In the experiments (Table 53) it was found that in dealing with this size of timber the direct-roading method is very effective. Large load volumes $(4,000$ board foot average) were obtained, little time was lost in assembling the loads; and as may be computed from the data in Table 53, it cost on the average only 7 cents per M to "yar.d" these logs and to place them in position under the fair-lead arch. In other words, the cost of yarding, applying this term to the work of getting the logs from stump to assembled load at the tractor road, has here reacned practically the irreducible minimum.

The average hauling (roading) distance from stump to landing is assumed to be 4,000 feet. At this distance the average output in the large timber cut, based on the performance shown in the foregoing experiments, as well as in the long distance roading study reported in Table 39 (Chapter VIII), is 45 M feet b.m. per 8-hour day, or $450 \mathrm{M}$ per day for 10 tractors.

"4the figmres in this paragraph are believed fairly representative of the region as a whole, being based ronghly on data taken in seven different operations. 
The average cost, based on an 8-hour machine l'ate of $\$ 36$, is $\$ 0.80$ per M.

The loading is to be independent of the roading. It will take place intermittently, using a special self-propelled loading outfit which serves all operating units, and which works steadily by shifting from one side to another. Independent loading is possible because of the large storage space at the landings.

\section{The Storage Landings}

The storage capacity of the landings will, of course, depend upon how the logs are stored. The average $\log$ in the large timber cut scales 2.500 board feet, which is equivalent to one 40 inches in diameter and 32 feet long. Such a $\log$ will cover about 130 square feet of storage area. Theoretically, then, if the logs of this size were laid end to end and side by side without any waste space between them, there would be room for $333 \operatorname{logs}$ of 2,500 board feet average volume, or 832 M feet b.m., on each acre of landing space. This, of course, might well shrink to about $100 \log$ s or less if the logs were left in the manner in which the tractor would dispose of them, were no special and systematic effort made to close up the space left between the logs after they have been unhooked. There should, however, be no practical difficulty in systematically filling the landings in a more effective way starting with a row of logs laid approximately parallel to the track and following up with row after row, using the tractor itself with its heavy steel bumpers to roll or crowd the $\operatorname{logs}$ of each row against the previous row so as to close up the original gaps left between the logs. This, it is here believed, will only require a few seconds of work per log with the cost per M touching close to zero, once the tractor driver has learned to systematize the work.

By this procedure the landing when filled will look like a flat raft of $\operatorname{logs}$, with perhaps 40 per cent of the available space wasted or reserved for an open lane at the upper side of the landing whereby the tractor road system will be kept connected up from landing to landing. This gives a capacity of about $500 \mathrm{M}$ ft.b.m. per acre. The five large landings (one acre each) will then hold 2,500,000 feet of logs or enough to keep a roading outfit busy for about two months when working at the rate of $45 \mathrm{M}$ per eight hour day. In addition to this, the five small landings will hold $750 \mathrm{M}$; and a total of 32 ,$500,000 \mathrm{bd}$. ft. of logs can be stored on the 65 acres of landing space that has been provided for the 10,000-acre area as a whole.
With this enormous storage capacity, the problem of synchronizing the loading and roading is a simple one. The loading outfit can be kept busy whether there are, for example, only four full landings ahead of it or whether there are forty. It will load on the average one large landing per day, and hence, moves to a new landing about once a day. Whether the moving distance from one full landing to the next one happens to be one-quarter of a mile or two miles is not a very important matter, because the difference will amount to only a few minutes of traveling time. The operator, therefore, will ordinarily have many millions of feet of logs to "play" with before the problem of synchronizing the loading and roading output demands urgent attention. The day-to-day and hour-to-hour problem of keeping the logs coming to the landing at the same pace as the loading crew can put them on the cars, which is an important problem where loading and roading are carried on concurrently (compare Sec. 21, Chapter IV), is thus entirely eliminated. Each one of the 10 tractor outfits as well as the loading outfit is here given a full opportunity to attain its maximum efficiency without interfering with the others and without requiring the intensive day-to-day field supervision and planning demanded in the synchronized tractor operations.

\section{Year-Round Logging}

Planning of a different sort, however, will be required in order to make the most of the opportunities presented for smooth and efficient year-round production through the use of large storage landings. In the operation here pictured, tractor roading can be carried on only during dry weather. The problem to be solved is to get year-round production from a seasonal tractor operation.

To illustrate how this might be accomplished the operating areas will be pictured as divided into a number of "zones" or bands of timber within which operations will be carried on at different times of the roading season. Zone 1 , for example, may take in timber within a distance of 2,000 feet from the landings; Zone 2 will extend from 2,000 to 4,000 feet; Zone 3 from 4,000 to 6,000 ; Zone 4 from 6,000 to 8 ,000 ; Zone 5 from 8,000 to 10,000 , etc. Zones 1 and 2 will contain about one half of the total of 260 million feet of large timber; Zones 3 , 4 , 5, etc., will contain the other half. Owing to irregular distances to the outside of the areas, the more distant zones may not appear in 
all of the operating units. Some operating units may have little timber beyond Zone 3 ; others may have a great deal in Zones 4,5 , or 6 .

As stated above, for the average hauling distance of 4,000 feet, the average 8-hour output is $45 \mathrm{M}$ feet per tractor, or 450 for 10 tractors. This is also about the average 8-hour capacity of the loader for this particular size class of $\operatorname{logs}(2,500$ board foot average $\log )$. The tractor output, however, will vary greatly with variation in hauling distance. This is shown below by listing average distances and corresponding 8-hour output per tractor for the five zones.

Zone 1: Average distance 1,000, 8-hr. output, $120 \mathrm{M}$ Zone 2: " " Zone 3: " " " Zone 4: " " " 7,000 , “ $\quad$ " $27 \mathrm{M}$ Zone 5: " " 9,000 , “ " $22 \mathrm{M}$

Here it will be seen that great variation in the rate of production can be obtained by shifting the scene of operation from one zone to another. Further variation can, of course, be obtained by varying the number of hours of work, for example, by changing to a double shift schedule.

The main roading season for this operation extends from about the beginning of May to the end of October, including a month or more of intermittent production both at the beginning and at the end. The dependable dry weather season usually lasts only from the middle of June to the latter part of September or for a period of about 100 calendar days, and even during this period a few days of rainy weather may occur.

At the beginning of the season, assuming that the landings are empty, the roading problem will center on getting enough $\operatorname{logs}$ to the landings to keep the loading outfit busy, and to build up a reserve to assure continuous loading operations until dependable dry weather arlives. Here is where Zone 1 , which is the high production zone, may be drawn upon for quick action in good weather. One tractor outfit will here produce an average of $120 \mathrm{M}$ feet per 8hour day, and 10 tractors, working two 8-hour shifts, will give a daily output of $2,400,000$ feet or about five times the corresponding 8-hour loading capacity.

As soon as a 5 or 6 million foot reserve of Zone 1 timber has been accumulated at the landings, Zone 2 will be brought into production, whenever the weather permits, again working on a double shift basis. On this basis, it would be possible to keep ahead of the loading even if roading operations were carried on for only five 16-hour days in Zone 1 between April 1 and May 15, and if only 10 day's additional were obtained in zone 2 between tho middle of May and the last part of June.

By this time the real dry-weather season will usually have arrived and the scene of operation will now move into Zones ?, 4, and 5 or beyond. The rate of production per day per tractor will here drop to 37,27 , and 22 M feet respectively, or an average for the three zones of about 600 $M$ feet per day for 10 tractors working on a double shift basis. This is about 30 per cent in excess of the 8-hour loading capacity, and thus allows a gradual building up of a surplus of $\operatorname{logs}$ on the landings so that by the middle of September most of the large landings will be filled. At this time the loader may be restricted to 10 large landings that are kept open for further storage-one for each operating unit. The other landings, filled with logs, are closed for the remainder of the roading season. Toward the end of the dry-weather season, the tractors will move back to Zone 2 and also into that part of Zone 1 which is tributary to the small landings. By thus shifting into high production territory, the remaining landing space will be filled rapidly. If the weather remains favorable after the landings are filled, the tractors will again be shifted back into Zones 3,4 , and 5 , but perhaps on a single shift basis or on a 10 or 12-hour schedule. If good weather continues intermittently through part of October, operations would be continued in whatever zone will give the right rate of production to keep the landings filled, so that whenever the winter shut down does occur, there will be some 30 million feet or more on the landings.

The tractors may now be sent to the shop for their annual overhauling, while the loading and other activities continue. With over 30 million feet of logs on the landings, and with a part of this on small landings which lack sidetracks and where loading capacity as a consequence will be lower than normal, the loading outfit will have steady work for over three months or well into the month of January. Allowing for the traditional winter shut down. which usually extends at least from lefore Christmas and through most of January, there will be $\operatorname{logs}$ enough to last till about the beginning of March. Before this time the tractors will be back in the woods, ready to operate in Zone 1 whenever conditions permit. 
In this operation one or more of the months of January, February, and March usuaily have occasional dry spells with freezing weathor, which for a day or a few days at a time offer good conditions for tractor roading. Ten days of suitable roading conditions, with the tractor's kept working 12 hours a day, would here give an opportunity to put in 18 million feet of $\operatorname{logs}$ from Zone 1, or enough to tide the operation over to the beginning of May.

With so large a slice taken out of the available timber in Zone 1 , the next intermittent periods of production might, of course, better be turned over to Zone 2 in order to conserve the remaining timber in Zone 1 for the following year's winter logging. The timber in Zone 1 , it will here be seen, has a most important function to serve, namely, to provide the means for sudden spurts of production for brief periods from October to May. For this timber, a strict "hands off" policy is most obviously in order during the June-September" dry weather season and the same policy should be applied as rigidly during the late spring months provided that continuous loading can be assured without it.

Reliance on a brief spurt of successful winter production as here suggested may not fit the majority of operations in this region. In operations located at high elevations, for example, deep snow will interfere. Operators, however, generally figure on a long winter shut down anyway, even under the donkey logging system, and so may not be handicapped more than usual by failure to get sufficient winter production for continuous operation.

Another obvious answer to this problem is to provide more storage space and/or to make fuller use of the space that has been provided by crowding in more logs when filling the landings for winter storage.

The principal point that stands out from the foregoing detailed discussions is that dryweather tractor roading does not necessarily make the logging operation seasonal. The key to year-round logging is the advance road construction program and the storage landings with a capacity large enough to provide for a two to four months reserve of logs. Well planned regulation of the rate of production by zoning the timber, together with a fixed policy of always being ready to take full advantage of brief spells of good weather during the offseason period, may do the rest. The main idea behind the tractor roading program here be- comes to "make hay while the sun shines." Incidentally, this will make it possible to wear out the tractors and arches at about as rapid a rate as in the year-round, 8-hour day operation; the working hours are simply distributed differently.

\section{Self-contained Operating Units are Essential}

One rather important requirement for the fullest success of this operating program is to have the roading crews available for intermittent operation at all times and at virtually all hours from January to October. The proposed plan of having the roading and felling and bucking operations carried on from small self-contained side camps would obviously be an important factor in making such a program run smoothly and efficiently, since the problem of feeding and transporting widely scattered crews, which often have to work irregular hours, would be intolerable in a large, centralized operation.

Here it will be seen that in each of these side camps may be placed a small crew of men to do both the roading and the felling and bucking, preferably, perhaps, on a piece rate or contract system. The piece rates will be worked out to apply to the large timber and will vary from zone to zone; after the large timber has been logged, they will, of course, be revised to fit in turn the medium and small-timber classes so that in all cases a fair system of paying a standard rate for a standard amount of work will be in effect. For each operating unit there will be at least two tractor drivers, one for each shift, to operate the tractor whenever the weather permits. When the weather does not permit efficient tractor operations, they will become a part of the felling and bucking crew or be at times assigned to other duties. The hookers, one for each shift, will likewise be shifted back and forth from felling and bucking to roading. This is the general system followed by "gyppo" truck or tractor loggers under similar circumstances.

Felling and bucking will require two or three times as many man-hours of work as the actual roading operation so that in addition to the four men required for intermittent operation of the tractors there will be six to eight full time fallers and buckers, some of whom may be assigned now and then to help out with the roading operations as needed.

There is a special reason why this close contact should be kept between felling-and-bucking and roading. The work of the roading crew 
is affected directly by the way in which the felling and bucking is done, because under this system of logging much of the work of getting the logs from the stump to the fair-lead arch and of building up the loads depends upon some rather fine points in regard to how the timber is handled. By having both the felling and bucking and the roading operations within each operating unit under the immediate supervision of a side foreman or head contractor whose interest lies in both of these operations, and by having some of the men shift back and forth from roading to felling and bucking, there will be better assurance of getting the work done right than if these two operations were departmentalized in the usual manner. It also makes it possible to furnish the tractor crews steady employment and breaks up the monotony of too specialized work.

\section{Selective Control to the $N$ th Degree}

Under this operating plan, it will require between two and three years of uninterrupted work to remove the large timber. In that interval each one of the large landings will be filled and emptied about 10 times; the small landings about three or four times.

In this size class of timber, as was shown in the tree selection experiments, the individual tree is for all practical purposes under full selective control. The operator is free to reach without reference to how far apart the trees so selected may be. Variations in the volume of timber per acre to be removed at any given time is of little practical consequence, because full loads can be gathered together about as efficiently if the logs are scattered as if they lie close together. The reason for this, of course, is that the logs are so large that a load will generally consist of only one or two logs. If a two or three log load is not available at one given point, the tractor outfit can first pick up one $\log$ and then move a short distance down the tractor road to another location to complete the load without any noticeable loss of efficiency.

Under these conditions it is feasible to practice almost any degree of intensive selection within the large-timber cut as whole. Each time the landings are filled a different type of timber may be removed. The first "cut" within the large-timber cut as a whole may thus consist of the windfalls. These may even be brought to the landings before the real logging operations start, following closely on the heels of the bulldozer, while the initial construction program is still under way. The standing large timber can thereafter be removed, so to speak, by "layers." The different species, for example, may be removed separately, or other classifications of material may be made for separate removal. It is not very important whether each class of timber so selected will fill a whole landing or whether two or three classes share the space on the landing, or, except at the end of the roading season, whether the landing is only partly filled with one class of logs with the rest of the space left vacant until the loading outfit has loaded out the particular class of $\operatorname{logs}$ that is wanted. The loading outfit, it is here scen, is just as mobile as the tractors and it is not an important matter whether it has to move to a landing to load out only 100 or $200 \mathrm{M}$ feet of logs instead of the 400 or 500 M feet that the landing can hold.

From this it will be seen that as far as this size class of timber is concerned, the operator is given virtually full selective control of his property. He can, so to speak, go into the woods and bring out a raft of cedar without bringing out any of the other timber. Or he can telephone the side foreman and order a raft ot No. 2 and No. 1 fir by such and such a date. Aside from the marketing advantages that this will obviously give, it will also simplify the booming and sorting operations. When the logs arrive at the pond there will be very little sorting to do in making up the rafts. The saving made at this end of the operation might very well be more than sufficient to offset the lost motion that the suggested procedure may cause in the woods operation.

\section{Specialization of Equipment for the Large-Timber Cut}

The above data on outputs and costs of roading the large timber represent the performance with the 60 h.p. tractors accoraing to the results of the roading studies and experiments heretofore reported. For roading heavy loads over prepared roads at long distances and under conditions where the tractors seldom have to leave the roads, it seems most logical to expect that considerably better restilts would be obtained with tractors of higher speed and greater power. Thus, 80 to 125 h.p. tractors should give lower costs and considerably higher output than the 60 h.p. This might, in the cast here presented, bring about a reduction of the number of operating units from 10 to 7 or 8 .

Skeleton $\log$ cars or disconnected trucks of conventional design would be used for hauling the logs. 
The loader would be specially designed for large timber but with the main emphasis laid on mobility. A self-propelling, swinging-boom loader, mounted on a heavily constructed car on which the machinery is placed off-center and which is specially designed for travel both on standard gauge track and on three-rail sidings might be the practical answer to this demand for extreme mobility and sufficient stability for efficient loading of large logs. The third rail on the sidings would be raised and laid to a gauge of about nine feet.

126. The Logging Program for the Small-Timber Cuts.-Passing over for the moment the logging of the medium size timber, a brief glimpse will now be given of small-timber logging. This timber, as well as most of the medium-timber cuts, would generally not be found ripe for immediate cutting if the principals of profitable and sound timber management are followed, but this is a question not to be considered at this point.

The trees in this cut will range from 32 inches in diameter down to about 20 inches or whatever size it may be desired to cut. The largest tree scales about 2,500, the largest 40 foot $\log$ about 1,000 , and the average $\log$, if logged in lengths of 40 and under, about 300 board feet. The total volume of small timber is 120 million feet or 12,000 feet per acre.

The tractor road system will have been completed by this time so that many small areas that were passed up in the large timber program will now be open for logging.

The direct-roading procedure followed in the large timber cut is no longer practiced; bunching and roading of standardized loads take its place. The bunching outfit may consist, for example, of a 30 h.p. tractor equipped with a drum and a fair-lead boom mounted directly on the tractor. Lighter line and rigging than that of the large-timber roading outfits will ba carried. Being a small compact outfit (without a trailer), it can be maneuvered more easily than the large trailer outfits both on and off the roads. Like the roading tractor, however, its travel will be confined mainly to the roads. The crew will consist of two men-a driver and a hooker.

The trees will be bucked in full tree lengths up to a certain maximum length. The volume of the average log may thereby be increased to 500 board feet. The bunching outfit will yard these logs and make up loads of, for example, not less than 3,000 board feet volume, with few exceptions allowed.
Some of the large logs may be direct-roaded with the large roading outfit (identical with that used in the large timber cut) and some may simply be "windrowed" to the roads where the roading tractor can pick them up. Actual bunching will, however, be practiced for the great majority of logs, although, with the fairlead method of picking up the loads, fine work in this respect is not necessary.

Most of the logs will be bucked on the landing, to an average $\log$ size of perhaps 300 board feet. The bucker in unhooking the loads scatters the logs about so as to permit bucking. Afterwards the buckers usually roll the logs toward the track to close up space. The smalllog landing when filled will hold about three times as many logs as the large-log landings with one third the volume. On the average the large landings will be filled and emptied about 12 times during the removal of the small timber cut. When the landing is filled for winter storage, greater care might be taken to find room for as many logs as possible. Decking of two or more tiers of logs may prove feasible.

Loading will be done with a special small$\log$ loader designed to handle an average of about 600 logs per day. Moving from landing to landing will occur about once a day, the same as for the large-timber loader.

The logs will be loaded on staked cars, giving an average load volume of 7,000 or 8,000 board feet. Except for the side stakes the cars may be the same as those for the large-timber cut.

\section{Bunching Increases Efficiency and Offers Selective Control}

Three advantages may be gained by resorting to bunching in this size class of timber.

The least important or assured of these is the possibility of reducing the cost of getting the logs from stump to assembled load under the arch of the roading tractor. In the directroading experiments, this work costs on the average $\$ 0.27$ per M (see hook-on time, Table 53) for an average log size of 617 board feet. This would indicate a cost of over $\$ 0.30$ per $\mathrm{M}^{2-5}$ for an average $\log$ of 500 board feet. The light bunching outfit, which can be operated at a machine rate of only about one-half that of the heavy-duty roading outfit and yet may handle the small logs as fast or faster, will show a much lower cost for assembling the loads. However, the loads have to be hooked on

In the tractor-yarding study reported in Table 5 , Chapter IV: the average cost of "hooking on" a 500 board fcot Iog was about $\$ 0.30$ per $\mathrm{M}$ b.m 
again in the roading operation, which will reduce, if not entirely wipe out, this saving.

A more important and definite advantage is that bunching makes it possible to enforce rigidly a policy of building up uniformly large loads whereby the roading operation will become highly efficient and standardized. The difference in the cost of roading the logs of the small-timber and the large-timber cuts will here correspond closely to the varying ratios of cubic feet to board feet for logs of different sizes as discussed in Section 108 (Table 52). To this basic handicap against the small log there must, of course, be added the cost of bunching.

Another important advantage of bunching is that it will for all practical purposes bring the same degree of selective control of individual trees and logs in the small timber class as the direct-roading method provides for the large timber class. In the bunching operation the $\operatorname{logs}$ are ordinarily handled one by one. If they lie close together a full load may be built up without moving the tractor. If the logs are very scattered a log may be yarded to the tractor and then without intervening delay roaded a short distance along the tractor road to a point where the load will be assembled; the tractor then runs along to some other point for another log. The cost of traveling along the road represents the extra cost of bunching scattered logs over that of closely spaced logs. For distances of a couple of hundred feet this will amount on the average to only about 5 to 10 cents per M. In other cases these scattered logs may simply be windrowed to the roads and picked up directly by the roading tractor with only a slight increase in hook-on time for the roading tractor. Within reasonable limits, variations in the density of the stand to be removed in any given cut will, therefore, add too small an amount to the cost of bunching-and none at all to that of roading and subsequent operations-to make any practical difference in deciding how far to go in the selection of individual trees or size classes of trees. The small timber cut as a whole may, again, be subdivided for logging, for example, by diameters or by species. This is a most important point in connection with controlled marketing of the timber and also in connection with improvement cuttings in stands that are to be placed under management.

In principle, the same procedure as here outlined for the small-timber cut of sawlogs may also be applied to whatever cuttings may be undertaken in timber under saw-timber size or quality, such as for ties, poles, pulpwond, or fuelwood. Here, however, the initial "bunching" might be done by hand, horses, or other special equipment. In considering the opportunities for low cost handling of this type of products, it should be borne in mind that under the intensive roading system it is on the average only a few steps from the tractor roads to the trees and that the storage landings provide ample room for storing large quantities of sorted and stacked material along the railroad track. For hauling bunched or stacked loads of this type of material from the woods to the landings the bunching tractor or other light tractors or trucks might serve to better advantage than the large roading tractor.

127. The Logging Program for the Medium. Timber Cuts.-The procedure for medium-size timber needs no detailed discussion. A large portion of this timber might best be directroaded, the roading crew going over the area first and simply "helping itself" to the largest and most handily located logs with which they can build up large loads with a minimum of delay in the hooking-on operations; thereafter the bunching tractor is sent in to bunch or windrow the remaining logs the same as in the small-timber logging. Long logs might feature most of the logging in this size class of timber. Again, it will be noted that selective control of the individual tree can be obtained as with the small and large timber cuts, and that the roarl to the attainment of this goal is the one that leads to increased operating efficiency.

128. Specialization of Equipment May Involve Few Radical Changes.-The ideal set-up for intensive specialization of logging equipment to fit the logging program outlined above is enough timber to keep each piece of equipment in use in the particular type of work for which it is designed. In the present example this would mean that the large, medium, or small timber equipment when finished with the 10.000 -acre area would be transferred to another two or three years of similar logging on another block of timber, and so on. Assuming as large scale an operation for each size class of timber as has here been discussed wouid thus obviously require a very large quantity of timber in order to work out in the most ideal way.

If, however, the hypothetical operator has ro other timber to log than on the 8-year operation described, and will not be able to sell or trade 
the equipment lie may wish to replace, even so a great deal can be done toward specialization without raising a very serious problem of how to get normal use of the equipment. In the stump-to-landing operation, for example, specialization might involve no other change than the addition of bunching equipment. since the large roading equipment might be just as desirable for roading large loads of small logs as for large loads of large logs. Further than this both the roading and bunching equipment is short-life equipment, and this offers the opporsirable to provide for further specialization whenever the equipment is replaced.

In the loading operations, the large-log loader may function quite effectively for the medium-size timber by replacing the heavy loading tongs and rigging with lighter ones, by reorganizing the crew or by some other minor changes which need involve 110 major capital expenditure. However, when the medium-size timber has been logged, this loader should ba replaced with a special small-log loader, even if that means writing off the unamortized inrestment. In the railroad operations, effective specialization might need go no further than adding side stakes to the cars used for the large and medium timber.

In brief, fairly effective specialization might be obtained without any more radical or costly changes of equipment than may be effected when replacing worn out, short life equipment, by adding side stakes and short life bunching equipment when needed, by adaptation of rigging and other small equipment, or by reorganizing the crews. Beyond these steps, a most important element in specialization is the manner in which each man will inevitably train himself in the effective handling of a given uniform size class of trees and $\log s$ as contrasted with an operation in which logs of all diameters, lengths, and species are handled.

Within the framework of the general operating plan outlined above, many methods and types of equipment other than those mentioned may, of course, be used. For the bunching operation, for example, almost any type of light, mobile equipment might be suggested. For the long hauls, motor trucks might be substituted for the roading tractors and may in some cases justify extending the length of haul to several miles to save railroad construction and to simplify the problem of landing and railroad location. Particularly promising is the use of trucks for hauling the small logs. Here the bunching outfit might be replaced, for example, by a tractor-mounted, heel-boom loader, capable of handling $\operatorname{logs}$ up to about 1,000 board feet in volume. It would take over the function of the bunching outfit in addition to loading the logs when the trucks arrive. The flexibility of the plan as a whole, with its many independent storage landings and vast network of roads, invites substitution of this type of equipment wherever conditions are favorable.

129. A Summary and Comparison of Cost Advantages of the Proposed Plan.-In looking back on the operating plan outlined above it will be of interest to compare, item by item, the relative cost of performing the principal tasks involved in conventional clear cut donkey logging and in the proposed plan. Such a comparison is given below mainly for the purpose of emphasizing the principles involved; but, in order to have meaningful figures to deal with, the cost of both operations will be set roughly at a level representative of low cost Douglas fir operations during the first half of the year 1931 .

\section{Spur Construction}

The cost of constructing logging railroads within the operating area proper is $\$ 1.00$ per M under the donkey logging plan compared with $\$ 0.30$ under the proposed plan, although, if the cost of the storage landings is included as a part of the railroad system, the latter cost rises to $\$ 0.35$ per $M$. The much lower cost of the proposed plan is explained by the extreme skeletonization of the railroad system under a system of logging that reaches out on the average to an external yarding distance of about 8,000 feet.

\section{Railroad Operating Costs and Track Maintenance}

For donkey logging, the cost of this item is set at $\$ 1.00$ per $\mathrm{M}$ wh:le the corresponding cost under the proposed plan is estimated at $\$ 0.40$.

Several important factors enter into this difference. First, there is the increase in carload capacity obtained through specialization of equipment. This, as discussed in Section 110 , Chapter XX, brings a reduction of about 33 per cent in the number of carloads to be hauled and is here taken as justifying a blanket cost reduction of about 25 per cent. Second, there is the shortening of the length of haul and elimination of the switching that donkey logging adds through the construction of a vast mileage of spurs; this in turn eliminates many odd jcbs connected with road construction and the hauling of crews and moving of logging equipment, 
as discussed in Chapter XIX. Third, there is the advantage of stabilized, high level production of logs obtainable in loading under conditions discussed below under "(3)". Under these conditions there will be little variation in the daily number of carloads produced in each major size class of timber, and this will permit fuller use of available facilities than is normal for a donkey operation. In brief, railroad operations have here been reduced to a simple, standardized mainline terminal-to-terminal service, with practically a fixed output to be moved each day.

\section{Loading}

Loading under the donkey-logging system costs about $\$ 0.50$ per M, while the corresponding cost under the proposed plan is $\$ 0.15$ per M.

This is seemingly a high cost for donkey logging, but in the 11 donkey operations studied the average cost of direct yarding-andloading and swinging-and-loading amounted to about $\$ 1.80$ per $\mathrm{M}$ and over 25 per cent of this is allocated to loading.

Two important factors are involved in the step-down of loading costs from $\$ 0.50$ to $\$ 0.15$. These are (1) the complete separation of loading from yarding or swinging, which eliminates waiting time and time lost through interference between the various operations; and (2) specialization of equipment.

How these factors operate to bring about so great a reduction in costs is shown in the following table:

Cost per $M$ jeet b.m. for logs of differcut sizes under. various conditions of louding

Vol. of $\log$

\begin{tabular}{|c|c|c|c|c|c|}
\hline (feet b.m.) & Case 1 & Case 2 & Case 3 & Case 4 & Case 5 \\
\hline 100 & $\$ 4.07$ & $\$ 1.37$ & $\$ 0.67$ & $\$ 0.45$ & $\$ 0.45$ \\
\hline 200 & 2.04 & .69 & .37 & .25 & .25 \\
\hline 400 & 1.02 & .36 & .22 & .16 & .16 \\
\hline 600 & .69 & .25 & .17 & .13 & .15 \\
\hline 800 & .53 & .20 & .13 & .12 & .15 \\
\hline 1,000 & .43 & .16 & .12 & $\ldots$ & .14 \\
\hline 1,200 & .37 & .14 & .11 &.-- & .13 \\
\hline 1,600 & .29 & .12 & .12 & $\ldots$. & .12 \\
\hline 2,000 & .25 & .10 & $\ldots$ & -... & .10 \\
\hline 3,000 & .23 & .08 & $\ldots$ & .... & .08 \\
\hline 4,000 & .20 & .09 & $\ldots$ & $\ldots$ & .09 \\
\hline 5,000 & .19 & $\ldots$ & -.- & $\ldots$ & .10 \\
\hline 6,000 & .18 & ...- & $\cdots .$. & $\cdots$ & .12 \\
\hline
\end{tabular}

Case 1 represents loading logs of different sizes under the donkey system of logging. The:e figures are derived from Table 40 and represent the average cost in 11 donkey operations. (Table 40, Studies 3 to 13 inclusive); in deriving these costs the waiting time multiplying factors listed at the frot of each column in Table 40 have been applied to the costs listed in the main body of the table in order to determine the full cost of loading. In computing the average costs for the 11 operations, each study has been given equal weight. Case 2 is a copy of Column 2 in Table 40 and repres nts the cost normally obtainable with a. large-log loader (compare studies $3,4,5$, and 6 in Table 40) when loading is independent of yarding. Case 3 is the same as Column 1 in Table 40 . and represents loading costs for a loader adapted for medium-to-small logs. Case 4 gives costs assumed for a specially designed small-log loader. In Case 5 are the composite average costs of loading under the proposed plan. The large log loader would here be confined to logs ranging in the main from 800 to 6,000 board feet in volume; while logs for the medium. size loader range from 400 to 2,500 , and for the smalllog loader up to 1,000 board feet. A comparison of Case 1 and Case 5 indicates the remarkable reduction of costs that takes place, particularly in the smaller log sizes. The weighted average cost for an average $\log$ volume of 900 feet drops from 48 to 15 cents per M.

Specialization accounts for a part of this drop, but the greatest average reduction comes as a result of keeping the loading entirely independent of the fluctuation of and the interference from the woods operation. Loading logs from a "raft" of uniform logs laid parallel to the track on a cleared and levelled storage landing should represent the most ideal form. of independent and standardized loading. Here a steady flow of logs will come from the loader at all times.

\section{Stump-to-Landing}

The weighted arerage cost of yarding. swinging, cold decking, and rigging ahead with donkeys is $\$ 1.75$ per M. Under the proposed plan the stump-to-track cost is $\$ 1.25$. This includes for roading, $\$ 0.90$, road construction, $\$ 0.20$, road maintenance, $\$ 0.05$, and bunching, prorated against the whole stand, $\$ 0.10$.

\section{Miscellaneous}

Other items are felling and bucking, \$0.90; mainline construction outside tract, \$0.25: booming and rafting, $\$ 0.20$; administration and general expense, $\$ 0.60$.

These last items will be conservatively considered to be equal under both plans, although a considerable reduction of Item 8 and some reduction of Item 6 might also be credited to the proposed plan. 


\section{Summary}

The foregoing comparisons are summarized below:

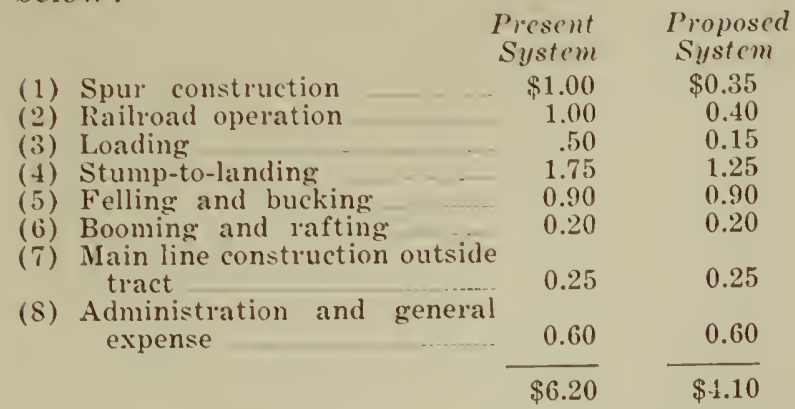

Donkey logging here represents the three donkey operations studies showing the lowest cost. The difference of $\$ 2.10$ between it and the proposed system appears only in part in the stump-to-track costs, most of it being accounted for by reduction of the first three items listed in the table. In other words much of the cost which, when compared with the proposed system, is chargeable to the cost of donkey yarding and indiscriminate clear cutting does not appear on the books under its proper name, but is designated instead as spur construction, railroad operation, depreciation and maintenance of railroad equipment, track maintenance, loading, etc. A look behind these designations shows that the cost of donkey yarding amounts in this case to $\$ 3.35$ instead of $\$ 1.75$. And by adding $\$ 0.65$ as a reasonable allowance for breakage, it rises to $\$ 4.00$. This represents in effect the cost of transporting logs an average distance of 4,000 feet. The corresponding transportation charges for the proposed system amount to $\$ 1.25$.

130. Application to Rough Country Logging and Other Problems.-With the last two figures in mind, the fact that the cost of $\$ 1.25 \mathrm{per}^{\circ} \mathrm{M}$ represents favorable topography, as illustrated in Figure 43, should not discourage the attempt to apply this system to rougher topography. Much can be done to overcome topographic difficulties if stump-to-landing costs may be allowed to rise all the way from $\$ 1.25$ to $\$ 4$ per M. Still more might be done if it be granted that the cost and breakage losses of donkey logging may also rise to a considerable extent under conditions severe enough to cause so sharp a rise in costs under the proposed plan.

Of great significance in considering this question is the point that the proposed plan provides for the complete separation of the stump-to-landing operation from the operations that follow-loading, railroad transportation, booming and rafting, and general overhead costs being entirely independent of the fluctuating costs and outputs of the roading operations. If steep slopes and broken topography cause, for example, the trebling of road construction costs and the doubling of the other elements of roading costs, there would still be a margin of over a dollar per M to go before the four dollar mark is reached. Ground yarding for distances of a few hundred feet, using tractor mounted donkeys for frequent set-ups along skeletonized tractor roads, may provide the means for extending the system into rough ground of the type shown in Figure 31, without a serious increase in costs. The loggers of this region have in the past been versatile in devising methods to meet the problems that have arisen as logging receded from easily operated water front areas to distant and difficult ground. They have drawn on every conceivable means of log transportation in solving their problems and this experience is available to devise any number of methods and mechanical devices whereby the main operating features of this system may be supplemented as necessary.

It must be recognized, however, that there are many timber areas in this region where the proposed system may be absolutely impracticable. It requires first of all a drastically skeletonized, low-level railroad system, level or downhill topography, large storage landings, and advance construction. Where these requirements cannot be met, the system may fail or lose much of its advantage even without the added handicap of excessively rugged topography. However, the ideal fulfillment of all of these requirements is not necessary for all settings. Large storage landings, for example, are desirable, but where topography or other factors prohibit, it would obviously be a simple matter to occasionally concentrate a whole fleet of tractors and the loading unit at one landing for loading and roading in the usual manner as discussed in Chapter IV, Section 21.

\section{Adaptation to Various Output Requirements}

By proper modification, the proposed system, being based on smaller yarding units than is customary for a donkey operation, is well adapted to suit the requirements of the small operator who wishes to produce only a few million feet per year or has only a few hundred acres to log. But, as demonstrated above, it is equally well designed to meet the problems of the large scale operator who 
may wish to produce several hundred million feet per year. The argument that small yarding units are incompatible with the requirements of the large scale operator does not hold well against a system based on decentralized yarding operations whose output is concentrated into large scale production at the landings. The greatest efficiency and economy in the stump-to-landing operation has here been shown to be obtainable with a small yarding unit. The economies of mass production apply only to the loading and railroad operation, and are here attainable in greater measure than is possible in the typical donkey operation. The operating side from this point of view is the loading unit, rather than the yarding or roading unit, and in a large operation it would obviously be practicable to run as many "loading sides" as the output requirements may dictate.

131. Flexible Logging Methods Promote Adaptation of Operating and Timber Investments to Changing Conditions.-Other considerations than the direct comparison of operating costs enter into the choice of logging methods. Other things being equal, a system which relies on short-life logging equipment is much to be preferred to one which centers around long-life equipment. Under the proposed system, the roading, bunching, and yarding equipment consists of machinery which requires replacement every three to five years; that is to say, each year an average of about 25 per cent of the cost of the equipment would be recovered through operation, and new equipment bought. This enables the operator to keep up with new developments and improvements in machinery. It also enables him, if he so desires, to gradually expand or contract his business with changing business conditions without being burdened with too rigid a capital set-up. As the gradual swing of the business cycle rises to the peaks of prosperity or drops into the depressions he can buy more or less of new equipment and so adjust at least a portion of his investments to a changing volume of business. Under the proposed plan the operator who in $19: 30$ was producing at normal capacity could have reduced his capacity an average of 25 per cent per year by not replacing worn out units of stump-totrack machinery; the reduction of volume of production and capital investments going hand in hand. By 1933, his investment and capacity io produce would be down to 25 per cent of normal. While this would not apply to the longlife railroad and loading equipment, it would nevertheless be an important factor in lessening the presure to overproduce against a falling market.

After all, it should be remembered that logging operations and investments should be kept subordinate to the larger problems of orderly timber marketing and the management of timber properties. The proposed system tends to give full management control of the individual tree or of groups of trees that are clear cut by small units of area. From a current marketing standpoint this means that the forest can become an orderly warehouse into which the manager reaches for those products which are in strong demand and which should properly be removed. From a long-term management standpoint it means that only those investments which have reached their financial maturity may be liquidated; that low earning investments may be retired, high earning investments continued, and larger growing stock recruited as smaller trees develop into merchantable sizes. None of these elements has been fully considered in the discussion of logging methods in this report. From any basic point of view, whether that of the individual owner, forest industry as a whole, or the public interest, these problems of timber management transcend in importance any consideration of temporary cost saving. This justifies as exhaustive a study of the effects of these methods on timber management as on immediate logging operations. To these problems the second report of this series will be devoted. 



\section{GLOSSARY OF LOGGING TERMS USED}

Carriage-A traveling block used on a skyline for yarding or swinging.

Chaser-The member of a yarding crew who unhooks the logs at the landing.

Choker-A noose of wire rope by which a log is dragged.

Choker setter (chokerman)-The member of a yarding crew who fastens the choker on the logs.

Cold deck--A pile of logs yarded at a point between stump and track and later swung to the landing with a separate machine.

Direct-yarding-Yarding directly to the track landing as contrasted with yarding to a cold deck or to a hot-swing.

Donkey-A portable logging engine, equipped with drum and cable, used for transporting logs from stump to track.

Donkey logging-A system of logging in which donkeys are used for yarding.

Duplex loader-A two drum loader for loading at a spar tree. (See Figure 4D).

Fair-lead arch-A trailer for hauling logs with a tractor. (See Figures $4 \mathrm{~A}$ and 6 ).

Head spar or Head tree-See Figure 2D.

Heel boom-A special type of swinging boom used for loading. (See Figures $4 \mathrm{~B}$ and 44.)

High-lead-A method of yarding. (See Figure $2 \mathrm{H}$ ).

Hooker-One who sets chokers in yarding with tractors; a choker setter.

Hot-yarding - The logs are relayed by a swing machine as fast as they arrive at the yarder landing.

Jammer-A special type of loading engine. (See Figures $4 \mathrm{~A}$ and 6.)

'Landing-A place to which logs are hauled or skidded preparatory to transportation by water or rail.
Loader-1. One who loads logs on cars; 2. The machine used for loading logs on cars.

McLean Boom-A method of loading. (See Figure 4C.)

North Bend System-A method of swinging or yarding. (See Figures $2 \mathrm{~F}$, and $2 \mathrm{~F}$.)

Rigging-The cables, blocks and hooks used in yarding, swinging, or loading.

Roading (tractor roading) - Hauling logs with a tractor and trailer on a prepared road, with one end of the logs dragging on the road.

Setting - The temporary station of a yarding engine, or other machine used in logging.

Skidder-A logging engine, usually operated from a railroad track, which skids logs over a skyline. (See Figures $2 \mathrm{~A}$ and 2B.)

Skidding-Yarding with a skidder.

Skyline-A cable supported between two spar trees. (See Figures $2 \mathrm{~A}$ to $2 \mathrm{G}$ inclusive.)

Slack line system-A method of yarding or swinging. (See Figure 2C.)

Spar tree-A tree rigged for yarding, swinging, or loading.

Swinging-Hauling of logs from a yarder landing, either from a cold deeck or directly as the logs come in (hot-swinging, hotyarding).

Stumpage-The value of timber as it stands uncut in the woods; or, in a general sense, the standing timber itself.

Tail spar or tail tree-See Figure 2D.

Tyler System-A method of swinging or yarding. (See Figures 2 and 6.)

Yarding-The first stage in hauling logs from stump to track; or, in a general sense, all phases of hauling and lcading from stump to car.

\footnotetext{
${ }^{26} \mathrm{~A}$ few of the definitions are from "Terms Used in Forestry and Logging", Bul. 61, U. S. Bureau of Forestry, Washington, 1905.
} 





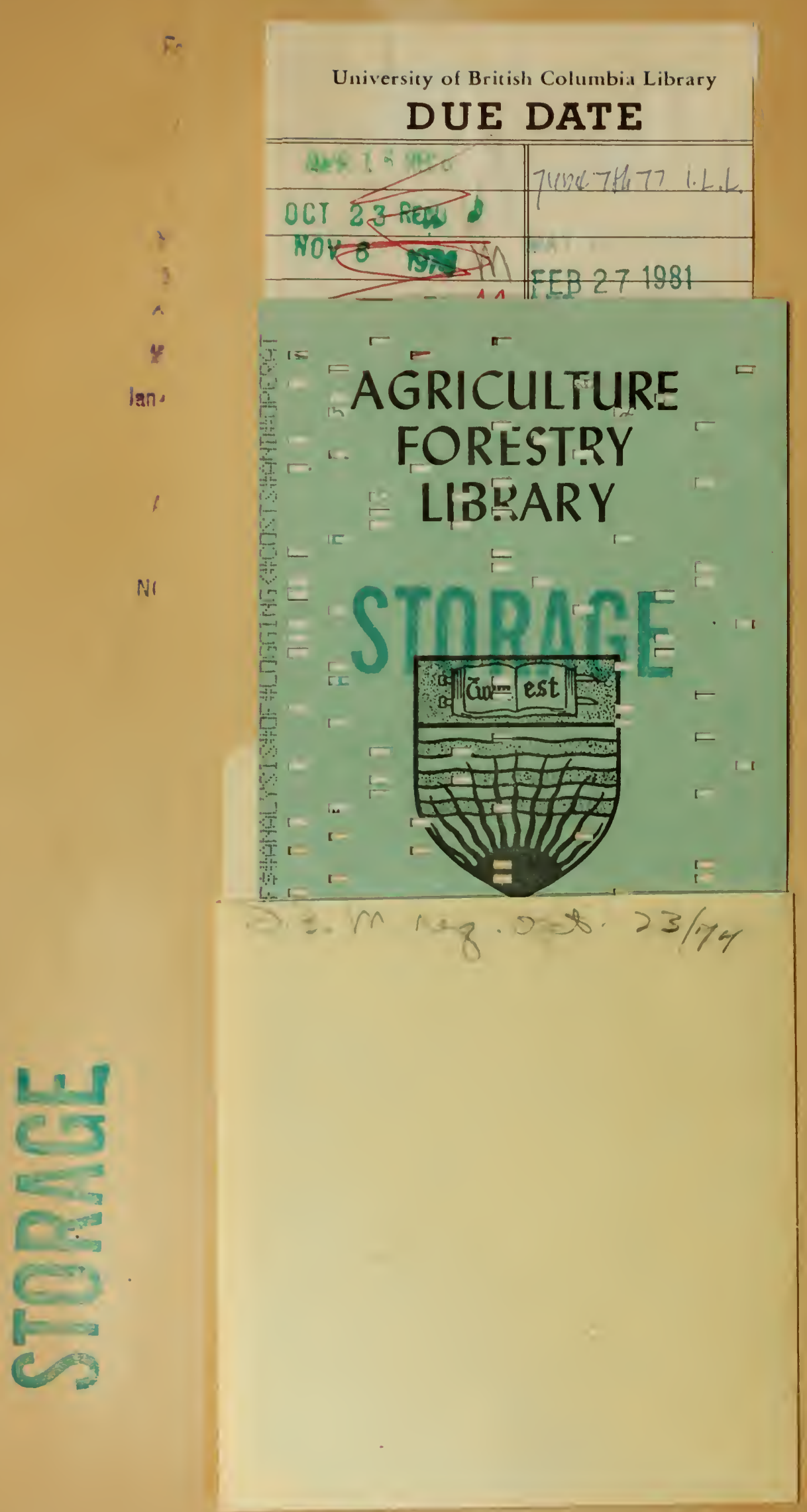



